\title{
Development and Characterization of Polymer-grafted Ceramic Membranes for Solvent Nanofiltration
}

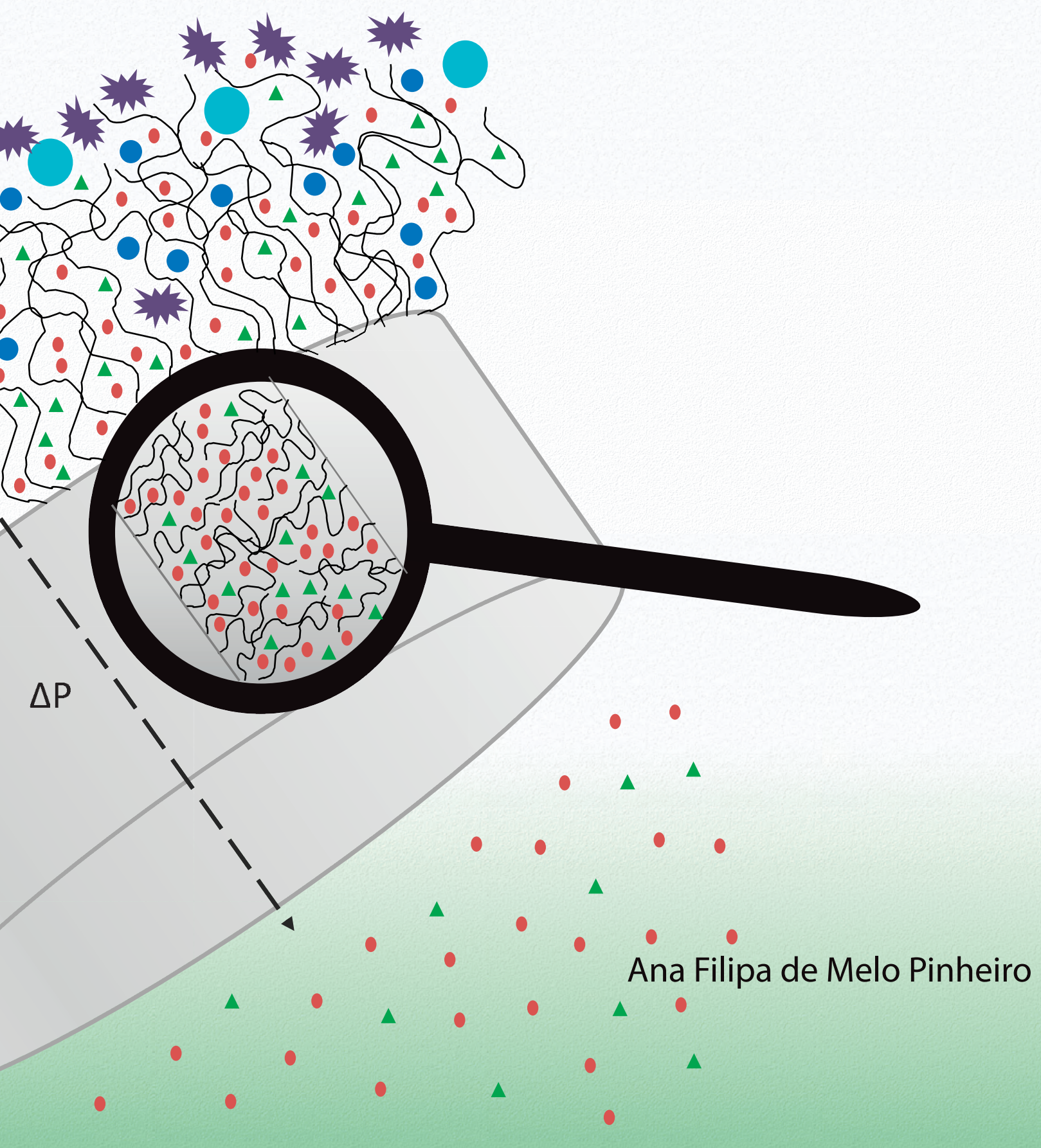



Development and Characterization of Polymer-grafted

Ceramic Membranes for Solvent Nanofiltration

Ana Filipa de Melo Pinheiro 
This is an ISPT project (Institute for Sustainable Process Technology)

\section{Promotion Committee}

Prof. Dr. G. van der Steenhoven (Chairman)

University of Twente

Prof. Dr. Ir. A. Nijmeijer (Promotor)

University of Twente

Dr. A. J. A. Winnubst (Assistant Promotor)

University of Twente

Prof. Dr. J. G. E. Gardeniers

University of Twente

Prof. Dr. Ir. J. E. ten Elshof

University of Twente

Dr. Ir. P. Jonkheijm

University of Twente

Prof. Dr. E. J. R. Sudhölter

Delft University of Technology

Dr. A. Buekenhoudt

Flemish Institute for

Ir. G. Bargeman

Technological Research AkzoNobel Chemicals BV

Development and Characterization of Polymer-grafted Ceramic Membranes for Solvent Filtration

ISBN: 978-90-365-3522-9

DOI: $10.3990 . / 1.9789036535229$

Design: Ferdinand van Nispen, Citroenvlinder-dtp.nl, Bilthoven, The Netherlands

Printed by GVO drukkers \& vormgevers B.V.| Ponsen \& Looijen, Ede, The Netherlands (O2013 Ana F. M. Pinheiro, Enschede, The Netherlands 


\title{
Development and Characterization of Polymer-grafted Ceramic Membranes for Solvent Nanofiltration
}

\author{
DISSERTATION \\ to obtain \\ the degree of doctor at the University of Twente, \\ on the authority of rector magnificus, \\ Prof. Dr. H. Brinksma, \\ on account of the decision of the graduation committee, \\ to be publicly defended \\ on Friday the $15^{\text {th }}$ of March 2013 at 14:45
}

by

Ana Filipa de Melo Pinheiro

born on 26 $6^{\text {th }}$ of June 1982

in Coimbra, Portugal 
This dissertation has been approved by:

Prof. Dr. Ir. A. Nijmeijer (Promotor)

University of Twente

Dr. A. J. A. Winnubst (Assistant Promotor)

University of Twente 


\section{Contents}

$\begin{array}{lll}\text { Chapter } 1 & \text { Introduction } & 7\end{array}$

Chapter 2 A state of the art on polymer-grafted ceramic membranes 27

Chapter 3 Effect of reaction conditions and silane nature on surface 83 grafting and pore- filling of titania membranes

Chapter 4 Efficient pore grafting of siloxane moieties onto gamma alumina flakes

Chapter 5 Development of a PDMS- $\mathrm{Al}_{2} \mathrm{O}_{3}$ grafted membrane and its evolution as a solvent resistant nanofiltration membrane

Chapter 6 BTDA-ODA imide grafting of ceramic membranes; Fabrication, microstructure and solvent permeation

Chapter 7 Fluoro-based polyimides grafted alumina as solvent resistant nanofiltration membranes

Chapter 8 Conclusions and recommendations

Summary 


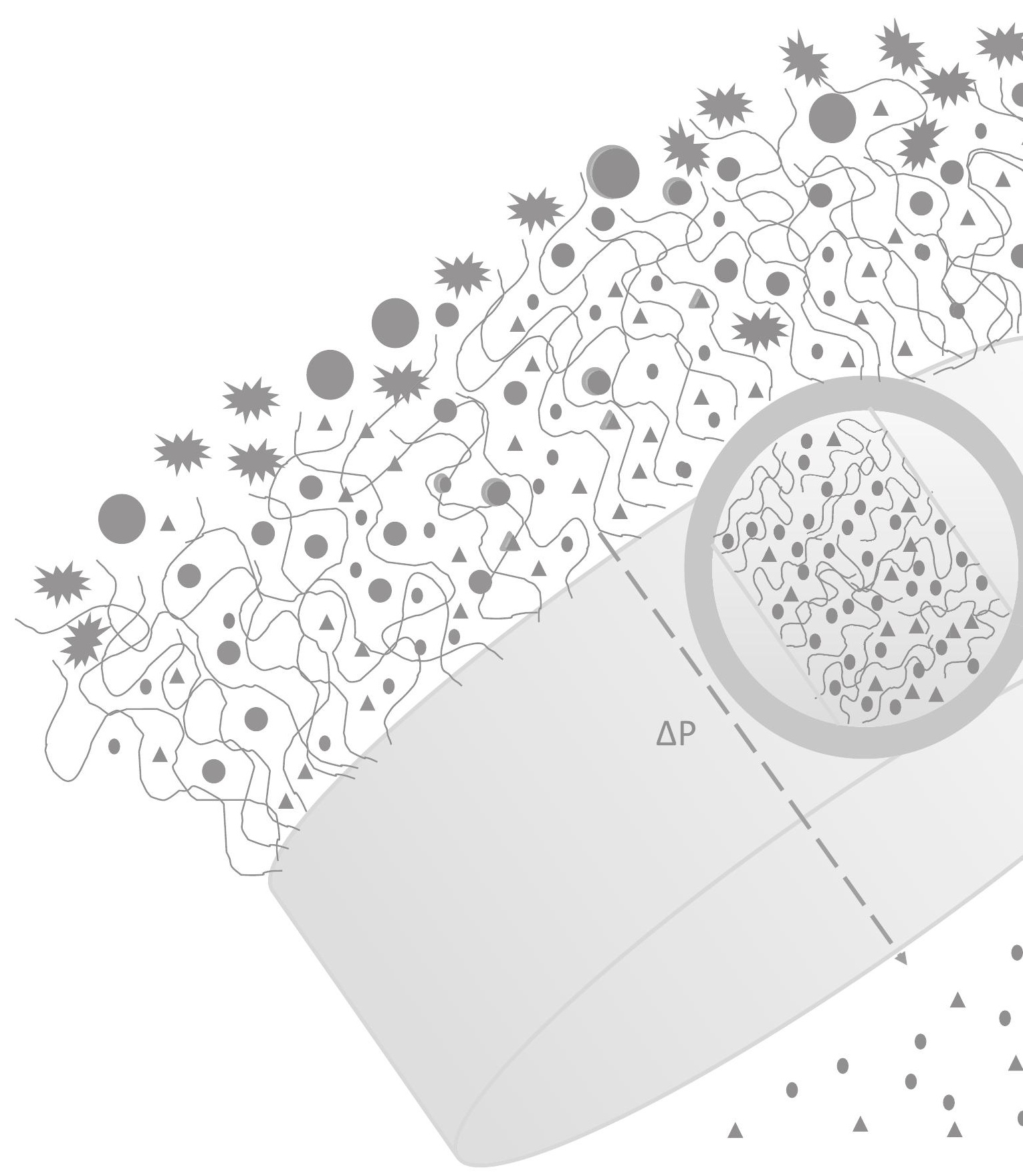




\subsection{Nanofiltration: Principles}

A membrane is a permselective barrier between two phases that facilitates separation of components on application of a driving force. This kind of separation can be classified as microfiltration (MF), ultrafiltration (UF), nanofiltration (NF) or reverse osmosis $(\mathrm{RO})$, depending on the size and charge of the components to be separated (Figure 1) [1]. Nanofiltration membranes are membranes that are used for molecular separation in the range of 200-1000 $\mathrm{g} \mathrm{mol}^{-1}$.

\begin{tabular}{|c|c|}
\hline & $\begin{array}{lll}5 & 10 & 100\end{array}$ \\
\hline $\begin{array}{l}\text { Pore size } \\
(\mathrm{nm})\end{array}$ & $-\mathrm{RO} \rightarrow \leftarrow \mathrm{NF} \rightarrow \longleftarrow$ UF $\longrightarrow \leftarrow \mathrm{MF}-$ \\
\hline$\alpha-\mathrm{Al}_{2} \mathrm{O}_{3}$ & Stable \\
\hline $\mathrm{V}-\mathrm{Al}_{2} \mathrm{O}_{3}$ & Unstable in aqueous solutions \\
\hline $\mathrm{TiO}_{2}$ & Stable in aqueous solutions \\
\hline $\mathrm{ZrO}_{2}$ & Stable in alkali solutions \\
\hline $\mathrm{SiO}_{2}$ & Unstable in aqueous solutions \\
\hline $\mathrm{SiO}_{2}-\mathrm{ZrO}_{2}$ & Improve stability \\
\hline Zeolite/template & 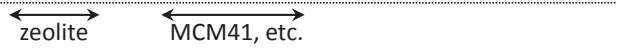 \\
\hline Carbon & $\overleftrightarrow{\text { gas separation }} \leftarrow$ \\
\hline \multicolumn{2}{|l|}{ Stainless steel } \\
\hline Polymer & 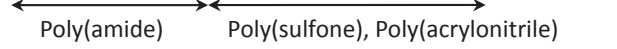 \\
\hline
\end{tabular}

Figure 1: Materials and pore sizes of porous materials ${ }^{[2]}$

Nanofiltration (NF) is the most recently developed pressure-driven membrane process [3] and is, with success, increasingly used as an alternative for reverse osmosis (RO) applications, like water softening [4-6], production of pure water by eliminating bivalent or trivalent salts from ground water [7, 8], the removal of middle to low molar mass molecules from aqueous solutions as pesticides and micro-pollutants [9-14], viruses and bacteria [15-17] and also in decontamination and recycling of industrial waste waters [18-22].

The success of NF in aqueous systems has triggered the expansion of NF for the separation and purification in non-aqueous systems. The application of these membranes introduces several benefits as:

- Use of low operation temperatures when compared with distillation. Besides 
energy reduction for separation processes, low temperatures are also important for thermal sensitive molecules in e.g. pharmaceutical industry.

- Recycling of solvents and/or valuable compounds and lower losses or exhaust, resulting too in a lower environmental impact.

- Easy installation in a continuous process.

- Can be combined with already existing technologies.

The established NF membranes for aqueous applications present still several limitations regarding non-aqueous applications, so solvent-resistant nanofiltration (SRNF) membranes are required. Therefore much research has been devoted in the development of new membrane materials.

\subsection{Solvent resistant nanofiltration membranes: Challenges and state of the art.}

Despite all these advantages, the implementation of nanofiltration membranes in chemical industry is very slow. One of the main reasons is related with the lack of membrane robustness. For this purpose, the main challenge for further expansion of solvent resistant nanofiltration (SRNF) membranes is the development of materials that are stable in a wide range of organic solvents and/or $\mathrm{pH}$ values, combined with high solvent permeabilities. Furthermore, no suitable mass transport models are available to explain membrane separation accurately, while no general methods are available for choosing materials for SRNF membrane applications. Until now it is not clear whether the transport of liquids through these type of membranes obeys a pore-flow or a solution-diffusion mechanism or even if it is a transient stage between these two mechanisms. This is mainly caused by the fact that each organic solvent has different properties and thus different interactions with the membrane material. The situation becomes even more complicated if we also take into account the great variety of available membrane materials. Finally, membrane fouling and concentration polarization have a huge impact on membrane performance. These phenomena are not fully understood for organic feeds.

Materials used for membranes are often divided in ceramic or polymeric. Ceramic (or inorganic) membranes generally show high fluxes and superior mechanical, chemical and thermal stability [23]. These membranes are easy to clean, do not swell in organic solvents, nor show any sign of compaction, but due to their limited 
available pore size they often lack the possibility to separate on a molecular level. Metal-oxide based ceramic membranes contain surface hydroxyl groups $(\mathrm{OH})$, which can easily link to water molecules and limit their application for non-aqueous separations. Verrecht et al. [24] and Van Gestel et al. [25] observed negligible fluxes of non-polar solvents, caused by the hydrophilic character of ceramic membranes. Other limitations of ceramic membranes are their brittleness (easy to crack), low surface-to-volume ratio and high production costs.

In contrast to ceramic membranes, polymeric membranes possess high selectivity on a molecular level, are easy to process and to scale up. Furthermore tailoring for a specific application is easier for those membranes. However, they suffer from extensive swelling and compaction [26, 27]. Swelling is caused by excessive solubility of a solvent into the polymer and as a result the plasticized polymer loses its selectivity. In general, it can be stated that polymer materials are less stable than inorganic materials. Even though, a number of polymeric SRNF membranes have been successfully developed but they do not cover all potential applications. A state of the art review for polymer nanofiltration membranes is made by Vandezande et al. [28].

The ideal SRNF membrane combines the thermal, chemical and mechanical stability, the non-swelling and non-compaction behavior of inorganic materials with the high selectivity of polymeric materials. By using this combination there is still much room for development both in the field of application, as well as in membrane stability/ performance. The development and characterization of these new type of ceramic/ polymeric composite membranes is therefore the main scope of this work.

\subsection{Inorganic membranes: Chemical stability}

High performance ceramic membranes, showing high selectivity and high fluxes, can only be obtained in an asymmetric multilayer configuration. The development of such multilayer configuration includes a macroporous support that provide the mechanical integrity, one or more mesoporous interlayers to reduce the surface roughness and for proper application of an active thin microporous top layer, which determines the membrane performance. The pore size of such an asymmetric composite membrane shows a gradient in order to minimize the resistance to permeation across the membrane. The mesoporous and microporous layers are normally prepared via sol-gel methods. 
For the development of high-quality membranes properties like pore size distribution, porosity and surface quality are of major importance, as well as a high mechanical and chemical stability. In this thesis we are especially concerned about the chemical stability of the mesoporous intermediate layer(s) and the microporous separation layer. Therefore, a comparative description of these properties is made for each ceramic material. Much research focuses to date on the development of ceramic NF membranes that presents a good performance in aggressive environments. As ceramic materials, mostly $\mathrm{Al}_{2} \mathrm{O}_{3^{\prime}}, \mathrm{ZrO}_{2}$ and $\mathrm{TiO}_{2}$ are considered.

Almost all literature mainly focuses on the structural properties of the developed membrane materials. Therefore, limited data on chemical stability of meso- or microporous membranes are available.

As referred in the previous section ceramic membranes are inert to virtually all organic solvents $[2,25,29-31]$ and as a result they have the potential for use in separation and filtration of nonaqueous solutions. However, their stability at high and low pH values is limited and depends on the metal oxide considered.

Hoffman-Züter [32] reported acid corrosion tests $\left(\mathrm{HNO}_{3^{\prime}} \mathrm{pH}\right.$ 1-3) on mesoporous $\mathrm{Y}-\mathrm{Al}_{2} \mathrm{O}_{3^{\prime}} \mathrm{TiO}_{2}$ (anatase) and $\mathrm{ZrO}_{2}$ membranes. Measurements of membrane corrosion, based on changes in permeability and the analysis of dissolved ions, showed that $\mathrm{TiO}_{2}$ and $\mathrm{ZrO}_{2}$ were less soluble under these circumstances than $\mathrm{Y}-\mathrm{Al}_{2} \mathrm{O}_{3}$ membranes. Unfortunately only a relative exposure time of 16 hours was applied.

Van Gestel et al. [31] analyzed the corrosion of micro- and mesoporous $\mathrm{Al}_{2} \mathrm{O}_{3^{\prime}} \mathrm{Al}_{2} \mathrm{O}_{3}$ $\mathrm{TiO}_{2}$ and $\mathrm{TiO}_{2} \mathrm{NF}$ membrane materials in acidic $\left(\mathrm{HNO}_{3}, \mathrm{pH} 1-3\right)$ and alkaline solutions $(\mathrm{NaOH}, \mathrm{pH}$ 11-13) using simple static corrosion experiments. They indicated the importance of material parameters like crystal structure, degree of crystallinity and the presence of amorphous phases. Anatase titania showed a high degree of crystallinity and almost no corrosion. Materials, containing transition $\mathrm{Al}_{2} \mathrm{O}_{3}$. phases, were characterized as being semi-crystalline or completely amorphous and high amounts of $\mathrm{Al}$ were released during corrosion tests. The order of corrosion was $\mathrm{\gamma}$-AlOOH $>\mathrm{Y}$-AlOOH/Anatase $>$ mixed $\mathrm{Al}_{2} \mathrm{O}_{3}-\mathrm{TiO}_{2}$, while the degree of crystallinity followed the opposite order.

Alumina, prepared at temperatures below $1000{ }^{\circ} \mathrm{C}(\mathrm{Y}-\mathrm{AlOOH}, \delta-\mathrm{AlOOH}$ or $\theta-\mathrm{AlOOH}$ ), with mesoporous properties showed high corrosion in strong acid solutions ( $\mathrm{pH} 1$ and 2), while after a thermal treatment at $1200{ }^{\circ} \mathrm{C}$, a very good stability was obtained but the corresponding pore size showed a transition from 
a fine mesoporous structure into a partially macroporous layer $\left(\mathrm{a}-\mathrm{Al}_{2} \mathrm{O}_{3}\right)$ with a pore size distribution in the range of 50-100 nm. For $\mathrm{Al}_{3} \mathrm{O}_{2}-\mathrm{TiO}_{2}$ materials an increase in firing temperature results in the formation of three chemically stable phases: $\mathrm{a}-\mathrm{Al}_{2} \mathrm{O}_{3}$ and rutile. This also results in a decrease in the corrosion behavior in the acid zone, while the pore structure remained relatively stable and kept its mesoporous properties (mean pore size $=8.0-9.0 \mathrm{~nm}$ ). Corrosion in $\mathrm{NaOH}$ solutions

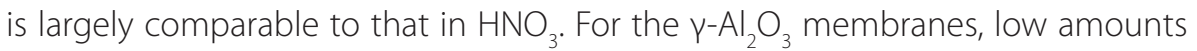
of Al were released up to $\mathrm{pH} \mathrm{11;} \mathrm{above} \mathrm{this} \mathrm{pH}$ large amounts were found. In this high $\mathrm{pH}$ range, mixed $\mathrm{a}-\mathrm{Al}_{2} \mathrm{O}_{3}$ /anatase showed a much lower corrosion rate. These membranes can represent an alternative for mesoporous $\gamma-\mathrm{Al}_{2} \mathrm{O}_{3}$ membrane layers. The price to pay is an increase of the average pore diameter to $7.5 \mathrm{~nm}\left(\mathrm{Al}_{3} \mathrm{O}_{2}\right.$ $\left.\mathrm{TiO}_{2}\right)$ compared with $4 \mathrm{~nm}\left(\mathrm{\gamma}-\mathrm{Al}_{2} \mathrm{O}_{3}\right)$. Finally, for titania in the anatase phase, a good resistance was obtained over the complete acid and basic ranges down to a $\mathrm{pH}$ of 1 and up to a pH of 13, respectively. Therefore, when smaller average pore size is required in combination with improved resistance; membrane interlayers of anatase are to be preferred.

More recently, Van Gestel et al. [33] reported long-term dynamic corrosion tests (6 weeks) for $\mathrm{Al}_{2} \mathrm{O}_{3}$ and $\mathrm{TiO}_{2}$ membranes in acid $\left(\mathrm{HNO}_{3}\right)$ and alkaline solutions $(\mathrm{NaOH})$

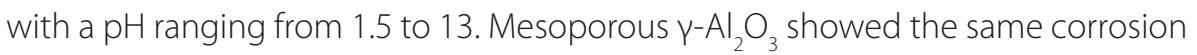
behavior as reported earlier [31]. Van Gestel et al. concluded that membrane failure is mainly due to dissolution of membrane material, especially in acid solutions with $\mathrm{pH}<3$. For titania membranes fired at $300{ }^{\circ} \mathrm{C}$ rapid degradation of the membrane performance took place with $\mathrm{pH} 2$ feed solutions. For titania NF membranes fired at $400{ }^{\circ} \mathrm{C}$, consisting of a strong crystalline membrane structure, a very good $\mathrm{pH}$ resistance was demonstrated. Corrosion tests, performed for more than one week, showed that a wide $\mathrm{pH}$ range from 1.5 to 13 can be applied with this type of membranes.

In conclusion, $\mathrm{TiO}_{2}$ and $\mathrm{ZrO}_{2}$ are suitable supports for either applications that involve aggressive solvents or extreme $\mathrm{pH}$ solutions. High quality $\mathrm{\gamma}$ - and $\mathrm{a}-\mathrm{Al}_{2} \mathrm{O}_{3}$ membranes in a wide range of pore sizes (e.g. 5, 10, 20,70,80 nm) and configurations (flat or tubular or multichannel) are commercial available and they are an excellent candidate for use in separation and filtration of aggressive solvents, even though they lack stability at high and low pH values. 


\subsection{Inorganic membranes as SRNF membranes}

Ceramic $\gamma$-alumina $(5 \mathrm{~nm})$, zirconia $(50 \mathrm{~nm}$ ) and silica (10 nm, $5 \mathrm{~nm}$ ) membranes are used in the petrochemical industry for the cleaning of waste lubricating oils at temperatures ranging from $150-260{ }^{\circ} \mathrm{C}$ [34]. Another application is the removal of asphaltenes from crude oil with zirconia and silica membranes [35].

The major challenge in broadening the range of molecular separation with ceramic membranes in solvents is the evolution towards smaller pore sizes of approximately $1 \mathrm{~nm}$. For a long time, the MWCO of ceramic membranes was retained at approximately 1000 Da. However, recently developed ceramic nanofiltration (NF) membranes, having molecular weight cut-offs (MWCO) in the range 200-1000 Da and estimated pore diameters from 1-2 nm, have opened new perspectives for SRNF. An example is a $\gamma$-alumina membrane with a MWCO of $900 \mathrm{Da}$ as prepared by calcining the system at $400{ }^{\circ} \mathrm{C}$ [36]. Here it was reported that increasing the firing temperature resulted in a larger MWCO.

Larbot et al. [37] successfully prepared alumina NF membranes by using a colloidal gel process. The pore size, and thus the MWCO, was controlled by the firing temperature as well as by varying different sol preparation conditions resulting in e.g. larger colloidal diameters. $y$-Alumina membranes having a MWCO of 350 Da and 450 Da were prepared by calcining at respectively $400{ }^{\circ} \mathrm{C}$ and $650{ }^{\circ} \mathrm{C}$. Witte et al. [38] have successfully recycled a homogenous catalyst (Sandwich type polyoxometalate, Q12POM) in a toluene solution by nanofiltration using an a-alumina supported mesoporous $\gamma$-alumina membrane with a pore size of around $5 \mathrm{~nm}$. Toluene soluble Q12POM was retained nearly quantitatively (99\%) by this inorganic membrane. The retention of the catalyst was mainly due to size exclusion. It was also shown that there was no loss in catalytic activity of the POM after 6 cycles. The same study was done for an a-alumina supported mesoporous y-alumina membrane calcined at higher temperature with a pore size around 8 $\mathrm{nm}$. Here retentions of $93 \%$ of toluene soluble POM were obtained [39].

Besides alumina membranes, NF titania membranes were developed [40-42]. Tsuru et al. [42-44] prepared a variety of titania membranes with different MWCO of approximately 500,600, 800 or > 1000 Da. These membranes were prepared by using sols with different sol particle diameters, which were coated onto an alumina membrane and fired at $450{ }^{\circ} \mathrm{C}$. Solvent performance for these membranes was reported [43, 44]. Voight et al. [41, 45], prepared titania-based NF membrane with a pore size of $0.9 \mathrm{~nm}$ showing a MWCO of 450 Da. These membranes were prepared 
by coating a polymeric titania sol on $\mathrm{TiO}_{2}$ intermediate layer (pore size $5 \mathrm{~nm}$ after calcining at $450^{\circ} \mathrm{C}$ ). This membrane has been applied since 2002 in the treatment of harsh textile waste water [22]. Other membranes as silica and titania with a pore size of $1 \mathrm{~nm}$ and a cut off of 650 and $750 \mathrm{Da}$, respectively are commercialized as well.

Another approach is the use of composite colloidal sols. Tsuru et al. [46] fabricated silica-zirconia membranes coated on an a-alumina support from Si/Zr sols (molar ratio Si/Zr=9/1). Pore sizes of 1, 1.6, $2.9 \mathrm{~nm}$ and MWCO of 200, 500 and $1000 \mathrm{Da}$ were obtained by regulating the colloidal diameter in the final coating stage. Solvent permeation data were reported [46-48]. These authors have also studied silica-titania NF membranes for separations in aqueous solutions [46, 49] and nonaqueous solutions [48]. It should be noted that the stability in aqueous solutions was improved by the incorporation of zirconia into silica.

Guizard et al. [50] prepared three different microporous mixed oxides membranes respectively $3 \mathrm{Al}_{2} \mathrm{O}_{3} / 2 \mathrm{ZrO}_{2}$ (pore size: $1.4 \mathrm{~nm}$ ), $\mathrm{SiO}_{2} / \mathrm{ZrO}_{2}$ (pore size: $1 \mathrm{~nm}$ ) and $\mathrm{SiO}_{2} /$ $\mathrm{TiO}_{2}$ (pore size: $1 \mathrm{~nm}$ ) by sol-gel methods and studied the effect of surface chemistry on the permeability of polar (toluene, heptane) and non-polar (ethanol) solvents. As expected, ethanol permeances were higher (1.0-10.3 $\mathrm{I} \mathrm{m}^{-2} \mathrm{hr}^{-1} \mathrm{bar}^{1}$ ) than the ones measured for heptane (0.1-1.3 $\left.\mathrm{I} \mathrm{m}^{-2} \mathrm{hr}^{-1} \mathrm{bar}^{-1}\right)$ and toluene $\left(0.2-2.5 \mathrm{I} \mathrm{m}^{-2} \mathrm{hr}^{-1}\right.$ bar $^{-1}$ ). more recently, Dobrak et al. [29] have studied the flux of alcohols, hexane and toluene and the retention characteristics (MWCO 275, 650, 1400, 7000 Da) as a function of the temperature using different microporous titania membranes. Solvent permeabilities could be increased by working at elevated temperatures by making use of the mechanism of activated permeability. However, the intrinsic hydrophilicity of the oxide pore surfaces results in low fluxes for several organics, e.g. alkanes, aromatics. As a consequence, only a few papers have been reported on the use of ceramic membranes in NF of organic solvents. Several approaches have been proposed in literature to cope with this problem. The modification of the pore surface by coupling agents and/or polymers has been found to be a good solution $[24,25,29,51,52]$. A detailed literature review on the preparation and applications of these hybrid systems (ceramic-grafted polymer membranes) is given in chapter 2 . 


\subsection{Polymeric membranes as SNRF}

Nowadays the majority of the SRNF membranes reported in literature are based on polymers, either comprising of a thin, dense polydimethylsiloxane (PDMS) selective layer applied on porous supports like polyacrilonitrile (PAN) [26, 27, 5356] and polyimides [53] or as integrally skinned, asymmetric, membranes, made of polyimides [28, 57-60]. Despite its broad chemical stability and its frequent use in SRNF applications (e.g. separation of dewaxed oil from MEK/toluene mixtures or the de-acidification of vegetable oils) the extensive, but reversible, swelling of PDMS in organic solvents limits its utility in some apolar solvents because of a decrease in selectivity, due to an increase in free space between polymer chains. Swelling has been identified as a key problem in the performance of PDMS membranes for organic-organic separations [27, 61-68]. For example, for hydrophobic membranes Van der Bruggen et al. [69] found lower solute rejection when hexane was used as solvent when compared with separations involving alcohols and water as solvent and they proposed that this was due to the interaction between membrane and solvent. In literature several methods have been proposed to suppress these swelling effects like the use of halogen-substituted silicon rubbers [70] or extra crosslinking via a plasma treatment [56]. Robinson et al. [60] and Tarleton et al. [26, 71] have used an electron beam irradiation technique to crosslink a PDMS/PAN composite NF membrane. Here the degree of crosslinking affected permeability and selectivity because this changed the degree of solvent induced swelling. At increasing degree of crosslinking, solute rejection increased, but a decrease in solvent permeability was observed as well. More recently, it was reported that the addition of fillers in silicon rubber reduced the swelling behavior [72-75]. For silica and zeolite fillers in PDMS such reduction in swelling was explained by adsorption of the PDMS polymer chains on the surface silanol groups of the filler [74]. At the same time it is expected that the use of porous zeolite fillers can prevent a reduction in permeability because solvent is transported through the porous zeolites as well. When the filler interacts well with the polymer the degree of crosslinking increases and swelling of the polymer network reduces. Gevers et al. [73] and Vankelecom et al. [74] prepared filled PDMS membranes using three different fillers (silica, carbon and zeolites). Incorporation of zeolites (silicalite) resulted in an increased solute rejection for nonpolar solvents (e.g. toluene, hexane, etc.) even at high temperatures (up to $80^{\circ} \mathrm{C}$ ) $[73,75]$. However, these membranes still showed low effective permeances, due to their large top layer thicknesses (> $20 \mu \mathrm{m})$. More 
recently the same authors [53] prepared different thin zeolite filled PDMS top layers on PAN or PI (Matrimid ${ }^{\circledR}$ based) by using a dipcoating procedure.

Another important class of membranes are polyimide (PI)-based membranes. The superior thermal stability, combined with their chemical resistance to organic solvents (e.g. toluene, hydrocarbons, alcohols, ketones and a broad range of pH's conditions) and excellent mechanical properties make these materials very attractive for gas separation [76], pervaporation [77, 78] and more recently for nanofiltration of organic solvents [57, 79-81]. SRNF PI-membranes present good performances in several organic solvents like toluene, hydrocarbons, alcohols, ketones, ethyl acetate, etc. [59, 82]. However polyimides are instable in amines like dimthylacetamide (DMAc) and have generally poor stability and performance in polar aprotic solvents such as dimethylsulfide (DMSO), tetrahydrofuran (THF), dimethyl formamide (DMF), methylene chlorine (DCM) and n-methyl pyrrolidone (NMP). [82]. A possibility to solve this problem is by cross-linking the PI polymer chains. It is shown that crosslinking these systems results in an increase in thermal and chemical stability and prevents the polymer from excessive swelling $[57,58$, 83-86]. A PI membrane can be cross-linked by radical initiation, through thermal treatments, by UV irradiation [84, 87] or by chemical crosslinking [57, 58, 88-91]. For SRNF, radical initiation is not suitable, because crosslinking cannot be throughout the whole membrane. Chemical crosslinking is selected as a better method for the preparation of an integrally-skinned asymmetric SRNF membrane from a Lenzing P84 membrane, chemically modified by aliphatic diamines [57]. In this work the porous PI film was submersed in a methanol solution of the diamines at room temperature, resulting in a stable membrane in polar, aprotic, solvents like DMF, DMSO, NMP, DMAc and DMF with permeability values of 1-8 $1 \mathrm{~m}^{-2} \mathrm{hr}^{-1} \mathrm{bar}^{-1}$ and MWCO values of 250-450 $\mathrm{g} \mathrm{mol}^{-1}$. By using a similar method Vanherck et al. [58] have cross-linked an integrally skinned asymmetric Matrimid ${ }^{\oplus}$-based polyimide membrane with aromatic diamines. They also prepared particle-filled cross-linked PI membranes by the addition of nano-sized zeolites. Both unfilled and filled membranes were stable in aprotic solvents DMF, NMP, DMAc and DMSO with permeabilities in DMF up to $5.4 \mathrm{I} \mathrm{m}^{-2} \mathrm{hr}^{-1} \mathrm{bar}^{-1}$ and rejections of 64\%-96\% for Methyl Orange (327 $\mathrm{g} \mathrm{mol}^{-1}$ ) and 95-98\% Bengal Rose (1017 $\mathrm{g} \mathrm{mol}^{-1}$ ). However, these post-synthesis crosslinking processes result in extra reaction time and solvent consumption and thus in an uneconomical and environmentally unfriendly step. In order to solve this issue Vanherck at al. [91] reported a new method for amine crosslinking, where crosslinking is performed during the phase inversion step 
by dissolving the aromatic diamines in the coagulation bath. This resulted in a cheaper and more environmentally friendly crosslinking. In this work four different commercial membranes were used: Lenpzing P84, Matrimid ${ }^{\oplus}$, Torlon 4000TF and a polyetherimide. For the Lenzing P84 membrane rejections of 97-98\% for Bengal Rose (MW $1017 \mathrm{~g} \mathrm{~mol}^{-1}$ ) with DMF and NMP fluxes of 0.43 and $0.191 \mathrm{~m}^{-2} \mathrm{hr}^{-1}$ (at 10 bar) were attained. More recently, an optimization of this membrane process is reported and this membrane shows 10 times better flux in DMF than a commercial Duramem ${ }^{\circledR}$ series at equal rejections [92]. This simpler amine crosslinking method can result in a more efficient and easier membrane fabrication process.

Even though much has been done in the last couple of years in the development of new polymeric materials, there still is an urgent need for robust SRNF membranes to cope with increasing separations demands in non-aqueous systems.

\subsection{Applications of SRNF membranes}

The developments in the area of solvent resistant nanofiltration membranes have led to many applications in the petrochemical, chemical synthesis, pharmaceutical and food industry.

SRNF membranes show a high potential in chemical synthesis as the recovery of homogeneous catalysts from reaction products [93][94-98]. Many of the reactions where these catalysts are used are performed in solvents, resulting in extensive and usually destructive separations. In most of these processes the purpose of separation is purification of the product rather than catalyst recovery. Since the size of the catalysts ( $M W>450 \mathrm{Da}$ ) is in most cases significantly larger than that of the reaction products, separation is feasible by SRNF. In fact catalyst recovery and product purification can be done simultaneously in this way. SRNF has also been applied in this sector for other applications e.g. the recovery of organometallic complexes [99] from organic solvents and separation of phase transfer catalysts (PTC) from toluene $[94,100,101]$.

In contrast to homogeneous catalyst separation, separations in petrochemical applications are often between compounds, which have very similar molecular properties. One of the first SRNF applications on industrial scale was the recovery of dewaxing solvents (e.g. methyl ethyl ketone and toluene) from lube oil filtrates [102-104][105]. Other examples of SRNF applications involve the enrichment of aromatic components in refinery streams [106], deacidification of crude oil [107] 
and desulfurization of gasoline [108]. More recently, a study by Othman et al. demonstrated the applicability in biodiesel production [109].

One of the main applications in food industry is the separation and purification of edible oils. Several papers have been published on the membrane applications in the edible oil industry for solvent recovery $[110,111]$ (hexane, acetone and isopropanol) and oil refining processes. This technology was proven to be safer and more cost efficient than conventional techniques [28]. The efficiency of SRNF in edible oil processing has now been demonstrated practically in vegetable oil and sun oil processing $[110,112]$.

Besides the petrochemical and chemical synthesis industry, SRNF has high potential in the pharmaceutical industry, since many active pharmaceutical ingredients are high-value natural molecules and sensitive to thermal degradation. The operating temperature can be minimized by using NF and consequently loss in activity and /or nutritive properties are minimized as well as lower energy consumption is required if compared to traditional techniques like evaporation and distillation $[113,114]$. One example is the recovery of 6-aminopenicilannic acid $\left(\mathrm{MW}=216 \mathrm{~g} \mathrm{~mol}^{-1}\right)$ an intermediate in the enzymatic manufacturing of synthetic penicillin [115]. Synthesis of pharmaceuticals often involve multi-step reactions, performed in different solvents, thus solvent exchange is required in most sequential synthesis pathways to concentrate active intermediates $[94,116,117]$. The use of SRNF can reduce energy and the amount of solvents.

Despite the wide range of potential applications in a large variety of industrial sectors, the use of SRNF is still limited. Actual limitations of SRNF are mainly related to membrane stability and lifetime and lack of fundamental understanding on modeling of the transport mechanism for SRNF.

\subsection{Hybrid membranes: Polymer-grafted ceramic membranes}

As discussed before, both polymeric and ceramic state of the art SRNF membranes present major drawbacks which hamper the expansion of SRNF, thus a new class of membranes are required. The strategy, as described in this thesis, is the combination of both organic and inorganic materials - hybrid inorganic-organic membranes. 
Hybrid inorganic-organic materials are usually classified in two categories. In the first category only weak interactions like Van der Waals and/or hydrogen bonds exist between the organic and inorganic moieties. These types of hybrid materials can be described as micro- or nanocomposites in which one part is dispersed in the other part that acts as host matrix. In the second category a covalent bond exists between the organic and inorganic moiety. This is the approach used in this thesis. The strategy for the polymer grafted membranes as developed in this work is to use the porous structure of the ceramic material as a stable support for the polymeric separation layer, which is terminally and covalently bonded onto the surface and in the pores of the ceramic support. This inorganic/organic hybrid membrane is expected to provide sufficient chemical and thermal stability to withstand highly aggressive organic solvents, oxidative environments and high temperatures. Furthermore, this approach allows us to engineer surface properties (e.g. hydrophobicity, surface chemistry, chemical affinity) that may result in enhancing and/or tuning the transport properties (permeability and selectivity). Up to now the majority of the reported applications for these type of membranes is either on gas separation [118-125] or pervaporation [126-128], while very few results are related to nanofiltration $[24,31,51,52]$. Some examples on nanofiltration of this polymer grafted ceramic membranes are discussed in chapter 3, 5, 6 and 7. In chapter 2, a more detailed description will be given about the fabrication, chemistry and reaction mechanisms on grafting of ceramic membranes as well as some applications of these new type of hybrid membranes. 


\subsection{References}

1. R. J. Peterson, in Nanofiltration. Principles and Applications. ed, A. I. Schafer, A. G. Fane and T. D. White, Elseviere, Oxford, 2005, foreword, pp xx-xxi

2. Tsuru, T., Inorganic porous membranes for liquid phase separation. Separation and Purification Methods, 2001. 30(2): p. 191-220.

3. M. Mulder, in Basic Principles of Membrane Technology, ed. M. Mulder, Kluwer Academic Publishers, Dordrecht, 2nd edn., 2004

4. Schaep, J., et al., Removal of hardness from groundwater by nanofiltration. Desalination, 1998. 119(1-3): p. 295-301.

5. Sombekke, H.D.M., D.K. Voorhoeve, and P. Hiemstra, Environmental impact assessment of groundwater treatment with nanofiltration. Desalination, 1997. 113(2-3): p. 293-296.

6. Watson, B.M. and C.D. Hornburg, Low-Energy Membrane Nanofiltration For Removal Of Color, Organics And Hardness From Drinking-Water Supplies. Desalination, 1989. 72(1-2): p. 11-22.

7. Pervov, A.G., et al., RO and NF membrane systems for drinking water production and their maintenance techniques. Desalination, 2000. 132(1-3): p. 315-321.

8. Hilal, N., et al., A comprehensive review of nanofiltration membranes: Treatment, pretreatment, modelling, and atomic force microscopy. Desalination, 2004. 170(3): p. 281308.

9. Berg, P., G. Hagmeyer, and R. Gimbel, Removal of pesticides and other micropollutants by nanofiltration. Desalination, 1997. 113(2-3): p. 205-208.

10. Ducom, G. and C. Cabassud, Interests and limitations of nano-filtration for the removal of volatile organic compounds in drinking water production. Desalination, 1999. 124(1-3): p. 115-123.

11. Kiso, Y., et al., Rejection properties of pesticides with a hollow fiber NF membrane (HNF-1). Desalination, 2002. 143(2): p. 147-157.

12. Kiso, Y., et al., Rejection properties of non-phenylic pesticides with nanofiltration membranes. Journal of Membrane Science, 2000. 171(2): p. 229-237.

13. Van der Bruggen, B., et al., Application of nanofiltration for removal of pesticides, nitrate and hardness from ground water: rejection properties and economic evaluation. Journal of Membrane Science, 2001. 193(2): p. 239-248.

14. Van der Bruggen, B., et al., Nanofiltration as a treatment method for the removal of pesticides from ground waters. Desalination, 1998. 117(1-3): p. 139-147.

15. Otaki, M., K. Yano, and S. Ohgaki, Virus removal in a membrane separation process. Water Science and Technology, 1998. 37(10): p. 107-116.

16. Urase, T., K. Yamamoto, and S. Ohgaki, Effect of pore structure of membranes and module configuration on virus retention. Journal of Membrane Science, 1996. 115(1): p. 21-29.

17. Yahya, M.T., C.B. Cluff, and C.P. Gerba, Virus Removal By Slow Sand Filtration And Nanofiltration. Water Science and Technology, 1993. 27(3-4): p. 445-448.

18. Afonso, M.D. and R.B. Yanez, Nanofiltration of wastewater from the fishmeal industry. Desalination, 2001. 139(1-3): p. 429-429.

19. Geraldes, V. and M.N. Depinho, Process Water Recovery From Pulp Bleaching Effluents By An Nf/Ed Hybrid Process. Journal of Membrane Science, 1995. 102: p. 209-221.

20. Rautenbach, R. and T. Linn, High-pressure reverse osmosis and nanofiltration, a "zero discharge" process combination for the treatment of waste water with severe fouling/ scaling potential. Desalination, 1996. 105(1-2): p. 63-70.

21. Rautenbach, R., T. Linn, and L. Eilers, Treatment of severely contaminated waste water by a combination of $\mathrm{RO}$, high-pressure $\mathrm{RO}$ and $\mathrm{NF}$ - potential and limits of the process. Journal of Membrane Science, 2000. 174(2): p. 231-241.

22. Voigt, l., et al., Integrated cleaning of coloured waste water by ceramic NF membranes. Separation and Purification Technology, 2001. 25(1-3): p. 509-512. 
23. Chang, C.H., R. Gopalan, and Y.S. Lin, A Comparative-Study On Thermal And Hydrothermal Stability Of Alumina, Titania And Zirconia Membranes. Journal of Membrane Science, 1994. 91(1-2): p. 27-45.

24. Verrecht, B., et al., Chemical surface modification of gamma-Al2O3 $\mathrm{TiO} 2$ toplayer membranes for increased hydrophobicity. Desalination, 2006. 200(1-3): p. 385-386.

25. Van Gestel, T., et al., Surface modification of $\mathrm{Y}$-Al2O3/TiO2 multilayer membranes for applications in non-polar organic solvents. Journal of Membrane Science, 2003. 224(1-2): p. 3-10.

26. Tarleton, E.S., J.P. Robinson, and M. Salman, Solvent-induced swelling of membranes Measurements and influence in nanofiltration. Journal of Membrane Science, 2006. 280(12): p. 442-451.

27. Tarleton, E.S., et al., New experimental measurements of solvent induced swelling in nanofiltration membranes. Journal of Membrane Science, 2005. 261(1-2): p. 129-135.

28. Vandezande, P., L.E.M. Gevers, and I.F.J. Vankelecom, Solvent resistant nanofiltration: separating on a molecular level. Chemical Society Reviews, 2008. 37(2): p. 365-405.

29. Dobrak, A., et al., Solvent flux behavior and rejection characteristics of hydrophilic and hydrophobic mesoporous and microporous $\mathrm{TiO}_{2}$ and $\mathrm{ZrO}_{2}$ membranes. Journal of Membrane Science, 2010. 346(2): p. 344-352.

30. Tsuru, T., et al., Permeation of Liquids through Inorganic Nanofiltration Membranes. Journal of Colloid and Interface Science, 2000. 228(2): p. 292-296.

31. Van Gestel, T., et al., Alumina and titania multilayer membranes for nanofiltration: preparation, characterization and chemical stability. Journal of Membrane Science, 2002. 207(1): p. 73-89.

32. Hoffman-Züter J. M., Chemical and Thermal Stability of Mesoporous Ceramic Alumina, Ph. D, Thesis, University of Twente, Enschede, The Netherlands, 1995

33. Van Gestel, T., et al., Corrosion properties of alumina and titania NF membranes. Journal of Membrane Science, 2003. 214(1): p. 21-29.

34. R. Higgins, B. Bishop, and R. Goldsmith, in "Proceedings of Third International Conference on Inorganic Membranes," 1993, 447.

35. C. Guizard, D. Rambault, D. Urhing, J. Dufour, and L. Cot, in“Proceedings of Third International Conference on Inorganic Membranes,"1993, 345.

36. Schaep, J., et al., Characteristics and retention properties of a mesoporous gamma-Al2O3 membrane for nanofiltration. Journal of Membrane Science, 1999. 163(2): p. 229-237.

37. Larbot, A., et al., Preparation Of A Gamma-Alumina Nanofiltration Membrane. Journal of Membrane Science, 1994. 97: p. 167-173.

38. Witte, P.T., et al., Highly efficient recycling of a "sandwich" type polyoxometalate oxidation catalyst using solvent resistant nanofiltration. Chemical Communications, 2005(9): p. 12061208.

39. Chowdhury S.R., Ordered And Disordered: Porous Materials For Nanofiltraion Application, University of Twente, 2005, Enschede

40. Sarrade, S., G.M. Rios, and M. Carles, Nanofiltration membrane behavior in a supercritical medium. Journal of Membrane Science, 1996. 114(1): p. 81-91.

41. Puhlfurss, P., et al., Microporous Tio, membranes with a cut off $<500$ Da. Journal of Membrane Science, 2000. 174(1): p. 123-133.

42. Tsuru, T., et al., Titania membranes for liquid phase separation: effect of surface charge on flux. Separation and Purification Technology, 2001. 25(1-3): p. 307-314.

43. Tsuru, T., et al., Inorganic porous membranes for nanofiltration of nonaqueous solutions. Separation and Purification Technology, 2003. 32(1-3): p. 105-109.

44. Tsuru, T., et al., Nanoporous titania membranes for permeation and filtration of organic solutions. Desalination, 2008. 233(1-3): p. 1-9.

45. Voigt, I., et al., $\mathrm{TiO}_{2}-\mathrm{NF}-\mathrm{memb}$ ranes on capillary supports. Separation and Purification Technology, 2003. 32(1-3): p. 87-91.

46. Tsuru, T., et al., Silica-zirconia membranes for nanofiltration. Journal of Membrane Science, 
1998. 149(1): p. 127-135

47. Tsuru, T., et al., Permeation of nonaqueous solution through organic/Inorganic hybrid nanoporous membranes. AlChE Journal, 2004. 50(5): p. 1080-1087.

48. Tsuru, T., et al., Nanofiltration in non-aqueous solutions by porous silica-zirconia membranes. Journal of Membrane Science, 2001. 185(2): p. 253-261.

49. Tsuru, T., et al., Temperature effect on transport performance by inorganic nanofiltration membranes. AlChE Journal, 2000. 46(3): p. 565-574.

50. Guizard, C., A. Ayral, and A. Julbe, Potentiality of organic solvents filtration with ceramic membranes. A comparison with polymer membranes. Desalination, 2002. 147(1-3): p. 275280.

51. Sah, A., et al., Hydrophobic modification of $y$-alumina membranes with organochlorosilanes. Journal of Membrane Science, 2004. 243(1-2): p. 125-132.

52. Tsuru, T., et al., Preparation of hydrophobic nanoporous methylated $\mathrm{SiO}_{2}$ membranes and application to nanofiltration of hexane solutions. Journal of Membrane Science, 2011. 384(1-2): p. 149-156.

53. Gevers, L.E.M., et al., Optimisation of a lab-scale method for preparation of composite membranes with a filled dense top-layer. Journal of Membrane Science, 2006. 281(1-2): p. 741-746.

54. Stafie, N., D.F. Stamatialis, and M. Wessling, Insight into the transport of hexane-solute systems through tailor-made composite membranes. Journal of Membrane Science, 2004. 228(1): p. 103-116.

55. Stafie, N., D.F. Stamatialis, and M. Wessling, Effect of PDMS cross-linking degree on the permeation performance of PAN/PDMS composite nanofiltration membranes. Separation and Purification Technology, 2005. 45(3): p. 220-231.

56. Aerts, S., et al., Plasma-treated PDMS-membranes in solvent resistant nanofiltration: Characterization and study of transport mechanism. Journal of Membrane Science, 2006. 275(1-2): p. 212-219.

57. See Toh, Y.H., F.W. Lim, and A.G. Livingston, Polymeric membranes for nanofiltration in polar aprotic solvents. Journal of Membrane Science, 2007. 301 (1-2): p. 3-10.

58. Vanherck, K., et al., Cross-linked polyimide membranes for solvent resistant nanofiltration in aprotic solvents. Journal of Membrane Science, 2008. 320(1-2): p. 468-476.

59. White, L.S., Transport properties of a polyimide solvent resistant nanofiltration membrane. Journal of Membrane Science, 2002. 205(1-2): p. 191-202.

60. Robinson, J.P., et al., Influence of cross-linking and process parameters on the separation performance of poly(dimethylsiloxane) nanofiltration membranes. Industrial \& Engineering Chemistry Research, 2005. 44(9): p. 3238-3248.

61. Bhanushali, D., S. Kloos, and D. Bhattacharyya, Solute transport in solvent-resistant nanofiltration membranes for non-aqueous systems: experimental results and the role of solute-solvent coupling. Journal of Membrane Science, 2002. 208(1-2): p. 343-359.

62. Bhanushali, D., et al., Performance of solvent-resistant membranes for non-aqueous systems: solvent permeation results and modeling. Journal of Membrane Science, 2001. 189(1): p. 1-21.

63. Gevers, L.E.M., et al., Physico-chemical interpretation of the SRNF transport mechanism for solutes through dense silicone membranes. Journal of Membrane Science, 2006. 274(1-2): p. 173-182.

64. Machado, D.R., D. Hasson, and R. Semiat, Effect of solvent properties on permeate flow through nanofiltration membranes. Part I: investigation of parameters affecting solvent flux. Journal of Membrane Science, 1999. 163(1): p. 93-102.

65. Machado, D.R., D. Hasson, and R. Semiat, Effect of solvent properties on permeate flow through nanofiltration membranes - Part II. Transport model. Journal of Membrane Science, 2000. 166(1): p. 63-69.

66. Robinson, J.P., et al., Solvent flux through dense polymeric nanofiltration membranes. Journal of Membrane Science, 2004. 230(1-2): p. 29-37.

67. Stamatialis, D.F., et al., Observations on the permeation performance of solvent resistant 
nanofiltration membranes. Journal of Membrane Science, 2006. 279(1-2): p. 424-433.

68. Vankelecom, I.F.J., et al., Physico-chemical interpretation of the SRNF transport mechanism for solvents through dense silicone membranes. Journal of Membrane Science, 2004. 231(1-2): p. 99-108.

69. Van der Bruggen, B., J. Geens, and C. Vandecasteele, Fluxes and rejections for nanofiltration with solvent stable polymeric membranes in water, ethanol and n-hexane. Chemical Engineering Science, 2002. 57(13): p. 2511-2518.

70. Bitter J. G. A, US Pat 4,748,288 (1998)

71. Tarleton, E.S., et al., The influence of polarity on flux and rejection behaviour in solvent resistant nanofiltration - Experimental observations. Journal of Membrane Science, 2006. 278(1-2): p. 318-327.

72. Gevers, L.E.M., et al., Optimisation of a lab-scale method for preparation of composite membranes with a filled dense top-layer. Journal of Membrane Science, 2006. 281(1-2): p. 741-746.

73. Gevers, L.E.M., I.F.J. Vankelecom, and P.A. Jacobs, Solvent-resistant nanofiltration with filled polydimethylsiloxane (PDMS) membranes. Journal of Membrane Science, 2006. 278(1-2): p. 199-204.

74. Vankelecom, I.F.J., et al., Parameters Influencing Zeolite Incorporation In Pdms Membranes. Journal of Physical Chemistry, 1994. 98(47): p. 12390-12396.

75. Gevers, L.E.M., I.F.J. Vankelecom, and P.A. Jacobs, Zeolite filled polydimethylsiloxane (PDMS) as an improved membrane for solvent-resistant nanofiltration (SRNF). Chemical Communications, 2005(19): p. 2500-2502.

76. Y. Kase, Gas separation by polyimide membranes, in: T. Matsuura (Ed.),Advances Membrane Technology and Applications, John Wiley \& Sons, Inc.,2008, pp. 581-598.

77. Kim, J.H., K.H. Lee, and S.Y. Kim, Pervaporation separation of water from ethanol through polyimide composite membranes. Journal of Membrane Science, 2000. 169(1): p. 81-93.

78. Qiao, X.Y. and T.S. Chung, Diamine modification of P84 polyimide membranes for pervaporation dehydration of isopropanol. AIChE Journal, 2006. 52(10): p. 3462-3472.

79. Kong, Y., et al., Separation performance of polyimide nanofiltration membranes for solvent recovery from dewaxed lube oil filtrates. Desalination, 2006. 191(1-3): p. 254-261.

80. Ba, C.Y., J. Langer, and J. Economy, Chemical modification of P84 copolyimide membranes by polyethylenimine for nanofiltration. Journal of Membrane Science, 2009. 327(1-2): p. 49-58.

81. Van Doorslaer, C., et al., Product recovery from ionic liquids by solvent-resistant nanofiltration: application to ozonation of acetals and methyl oleate. Green Chemistry, 2010. 12(10): p. 1726-1733.

82. Silva, P., S.J. Han, and A.G. Livingston, Solvent transport in organic solvent nanofiltration membranes. Journal of Membrane Science, 2005. 262(1-2): p. 49-59.

83. Tin, P.S., et al., Effects of cross-linking modification on gas separation performance of Matrimid membranes. Journal of Membrane Science, 2003. 225(1-2): p. 77-90.

84. Kita, H., et al., Effect Of Photo-Cross-Linking On Permeability And Permselectivity Of Gases Through Benzophenone-Containing Polyimide. Journal of Membrane Science, 1994. 87(12): p. 139-147.

85. Bos, A., et al., Suppression of gas separation membrane plasticization by homogeneous polymer blending. AlChE Journal, 2001. 47(5): p. 1088-1093.

86. Vanherck, K., et al., Hollow filler based mixed matrix membranes. Chemical Communications, 2010. 46(14): p. 2492-2494.

87. Liu, Y., et al., Effect of crosslinking distribution on gas permeability and permselectivity of crosslinked polyimides. European Polymer Journal, 1999. 35(9): p. 1739-1741.

88. Liu, Y., R. Wang, and T.S. Chung, Chemical cross-linking modification of polyimide membranes for gas separation. Journal of Membrane Science, 2001. 189(2): p. 231-239.

89. Park, H.B., et al., Effect of crosslinked chain length in sulfonated polyimide membranes on water sorption, proton conduction, and methanol permeation properties. Journal of 
Membrane Science, 2006. 285(1-2): p. 432-443.

90. Shao, L., et al., Transport properties of cross-linked polyimide membranes induced by different generations of diaminobutane (DAB) dendrimers. Journal of Membrane Science, 2004. 238(1-2): p. 153-163.

91. Vanherck, K., et al., A simplified diamine crosslinking method for PI nanofiltration membranes. Journal of Membrane Science, 2010. 353(1-2): p. 135-143.

92. Hendrix, K., K. Vanherck, and I.F.J. Vankelecom, Optimization of solvent resistant nanofiltration membranes prepared by the in-situ diamine crosslinking method. Journal of Membrane Science, 2012. 421-422(0): p. 15-24.

93. N. J. Ronde and D. Vogt, in Catalysis by Metal Complexes catalyst Separation, Recovery and Recycling, Chemistry and Process Design, ed, D. J. Cole Hamilton and R. P. Tooze, Springer, Dordrecht, The Netherlands, ch 4., pp 73-104

94. Livingston, A., et al., Membrane separation in green chemical processing - Solvent nanofiltration in liquid phase organic synthesis reactions, in Advanced Membrane Technology, N.N. Li, et al., Editors. 2003, New York Acad Sciences: New York. p. 123-141.

95. Aerts, S., et al., The use of solvent resistant nanofiltration in the recycling of the Co-Jacobsen catalyst in the hydrolytic kinetic resolution (HKR) of epoxides. Journal of Membrane Science, 2006. 280(1-2): p. 245-252.

96. Nair, D., et al., Homogeneous catalyst separation and re-use through nanofiltration of organic solvents. Desalination, 2002. 147(1-3): p. 301-306.

97. Janssen, M., C. Muller, and D. Vogt, Molecular weight enlargement-a molecular approach to continuous homogeneous catalysis. Dalton Transactions, 2010. 39(36): p. 8403-8411.

98. Mertens, P.G.N., et al., Catalytic oxidation of 1,2-diols to alpha-hydroxy-carboxylates with stabilized gold nanocolloids combined with a membrane-based catalyst separation. Catalysis Letters, 2005. 102(1-2): p. 57-61.

99. Scarpello, J.T., et al., The separation of homogeneous organometallic catalysts using solvent resistant nanofiltration. Journal of Membrane Science, 2002. 203(1-2): p. 71-85.

100. Luthra, S.S., et al., Phase-transfer catalyst separation and re-use by solvent resistant nanofiltration membranes. Chemical Communications, 2001(16): p. 1468-1469.

101. Luthra, S.S., et al., Homogeneous phase transfer catalyst recovery and re-use using solvent resistant membranes. Journal of Membrane Science, 2002. 201(1-2): p. 65-75.

102. Bhore, N.A., et al., New membrane process debottlenecks solvent dewaxing unit. Oil \& Gas Journal, 1999. 97(46): p. 67.

103. White, L.S. and A.R. Nitsch, Solvent recovery from lube oil filtrates with a polyimide membrane. Journal of Membrane Science, 2000. 179(1-2): p. 267-274.

104. Gould, R.M., L.S. White, and C.R. Wildemuth, Membrane separation in solvent lube dewaxing. Environmental Progress, 2001. 20(1): p. 12-16.

105. a) US Pat., 5651877,1997

106. White, L.S. and C.R. Wildemuth, Aromatics enrichment in refinery streams using hyperfiltration. Industrial \& Engineering Chemistry Research, 2006. 45(26): p. 9136-9143.

107. Eur. Pat., WO 02/050212 A3, 2002

108. White, L.S., Development of large-scale applications in organic solvent nanofiltration and pervaporation for chemical and refining processes. Journal of Membrane Science, 2006. 286(1-2): p. 26-35.

109. Othman, R., et al., Application of polymeric solvent resistant nanofiltration membranes for biodiesel production. Journal of Membrane Science, 2010. 348(1-2): p. 287-297.

110. Subramanian, R., et al., Differential permeation of oil constituents in nonporous denser polymeric membranes. Journal of Membrane Science, 2001. 187(1-2): p. 57-69.

111. Zwijnenberg, H.J., et al., Acetone-stable nanofiltration membranes in deacidifying vegetable oil. Journal of the American Oil Chemists Society, 1999. 76(1): p. 83-87.

112. Koseglu, S.S. and D.E. Engelgau, Membrane Applications And Research In The Edible Oil Industry - An Assessment. Journal of the American Oil Chemists Society, 1990. 67(4): p. 239-249. 
113. Shi, D.Q., et al., Separation performance of polyimide nanofiltration membranes for concentrating spiramycin extract. Desalination, 2006. 191(1-3): p. 309-317.

114. Whu, J.A., B.C. Baltzis, and K.K. Sirkar, Nanofiltration studies of larger organic microsolutes in methanol solutions. Journal of Membrane Science, 2000. 170(2): p. 159-172.

115. Cao C. at al., , Biotechnol. Bioprocess Eng. 2001,6: p. 2728-2736

116. Sheth, J.P., et al., Nanofiltration-based diafiltration process for solvent exchange in pharmaceutical manufacturing. Journal of Membrane Science, 2003. 211 (2): p. 251-261.

117. Lin, J.C.T. and A.G. Livingston, Nanofiltration membrane cascade for continuous solvent exchange. Chemical Engineering Science, 2007. 62(10): p. 2728-2736.

118. Leger, C., H.D.L. Lira, and R. Paterson, Preparation and properties of surface modified ceramic membranes. Part II. Gas and liquid permeabilities of $5 \mathrm{~nm}$ alumina membranes modified by a monolayer of bound polydimethylsiloxane (PDMS) silicone oil. Journal of Membrane Science, 1996. 120(1): p. 135-146.

119. Javaid, A. and D.M. Ford, Solubility-based gas separation with oligomer-modified inorganic membranes - Part II. Mixed gas permeation of $5 \mathrm{~nm}$ alumina membranes modified with octadecyltrichlorosilane. Journal of Membrane Science, 2003. 215(1-2): p. 157-168.

120. Javaid, A., et al., Nanocomposite membranes of chemisorbed and physisorbed molecules on porous alumina for environmentally important separations. Journal of Membrane Science, 2006. 275(1-2): p. 255-260.

121. Javaid, A., et al., Solubility-based gas separation with oligomer-modified inorganic membranes. Journal of Membrane Science, 2001. 187(1-2): p. 141-150.

122. Leger, C., H.D. Lira, and R. Paterson, Preparation and properties of surface modified ceramic membranes .3. Gas permeation of $5 \mathrm{~nm}$ alumina membranes modified by trichlorooctadecylsilane. Journal of Membrane Science, 1996. 120(2): p. 187-195.

123. Miller, J.R. and W.J. Koros, THE FORMATION OF CHEMICALLY MODIFIED GAMMA-ALUMINA MICROPOROUS MEMBRANES. Separation Science and Technology, 1990. 25(13-15): p. 1257-1280.

124. Hyun, S.H., S.Y. Jo, and B.S. Kang, Surface modification of gamma-alumina membranes by silane coupling for $\mathrm{CO}_{2}$ separation. Journal of Membrane Science, 1996. 120(2): p. 197-206.

125. Abidi, N., et al., Surface modification of mesoporous membranes by fluoro-silane coupling reagent for $\mathrm{CO}_{2}$ separation. Journal of Membrane Science, 2006. 270(1-2): p. 101-107.

126. Yoshida, W. and Y. Cohen, Ceramic-supported polymer membranes for pervaporation of binary organic/organic mixtures. Journal of Membrane Science, 2003. 213(1-2): p. 145-157.

127. Younssi, S.A., et al., gamma alumina membranes grafting by organosilanes and its application to the separation of solvent mixtures by pervaporation. Separation and Purification Technology, 2003. 32(1-3): p. 175-179.

128. Kujawski, W., et al., Pervaporation properties of fluoroalkylsilane (FAS) grafted ceramic membranes. Desalination, 2007. 205(1-3): p. 75-86. 


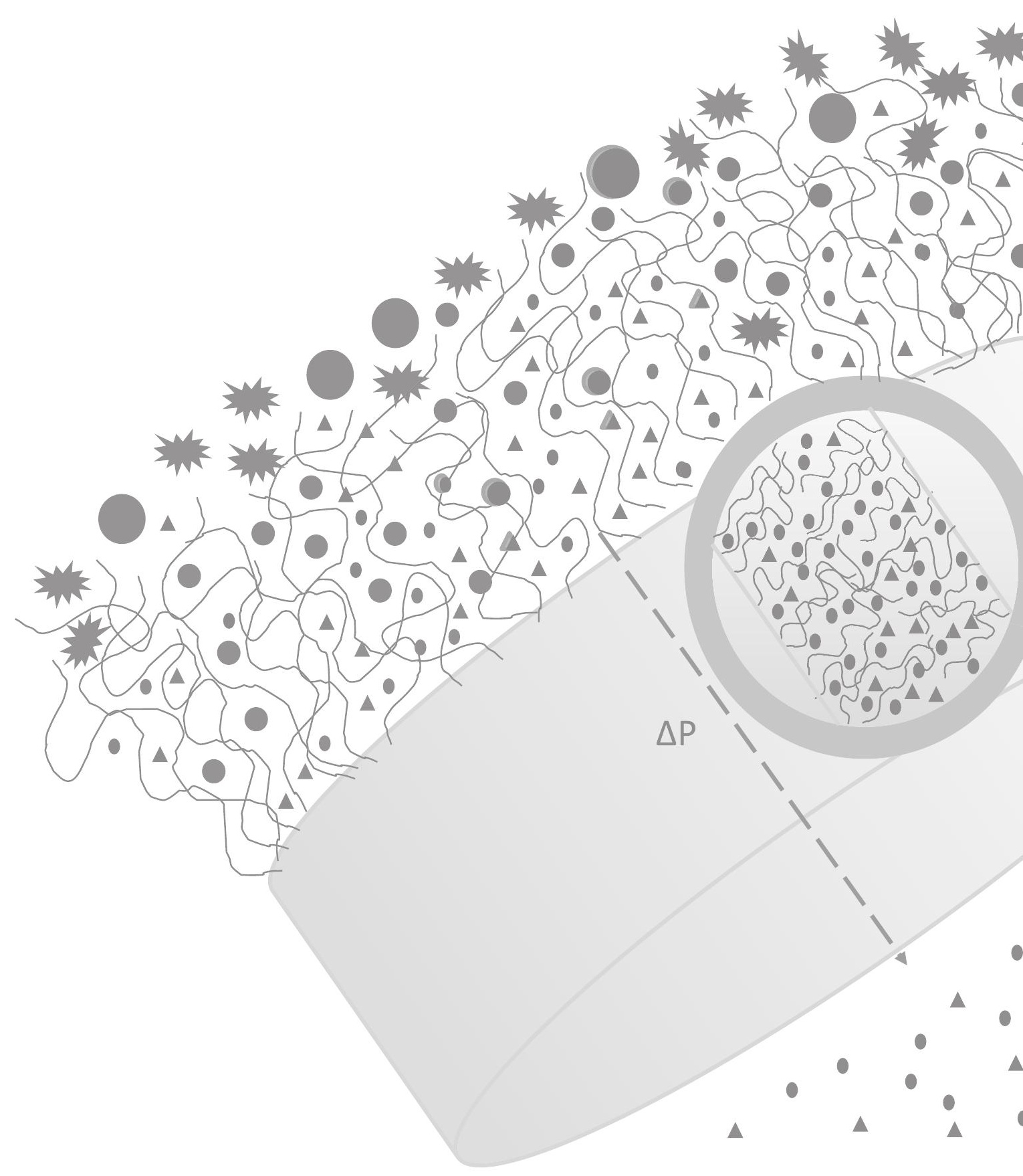


Chapter

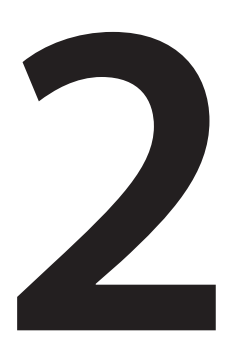

A state of the art on

Polymer-grafted ceramic

membranes

$$
\begin{aligned}
& \Delta \quad \Delta \quad \Delta \\
& 0_{0}^{\Delta} \bullet_{0}^{\Delta} \bullet^{\Delta} \\
& \begin{array}{llllll}
1 & \Delta & 0 & 0 & 0 \\
0 & 0 & 0 & 0 & 0
\end{array}
\end{aligned}
$$

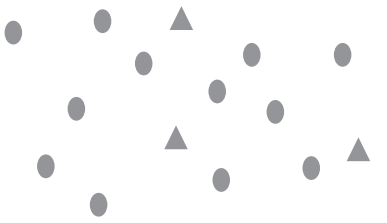




\subsection{Polymer-grafted ceramic membranes}

Solvent separations typically rely on energy intensive processes to create a liquidvapor interface. When dealing with macromolecular solutes and suspended particles (hydrophobic nanoparticles), continuous nanofiltration can be used to concentrate the processing phase and to reduce the energy consumption for product and solvent recovery. The ideal membrane would be capable of handling aggressive multicomponent solvent streams with large variations in feed pressure and temperature. Moreover, it is well known that nanofiltration separations are not only based on the pore size but also on factors as surface charge, polarity, hydrophobicity and surface energy.

Various chemical and physical techniques are proposed to modify existing membranes with the goal to improve membrane performance, e.g. chemical, mechanical and thermal stability as well as, eliminating swelling effects in polymeric membranes and enhancing permeability of ceramic membranes.

The majority of inorganic-polymer composite membranes rely on the physical attachment of the polymer or other compounds onto the surface of the inorganic substrate via solution casting [1], coating [2], coating a substrate followed by subsequent crosslinking [3, 4] or asymmetric incorporation of inorganic materials like powders [5] or zeolites $[6,7]$ in a polymer matrix .

In contrast, the ceramic-supported polymeric membranes, as discussed in this thesis, are based on a chemical modification. They are created by terminally and covalently bonding a layer of polymer chains onto the surface and in the pores of a porous ceramic support. Consequently, the polymer phase is even stable when, in contact with liquid mixtures in which the native polymer is (completely) soluble. The polymer imparts the desired membrane selectivity and hydrophobicity, while the ceramic support provides the structural integrity to the membrane system. This bonding of the polymer matrix to the ceramic and confinement in the pores is expected to reduce swelling of the polymer in organic solvents. Finally a wide variety of monomers can be used allowing one to design a tailor-made membrane, suitable for a specific separation. Such modifications can increase the performance of the membrane, on one hand by reducing the mean pore size, and on the other hand, by promoting an eventual specific interaction between the surface of the membrane and the permeating molecules, to enhance permeation and selectivity. 
Polymers can be chemically attached to metal oxide supports via:

- Surface-initiated radical polymerization [8] techniques as:

- Bulk or solution free-radical graft polymerization (FRGP) to reactive sites in the surface - "grafting from" or "graft polymerization" (Figure 1 right). The polymer chains are synthesized from the monomer molecules by initiating chain growth from an active center on the substrate surface [9-11]. e.g. azo [12-15], peroxo [16, 17], etc.

- Atomic transfer radical polymerization (ATRP) [18-20]

- Anionically-initiated polymerization (AGP) $[21,22]$

- Cationically-initiated polymerization (CGP)

- Reversible-addition and fragmentation chain transfer (RAFT) [23]

- Nitroxide mediated polymerization (NMP) [24, 25]

- Grafting of"living" polymer chains onto the surface - "grafting onto" or"polymer grafting" (Figure 1 left). Direct attachment of preformed chains, with one reactive end, to an anchoring site of the (ceramic) substrate surface [26]. For example poly(ethylene oxide) chains are grafted onto a silica surface group by direct covalent esterification of the silanol groups. An example is given in chapter 4 and 5, where a preformed PDMS polymer is grafted onto a $5 \mathrm{~nm}$ APTES grafted $\gamma$ - $\mathrm{Al}_{203}$ membrane.

- Plasma polymerization and deposition.

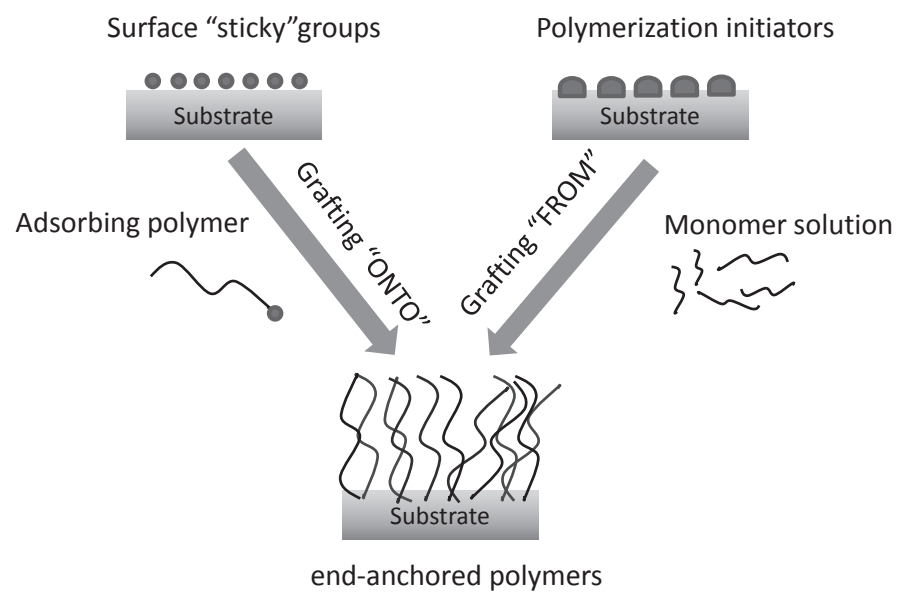

Figure 1: Right: Monomer addition to a growing chain, "grafting from" (graft polymerization); Left: Attachment of a growing chain from the bulk to the surface "grafting onto" (polymer grafting). 
All these processes result in a covalently bonded tethered polymer chain on the substrate surface.

The main advantage of polymer grafting over graft polymerization is a better control of the surface chain size of the grafted layer, however it also leads to a reduction in degree of coverage and graft yield, due to steric hindrance and diffusion limitation, associated with chain crowding as the homopolymer chains approach the surface. In contrast, for the process of graft polymerization: coverage is mainly affected by the diffusion of smaller monomers to the reactive sites on the surface, permitting a more uniform and dense surface coverage. When a more dense and uniform layer is preferred, the contribution of graft polymerization has to dominate relative to polymer grafting. A drawback for grafting can be the density of grafting sites, which in most cases is determined by the availability of surface hydroxyl groups on the oxide surface, serving as anchoring sites.

This literature report will focus on both polymer grafting which relies on the initiator species, in which polymers, as grown in solution, bind to reactive surface sites by polymer grafting, or on surface polymerization in which monomers undergo direct surface grafting from immobilized surface initiators by graft polymerization (e.g. surface-grafted reactive groups)

Generally, the grafted compound must contain two or three fragments: 1) a functional group that determines the chemical properties of the surface to be modified, 2) an anchoring group responsible for the immobilization of the grafted layer through covalent bonding and 3) a spacer (or linker) that connects the functional group to the anchoring group (Figure 2). In some cases the linker is already incorporated in the polymer structure, and thus the spacer is not required.
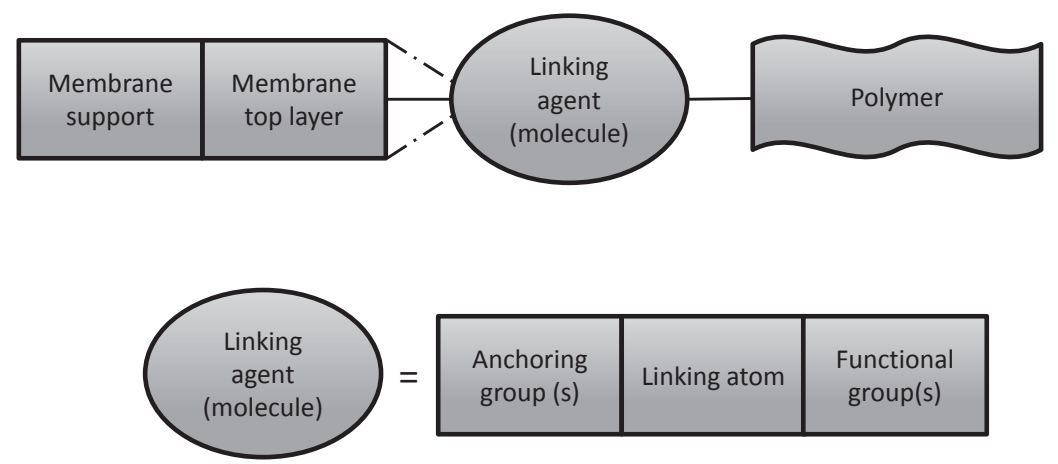

Figure 2: Structure of the surface of a chemically modified support. 
Modification of the surface of the oxide materials by an anchoring group usually involves electrophilic substitution, where a proton or a surface hydroxyl group is replaced by the anchoring group of the grafted group. Therefore the grafted molecule must contain a leaving group that forms a stable compound with a proton. One of the requirements for the cation of the anchoring group is that it should have at least a valence of two. Most often silicon and phosphorous compounds are used as anchoring elements. Other anchoring elements include B, C, N, S, Ge, As, Sn, Sb, Hg and Pb. Several surface modification methods have been described in the literature, including:

- Grafting of hydrophobic/hydrophilic silane molecules: alkoxysilanes $\left(\mathrm{R}_{4-\mathrm{n}} \mathrm{SiX}_{\mathrm{n}^{\prime}}\right.$ $\mathrm{X}=\mathrm{Cl}, \mathrm{OCH}_{3}, \mathrm{OC}_{2} \mathrm{H}_{5}$ ) e.g. alkyl- [27], chloro-, amino- [28-31], thiol- [32, 33], epoxy- [18], vinyl- [34-36] or fluoroalkylsilanes [37-39].

- Grafting of phosphorous organic compounds (e.g. phosphonic acids) [40].

- Esterification by alcohols (e.g. methanol, ethanol. 1-propanol) [41].

- Chlorination by thionyl chloride $\left(\mathrm{SOCl}_{2}\right)$ [20, 42-44].

- Chlorination by thionyl chloride followed by the reaction with $\mathrm{LiAlH}_{4}$ generating an $\mathrm{M}$ (metal) - $\mathrm{H}$ surface which then by an hydrosilylation reaction with a with a vinyl-terminated compound generates a $\mathrm{M}$ (metal) - $\mathrm{H}-\mathrm{CH}_{2}-\mathrm{CH}_{2}-\mathrm{R}$ [45].

- Modification by dehydroxylation route by using Grignard reactants (RMgX) or lithium coumpounds (RLi) $[44,46,47][48]$. This is usually performed in activated surfaces, e.g. Si-Cl, Si-Br, Si-I, Si-H.

- Grafting of polymeric alcohols, like poly(vinyl alcohol) (PVA) and high boiling alcohols (e.g. octanol, octadecanol) [49, 50].

- Grafting of silanated-terminated polymers, e.g. silanated-poly(ethylene glycol) (PEG) [51, 52], 3-(trimethoxysilyl)propyl methacrylate [53] and a poly $(\mathrm{N}$ acetylethylenimine) [54].

- Grafting of polysiloxanes (e.g. PDMS) [55].

- Grafting isocyanate-terminated polybutadiene [56], poly(ethelyne oxide) (PEO) [57], poly(propylene glycol) (PPG) [58, 59].

- Chemical vapor deposition (CVD) [60-63].

- Chemical vapor infiltration (CVI) [64].

- Plasma graft polymerization of several polymers, e.g. polyvinyl polymers [65].

- Induced plasma chemical process-vapor deposition (SPCP-CVD) [66, 67]

In section 2.2 a detailed description is given of the silylation mechanism and the influence of several reaction parameters (e.g. water content,reaction phase, nature 
of the silane, reaction temperature and time) will be discussed. Some examples of silane grafted membranes and their applications are also reported. In section 2.3 phosphorous coupling will be introduced. The reaction mechanism and some examples will be also discussed. In section 2.4 a detailed description of different modification methods of ceramic surfaces by different grafted polymers (e.g. PDMS, polyimides, polyvinyl polymers, etc.) will be treated.

\subsection{Silane coupling agents as surface modifiers}

Silane coupling agents are silicon based chemicals that contain two types of reactive groups - inorganic and organic - in the same molecule. A typical structure of such a coupling agent is:

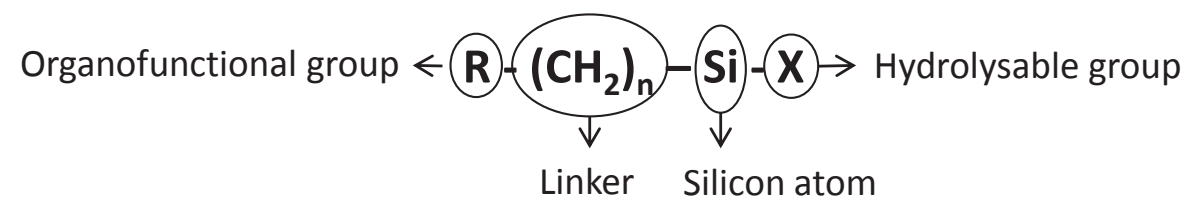

where $\mathrm{X}$ is a hydrolysable group typically alkoxy, chloro and $\mathrm{R}$ is a non-hydrolysable organo-functional group that possesses a functionality (amino, epoxy, vinyl, metacrylate, thiol, etc) that imparts the desired (separation) characteristics or the proper chemistry for further grafting of the polymer.

A silane coupling agent will act as an interface (anchoring group) between an inorganic material (including metals) and an organic material. The final result of the reaction of an organosilane with a substrate ranges from altering the wetting or adhesion characteristics of the substrate, utilizing the substrate to catalyze chemical transformations at the heterogeneous interface, ordering the interfacial region and modifying the partition properties. Especially, it includes the ability to realize a covalent bond between organic and inorganic materials, providing a stable bond between two otherwise poorly bonding surfaces. Besides coupling agents, silanes can be used as agents to crosslink polymers (Figure 3) such as acrylates, polyethers, polyurethanes and polyesters which then by a silylation reaction can be reacted with the inorganic surface.

Vinyl silanes, like vinyltriethoxysilanes, can form covalent bonds to the polyethylene backbone, yielding a silane-modified polyethylene that contains a pendant trialkoxysilyl functionality. This type of functionalization can represent an 
interesting path to promote the attachment of polymeric materials to inorganic surfaces by a silylation reaction between the pendant silyl groups and the $\mathrm{OH}$ groups of the inorganic material.

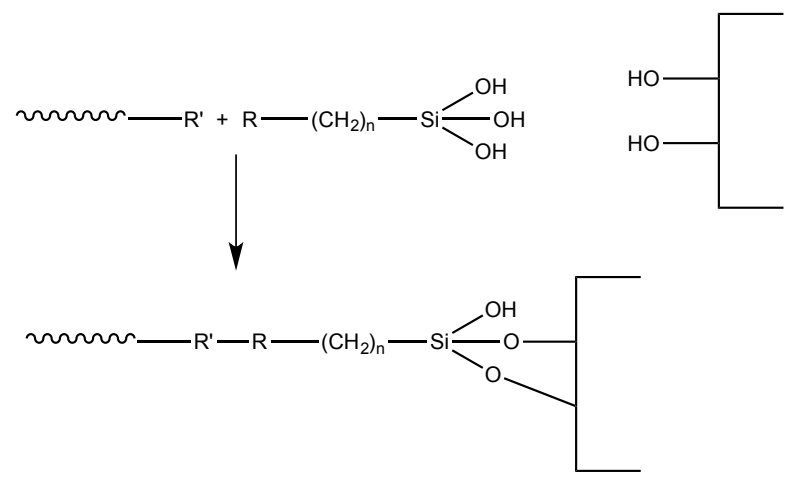

Figure 3: Schematic representation of the attachment of a polymer-silane molecule to a silica oxide surface.

Another advantage of these compounds is their ability to change the hydrophilic character of a surface to a hydrophobic one. For instance, silanes with alkyl groups (such as butyl and octyl) and aromatic groups (such as phenyl) and even some organofunctional groups (such as chloropropyl and methacrylate) are hydrophobic. The selection of the silane has therefore a major influence with regard to application. Two different perspectives should be taking into account:

- The properties of the polymeric matrix such as: chemical reactivity, solubility and structural characteristics. These should match with the ones of the silane.

- The physical and chemical properties of the inorganic interphase such as: type and concentration of surface hydroxyl groups, water content, hydrolytic stability of the bond formed, physical dimensions of the substrate (pore size, pore structure) or substrate features (roughness).

Therefore, a better understanding of the silylation reaction is needed. A detailed description of the reaction mechanism, synthetic routes and some examples will now be described. 


\subsubsection{Silylation reaction mechanism and influence of the reaction conditions}

Chemical modification of oxide surfaces (e.g. silica, alumina, zirconia) by silylation is a well-known method for altering the chemical and physical properties of ceramic substrates. Two general strategies can be followed. The first strategy is to make a hydrophobic layer by in situ hydrolysis and condensation of alkoxide precursors with hydrophobic side groups, such as organosilanes or bridged silsesquioxanes, the so-called hybrid membranes [68-76]. De Vos and Verweij [76] prepared hydrophobic silica layers using a combination of tetraethoxysilane and methoxysilane as a hydrophobic agent, which results in a microporous silica membrane with ethyl groups incorporated in the silica structure. As a result the surface and microstructural properties of the microporous silica changed significantly.

The second strategy, which is going to be employed in the present project, is to post-modify a mesoporous inorganic membrane by grafting the internal pore surface with organosilanes [14, 27, 29, 37, 38, 55, 77-86]. Hydroxyl groups covering the surface of metal oxides can serve as reactive sites to anchor monolayers by covalent bonds. Reaction with mono-, di- and trifunctional organosilanes are of particular interest. Apart from good thermal stability, such layers also resist in some extend to hydrolytic degradation, especially with increasing surface coverage [87]. Modification of a surface can be achieved either by:

- Exposing it directly to a silane vapor (vapor phase reaction).

- Immersing it in a solution containing the silane reagent (liquid phase reaction). It is generally accepted that silylation performed in the vapor phase or with monofunctional silanes result in a monolayer or near-monolayer surface coverage. For several applications monolayer silylation coverage may be desired, such as promotion of adhesion between polymers and ceramics, for molecular recognition sensors, lubricating films in digital mirror devices, etc. However, for applications where the organosilane molecules provide a specific functionality, multilayer coverage can be more appropriate. For example, in the free-radical graft polymerization the vinyl-silane groups, bonded to the surface during silylation, provide vinyl anchoring sites for polymer chains $[9,11]$. In this case the maximum chain surface density is largely controlled by the initial surface concentration of the vinyl groups, which also affects the yield and distribution of grafted polymer chains on the support surface $[10,88]$.

Coverage by multilayer silylation can be achieved using a di- or trifunctional 
silylating agents in either aqueous or anhydrous (i.e., organic solvent) solvents, while the choice of the solvent largely affects the resulting silylation coverage [89-92]. Specifically, in an aqueous environment the chloro and alkoxy groups of multifunctional organosilanes undergo bulk hydrolysis and (inter)condensation, forming polysilane networks before depositing onto the substrates [92]. As a result, the fraction of initial surface silanols that reacts with the functional organosilanes is quite small, and the silylation process is usually nonuniform and difficult to control $[29,31]$.

In contrast, in an anhydrous silylation reaction (e.g. in toluene) condensation and hydrolysis between one or more functional groups of neighboring silane molecules mainly occurs on the surface with minimal intercondensation between silane molecules in the bulk phase $[85,89,92]$. For these multifunctional silanes, silylation occurs by hydrolysis of one or more of the chloro or alkoxy groups by water, which is preadsorbed on the support surface [89, 91, 93], present in the solvent (traces of humidity) [93, 94] or provided by a post-silylation curing [93], followed by releasing of hydrochloric acid $(\mathrm{HCl})$ or an alcohol $\left(\mathrm{CH}_{3} \mathrm{OH}\right.$ or $\left.\mathrm{CH}_{3} \mathrm{CH}_{2} \mathrm{OH}\right)$ for chloroor alkoxysilanes, respectively (equation 1). In a second step the hydrolyzed silane is adsorbed via hydrogen bonding and reacts with the surface $\mathrm{OH}$ group to form a M-O-Si bond via a condensation reaction (equation 2):

$$
\begin{aligned}
& \mathrm{RSi}(\mathrm{X})_{f}+m \mathrm{H}_{2} \mathrm{O} \longrightarrow \mathrm{RSi}(\mathrm{X})_{(f-m)}(\mathrm{OH})_{m}+\mathrm{HX}_{m} \\
& \text { Hydrogen bond: } \mathrm{RSi}-\mathrm{OH}+\mathrm{OH}-\mathrm{M} \rightleftarrows \mathrm{RSi}-\phi-H^{\prime} \\
& \text { H-O-M } \\
& \mathrm{RSi}(\mathrm{X})_{(f-m)}(\mathrm{OH})_{m}+\mathrm{HO}-\mathrm{M} \rightleftarrows \mathrm{RSi}(\mathrm{X})_{(f-m)}(\mathrm{OH})_{m-1}-\mathrm{O}-\mathrm{M}+\mathrm{H}_{2} \mathrm{O}
\end{aligned}
$$

Where $\mathrm{X}$ is an alkoxy or chlorine $\left(-\mathrm{OCH}_{3^{\prime}}-\mathrm{OCH}_{2} \mathrm{CH}_{3}\right.$ or $\left.\mathrm{Cl}\right)$ group, $\mathrm{M}$ is a surface molecule (i.e. $\mathrm{Si}, \mathrm{Al}, \mathrm{Zr}$ ), and the number of hydrolyzed groups, $m$, is less than or equal to the maximum functionality, $f$, of the precursor silane. It should be noted that the general forms of equations 1 and 2 do not preclude the possibility of silane attached to the surface via multiple points through sequential or simultaneous steps. The hydrolysis reaction (equation 1) is a requirement for condensation; direct condensation between chloro- or alkoxysilanes and surface hydroxyl groups, in the absence of an amine catalyst or water, is not observed [31, 82, 94-96]. 
Once initial surface silylation is achieved via a first-layer reaction (equation 1 and equation 2; see also Figure 4a), a subsequent growth of the silylated surface layer will proceed by multilayer silylation reactions (Figure 4b). Nevertheless, first layer and multilayer reactions can proceed simultaneously at different places of the surface.

a)<smiles>[X][Si]([R])([X])C(C)O</smiles>

b)

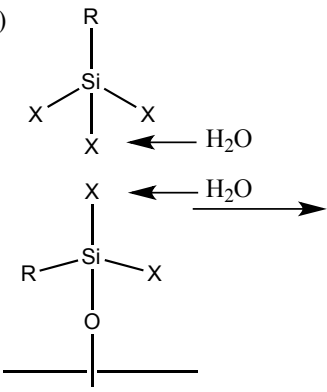<smiles>[R][Si]([X])([X])O</smiles>

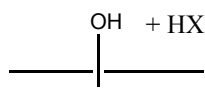<smiles>[R][Si]([X])([R])O</smiles><smiles>[X][Sn]([R])([X])OC(C)C</smiles>

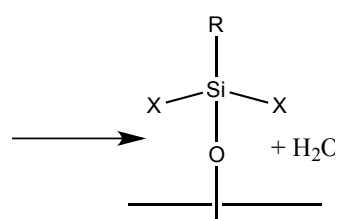

$\longrightarrow$ -

c)

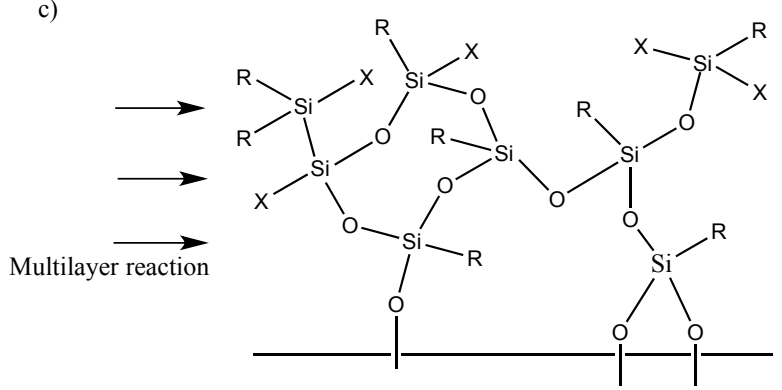

Figure 4: (a) Reaction of initial silane coverage (hydroxyl/alkoxy/chlorine), (b) Reaction for multilayer silane coverage (alkoxy/alkoxy or chlorine/chlorine), (c) Surface-bonded multilayer polysiloxane resulting from initial and multilayer reactions.

In a multilayer silylation reaction (Figure 4b and c) hydrolyzed alkoxy groups of a free silane (molecule 1, M1) (equation 3) undergo hydrolysis with a surface silane (molecule 2, M2) (equation 4) followed by a homocondensation reactions (equation 5)

$\mathrm{RSi}(\mathrm{X})_{\mathrm{m} 1}+\mathrm{H}_{2} \mathrm{O} \longrightarrow \mathrm{RSi}(\mathrm{X})_{m 1-1}(\mathrm{OH})+\mathrm{HX}$ 
$\mathrm{RSi}(\mathrm{X})_{\mathrm{m} 2}-\mathrm{M} \equiv+\mathrm{H}_{2} \mathrm{O} \longrightarrow \mathrm{RSi}(\mathrm{X})_{m 2-1}(\mathrm{OH})-\mathrm{M} \equiv+\mathrm{HX}$

$\mathrm{RSi}(\mathrm{X})_{m 1-1}(\mathrm{OH})+\mathrm{RSi}(\mathrm{X})_{m 2-1}(\mathrm{OH})-\mathrm{M} \equiv \longrightarrow \mathrm{RSi}(\mathrm{X})_{m 1-1} \mathrm{Si}-\mathrm{O}-\mathrm{Si}(\mathrm{R})(\mathrm{X})_{m 2-1}(-\mathrm{M} \equiv)+2 \mathrm{H}_{2} \mathrm{O}$

The presence of water appears to be necessary for complete monolayer formation. However, as we can see in equations 3 and 4, homocondensation increases as the water content increases and the risk therefore is to form multilayers by polymerization of multifunctional organosilicon molecules (Figure 4c). Because, usually the silylation agent used is greatly in excess, the degree of multilayer silylation coverage is limited by the consumption of surface water.

The influence of water content in the silylation coverage and in the quality of the monolayer has been extensively studied [90, 96-99]. Silberzan et al. [94], along with Angst et al. [97] have shown that the water content on the surface is vital for the formation of a complete monolayer. Angst and Simmons were able to obtain a tightly packed monolayer on a fully hydrated oxidized silicon wafer, whereas reaction with a dry silicon wafer gave a disordered monolayer with a lower surface coverage. Yoshida et al. [85] demonstrated for the silylation with VTMS (vinyltrimethoxysilane) onto a zirconia or silica surface that the surface silylation coverage was found to be negligible at low surface water coverage (Figure 5) but increases quickly with the number of water monolayers to a maximum at around 2-3 water monolayers - thickness between 2.69-4.27 ^ followed by a marked decline at higher initial surface water coverage.

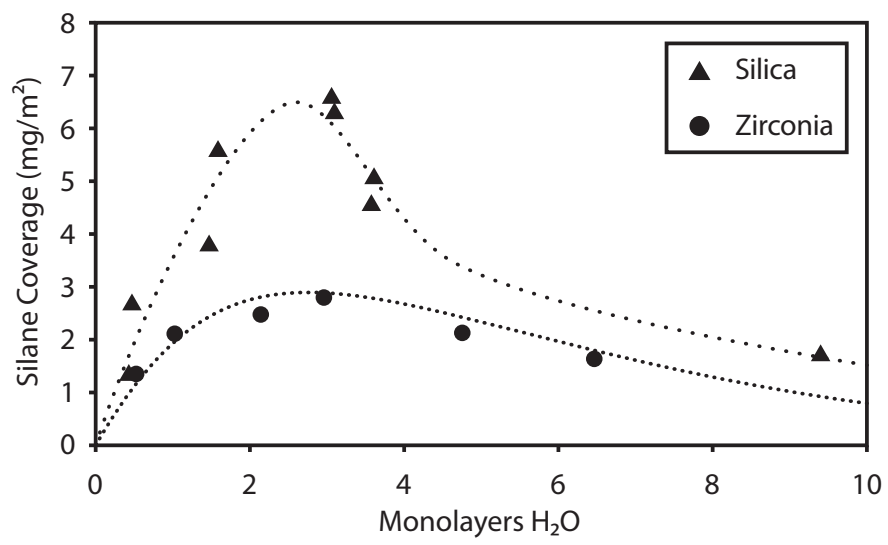

Figure 5: Effect of surface water on the silylation coverage for silica and zirconia particles [85]. 
Yoshida et al. propose that this tendency in the trend on silylation coverage at high surface water concentration is related to the hydrophobic nature of the nonreacting group, in this case the vinyl group. Therefore, if the thickness of the surface water layer exceeds the size of the VTMS molecule $(3,02 \AA)$, which correspond to a thickness of 2-3 water monolayers, the penetration and access to the surface would become increasingly difficult. The silane molecules might condense in the water layer without covalent attachment to the surface. Once these agglomerates reacted with the external support surface they could further reduce the uniformity of the monolayer by blocking other, non-polymerized silanes from diffusing into the pore openings, forming a thin polymeric layer, which would affect the performance of the membrane due a less deeply penetrating silane layer. Another interesting observation was that lower silylation coverage for zirconia particles was observed (see Figure 4). This may be due to the lower $[\mathrm{OH}]_{\text {surface }}$ of the fully hydroxylated zirconia (5.6-5.9 $\left.\mathrm{mmol} \mathrm{m}^{-2}\right)$ compared with silica $\left(7.4 \mu \mathrm{mol} \mathrm{m} \mathrm{m}^{-2}\right)$. Similar observations were reported by McGovern et al. [90], where an excess of water resulted on the condensation of the silanes on the top of the water monolayers. In this case the silane layer could be easily floated off [94]. Tripp and Hair [96] also reported that, if a thick surface layer is present, silane molecules might condense in the water layer without covalent attachment to the surface preventing the subsequent attachment by other silane molecules. However, extensive washing could help to remove these physically deposited silanes [85].

Simon et al. [100] have studied the influence of a water film, adsorbed on the surface and the amount of water on the grafting of a hydrophilic 3-aminopropyltriethoxysilane (APTES) onto a silica surface. They demonstrated that grafting in an anhydrous solution is more homogeneous and thermally stable than grafting in an acid-aqueous solution resulting in a limited number of APTES aggregates. Furthermore, results showed that anhydrous silylation promote the formation of a more hydrophobic and homogeneous monolayer.

Kurth et al. [29] modified aluminum oxide with a 3-aminopropyltriethoxysilane (APTES) and studied the influence of using an aqueous or anhydrous solvent for the silylation reaction on the type of layer formed. Results showed that adsorption from aqueous solutions results in oligomeric species and the film thickness is greater than that of monolayers, whereas adsorption from boiling vapors results in thin films of approximately two or three layers of thickness. In a humid atmosphere it is also shown that the thickness increases with exposure time.

In conclusion, the structure of these hybrids, based on silicon coupling 
molecules (alkoxy- and chlorosilanes), is governed by a competition between heterocondensation and homocondensation reactions. This balance depends on the nature of the support as mentioned earlier for Si and $\mathrm{Zr}$ (Figure 5), on the water content and on the nature of the organosilanes. The nature of the organosilanes (number and type of functional groups) can also influence the silylation coverage to a great extent.

An alternative strategy for the use of water as a catalyst is the use of a base catalyst to promote the reaction of silanes with surface $\mathrm{OH}$ [89, 101-103]. Tripp et al. [101], reported a method that uses a nitrogen-containing base (e.g. triethylamine, TEA) to promote the direct reaction of the chlorosilyl head group with the surface hydroxyl group, where the amine and the silane are added sequentially in two steps. First, the silica is evacuated and exposed to the vapor of the nitrogen containing base which forms a strong hydrogen bond with the surface silanols. The excess base is removed by evacuation and the silica is then placed in contact with the chlorosilane. It is the evacuation of the excess of the amine that suppresses the polymerization. The base catalyzes the reaction immediately and leaves the chlorosilane chemically attached to the surface of the silica. Through this method, it is possible to control the amount of silane attached by limiting the amount of base initially attached to the surface. This results in the formation of multilayer systems in a controlled manner, by the deposition of sequential layers of silanes, with potential applications as chromatography and moleculair recognizing sensors.

The degree of silylation coverage, obtained via anhydrous silylation of an inorganic oxide surface, not only depends on the degree of hydration but also on the hydroxylation degree of the surface. During the preparation of ceramic membranes firing at high temperatures is usually required $\left(650-1200{ }^{\circ} \mathrm{C}\right)$. This results in the depleting of the $\mathrm{OH}$ surface groups. To restore the $\mathrm{OH}$ groups a pretreatment step is usually required.

Luebke et al [104], have studied the impact of different parameters during the pretreatment upon the silylation of alumina membranes with octadecyltrichlorosilane. These include: firing temperature, hydroxylation technique $\left(\mathrm{H}_{2} \mathrm{O}_{2} \mathrm{H}_{2} \mathrm{O}_{2}\right)$, drying temperature $\left(80{ }^{\circ} \mathrm{C}\right.$ or $\left.150{ }^{\circ} \mathrm{C}\right)$, and silylation temperature $\left(25^{\circ} \mathrm{C}\right.$ or $\left.0^{\circ} \mathrm{C}\right)$. An increase in the intensity of the FTIR band of the bound silanes $\left(\omega=2800-3000 \mathrm{~cm}^{1}\right)$ species were observed when $\mathrm{H}_{2} \mathrm{O}_{2}$ was used as hydroxylation agent and by drying at $80^{\circ} \mathrm{C}$ rather than at $150^{\circ} \mathrm{C}$. Moreover, it was demonstrated that a reduction in reaction temperature results in greater penetration of the silane into pores of the support and a corresponding increase in overall silane loading of the membrane. 
Besides the water content and the solvent nature, other experimental parameters as the temperature $[31,94,105]$, reaction time [106] and silane concentration plays a crucial role in the surface coverage and in the thickness of the grafted layer and it's homogeneity.

\subsubsection{Vapor phase vs. solution phase silylation}

As discussed before, deposition of silanes from the liquid phase has been found to suffer from the deposition of aggregated alkylsilane molecules, which can result in non-uniform layers with poor quality or in multilayer formation. The main reason is the presence of water or traces of humidity that are difficult to eliminate even in reactions performed in nonaqueous solvents, as discussed before, whereas the water adsorbed onto the metal oxide surface can easily be removed e.g. by evacuation at room temperature [107]. However, in practice it is impossible to stop the competitive self-polymerization reactions taking place in solution. An alternative is the use of vapor phase methods $[27,29,107,108]$. Several studies involving silylation in the gas phase have been performed by using alkyl-[108], alkoxy- [29, $107,109-112]$ or chlorosilanes $[27,113,114]$ as well as hexamethyldisilazane $[115$, 116]. This vapor phase reaction is considered to be more convenient since the presence of water can be excluded in a simple way and undesired adsorption of silane aggregates can be prevented because oligimeric precursors in solution have lower vapor pressure and are rarely vaporized. Furthermore the use of a vapor-phase process allows for higher reaction temperatures meaning that a direct reaction of gaseous alkoxy- or chlorosilanes can occur via surface hydroxyl groups occurs of silica at $300{ }^{\circ} \mathrm{C}$ with no need of water $[107,117]$. The use of vapor phase methods also eliminates many of the tedious operations of the alternative methods, such as solvent removal and recovery, washing procedures and many other manipulations. It has also been observed that alkylsilane overlayers, deposited from the gas phase, are better ordered than layers deposited in toluene solutions [108].

The sensitivity of silane molecules towards water is even more enhanced for amino silanes like aminoalkoxysilanes, since the amino groups self-catalyzes the formation of both chemisorbed species and polymerized products. Further complications arise because the amine functionalities compete with the alkoxy moieties for surface sites [30, 107, 118-120]. The adsorbed amine groups interact with $\mathrm{OH}$, present at the metal oxide surface, and/or with adjacent hydrolyzed APTES via hydrogen bonding or electrostatic interactions. This considerably reduces the number of available $\mathrm{OH}$ groups on both the metal oxide surface 
and for further siloxane condensation. The amount of $\mathrm{H}$-bonded and protonated species is dependent on the amount of water. Therefore, the use of a vapor phase method for grafting of aminoalkoxysilanes can be very advantageous. In chapter 4, 5, 6 and 7 examples are given.

Kurth et al. [29], demonstrated that vapor phase adsorption of APTES at room temperature is a convenient method to prepare thin films when compared with solution phase methods (boiling solvent). Ek et al. [28], modified a porous silica with mono-, di- and triaminopropylalkoxysilanes by a gas-phase, atomic layer deposition (ALD). By means of this technique, surface-saturated overlayers can be reproducibly deposited on solid surfaces. Physisorption of precursors could be avoided by using elevated temperatures to promote evaporation and purging physisorbed molecules from the surface with inert gas. Hydrogen bonding of precursors with silanols of silica, hydrolysis of alkoxy groups of cross-polymerization was avoided by depositing via the gas phase. A reaction temperature of $150{ }^{\circ} \mathrm{C}$ (at a pressure 20-50 mbar) was enough to achieve saturation of the silica surface with all aminosilanes studied. The degree of hydroxylation and in some degree the structure of the precursor, was found to affect the surface density of amino groups and surface species in silica. The densest surface-saturated molecular layers were achieved with difunctional and trifunctional silanes that are 2.0-2.1 molecules $\mathrm{nm}^{-2}$, on silica pretreated at $200^{\circ} \mathrm{C}$. The pretreatment temperatures of silica $\left(200-800{ }^{\circ} \mathrm{C}\right)$ can also control the surface density of amino groups (2.1-1.1 molecules $\mathrm{nm}^{-2}$ ). The surface density of amino silanes on silica decreased when the heat-treatment of silica was increased.

Modifications based on vapor phase methods have also been reported for the deposition of fluoroalkylsilanes [121-123].

\subsubsection{The influence of the silane nature in the silylated grafted layer.}

Depending on the reaction conditions (temperature, time, and solvent) surface history, as mentioned earlier, a number of different structures can be produced as discussed before. Another parameter that has a crucial influence on the properties of the layer formed is the nature of the silane like the size $[27,78]$, the number of functional groups $[95,117,124]$, the hydrophilicity/hydrophobicity $[125,126]$, and steric hindrance [127]. The complexity of this chemistry is illustrated in Figure 6 for a silicon dioxide surface [128] 


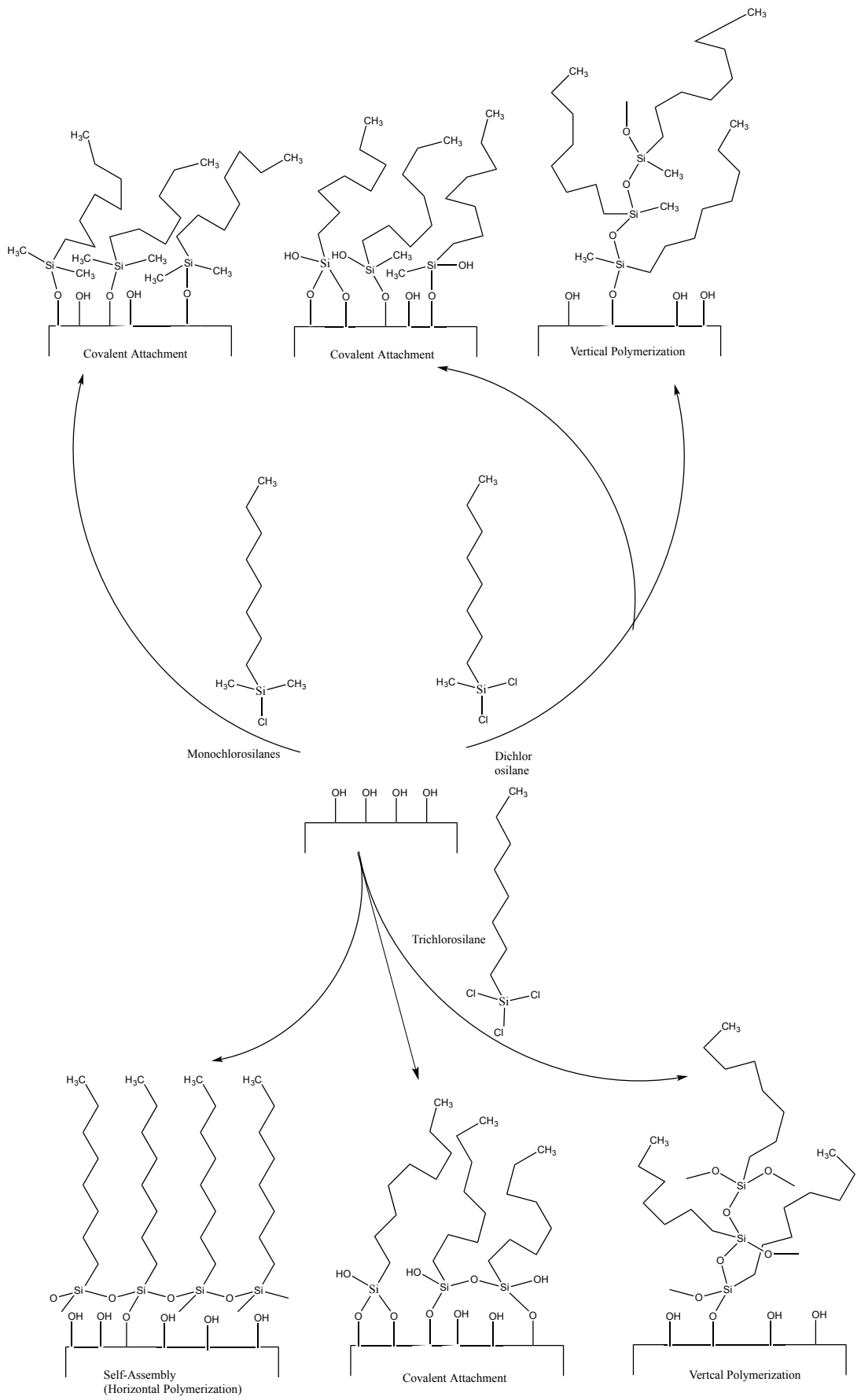

Figure 6: Possible products of the reaction of alkylchlorosilanes onto a silica dioxide surface [128] 
Monofunctional organosilanes $\left(\mathrm{R}_{3} \mathrm{SiX}, \mathrm{X}=\mathrm{Cl}, \mathrm{OR}, \mathrm{N}\left(\mathrm{CH}_{3}\right)_{2}{ }_{2} \mathrm{OH}, \mathrm{H}\right)$, having only one hydrolysable group in the molecule are attractive in terms of reproducible surface structures, because only one type of grafting is possible in the system (Figure 6), namely a covalent attachment to the surface by chemical bonds (Si-O-Si). In solution the reaction of multifunctional silanes with solid interfaces are very slow in the later stages of the reaction and long reaction times are required to maximum bonding densities [129]. Trifunctional organosilanes ( $\mathrm{RSiX}_{3}$ ), if compared with their monofunctional analogues, are more reactive and are capable to polymerize in the presence of water, which gives rise to a number of possible surface structures (Figure 6). Under certain conditions the reaction of long-chained trifunctional silanes gives monolayers that are closely packed and highly ordered. These monolayers are usually referred to as self-assembled monolayers (SAMs). For difunctional organosilanes $\left(\mathrm{R}_{2} \mathrm{Si} \mathrm{X}_{2}\right)$, covalent attachments as well as surfaceinduced polymerization to form grafted polysiloxanes are conceived reactions with inorganic substrates. Dimethyldichlorosilane and octadecylmethyldichlorosilane were shown to react with silica surface, yielding covalently attached monolayers $[130,131]$.

Granier et al. [132] grafted oxidized silicon wafers with octadecylchlorosilanes under anhydrous conditions to determine the influence of the number of hydrolysable functions on the quality of the film deposited on the surface. The surfaces obtained after grafting of the tri- and difunctional silanes, where cross-linking is possible, are hydrophobic with a very dense film of organized alkyl chains in the all-trans configuration. On the other hand, in the case of the monochlorosilane which can attach to the surface only by reaction with surface silanol a less organized and dense film of monografted species is obtained.

\subsubsection{Silane Grafted Membranes: Applications}

Modification of ceramic surfaces by silanes has been extensively reported in the literature. The majority of these studies are focused on gas separations, pervaporation or desalination and only a few in liquid separations, particularly in non-aqueous applications. In Table 1 some examples of silylating agents used for modification of inorganic surfaces are listed. Applications and information about the support is also included. 
Table 1: Some examples of silylating agents used for modification of inorganic surfaces

\begin{tabular}{|c|c|c|c|c|}
\hline Silane Agent & Inorganic support & $\begin{array}{l}\text { Silylation } \\
\text { method }\end{array}$ & Application & Ref \\
\hline \multicolumn{5}{|l|}{ Alkoxysilanes } \\
\hline MTMS, DMDMS & $\mathrm{v}-\mathrm{Al}_{2} \mathrm{O}_{3} / \mathrm{a}-\mathrm{Al}_{2} \mathrm{O}_{3}(5 \mathrm{~nm})$ & Liquid & $\begin{array}{l}\text { Pervaporation of different } \\
\text { solvent mixtures } \\
\text { (e,g. Ciclohexane/toluene } \\
\text { MEK/ciclohexano) }\end{array}$ & {$[86,133]$} \\
\hline MPTMS & Silica molecular sieves & & $\begin{array}{l}\text { Adsorbents for heavy metal } \\
\text { ions }\end{array}$ & $\begin{array}{l}{[134,} \\
135]\end{array}$ \\
\hline PTES & $\begin{array}{l}\mathrm{Y}-\mathrm{Al}_{2} \mathrm{O}_{3} / \mathrm{TiO}_{2} \\
\quad(4.4 \mathrm{~nm})\end{array}$ & Liquid & Gas separation & [136] \\
\hline \multicolumn{5}{|l|}{ Aminoalkoxysilanes } \\
\hline APTMS, APTES, APDMES & $\mathrm{a}-\mathrm{Al}_{2} \mathrm{O}_{3}(100 \mu \mathrm{m})^{1}$ & Liquid & $\begin{array}{l}\text { Separation of a racemic of } \\
\text { D, L-tryptophan }\end{array}$ & [137] \\
\hline APTES & SBA-15 & Liquid & $\begin{array}{l}\text { Removal of heavy metals } \\
\text { from aqueous solutions }\end{array}$ & $\begin{array}{l}{[138,} \\
139]\end{array}$ \\
\hline \multicolumn{5}{|l|}{ Flouroalkoxysilanes } \\
\hline $\begin{array}{l}\text { n-octadecyltriflouroace- } \\
\text { toxysilane }\end{array}$ & Silica particles & $\begin{array}{l}\text { Liquid/ } \\
\text { Vapor }\end{array}$ & $\begin{array}{l}\text { Reverse-phase packings for } \\
\text { HPLC }\end{array}$ & [140] \\
\hline FOTES & Silica wafers & Vapor & No application & $\begin{array}{l}{[121,} \\
141]\end{array}$ \\
\hline $\begin{array}{l}\text { FMTES, FOTES, FHTES, } \\
\text { FPTS }\end{array}$ & $\begin{array}{c}\mathrm{Y}-\mathrm{Al}_{2} \mathrm{O}_{3} / \mathrm{a}-\mathrm{Al}_{2} \mathrm{O}_{3}(5 \mathrm{~nm}), \\
\mathrm{a}-\mathrm{Al}_{2} \mathrm{O}_{3} / \mathrm{ZrO}_{2} \mathrm{NF} \\
\mathrm{Anodisc}^{\mathrm{TM}} \\
(20,200 \mathrm{~nm})\end{array}$ & Liquid & $\begin{array}{l}\text { Desalination of salt solutions } \\
\text { (NaCl) } \\
\text { Pervaporation of } \mathrm{H}_{2} \mathrm{O} / \mathrm{EtOH} \\
\text { and } \mathrm{H}_{2} \mathrm{O} / \mathrm{MTBE} \\
\text { Water ozonation }\end{array}$ & $\begin{array}{l}{[37,39} \\
142-146]\end{array}$ \\
\hline FOTS & Membralox ${ }^{\oplus}(4 \mathrm{~nm})$ & Vapor & $\begin{array}{l}\text { Gas separation } \\
\text { Recuperation of toluene from } \\
\left.\text { lube oil (MW=600 } \mathrm{gmol}^{-1}\right)\end{array}$ & {$[147]$} \\
\hline FOTES & $\mathrm{\gamma}-\mathrm{Al}_{2} \mathrm{O}_{3}(5 \mathrm{~nm})$ & Liquid & Gas separation & [148] \\
\hline \multicolumn{5}{|l|}{ Chlorosilanes } \\
\hline OTS & $\begin{array}{l}\text { Membralox } \\
\gamma-\mathrm{Al}_{2} \mathrm{O}_{3} 4 \mathrm{~nm}\end{array}$ & Liquid & $\begin{array}{l}\text { Removal of VOCs from water } \\
\text { or air }\end{array}$ & [149] \\
\hline $\begin{array}{l}\text { Alkyltriclhorosilanes, } \\
\text { number of car- } \\
\text { bons=1-18 }\end{array}$ & $\begin{array}{c}\mathrm{Y}-\mathrm{Al}_{2} \mathrm{O}_{3} \\
(5,10,12 \mathrm{~nm})\end{array}$ & Liquid & $\begin{array}{l}\text { Gas separation } \\
\mathrm{CO}_{2} \text { separation fom fuel gas }\end{array}$ & $\begin{array}{l}{[79,80} \\
150-154]\end{array}$ \\
\hline PTS & $\mathrm{\gamma}-\mathrm{Al}_{2} \mathrm{O}_{3}(2.2 \mathrm{~nm})$ & & Gas separation & [136] \\
\hline TCMS & $\begin{array}{l}\text { Anodisc }{ }^{\mathrm{TM}} \\
(200 \mathrm{~nm})\end{array}$ & Liquid & Membrane distillation & [146] \\
\hline
\end{tabular}

${ }^{1}$ pore size $28 \mathrm{~nm}$, particle size $10 \mu \mathrm{m}$

Until now only a few reports are available on the use of ceramic membranes in NF in organic solvents. In order to optimize membranes for non-aqueous application, Tsuru et al. have hydrophobized these membranes via gas-phase reaction with trimethylchlorosilane at $200{ }^{\circ} \mathrm{C}$ [155]. Two systems were studied. In the first, 
permeation experiments with pure solvents were carried out (hexane, methanol, toluene, and ethanol) at different temperatures (from $25^{\circ} \mathrm{C}$ to $60{ }^{\circ} \mathrm{C}$ ). In a second report they applied these hybrid membranes to the separation by $\mathrm{RO}$ of alcohols (hexanol, octanol, decanol) and alkanes (hexane, decane, tetradecane) in ethanol solutions at the same temperature ranges [156]. Ethanol fluxes of up to $3 \mathrm{~kg} \mathrm{~m}^{-2}$ $\mathrm{hr}^{-1}$ at $30 \mathrm{bar}$ and $60^{\circ} \mathrm{C}$ were obtained with a membrane containing pores of $1 \mathrm{~nm}$ diameter and a MWCO as low as $200 \mathrm{Da}$ [157].

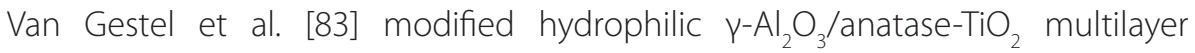
membranes with trichloromethylsilane $\left(C_{1}\right)$ and octyltrichlorosilane $\left(C_{8}\right)$ in ethyl acetate. Hexane and water permeability were studied before and after silane treatment as an indication of the effect of the modification. Two membranes with different pore sizes were used (mesoporous or microporous top layer). For (partly) mesoporous membranes fired at temperatures ranging from $400-500{ }^{\circ} \mathrm{C}$, permeability results indicated that silanes could be successful introduced in the pore structure of the membrane. On the other hand, for the microporous membrane fired at $300{ }^{\circ} \mathrm{C}$, it was shown that the silane coupling reactions occurred in the pores only at the outer part of the membrane, but leaving the internal pore unaffected as a consequence of steric hindrance, due to the relatively small pore size $(1.5 \mathrm{~nm})$. The membrane consisting of $C_{8}$ silanes shows a MWCO of $400 \mathrm{Da}$ and hexane permeability of $3 \mathrm{I} \mathrm{m}^{-2} \mathrm{hr}^{-1} \mathrm{bar}^{-1}$. A higher permeability of $5 \mathrm{I} \mathrm{m}^{-2} \mathrm{hr}^{-1} \mathrm{bar}^{1}$ is obtained for the membrane with an inorganic top layer fired at $450{ }^{\circ} \mathrm{C}$ and modified with a $C_{1}$ silane, but that membrane shows a slighter higher MWCO of $620 \mathrm{Da}$. For the ceramic membrane fired at $500{ }^{\circ} \mathrm{C}$ and treated with $\mathrm{C}_{8}$ silane a complete hydrophobic behavior was attained. Therefore, these authors concluded that the degree of hydrophilic/hydrophobic modification (indicated by the hexane/water permeability ratio) increased with increasing firing temperature of the ceramic support and increasing alkyl chain length.

Sah et al. [81] have modified $\gamma^{-} \mathrm{Al}_{2} \mathrm{O}_{3}$ membranes (pore size $5 \mathrm{~nm}$ ) with a series of monofunctional, difunctional and trifunctional organochlorosilanes with organic groups of different sizes (phenyl, methyl and t-butyl) to study the influence of the of the nature of the modifying agent on the extent of grafting and the selectivity of these grafted membranes towards liquids with different polarities (hexane, toluene and water). The toluene/water permeability ratio appears to increase slightly after grafting from 0.6 for the unmodified membrane to 0.8 for the trimethylchlorosilane, 1.0 for the dichloromethylsilane and 1.1 for the trichloromethylsilane indicating that for both mono and difunctional silanes a low 
level of hydrophobic modification is achieved. Therefore, the trichloromethylsilane was the only one imparting predominant hydrophobic character. Alami Younssi et al. [86] also show that hydrophobic modification is more efficient with multifunctional silanes. However, the permeability of these membranes was very low in comparison with the results obtained on other grafted membranes. The reason for this behavior was the creation of a polymerized network for both di- and trifunctional silanes that blocks the small pores, thereby decreasing the overall permeability with a more profound effect for the trifunctional silane, as demonstrated by the decreased pore size after modification when compared with the unmodified membrane. As a result the permeation is the result of porosity and pore-size reduction as well as hydrophobization of the pores which is dependent on the nature of the silane (size and functionality) and the extension of modification on both surface and pore wall. More recently, Verrecht et al. [84] have studied the influence of different silane treatments on the hexane and water permeabilities of $\gamma$-alumina membranes (MWCO 2000 Da and 2300 Da). It was demonstrated that for these mesoporous membranes, trifunctional silanes cause a much sharper increase in contact angle than the less reactive di- and monofunctional chlorosilanes, independently of the length of the hydrophobic tail. However, for smaller pores, due to steric hindrance, this can be a problem as discussed before $[81,83,158]$. Difunctional and trifunctional silanes provide the best results, probably due to their higher reactivity: hexane permeability increases, while water permeability decreases. For the membrane grafted with the octyldichloromethylsilane, the ratio hexane/water increases from zero for the unmodified membrane (no hexane permeation) to 3.23 after modification. For the membrane treated with the trichloromethylsilane no water permeation was observed and a hexane permeability of $1.98 \mathrm{I} \mathrm{m}^{-2} \mathrm{hr}^{-1} \mathrm{bar}^{-1}$ was measured. However, the monofunctional silanes show no hexane permeability and the water permeability stays at the same level. Preliminary results show that surface and pore modification by silane results in hydrophobic membranes and thus improved solvent permeation properties.

The modification of ceramic mesoporous membranes $\left(\mathrm{TiO}_{2}\right.$, pore size $=5 \mathrm{~nm}$ and $\mathrm{ZrO}_{2}$, pore size $=3 \mathrm{~nm}$ ) with silylating agents has been patented by HITK. They claimed toluene and methanol fluxes of 52 and $22 \mathrm{I} \mathrm{m}^{-2} \mathrm{hr}^{-1}$ bar $^{-1}$ respectively and MWCO down to 660 Da [159]. For a 3 nm UF-ZrO membrane (MWCO 1300 Da) modifications, made by grafting n-octyldimethychlorosilane or tridecafluoro-1,1,2,2 terahydrooctyltriethoxysilane, resulted in a permeance increase for toluene up to 16.5 and $7 \mathrm{~kg} \mathrm{~m}^{-2} \mathrm{hr}^{-1} \mathrm{bar}^{-1}$, respectively and for ethanol up to 52 and $16 \mathrm{~kg}$ 
$\mathrm{m}^{-2} \mathrm{hr}^{-1} \mathrm{bar}^{-1}$, respectively [160]. A decrease in water permeance was observed for both membranes and molecular weight cut off measurements of $600 \mathrm{~g} \mathrm{~mol}^{1}$ were reported. It was then demonstrated that, if a proper modification of the pores is preformed, permeation of (non-polar) solvents can be enhanced through inorganic membranes.

An important category among the silanes is that of the fluoroalkylsilanes. These compounds present low water adsorption and high resistance to oxidation or strong solvents. Fluoroakylsilanes are the group of compounds which can be efficiently used to create hydrophobic surfaces due to their hydrophobic fluorocarbon groups. This is achieved by the reaction between the $-\mathrm{OH}$ groups of the ceramic and the chloro/alkoxy groups of the fluorosilane, forming a hydrophobic layer of the silane on the surface of the membrane.

Picard and co-workers [38, 39] grafted zirconia, titania, alumina and silica membranes with fluorosilanes $\mathrm{C}_{2} \mathrm{~F}_{2 n+1} \mathrm{C}_{2} \mathrm{H}_{4}\left(\mathrm{OR}_{3}\right),\left(\mathrm{n}=1,6,8 ; \mathrm{R}=\mathrm{OCH}_{3^{\prime}} \mathrm{OC}_{2} \mathrm{H}_{5}\right)$. This had led to super hydrophobic surfaces, with contact angles between 116 and $145^{\circ}$. The influence of different reaction parameters, as number of soakings, grafting time and drying steps, on the membrane hydrophobicity was evaluated. Water permeability significantly decreases with increased grafting time (higher concentrations of surface modifier). However, no solvent permeation data were reported in this work.

More recently Bothun et al. [78], using a similar method as described by Van Gestel et al. [83], modified $\gamma$-alumina $(5 \mathrm{~nm})$ and titania $(9.8 \mathrm{~nm})$ ceramic membranes with fluorosilanes (trichloroperfluorooctylsilane, $\mathrm{Cl}_{3} \mathrm{SiC}_{2} \mathrm{H}_{4} \mathrm{C}_{6} \mathrm{~F}_{13}$ ) and an alkyltrichlorosilane (octyltrichlorosilane) and they reported some data on liquid permeation performance (ethanol, hexane and liquid $\mathrm{CO}_{2}$ ). The effect of tail chemistry on the extent of modification and liquid transport was evaluated. For the fluorinated titania membrane $\mathrm{Km}$ (hexane) $>\mathrm{Km}$ (ethanol) $>\mathrm{Km}$ (liquid $\mathrm{CO}_{2}$ ). The membrane was nearly impermeable to water $(\mathrm{Km}<0.01)$ due to an unfavorable interaction with the fluorine. Unlike the grafted titania membrane, the fluorinated alumina membrane was nearly impermeable to liquids. This was attributed to pore blocking by the fluorosilane. For membranes modified with alkylchlorosilanes permeability values were one order higher than the fluorinated membranes, where hexane presents the highest value of all. However, water was still able to permeate $\left(\mathrm{Km}=25.2 \times 10^{-15} \mathrm{~m}\right.$ for titania and $\mathrm{Km}=1.6 \times 10^{-15} \mathrm{~m}$ for alumina membranes).

For the octyltrichlorosilane grafted titania membrane Km (hexane) $>\mathrm{Km}$ (ethanol)> $\mathrm{Km}$ (water) while in the case of the alumina grafted membranes permeability through these membrane was similar for both polar and apolar solvents. A 
plausible explanation for the difference in solvent permeability between the two membranes can be related with the extension of modification. As demonstrated by higher $\mathrm{Si} / \mathrm{Ti}$ ratios when compared by the Si/Al ratios as determined by SEM/EDX. Therefore, it was proposed that permeability behavior was the result of (organic) solvent transport through both small-inaccessible pores and large accessible pores of the silane-modified $\gamma$-alumina membrane. This was confirmed before by Van Gestel et al. [83] and Sah et al. [81]. These authors also shown that for each membrane similar $\mathrm{Si} / \mathrm{Ti}$ and $\mathrm{Si} / \mathrm{Al}$ ratios were obtained independently of the silane, indicating that the size of the organic molecule does not influence the extension of modification whereas steric hindrance and nature of the surface reactions control the silylation. A tribonding mechanism was evident and no evidence of thick polymeric surface layer was observed. These results demonstrated that silane surface modifications can be used to tailor liquid transport behavior and improve apolar solvent flux in ceramics relatively to polar solvents. In addition water permeability can be inhibited which can prevent water fouling and capillary condensation in partially hydrated solvents.

These results validate silylation as a promising method for SRNF membranes however conclusions about their application should be done carefully, due to the limited data available.

\subsection{Phosphorous coupling agents as surface modifiers}

Organophosphorous precursors can offer an attractive alternative to silicon-based coupling in the design of organic-inorganic hybrid systems either by sol-gel processing or by surface modification of inorganic supports. Organophosphorous coupling agents (OPCA), with general formula RXP(O)(OX) ${ }_{3-x}(x=1$ or $2, X=H, N a$, alkyl, etc.) are quite complementary to organosilane coupling agents: organosilane are more suitable for anchoring organic groups to silicon containing-inorganic matrices or supports such as silica, silicates and silicon whereas, while OPCA appear te be best suited for the preparation of hybrid materials based on metals or transition metals such as $\mathrm{Al}_{2} \mathrm{O}_{3^{\prime}} \mathrm{ZrO}_{2}$ and $\mathrm{TiO}_{2}$. In order to provide strong bonds with the surface $\mathrm{OH}$ groups, the coupling molecule should be an organic phosphorous acid (phosphoric, phosphonic and phosphinic acids) and its derivatives (salts or esters) exemplified in Figure 7. 

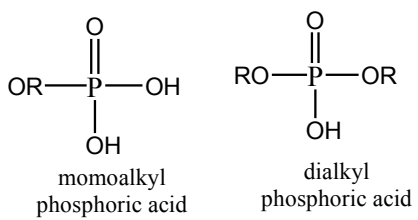<smiles></smiles>

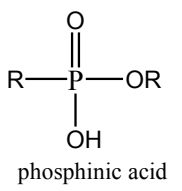

Figure 7: Organophosphorous acids used as coupling agents.

Thanks to the versatility of phosphor chemistry a wide range of functional organic groups are available (see Table 2).

Table 2: Examples of organophosphorous coupling molecules reported in literature.

\begin{tabular}{|c|c|}
\hline Phosphorous coupling molecule & Reference \\
\hline $\mathrm{H}\left(\mathrm{CH}_{2}\right)_{\mathrm{n}} \mathrm{PO}\left(\mathrm{OH}_{2}\right) \mathrm{n}=1-18$ & {$[161-163]$} \\
\hline $\mathrm{F}\left(\mathrm{CH}_{2}\right) 8\left(\mathrm{CH}_{2} \mathrm{PO}\left(\mathrm{OH}_{2}\right)\right.$ & [164] \\
\hline$(\mathrm{OH})_{2} \mathrm{OP}\left(\mathrm{CH}_{2}\right)_{\mathrm{n}} \mathrm{PO}(\mathrm{OH})_{2} \mathrm{n}=10,12$ & {$[162,165]$} \\
\hline$(\mathrm{OH})_{2} \mathrm{OP}\left(\mathrm{CH}_{2}\right)_{n} \mathrm{~S}_{x}\left(\mathrm{CH}_{2}\right)_{n} \mathrm{PO}(\mathrm{OH})_{2} \mathrm{n}=3,4 \mathrm{x}=2-4$ & {$[165],[166]$} \\
\hline $\left.\mathrm{PhPO}(\mathrm{OH})_{2^{\prime}} \mathrm{PhPO}(\mathrm{OSiMe})_{3}\right)_{2^{\prime}} \mathrm{PhPO}(\mathrm{OEt})_{2} \mathrm{Ph}_{2} \mathrm{PO}(\mathrm{OH}) \mathrm{Ph}_{2} \mathrm{PO}\left(\mathrm{OSiMe}_{3}\right), \mathrm{Ph}_{2} \mathrm{PO}(\mathrm{OEt})$ & [167] \\
\hline $\mathrm{H}_{2} \mathrm{O}_{3} \mathrm{PO}\left(\mathrm{CH}_{2}\right)_{3} \mathrm{OCOC}_{3} \mathrm{H}_{5}$ & [168] \\
\hline $\mathrm{H}_{2} \mathrm{O}_{3} \mathrm{P}-\mathrm{O}-\left(\mathrm{CH}_{2}\right)_{6}-\mathrm{SH}$ & [168] \\
\hline $\mathrm{H}\left(\mathrm{CH}_{2}\right)_{18} \mathrm{OPO}(\mathrm{OH})_{2}$ & [169] \\
\hline $\mathrm{H}\left(\mathrm{CH}_{2}\right)_{12} \mathrm{OPO}\left(\mathrm{ONH}_{4}\right)_{2}, \mathrm{HO}\left(\mathrm{CH}_{2}\right)_{12} \mathrm{OPO}\left(\mathrm{ONH}_{4}\right)_{2}$ & {$[170]$} \\
\hline
\end{tabular}

The attachment of an OPCA to oxide surfaces can result in more stable systems in comparison with silica-based coupling agents. The linkage mode between the coupling agent and the surface plays a crucial role in stability. The OPCA's are in most cases potentially tridentate species, like phosphonic acids and monoalkylphosporic acids (or the corresponding ammonium salts) [170-172]. Only a few work deals with potentially bidentate species such as phosphinic acids and dialkylphosphoric acids [167]. Anchoring of the OPCA to oxide surfaces most probably involves the formation of M-O-P bridges. These bridges result from heterocondensation of the surface hydroxyl groups with $\mathrm{P}-\mathrm{OH}\left(\mathrm{Or} \mathrm{P}-\mathrm{ONH}_{4}\right)$ groups of the OPCA, owing to the protonation of the leaving alkoxy group by acidic $\mathrm{P}-\mathrm{OH}$ groups, equation (6), and from the complexation of the phosphoryl oxygen surface metal atoms (Figure 8). In the case of titanium and aluminum oxide, FTIR experiments suggest that phosphonate surface species are predominantly tridentate $\mathrm{RP}(\mathrm{OM})_{3}$ species [167, $173,174]$ 


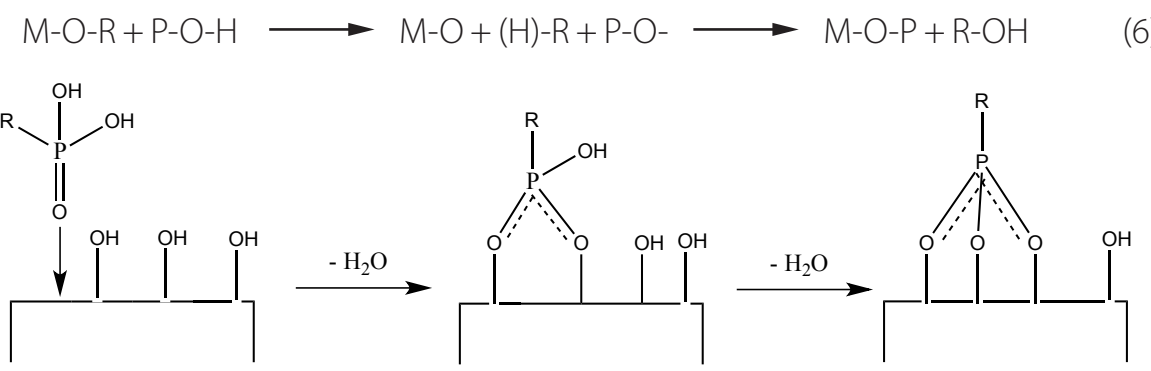

Figure 8: Schematic representations of the formation of a mono-, bi-, tridentate phosphonate surface species by coordination and condensation to the surface [175].

However, the bonding mode of OPCA surface species appears to depend strongly on the nature of both the OPCA and the surface, and on the reaction conditions (time, temperature).

Unlike organosilanes, P-O-P bridges, formed by homocondensation of OPCA, are not observed. This has two important consequences:

- P-O-C bonds are quite stable towards hydrolysis.

- The surface modification can be done in water.

- The formation of multilayers by homocondensation of the OPCA can be discarded and, under mild conditions, only (partial) monolayers are formed [175]. The adsorption of phosphonate or phosphate containing long alkyl chains (typically from 6 to 18 carbon atoms) on metal or metal oxide surfaces leads to the formation of self-assembled monolayers (SAMs). Self-assembly results from nonbonding interactions between the long alkyl chains that induce a high grafting density and a high chain organization. These represent the best grafted layer.

Different studies with octadecylphosphonic acid (OPDA) [176-178] on metal oxide supports showed the formation of well-ordered monolayers with high grafting densities of about 4 groups $/ \mathrm{nm}^{-2}$. Self-assembly monolayers, comprising the molecules of three phosphonic acids, namely $\mathrm{CF}_{3}\left(\mathrm{CF}_{2}\right)_{7}\left(\mathrm{CH}_{2}\right)_{11} \mathrm{PO}_{3} \mathrm{H}_{2}, \mathrm{n}-\mathrm{C}_{16} \mathrm{H}_{33} \mathrm{PO}_{3} \mathrm{H}_{2}$ and $n-\mathrm{C}_{22} \mathrm{H}_{45} \mathrm{PO}_{3} \mathrm{H}_{2^{\prime}}$ on the surface of aluminium metal covered with a native oxide film were studied [179]. These authors demonstrated that in all cases a monolayer is formed, however, in the case of the fluorinate acids more time is needed. Contact angle measurements show that surface modification imparts high hydrophobic character, that is, the water contact angle for the modification with hexadecylphosphonic and dodecylphosphonic acids is $110^{\circ}$ and $122^{\circ}$ for the partially fluorinated acid. In other studies, it was demonstrated that the longer the alkyl group in the modifier the larger the contact angle [180, 181]. The explanation 
proposed was that an elongation of the alkyl chain will led to an increase in the degree of ordering of the grafted layer.

Gao et al. [176] demonstrate that for long chains phosphonic acids, $\mathrm{ZrO}_{2}$ appears to be the best substrate for the formation of ordered monolayers. Despite the large size of the phosphonic acid headgroup and the fact that the surface bonding is not homogeneous, monolayers on this substrate display a high degree of conformational order, similar to SAMs on planar surfaces. Octadecylphosphonic acids adsorb less strongly onto $\mathrm{TiO}_{2}$ and domains of disordered chains are present, specially in the region of terminal chain segments (the use of short acids causes the formation of dense layers) [173]. Most likely, the octadecylphosphonic acid molecules are attached to the surface in a bidentate fashion (free $\mathrm{P}-\mathrm{OH}$ groups). Aluminium oxide, on the other hand, seems to be a less suitable substrate when compared with titania or zirconia, due to the formation of bulk (aluminoalkyl) phosphonate in some cases (Figure 9)

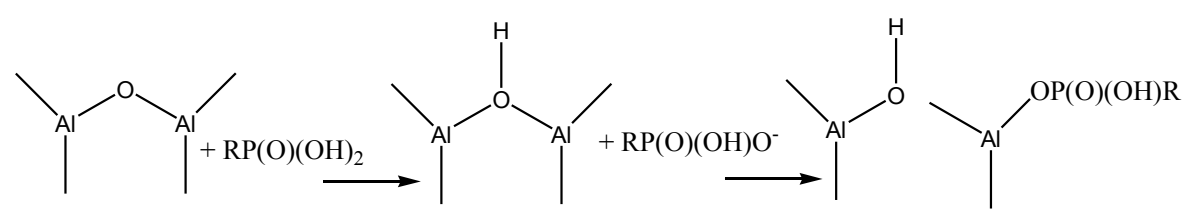

Figure 9: Formation of a bulk (aluminoalkyl)phosphonate phase.

The adsorption of alkylphosphonic and alkanecarboxilic acids and aliphatic triethoxysilanes, trichlorosilanes, amines and epoxides on the surface of magnetron-sputtered aluminium was also studied [182]. Prior to modification the aluminium surface was exposed to air for a short time, which resulted in the formation of a thin oxide layer. The modification was carried out in toluene. It was found that phosphonic acids and carboxylic acids form well-ordered layers with grafting densities of about $5 \mathrm{~nm}^{-2}$, whereas trichlorosilanes form polymeric layers and other compounds form disordered layers with low grafting density. The maximum contact angle values attained in these experiments were $120^{\circ}$ for phosphonic acids and $117^{\circ}$ for carboxylic acids.

In the case of silica, a different strategy to attach phosphonic acids, other than direct zirconation, is necessary. Although a high degree of conformational order is present in alkylphosphonate layers on zirconated silica, it results in lower coverage as well as the formation of some bulk Zr-OPCA when this type of primary layer is used. In order to consider if this modification strategy is suitable for our applications, some 
more data are needed, namely, their hydrolytic and thermal stability. In literature few reports have focused on these characteristics. A comparative analysis [178] of the stability of the grafted layers, formed on a $\mathrm{TiO}_{2}$ (anatase) surface treated with octadecylphosphonic acid and various octadecylsilanes (with $\mathrm{SiH}_{3^{\prime}} \mathrm{SiCl}_{3^{\prime}}$ $\mathrm{Si}(\mathrm{OMe})_{3}$ and $\mathrm{SiMeCl}$ anchoring groups), reveal the formation of highly ordered monolayers with high grafting densities in all cases, except for the modification with dimethyloctadecylchlorosilane. The thermal stability of the grafted layers is rather high, $200{ }^{\circ} \mathrm{C}$ in air and $300{ }^{\circ} \mathrm{C}$ in inert atmosphere.

The hydrolytic stabilities of the surfaces of $\mathrm{TiO}_{2}$ (anatase) and $\mathrm{ZrO}_{2}$ (monoclinic) powders modified with $\mathrm{C}_{18}$-monolayers of organosilanes and organophosphorous compounds $\left(\mathrm{C}_{18} \mathrm{H}_{37} \mathrm{SiH}_{3^{\prime}} \mathrm{C}_{18} \mathrm{H}_{37} \mathrm{Si}\left(\mathrm{CH}_{3}\right)_{2} \mathrm{Cl}\right.$ and $\left.\mathrm{C}_{18} \mathrm{H}_{37} \mathrm{P}(\mathrm{O})(\mathrm{OH})_{2}\right)$ [183] showed that the acid forms highly ordered surface monolayers with a grafting density of 4-5 nm-2, while the silane forms disordered layers with a grafting density of at most $2.2 \mathrm{~m}^{-2}$, as expected. Hydrolysis was performed using tetrahydrofuran/ water mixtures. The $\mathrm{C}_{18} \mathrm{H}_{37} \mathrm{P}(\mathrm{O})(\mathrm{OH})_{2}$ monolayer represents the best hydrolytic stability (mass loss $2 \%$ ) among the surfaces studied in the $\mathrm{pH}$ range of 1 to 10 . The extent of hydrolysis $\left(\theta_{\text {hydrolyzed }}\right)$ for the $\mathrm{TiO}_{2}$ and $\mathrm{ZrO}_{2}$ supported surfaces was $0.02-0.05$. At $65^{\circ} \mathrm{C}$, the stability of the layers somewhat decreases but remains high $\left(\theta_{\text {hydrolyzed }}=\right.$ 0.05-0.15 for zirconia and 0.15-0.2 for titania). High stability of these monolayers is due to the strong specific interactions of the phosphonic acid group with the surfaces of the metal oxide. The presence of strong acid sites on the surface of $\mathrm{ZrO}_{2}$ and $\mathrm{TiO}_{2}$ facilitates the donor-acceptor interaction of the phosphoryl group of the modifier with the Lewis acid sites. This interaction makes the phosphorus atom more electrophilic and facilitates a subsequent reaction between the modifier and the surface hydroxyl group. Besides this donor-acceptor interaction the anchoring group of the modifier molecules helps to block efficiently the surface acid sites, so the surface becomes more uniform and non-specific. A somewhat higher hydrolytic stability of the monolayers supported on $\mathrm{ZrO}_{2}$ may be explained by their more basic character (IEP: 7-10) compared to $\mathrm{TiO}_{2}$-supported monolayers (IEP: 4-7), or in less extension due to the higher $\mathrm{OH}$ concentration on the $\mathrm{ZrO}_{2}$ surface.

Rigney et al. [184], reported high stabilities for zirconia and alumina phosphate modified particles for alkaline stable HPLC supports. Several phosphonic and phosphinic acids (phenyl phosphonic acid, diphenyl and triphenyl phosphinic acid and diphenyl phosphonate) were used. Static pH stability studies showed no evidence of dissolution of zirconia particles at any pH conditions between 1-14, whereas more than $1 \%(\mathrm{w} / \mathrm{w})$ of a $10 \mathrm{mg}$ sample of alumina dissolved in $900 \mathrm{ml}$ 
aliquots of aqueous solutions at any $\mathrm{pH}<3$ or $\mathrm{pH}>12$.

In the case of phosphonic and phosphoric acids it was shown that, depending on the oxide chemical stability and on the grafting conditions (temperature, $\mathrm{pH}$, concentration of OPCA, time of reaction), a dissolution-precipitation mechanism can be operative, leading to the formation of metal phosphonate or phosphinate phases (Figure 10), even in the case of chemically stable oxides like zirconia and titania $[167,176]$. Considering the excellent stability of these oxides, the cleavage of M-O-P bonds by phosphonic acids and phosphoric acids was proposed.

Furthermore, owing to the relative stability of the P-C bond, it was demonstrated by Caro et al. [154], that alkyl and aryl-phoshonic grafted alumina membranes were stable up to $400{ }^{\circ} \mathrm{C}$. Even after a thermal treatment for over 45 hours at $400{ }^{\circ} \mathrm{C}$, by rehydration, the former gas permeation behaviour could be restored. However, for the silylated-grafted membranes using a alkyltriclorosilane (OTS) a stability up to $250^{\circ} \mathrm{C}$ is reported.

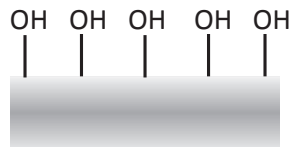

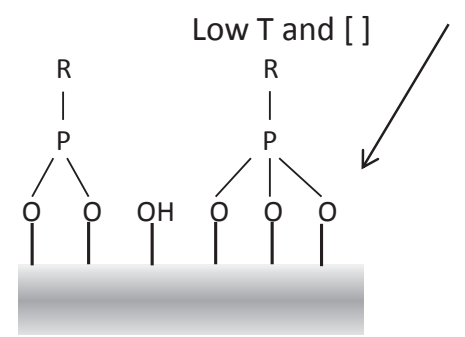

Surface Modification

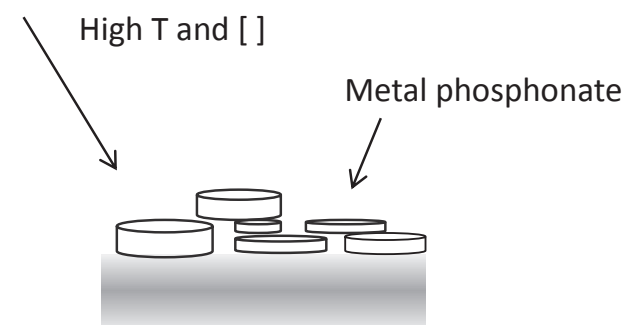

Dissolution/Precipitation

Figure 10: Schematic representation of the competition between surface modification and dissolution-precipitation [185].

The use of $\omega$-functionalized phosphoric acids for SAM formation was also investigated. The hydrophilicity of SAMs can be controlled by co-adsorption of methyl- and hydroxyl-terminated dodecyl phosphate monolayers [186].

Carboxyalkylphosphonic acids $\mathrm{HO}_{2} \mathrm{C}\left(\mathrm{CH}_{2}\right)_{n} \mathrm{PO}(\mathrm{OH})_{2}(\mathrm{n}=2,3,11,15)$ have also shown the ability in forming self-assembled monolayers on $\mathrm{TiO}_{2}[187,188]$ and $\mathrm{ZrO}_{2}[189]$ surfaces by selective binding of the phosphoric end group on the metal oxide surface, leaving the carboxylic acid as a free pendant group. The conformation of the $\left(\mathrm{CH}_{2}\right)_{n} \mathrm{CO}_{2} \mathrm{H}$ chains in the formed grafted layer depends on the chain length. 
Moreover, a trend to the formation of poly-layer coatings on both surfaces is observed. In the case of $\mathrm{TiO}_{2}$, these poly layers are however removed by washing the samples with polar solvents (e.g. acetone). On the other hand $\mathrm{ZrO}_{2}$ multilayers remain stable to multiple washing with acetone but not when washed with methanol or aqueous acetone solutions.

Phosphinic acids can also be used to modify the surface of inorganic materials. Di-n-buthylphosphinic acid interacts with $\gamma$-alumina to give an aluminium dibuthylphosphinate surface layer with a high grafting density $\left(4.8 \mathrm{~nm}^{-2}\right)$. The hydrolytic stability of the obtained coating is relatively high (phosphoryl oxygen atom forms a rather strong donor-acceptor bond with Lewis acid site). The grafting intensity remains almost unchanged after two days of treatment with aqueous dioxane in a $\mathrm{pH}$ range of 2 to 7 . However, it appreciably decreases beyond these limits.

At present covalent hybrid materials based on OPCA have found relatively few applications. In separation domains, OPCA have been used to modify inorganic membranes [154] or supports for chromatography [190]. Random etal. [40] prepared an organo-ceramic membrane by grafting n-butylphosphonic acid and dodecylphosphonate on the surface of an alumina membrane with a pore diameter of $5 \mathrm{~nm}$. Modified membranes have been tested for various gas permeations $\left(\mathrm{CH}_{4^{\prime}}\right.$ $\mathrm{C}_{2} \mathrm{H}_{6^{\prime}} \mathrm{C}_{3} \mathrm{H}_{8^{\prime}} \mathrm{N}_{2^{\prime}} \mathrm{H}_{2}$ and $\mathrm{CO}_{2}$ ) at room temperature. The membrane displayed high permeability and a high selective coefficient for propane/nitrogen mixture. The same membrane modification was used recently on $\mathrm{TTiO}_{2}$ for separation of bovine serum albumin from native bovine by ultrafiltration. The acid modified membrane is highly hydrophobic [191]. The acid-modified membrane is highly hydrophobic.

\subsection{Graft polymerization onto silylated surfaces}

In this section some examples are given of polymers used to functionalize inorganic surfaces. Many more are described in literature reviews [14, 192-197] but the majority is focused on the functionalization of metal oxide particles. Due to the same type of chemistry, involving the $\mathrm{OH}$ surface groups onto an inorganic support, these studies can be interesting future paths for surface modification of flat sheet supports and tubular membranes regarding our application. Examples are:

- Poly(vinyl actetate) $[36,198,199]$

- Poly(vinyl pyrrolidone) $[11,17,36]$ 
- Polybutadiene $[26,56,200]$

- Polyimide [201-203]

- Polyamide [204-206]

- Polystyrene $[12,16,17,207,208]$

- poly(ethylene glycol) [34, 59, 209-212]

- poly(acrylamide) [14, 213]

- poly(butylacrylate) [214]

- poly(acrylonitrile) [14] and poly(acrylic acid) [14, 215, 216]

- poly(methyl metacrylate) [17, 25, 217-219]

- polycarbonate [220, 221]

- Polysulfone [221-223]

- Polyamidoamine [224]

- Poly(maleic anhydride) [207, 225, 226]

In the next sections some more detailed examples are given of different classes of polymers grafted onto inorganic materials.

\subsubsection{Polysiloxanes}

PDMS is the most important elastomeric member of the organosiloxanes, usually known as silicone. It is chemically stable in all organic solvents when cross-linked, but it is preferably used in apolar solvents, due to its low polarity. It also presents a robust backbone and superior thermal stability. This polymer already showed great utility in membranes for industrial applications with organic solvents. Despite its broad chemical stability and its frequent use in SRNF applications, the extensive swelling of PDMS in organic solvents is an important issue which limits its utility in some apolar solvents. Since ceramic membranes do not present swelling behavior, the covalent bonding to a metal oxide support and confinement in the pores can eventually reduce the swelling and render to the top-layer a higher chemical and mechanical stability. Therefore some examples of grating PDMS on metal oxide particles/surfaces will be discussed.

Leger et al. [55], grafted polydimethylsiloxane oil onto a porous alumina membrane (pore size $=5 \mathrm{~nm}$ ) by heating to $180^{\circ} \mathrm{C}$ producing a covalently grafted monolayer (Figure 11). These membrane were tested for both pervaporation and gas separation. 


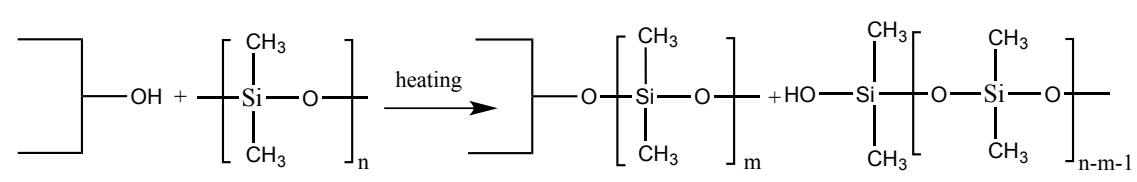

Figure 11: Scheme for the attachment of PDMS to a alumina oxide surface. The reactions consist of the cleavage of the Si-O of the silicone polymer with recombination of the hydroxylated alumina surface.

The membrane proved to be selective for volatile organic compounds (VOCs) over water by pervaporation. The monolayer formed was chemically and thermal stable (up to $300{ }^{\circ} \mathrm{C}$ ), unaffected by organic solvents. The silicon layers were not altered or removed by solvents or liquids (alcohols with low MW, toluene, THF, acetone, $\mathrm{CHCl}_{3^{\prime}} \mathrm{Et}_{2} \mathrm{O}$ ) and gases, but were susceptible to alkaline attack (as the silicone oil itself). The membrane is totally impermeable to water, which makes it interesting for recovering of organic solvents from aqueous systems. Therefore, testing of these hybrid membranes for SRNF applications should be performed.

Y-Alumina nanoparticles were also modified by surface functionalization with a vinyltrimethoxysilane followed by the grafting of the silicone polymer (hydrideterminated poydimethylsiloxane) through an hydrosilylation reaction catalyzed by a platinum catalyst (e.g. Karstedt catalyst) [227]. Thermal, chemical and mechanical stabilities were evaluated in order to access potential applications as encapsulation of organic devices such as photovoltaic devices. The samples were then dipped into deionized water for 24 hours and put into an excess of acidic (1 $\mathrm{N}$ hydrochloric acid) and basic ( $1 \mathrm{~N}$ sodium hydroxide) solutions. The samples were then dipped into deionized water again to remove dissolved alumina. No weight loss was observed under these extreme conditions and FTIR did not observe any evidence for degradation. Furthermore, these composites were thermally stable up to $400{ }^{\circ} \mathrm{C}$ (10\% weight loss).

Phosphonic acids were also used for preparing a grafted PDMS aluminum oxide particle [228]. The PDMS was firstly modified through a radical addition reaction of the PDMS thiol onto vinyl phosphonate ester. This is followed by the cleavage of the ester unit followed by the protonation of the disalt forming the bisphosphonicpolydimethylsiloxane (PDMS) (Figure 12). After which the polymer is grafted onto the alumina surface. In a final stage nanocomposites were prepared by melt blending polymerization in poly(methyl metacrylate). Besides PDMS bisphosphonic aromatic polyester (PET) and a polyether (TER) were also grafted.

Fadeev at al. [229] covalently attached monolayers of oligo(dimethylsiloxane)s on silica particles by liquid and gas phase reactions. Examples of a series of $a, \omega$ - 
diclorodimethylsiloxanes are given in Figure 13.

Monomeric and oligomeric surfaces were prepared. As referred before, in chapter 2.1., for the organosilanes, these reactions are also controlled by the amount of pre-adsorbed water on silica. TGA analysis showed that dimethylsiloxane surfaces have superior thermal and oxidative stability. Oligomeric surfaces show no weight loss until $350{ }^{\circ} \mathrm{C}-380^{\circ} \mathrm{C}$. Monomeric surfaces are even more stable and show no weight loss until $550{ }^{\circ} \mathrm{C}-650{ }^{\circ} \mathrm{C}$ in air. The easy preparation and the control of bonding, accompanied by excellent thermal stability, make these layer a superior alternative to conventional silanes with alkyl or fluoroalkyl groups.

Many other studies have been reported in literature, that makes use of these family of polymers, including: poly(methyloctylsiloxane) (PMOS) [230], poly(dimethyloctadecylsiloxane) (PMODS) [231].
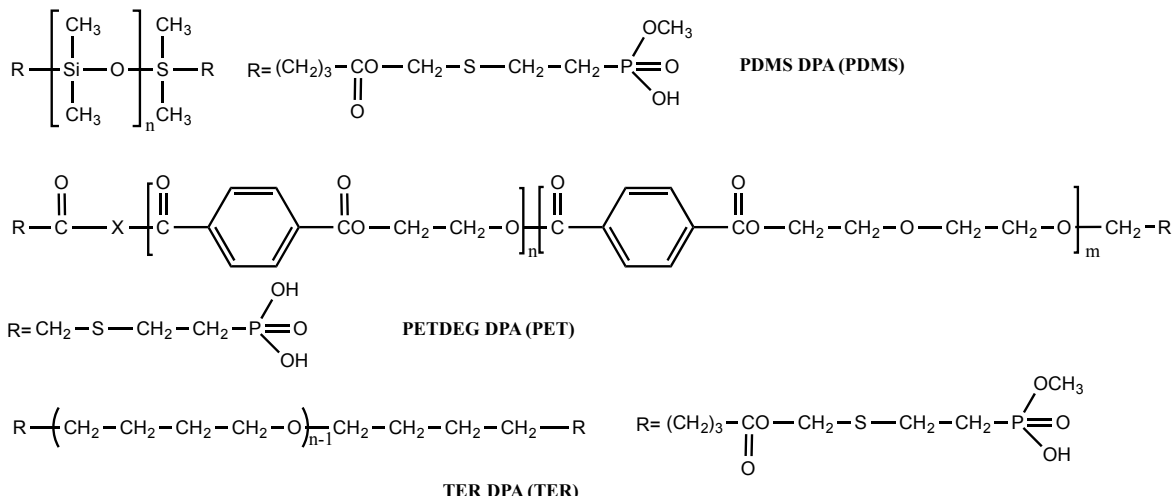

Figure 12: Bis- phosphonic acid oligomers based on polydimethylsiloxane (PDMS), polyethylene teraphtalate diethylene glycol (PET) and Terathane "(TER).

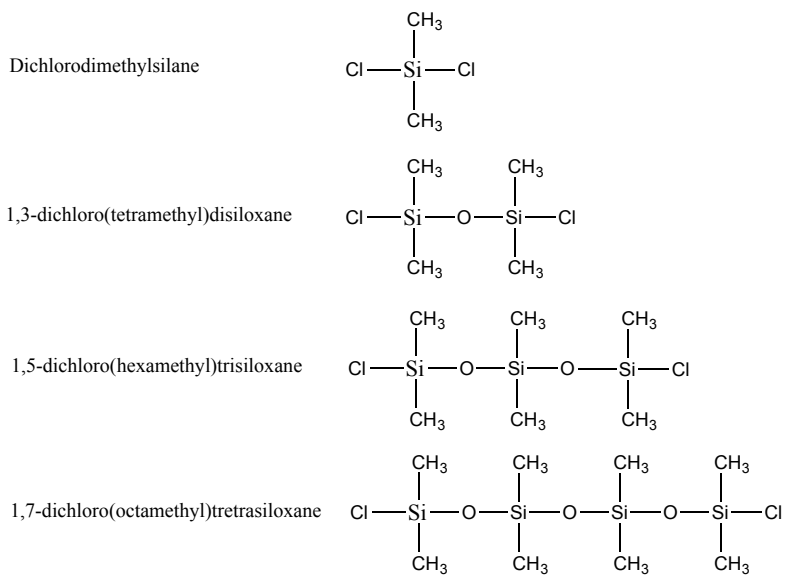

Figure 13: Structures of the precursors to dimethyl surfaces [229]. 


\subsubsection{Polyvinyl monomers}

Themodification ofoxidesurfaceswith polyvinyl monomerslikepoly(vinylpyrrolidone) (PVP) and polyvinyl acetate (PVAc) were first described by Cohen et al.[232] for separation of resins used in size exclusion chromatography (SEC). More recently, surface modifications of silica, zirconia and alumina substrates, grafted with PVAc and PVP, were also demonstrated to be successful for membrane separations processes like: a) pervaporation of organics from aqueous systems and non-aqueous systems; b) ultrafiltration of oil-in-water emulsions. Some examples are described in Table 3.

Table 3: Examples of graft polymerization with polyvinyl polymers onto different metal oxide supports and applications reported in the literature.

\begin{tabular}{|c|c|c|c|c|}
\hline Oxide Support & $\begin{array}{l}\text { Graft } \\
\text { polymer }\end{array}$ & $\begin{array}{l}\text { Membrane } \\
\text { Process }\end{array}$ & Application & Observations \\
\hline $\begin{array}{l}\text { Silica; } \\
\text { Pore size : 500Å [88] }\end{array}$ & PVAc & Pervaporation & $\begin{array}{l}\text { Removal of trichlo- } \\
\text { roethylene (TCE) } \\
\text { from water } \\
\text { Removal of chloro- } \\
\text { form from water }\end{array}$ & $\begin{array}{l}\text { High selectivity for TCE and chlo- } \\
\text { roform } \\
\text { Separation factors: TCE-106, Chlo- } \\
\text { roform-118 } \\
\text { Permeation fluxes: } 0,37 \mathrm{Kg} \mathrm{m}^{-2} \mathrm{~h}^{-1} \\
\text { Negligible membrane mass trans- } \\
\text { fer resistance for organic species }\end{array}$ \\
\hline Zirconia UF [85] & PVP & Ultrafiltration & $\begin{array}{l}\text { Separation of oil/ } \\
\text { water microemul- } \\
\text { sions }\end{array}$ & $\begin{array}{l}\text { Fouling resistance despite mem- } \\
\text { brane roughness } \\
\text { High oil rejection and low surfac- } \\
\text { tance rejection }\end{array}$ \\
\hline $\begin{array}{l}\text { Y-Alumina }(50 \AA) \text { in } \\
\text { a a-Alumina su- } \\
\text { pport [36] }\end{array}$ & $\begin{array}{l}\text { PVAc } \\
\text { PVP }\end{array}$ & Pervaporation & $\begin{array}{l}\text { Separation of } \\
\text { methanol /methyl } \\
\text { tert-butyl ether } \\
\text { (MBTE) }\end{array}$ & $\begin{array}{l}\text { Methanol selectiveSeparations } \\
\text { factors: } \\
\text { PVA-100, PVP-26 } \\
\text { Permeation fluxes: } \\
\text { PVA: } 0,055-1,26 \mathrm{Kg} \mathrm{m}^{-2} \mathrm{~h}^{-1} \\
\text { PVP: } 0,55-6,19 \mathrm{Kg} \mathrm{m}^{-2} \mathrm{~h}^{-1}\end{array}$ \\
\hline $\begin{array}{l}\text { Sílica } \\
\text { Pore size: } \\
\text { 500A [233] }\end{array}$ & PVAC & Pervaporation & $\begin{array}{l}\text { Removal of MBTE } \\
\text { from water }\end{array}$ & $\begin{array}{l}\text { MBTE selective } \\
\text { Separation factors (MBTE): } 68-77 \text { at } \\
\text { corresponding total flux of 0,31- } \\
0,71 \mathrm{Kg} \mathrm{m}^{-2} \mathrm{~h}^{-1} \text {. Negligible mem- } \\
\text { brane mass transfer resistance for } \\
\text { organic species }\end{array}$ \\
\hline
\end{tabular}

This surface modification is achieved by a two-step process consisting of a surface activation by silylation followed by free radical graft polymerization resulting in a macromolecular phase of polymer chains that are terminally and covalently attached onto the surface of the ceramic membrane as shown in the mechanism presented in Figure 14, for the graft polymerization of PVAc and PVP on to a silica surface. The silylation is promoted by the reaction of a trifunctional silane like trimetoxyvinylsilane (VTMS) in xylene in an anhydrous environment, which results in the introduction of vinyl active sites that will act as the anchoring sites 
on the ceramic surface for the grafted chains. This step is usually preceded by a pre-treatment that involves a cleaning and a hydroxylation of the surface -OH groups with $\mathrm{HCl}$ and water, followed by drying. The subsequent step consists of the graft polymerization of vinyl monomers onto the support surface in such a way that the polymer chains are grown from the vinyl active sites. In general this involves the addition of the monomer to the pre-silylated membranes in a suitable reaction medium (temperature, solvent, presence of initiators and/or co-catalyst). Depending on the type of polymer, graft polymerization has to be performed in an inert (nitrogen) atmosphere in order to prevent attack from oxygen radicals.

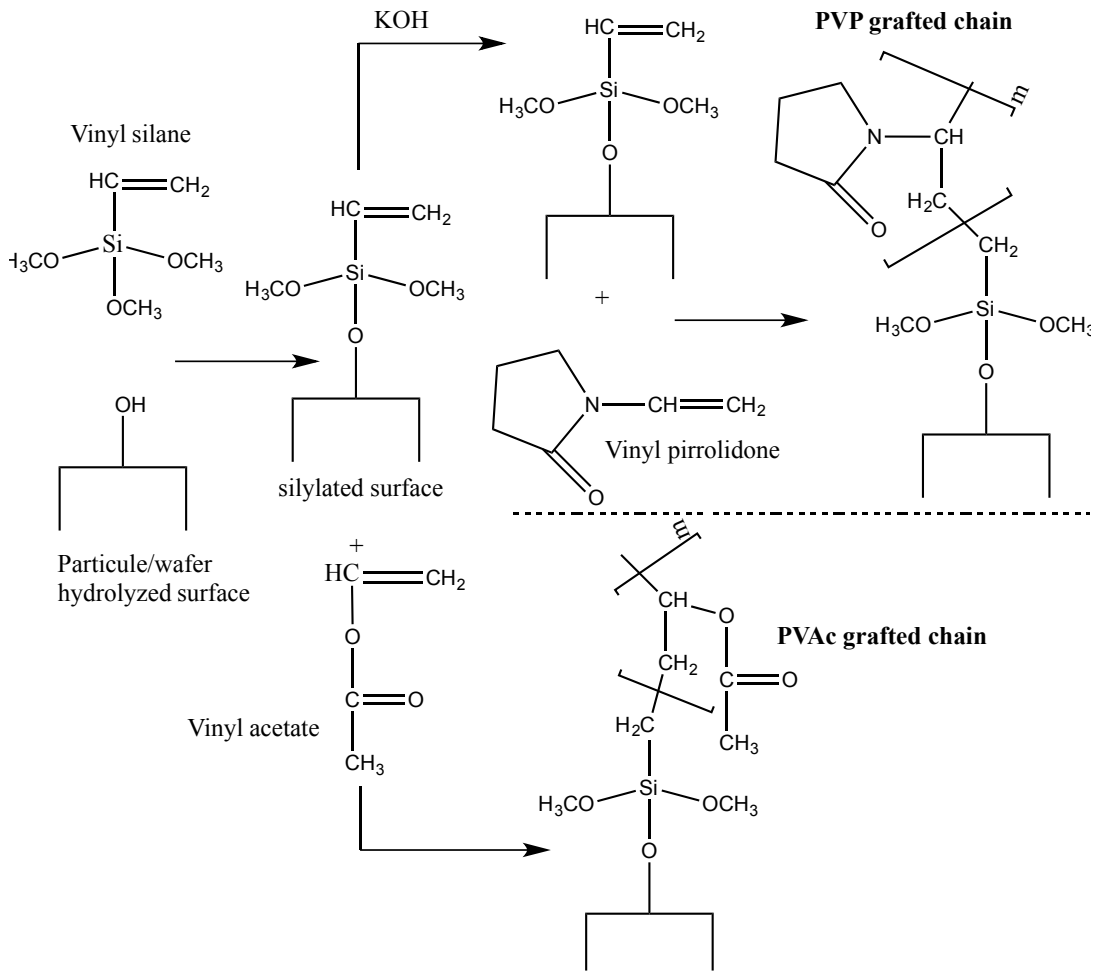

Figure 14: Scheme of a two-step graft polymerization mechanism for the 1-vinyl-2-pyrrolidone (VP) and vinyl acetate (VAc) onto a silica surface [234].

Many studies have demonstrated the influence of parameters such as polymer configuration [36] and graft polymer yield [88] on the selectivity and permeate flux of the CSP membranes. An important advantage of this surface modification is that through the control of the silane coverage and polymerization conditions [199] (temperature, time, monomer concentration) and by enhancing graft 
polymerization over polymer grafting we can adjust the parameters as mentioned earlier. However, increase in selectivity by grafting will also require careful optimization of the grafted polymer chain spacing and chain length relative to the native support pore size. By choosing a proper selection of these variables, membranes can be tailored for a variety of separation applications.

Radical polymerization of vinyl monomers, initiated by peroxyester- [235], peroxide- [236] and azo- [217] groups, has also been reported for ultrafine silica. In addition, it has been reported that acylium perchlorate groups are successfully introduced onto silica followed by the cationic polymerization of vinyl monomers to give the corresponding polymer-grafted silica [237]. For instance, the introduction of vinyl monomers, like styrene (St), N-vinyl-2-pyrrolidinone (NPV) and 2-hydroxyethylacrylate (HEMA) onto a silica surface initiated by peroxycarbonate groups were investigated by Hayashi et al. [17]. The introduction of peroxycarbonate groups onto a silica surface was achieved by Michael addition of amino groups, introduced onto a silica surface by t-butylperoxy-2methacryloyloxyethylcarbonate (HEPO). The introduction of the amino groups was achieved by the reaction of the $\gamma$ - aminopropylethoxysilane (APTES) with surface silanol groups (Figure 15).
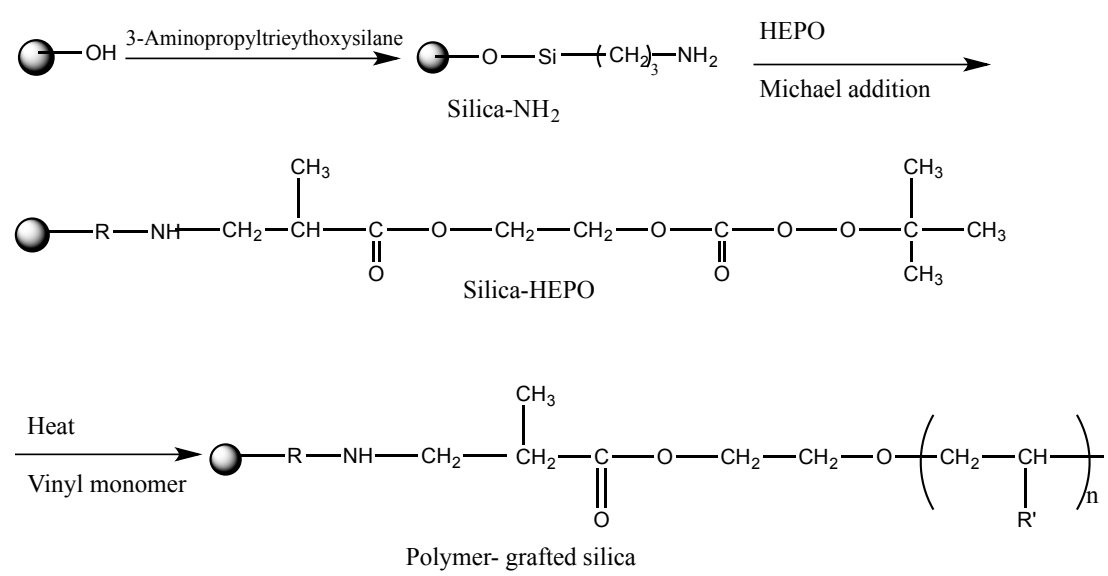

Figure 15: Scheme for the graft polymerization of vinyl monomers: (1) Introduction of peroxycarbonate groups onto a silica surface by Michael addition of amino groups previously introduce on the silica surface to HEPO; (2) Radical graft polymerization of vinyl monomers initiated by peroxycarbonate groups [17].

No studies are reported on the chemical stability of these systems in extreme conditions, or even for nanofiltration application applications. One can expect that these membranes show some limitations due to the low resistance to hydrolytic 
attack of the Si-O-Si bond. Nevertheless, the incorporation of a polymer can eventually prevent this attack, stabilizing these bonds towards hydrolytic attack in extreme conditions.

\subsubsection{Poly(ethyleneimine) (PEI)}

Recently, Kumar et al. [238], have developed an ordered mesoporous silica MCM48 membrane modified with amino-containing polymers for $\mathrm{CO}_{2}$ separations from flue gas. These membranes were applied on an a-alumina support. PEl containing primary amines, secondary amines and tertiary amines were attached to the surface of the mesoporous silica by a two-step grafting procedure:

$$
\begin{aligned}
& -\mathrm{Si}-\mathrm{OH}+\mathrm{C}_{2} \mathrm{H}_{5}-\mathrm{O}-\mathrm{Si}-\mathrm{R}-\mathrm{Cl} \longrightarrow-\mathrm{Si}-\mathrm{O}-\mathrm{Si}-\mathrm{R}-\mathrm{Cl}+\mathrm{C}_{2} \mathrm{H}_{5} \mathrm{OH} \\
& -\mathrm{Si}-\mathrm{O}-\mathrm{Si}-\mathrm{R}-\mathrm{Cl}+\mathrm{R}-\mathrm{NH}-\longrightarrow \text {-Si-O-Si-R-NH-R' }+\mathrm{HCl}
\end{aligned}
$$

In the first step, the silica silanol groups of MCM-48 silica reacted with 3-chloropropryltriethoxysilane to form surface chloroporpyl-silyl groups. These groups served as a linker for attachment of PEl to the surface of mesoporous channels in MCM-48. Further on they were functionalized with branched PEl by nucleophilic substitution of the chlorine atom with the primary, secondary and tertiary amino groups of the PEl in THF. A schematic of PEl attachment is shown in Figure 16.

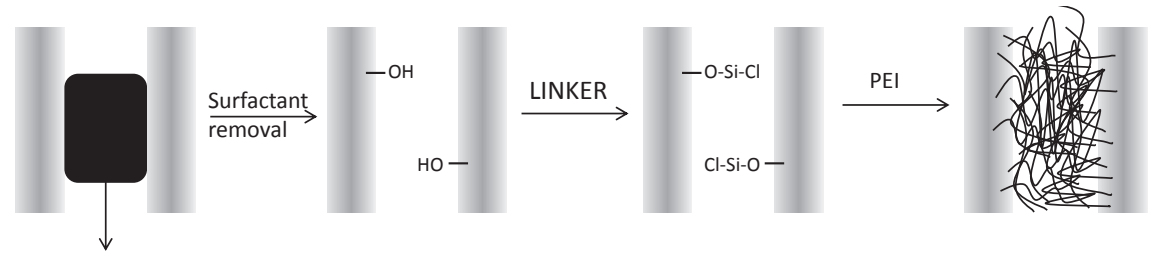

Figure 16: Schematic of PEl attachment on MCM-48 mesoporous silica [238].

\subsubsection{Polyimides}

Polyimides (PI) show an excellent thermal and mechanical stability due to their stiff aromatic backbone. They are also resistant at room temperature to a number of solvents such as aromatics, aliphatic, ketones, esters, alcohols and concentrated acids [239]. Therefore these materials have been extensively used as SRNF membranes [239-244]. However, PI membranes can become instable in certain classes of solvents such as amines (DMAc and DMSO) as well as chlorinated and protic solvents (NMP, THF, DMF), which hampers the application of these membranes. Several cross- 
linking methods have been proposed in order to increase the chemical stability these membranes, [242-248]. Another approach can be grafting polyimide polymers onto ceramic supports which contain superior chemical stability.

More recently, Cheng et al. [249], prepared a covalently bonded nanoscale mesoporous silica $(60 \mathrm{~nm})$ polyimide ODPA (4,4'-oxydiphtalic anhydride)-BAPP (2,2-bis[4(4-aminophenoxy)phenyl] propane) nanocomposite by pre-modification with a grafted 3-aminopropyltrinethoxysilane, as illustrated in Figure 17. The amino groups inside the mesoporous channels can interconnect with the polyimide main chains forming a multi-linked and complex silica/Pi network. This approach resulted in increased thermal (increased Tg) and mechanical stability. Moreover, polymer chains were not only bond to the silica particle surface but also penetrated the pore channel, becoming tethered to the channel surface.

Leu et al. [250] modified a Na-kenyaite by first grafting with 3-aminopropyltriethoxysilane (APTES) followed by the grafting of a pre-formed poly (amic acid) BTDA (3,3',4,4' Benzophenone tetracarboxylic dianhydride)-ODA (4,4'-oxydianiline) type followed by a thermal imidization step. The amino group of the APTES can react with the anhydride end group of the poly (amic acid) to form a covalently bonded polymer tethered silicate. It was also demonstrated that an increase in both thermal and mechanical stability was attained.

Mixed matrix membranes, consisting of polyimides and zeolites, have been extensively studied $[6,7,251,252]$. However, the majority of these systems rely on physical attachments, even though few papers have reported the formation of a covalent bond between the polyimide and the zeolite particle, by grafting silane coupling agents on the surface of the sieve, as discussed before. Mahajan et al. [253] prepared a mixed matrix membrane composed of a APTES modified zeolite/Matrimid ${ }^{\circledR}$ membrane. The polyimide polymer was covalently bonded through the introduction of a bridged silane (APTES). Pechar et al. [254] use of a similar approach for the preparation of a mixed matrix membrane composed of a zeolite covalently bonded to a 6FDA-6FpDA-DABA. In both cases increased adhesion between the organic and inorganic moiety was achieved wth increased gas permeability at the cost of selectivity.

\subsubsection{Polyethylene (PE), polypropylene (PP)}

Hydrophobic polymers like PE and PP, especially the latter, offer a promising approach. Due to its high durability and stability in the wide $\mathrm{pH}$ and solvent range 


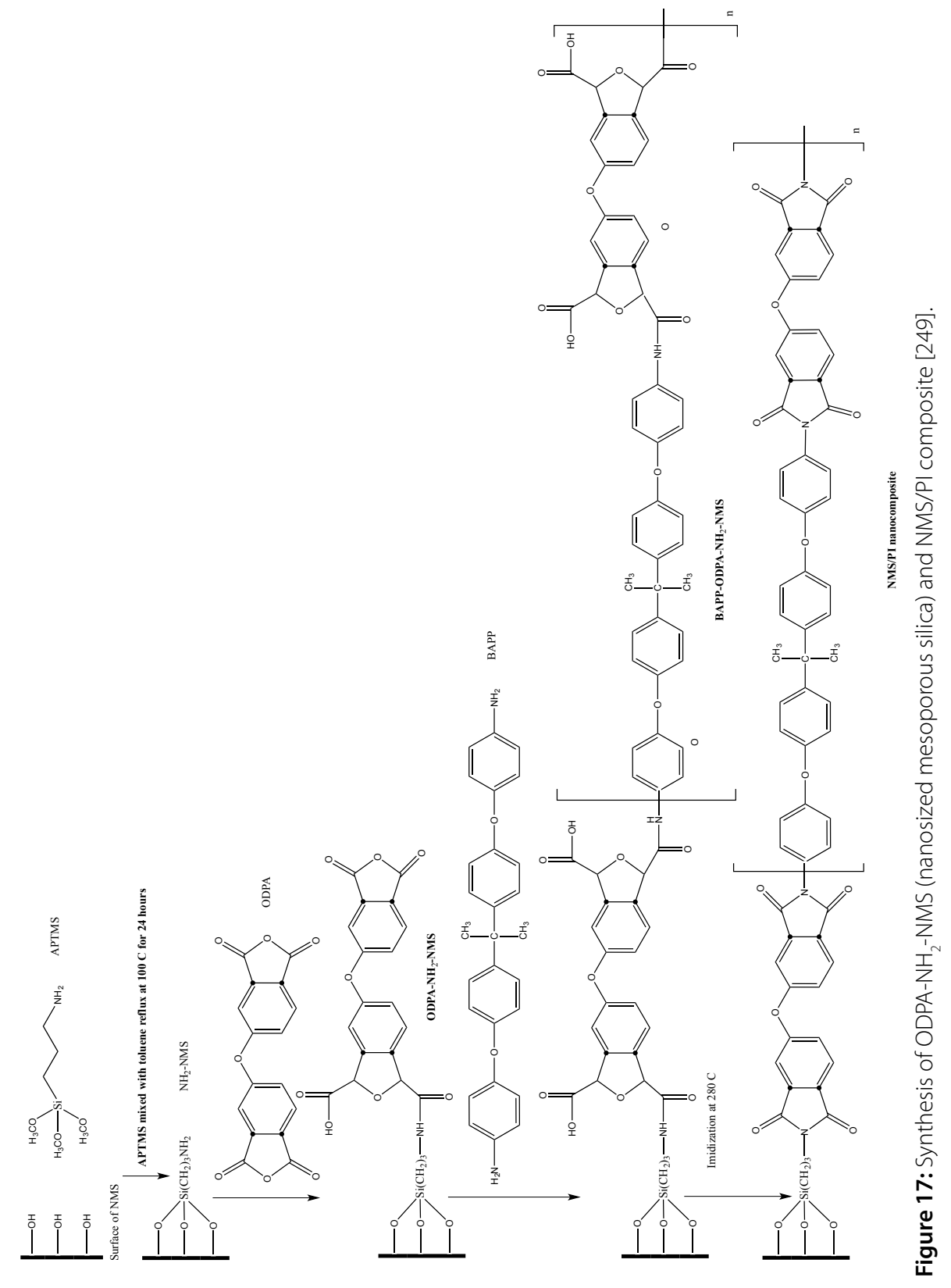


polypropylene is particularly interesting supporting material for solvent resistant membranes $[255,256]$.

Lui et al. [257] have immobilized three different polymers (PP, PE, PEG) onto a silica wafer via a photoactive heterofunctional crosslinker, using a silane-functionalized perfluorophenylazide (PFPA-silane) as a photoactive crosslinker. The immobilization of polymers (polypropylene, poly(ethyleneglycol) with low molecular weight and polystyrenes was studied (Figure 18)
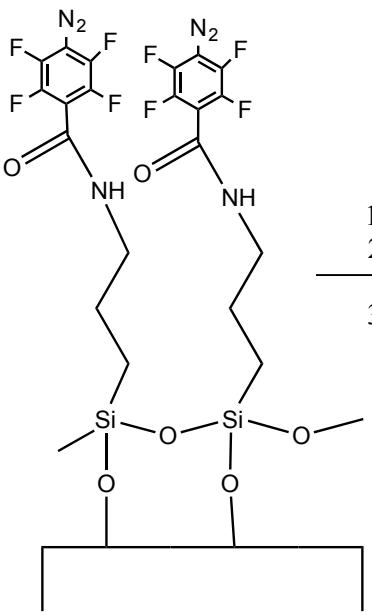

1) Coat polymer

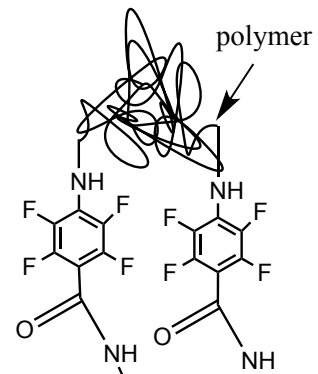

2) hv or heat

3) solvent extract

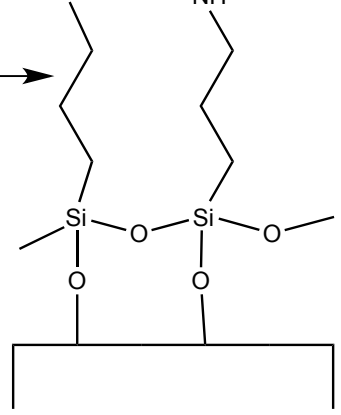

Figure 18: Covalent immobilization of a polymer on a PFPA-functionalized surface [257] .

The process is relative simple to perform. It involves coating of the polymer on the photolinker-functionalized surface (PFFA-silane-M, $M=$ metal oxide) followed by UV radiation. Upon irradiation perfluorophenylnitrenes are generated and undergo efficient $\mathrm{C}-\mathrm{H}$ and/or $\mathrm{N}-\mathrm{H}$ insertion reactions of the reactive intermediate. For this reason, there is no need to functionalize the molecule to be immobilized as long as it possesses $\mathrm{C}-\mathrm{H}$ and/or N-H bonds. On the other hand only a monolayer of the polymer is covalently immobilized. This immobilization technique appears to be highly reproducible and defect-tolerant. 


\subsection{6. "Dendrimer-like" highly branched polymers}

Dendrimers, hyperbranched polymers are able to entrap a diversity of organic molecules in their interior. Tsubokawa et al. [258], reported grafting of a polyamidoamine dendrimer onto a silica surface. Introduction of amino groups as an initiator site on the silica surface was achieved by the treatment of the silica with $\gamma$-aminopropyltriethoxysilane (APTES). The polyamidoamine dendrimer was propagated on the silica surface by repeating two processes: (1) Michael addition of methyl acrylate to surface amino groups, and (2) amidation of the resulting esters with ethylenediamine (Figure 19).

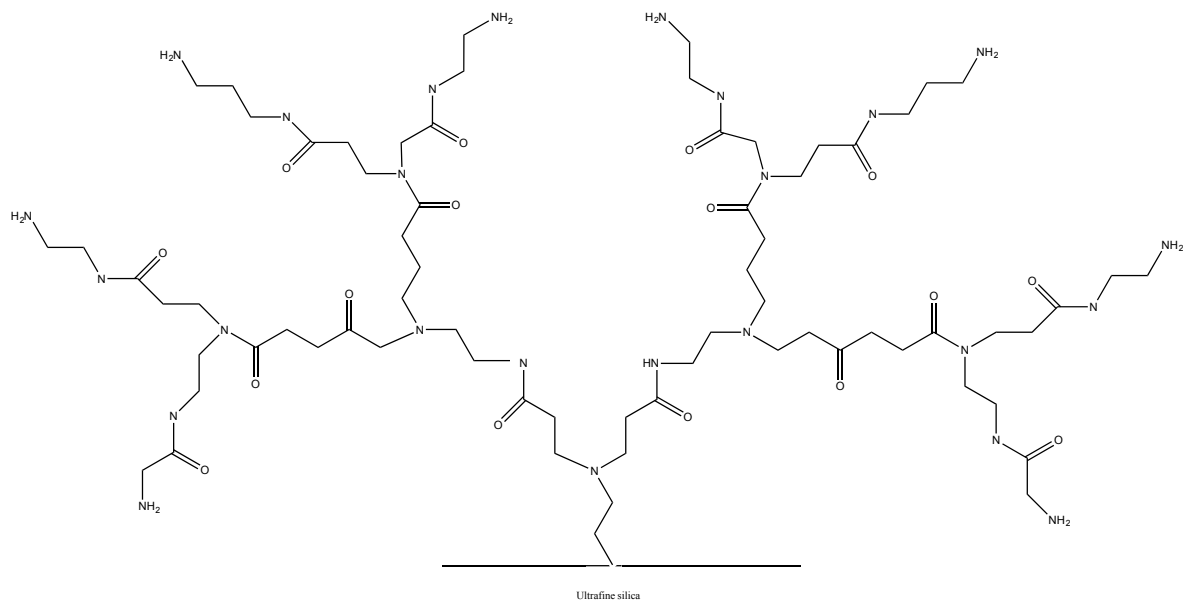

Figure 19: Polyamidoamine dendrimer-grafted silica [258].

These compounds present a controlled molecular weight building structure, controlled branching and versatility in design and modification of terminal end groups. These characteristics can be interesting for design of structures with controlled pore size with suitable functional groups, regarding the application in question.

Another example of a highly branched compound was investigated by Javaid et al. [149], where $\mathrm{yAl}_{2} \mathrm{O}_{3}$ membrane (pore size = 5-10nm) was modified with a triazinebased hyperbranched molecule presented in Figure 20. For comparison they used two chlorosilanes: Otcadecyltrichlorosilane (OTS) and phenyltrichlorosilane (PTS). Pervaporation of organic liquid/ liquid solutions (nitrogen, methane, propane and toluene) was evaluated. 


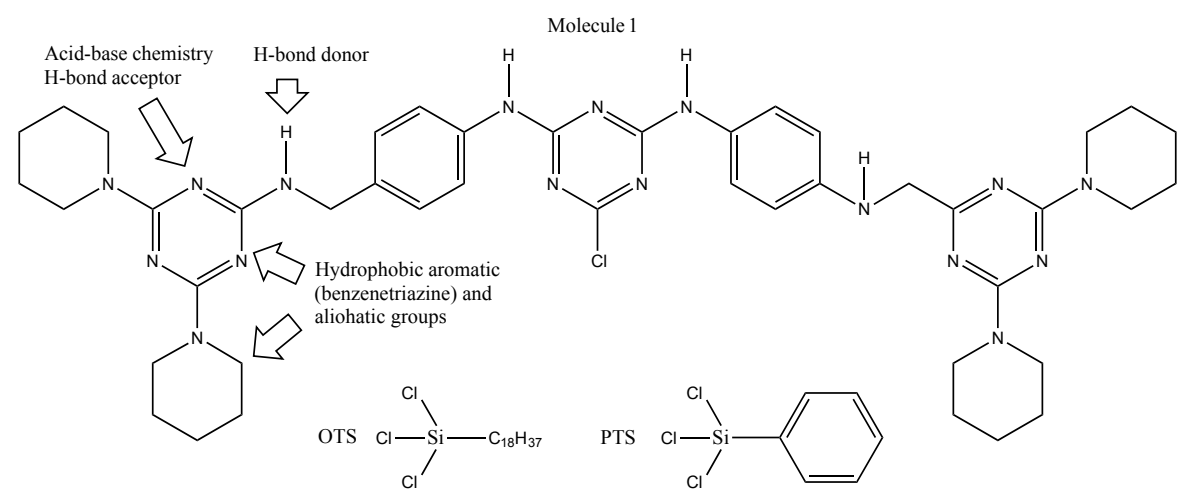

Figure 20: Chemical structures of theorganicmodifiers used inthis study: Octadecyltrichlorosilane (OTS), Phenyltrichlorosilane (PTS), Triazine-based hyperbranched molecule (molecule 1) [149] .

All membranes were solubility-selective (SF>1) for the separation of toluene from nitrogen. The apparently very densely-packed structure presented by PTS and the large resistance to toluene due to its large size compared to nitrogen, yielded extremely low permeability and selectivity. Moreover, they became mobilityselective for nitrogen, in one case. Whereas, the hyperbranched triazine molecule apparently formed a much looser structure that yielded good stability and high permeability. The selectivity of the OTS membrane was slightly higher than that of the hyperbranched triazine molecule, but its permeability was lower.

\subsection{Conclusions}

Based on this literature search the following grafting methods are proposed for the work, as described in this thesis:

1. The use of silanes as surface modifiers seems to be a promising grafting route for hydrophobizing ceramic membranes. The attaching of hydrophobic silanes onto inorganic surfaces seems special suitable for organic solvents, where the chemical stability in very low and high pHs is not a issue.

2. Along with silylation, the grafting of polysiloxanes polymers (chapter 3 and 4) and polyimides (chapter 6 and 7) has been selected as a second functionalization route. An amino trialkoxysilane was selected as the silane coupling agent, e.g. APTES. 


\subsection{List of Abbreviations}

AGP: $\quad$ Anionic graft polymerization

APTES: $\quad 3$-aminopropylethoxysilane

APTMS: $\quad 3$-aminopropylmethoxysilane

APDMES: 3-aminopropyldimethylethoxysilane

CGP: $\quad$ Cationic graft polymerization

CSP: $\quad$ Ceramic supported polymeric membranes

DMDMS: Dimethyldimethoxysilane

FMTES: $\quad 1 \mathrm{H}, 1 \mathrm{H}, 2 \mathrm{H}, 2 \mathrm{H}$-perfluoromethyltriethoxysilane

FOTES: $\quad 1 \mathrm{H}, 1 \mathrm{H}, 2 \mathrm{H}, 2 \mathrm{H}$-perfluorooctyltriethoxysilane

FOTS: $\quad 1 \mathrm{H}, 1 \mathrm{H}, 2 \mathrm{H}, 2 \mathrm{H}$-perfluorooctyltrichlorosilane

FDTES: $\quad 1 \mathrm{H}, 1 \mathrm{H}, 2 \mathrm{H}, 2 \mathrm{H}$-perfluorodecyltriethoxysilane

FHTES: $\quad 1 \mathrm{H}, 1 \mathrm{H}, 2 \mathrm{H}, 2 \mathrm{H}$-perfluorohexylltriethoxysilane

FPTES: $\quad 1 \mathrm{H}, 1 \mathrm{H}, 2 \mathrm{H}, 2 \mathrm{H}$-perfluorophenyltriethoxysilane

FRGP: $\quad$ Free radical graft polymerization

FTIR: $\quad$ Fourier transform infrared

HEMA: 2-Hydroxyethylacrylate

HEPO: $\quad$ t-Butylperoxy-2-methacryloyloxyethylcarbonate

Km: $\quad$ Permeability coefficient

MTBE: Methyl-tert-buthyl ether

MTMS: Methyltrimethoxysilane

MPTMS: 3-mercaptotrimethoxysilane

MWCO: $\quad$ Molecular weight cut-off

NVP: $\quad$ N-Vinyl-2-pyrrolidone

OPCA: $\quad$ Organophorous coupling agents

OTS: $\quad$ Octadecyltrichlorosilane

PDMS: $\quad$ Poly(dimethylsiloxane)

PE: $\quad$ poly(ethylene)

PEG: $\quad$ Poly(ethyleneglycol)

PEl: $\quad$ Poly(ethyleneimine)

PEO: $\quad$ Poly (ethylene oxide)

PFPA: Perfluorophenylazidesilane

PMODS: $\quad$ Poly(dimethyloctadecylsiloxane)

PMOS: $\quad$ Poly(methyloctylsiloxane)

PP: Polypropylene 
PPG: $\quad$ Polypropylene glycol

PTS: $\quad$ Phenyltrichlorosilane

PVA: $\quad$ Poly (vinyl alcohol)

PVAc: $\quad$ Poly(vinyl actetate)

PVP: $\quad$ Poly(vinyl pyrrolidone)

SAMs: $\quad$ Self-assembly monolayers

SRNF: $\quad$ Solvent resistant nanofiltration membranes

St: $\quad$ Styrene

TCMS: $\quad$ Trichloromethylsilane

TCE: $\quad$ Trichloroethene

TGA: $\quad$ Thermogravrimetric Analysis

THF: $\quad$ Tetrahydrofuran

Vac: Vinyl acetate

VP: $\quad$ 1-Vinyl-2-pyrrolidone

VTMS: Vinyltrimethoxysilane 


\subsection{References}

1. Goldman, M., D. Fraenkel, and G. Levin, A zeolite/polymer membrane for separation of ethanol-water azeotrope. Journal of Applied Polymer Science, 1989. 37(7): p. 1791-1800.

2. Song, K.M. and W.H. Hong, Dehydration of ethanol and isopropanol using tubular type cellulose acetate membrane with ceramic support in pervaporation process. Journal of Membrane Science, 1997. 123(1): p. 27-33.

3. Zhu, Y.S. and H.F. Chen, Pervaporation separation and pervaporation-esterification coupling using crosslinked PVA composite catalytic membranes on porous ceramic plate. Journal of Membrane Science, 1998. 138(1): p. 123-134.

4. Xiangli, F.J., et al., Polydimethylsiloxane (PDMS)/ceramic composite membrane with high flux for pervaporation of ethanol-water mixtures. Industrial \& Engineering Chemistry Research, 2007. 46(7): p. 2224-2230.

5. Park, H.B., et al., Imide-siloxane block copolymer/silica hybrid membranes: preparation, characterization and gas separation properties. Journal of Membrane Science, 2003. 220(12): p. 59-73.

6. Qiao, X., T.-S. Chung, and R. Rajagopalan, Zeolite filled P84 co-polyimide membranes for dehydration of isopropanol through pervaporation process. Chemical Engineering Science, 2006. 61(20): p. 6816-6825.

7. Yong, H.H., et al., Zeolite-filled polyimide membrane containing 2,4,6-triaminopyrimidine. Journal of Membrane Science, 2001. 188(2): p. 151-163.

8. Pyun, J. and K. Matyjaszewski, Synthesis of Nanocomposite Organic/Inorganic Hybrid Materials Using Controlled/“Living” Radical Polymerization. Chemistry of Materials, 2001. 13(10): p. 3436-3448.

9. Castro, R.P., Y. Cohen, and H.G. Monbouquette, The Permeability Behavior Of Polyvinylpyrrolidone-Modified Porous Silica Membranes. Journal of Membrane Science, 1993. 84(1-2): p. 151-160.

10. Castro, R.P., Y. Cohen, and H.G. Monbouquette, Silica-supported polyvinylpyrrolidone filtration membranes. Journal of Membrane Science, 1996. 115(2): p. 179-190.

11. Chaimberg, M. and Y. Cohen, Free-Radical Graft-Polymerization Of Vinylpyrrolidone Onto Silica. Industrial \& Engineering Chemistry Research, 1991. 30(12): p. 2534-2542.

12. Czaun, M., et al., Novel Surface-Attachable Multifunctional Initiators: Synthesis, Grafting, and Polymerization in Aprotic and Protic Solvents. Macromolecules, 2009. 42(13): p. 45394546.

13. Dekking, H.G.G., Propagation Of Vinyl Polymers On Clay Surfaces .I. Preparation Structure And Decomposition Of Clay Initiators. Journal of Applied Polymer Science, 1965. 9(5): p. $1641-\&$.

14. Laible, R. and K. Hamann, Formation of chemically bound polymer layers on oxide surfaces and their role in colloidal stability. Advances in Colloid and Interface Science, 1980. 13(1-2): p. 65-99.

15. Dekking, H.G.G., Propagation Of Vinyl Polymers On Clay Surfaces .2. Polymerization Of Monomers Initiated By Free Radicals Attached To Clay. Journal of Applied Polymer Science, 1967. 11(1): p. 23-\&.

16. Bachmann, S., et al., Graft polymerization of styrene initiated by covalently bonded peroxide groups on silica. Journal of Colloid and Interface Science, 2007. 309(1): p. 169-175.

17. Hayashi, S., et al., Graft polymerization of vinyl monomers initiated by peroxycarbonate groups introduced onto silica surface by Michael addition. Journal of Applied Polymer Science, 1999. 71(9): p. 1491-1497.

18. Kang, S., et al., Preparation and characterization of epoxy composites filled with functionalized nanosilica particles obtained via sol-gel process. Polymer, 2001. 42(3): p. 879-887.

19. Parvole, J., et al., Initiator-grafted silica particles for controlled free radical polymerization: Influence of the initiator structure on the grafting density. Macromolecular Rapid 
Communications, 2003. 24(18): p. 1074-1078.

20. Wang, Y.P., X.W. Pei, and K. Yuan, Reverse ATRP grafting from silica surface to prepare welldefined organic/inorganic hybrid nanocomposite. Materials Letters, 2005. 59(4): p. 520523.

21. Fery, N., R. Laible, and K. Hamann, Polyreactions On Pigment Surfaces .3. Polyreactions On Sio2 Surfaces. Angewandte Makromolekulare Chemie, 1973. 34(DEC): p. 81-109.

22. Tsubokawa, N., A. Kogure, and Y. Sone, Grafting Of Polyesters From Ultrafine Inorganic Particles - Copolymerization Of Epoxides With Cyclic Acid Anhydrides Initiated By Cook Groups Introduced Onto The Surface. Journal of Polymer Science Part a-Polymer Chemistry, 1990. 28(7): p. 1923-1933.

23. Hansen, N.M.L., K. Jankova, and S. Hvilsted, Fluoropolymer materials and architectures prepared by controlled radical polymerizations. European Polymer Journal, 2007. 43(2): p. 255-293.

24. Hawker, C.J., A.W. Bosman, and E. Harth, New polymer synthesis by nitroxide mediated living radical polymerizations. Chemical Reviews, 2001. 101(12): p. 3661-3688.

25. Weimer, M.W., et al., Direct synthesis of dispersed nanocomposites by in situ living free radical polymerization using a silicate-anchored initiator. Journal of the American Chemical Society, 1999. 121(7): p. 1615-1616.

26. Le Déoré, C., et al., Grafting 1,2-polybutadiene onto porous silica. Polymer, 1993. 34(14): p. 3048-3051.

27. Fadeev, A.Y., R. Helmy, and S. Marcinko, Self-assembled monolayers of organosilicon hydrides supported on titanium, zirconium, and hafnium dioxides. Langmuir, 2002. 18(20): p. 7521-7529.

28. Ek, S., E.I. liskola, and L. Niinisto, Gas-phase deposition of aminopropylalkoxysilanes on porous silica. Langmuir, 2003. 19(8): p. 3461-3471.

29. Kurth, D.G. and T. Bein, Thin-Films Of (3-Aminopropyl)Triethoxysilane On Aluminum-Oxide And Gold Substrates. Langmuir, 1995. 11(8): p. 3061-3067.

30. Chiang, C.H., H. Ishida, and J.L. Koenig, The Structure OfGamma-Aminopropyltriethoxysilane On Glass Surfaces. Journal of Colloid and Interface Science, 1980. 74(2): p. 396-404.

31. Vandenberg, E.T., et al., Structure Of 3-Aminopropyl Triethoxy Silane On Silicon-Oxide. Journal of Colloid and Interface Science, 1991. 147(1): p. 103-118.

32. Feng, X., et al., Functionalized monolayers on ordered mesoporous supports. Science, 1997. 276(5314): p. 923-926.

33. Bibby, A. and L. Mercier, Mercury(II) ion adsorption behavior in thiol-functionalized mesoporous silica microspheres. Chemistry of Materials, 2002. 14(4): p. 1591-1597.

34. Sharma, R.K., S. Das, and A. Maitra, Surface modified ormosil nanoparticles. Journal of Colloid and Interface Science, 2004. 277(2): p. 342-346.

35. Sandoval, J.E. and J.J. Pesek, Synthesis And Characterization Of A Hydride-Modified Porous Silica Material As An Intermediate In The Preparation Of Chemically Bonded Chromatographic Stationary Phases. Analytical Chemistry, 1989. 61(18): p. 2067-2075.

36. Yoshida, W. and Y. Cohen, Ceramic-supported polymer membranes for pervaporation of binary organic/organic mixtures. Journal of Membrane Science, 2003. 213(1-2): p. 145-157.

37. Kujawski, W., et al., Pervaporation properties of fluoroalkylsilane (FAS) grafted ceramic membranes. Desalination, 2007. 205(1-3): p. 75-86.

38. Picard, C., et al., Grafting of ceramic membranes by fluorinated silanes: hydrophobic features. Separation and Purification Technology, 2001. 25(1-3): p. 65-69.

39. Picard, C., et al., Characterisation of hydrophilic ceramic membranes modified by fluoroalkylsilanes into hydrophobic membranes. Solid State Sciences, 2004. 6(6): p. 605612.

40. Randon, J. and R. Paterson, Preliminary studies on the potential for gas separation by mesoporous ceramic oxide membranes surface modified by alkyl phosphonic acids. Journal of Membrane Science, 1997. 134(2): p. 219-223.

41. Okubo, T. and H. Inoue, Improvement of surface transport property by surface modification. 
AlChE Journal, 1988. 34(6): p. 1031-1033.

42. Kamitori, Y., et al., Selective protection of carbonyl compounds. Silica gel treated with thionyl chloride as an effective catalyst for thioacetalization. The Journal of Organic Chemistry, 1986. 51(9): p. 1427-1431.

43. Locke, D.C., Schmermu.Jt, and B. Banner, Bonded Stationary Phases For Chromatography. Analytical Chemistry, 1972. 44(1): p. 90

44. Tao, T. and G.E. Maciel, Reactivities of silicas with organometallic methylating agents. Journal of the American Chemical Society, 2000. 122(13): p. 3118-3126.

45. Tertykh, V.A. and L.A. Belyakova, Chapter 1.6 Solid-phase hydrosilylation reactions with participation of modified silica surface, in Studies in Surface Science and Catalysis, A. Dąbrowski and V.A. Tertykh, Editors. 1996, Elsevier. p. 147-189.

46. Lim, S.J., et al., Photoswitchable organic nanoparticles and a polymer film employing multifunctional molecules with enhanced fluorescence emission and bistable photochromism. Angewandte Chemie-International Edition, 2004. 43(46): p. 6346-6350.

47. Husain, S. and W.J. Koros, Mixed matrix hollow fiber membranes made with modified HSSZ-13 zeolite in polyetherimide polymer matrix for gas separation. Journal of Membrane Science, 2007. 288(1-2): p. 195-207.

48. Eur. Pat., EP053616, 2010

49. Ossenkamp, G.C., T. Kemmitt, and J.H. Johnston, New approaches to surface-alkoxylated silica with increased hydrolytic stability. Chemistry of Materials, 2001. 13(11): p. 3975-3980.

50. Dafinov, A., R. Garcia-Valls, and J. Font, Modification of ceramic membranes by alcohol adsorption. Journal of Membrane Science, 2002. 196(1): p. 69-77.

51. Jo, S. and K. Park, Surface modification using silanated poly(ethylene glycol)s. Biomaterials, 2000. 21(6): p. 605-616.

52. Oh, C., et al., Facile synthesis of PEG-silica hybrid particles using one-step sol-gel reaction in aqueous solution. Colloids and Surfaces A: Physicochemical and Engineering Aspects, 2009. 349(1-3): p. 145-150.

53. Pardal, F., V. Lapinte, and J.J. Robin, Modification of Silica Nanoparticles by Grafting of Copolymers Containing Organosilane and Fluorine Moities. Journal of Polymer Science Part a-Polymer Chemistry, 2009. 47(18): p. 4617-4628.

54. Chujo, Y., et al., A Novel Silane Coupling Agent .1. Synthesis Of Trimethoxysilyl-Terminated Poly(N-Acetylethylenimine). Macromolecules, 1989. 22(5): p. 2040-2043.

55. Leger, C., H.D.L. Lira, and R. Paterson, Preparation and properties of surface modified ceramic membranes. Part II. Gas and liquid permeabilities of $5 \mathrm{~nm}$ alumina membranes modified by a monolayer of bound polydimethylsiloxane (PDMS) silicone oil. Journal of Membrane Science, 1996. 120(1): p. 135-146.

56. Pourhossaini, M.R. and M. Razzaghi-Kashani, Grafting hydroxy-terminated polybutadiene onto nanosilica surface for styrene butadiene rubber compounds. Journal of Applied Polymer Science, 2012. 124(6): p. 4721-4728.

57. Bridger, K. and B. Vincent, The terminal grafting of poly(ethylene oxide) chains to silica surfaces. European Polymer Journal, 1980. 16(10): p. 1017-1021.

58. Guo, Z.X., et al., Grafting of Poly(ethylene glycol)s onto Nanometer Silica Surface by a One Step Procedure. Journal of Macromolecular Science, Part A, 2005. 42(2): p. 221-230.

59. Tsubokawa, N., et al., Grafting Onto Ultrafine Ferrite Particles - Reaction Of IsocyanateCapped Polypropylene Glycol With Hydroxyl-Groups On The Surface. Colloid and Polymer Science, 1989. 267(6): p. 511-515.

60. Zhang, F., et al., Chemical Vapor Deposition of Three Aminosilanes on Silicon Dioxide: Surface Characterization, Stability, Effects of Silane Concentration, and Cyanine Dye Adsorption. Langmuir, 2010. 26(18): p. 14648-14654.

61. Senkevich, J.J. and S.B. Desu, Compositional studies of near-room-temperature thermal CVD poly(chloro-p-xylylene)/SiO 2 nanocomposites. Applied Physics A, 2000. 70(5): p. 541-546.

62. Senkevich, J.J. and S.B. Desu, Near-Room-Temperature Thermal Chemical Vapor Deposition of Poly(chloro-p-xylylene)/ $/ \mathrm{SiO}_{2}$ Nanocomposites. Chemistry of Materials, 1999. 11(7): p. 1814-1821. 
63. Suffner, J., et al., In-Situ Coating of Silica Nanoparticles with Acrylate-Based Polymers. Chemical Vapor Deposition, 2007. 13(9): p. 459-464.

64. Nijmeijer, A., B.J. Bladergroen, and H. Verweij, Low-temperature CVI modification of Y-alumina membranes. Microporous and Mesoporous Materials, 1998. 25(1-3): p. 179-184.

65. Lewis, G.T., et al., Inorganic surface nanostructuring by atmospheric pressure plasmainduced graft polymerization. Langmuir, 2007. 23(21): p. 10756-10764.

66. Ida, J.-i., T. Matsuyama, and H. Yamamoto, Surface modification of a ceramic membrane by the SPCP-CVD method suitable for enzyme immobilization. Journal of Electrostatics, 2000. 49(1-2): p. 71-82.

67. Ida, J.-i., T. Matsuyama, and H. Yamamoto, Immobilization of glucoamylase on ceramic membrane surfaces modified with a new method of treatment utilizing SPCP-CVD. Biochemical Engineering Journal, 2000. 5(3): p. 179-184.

68. Paradis, G.G., et al., Amino-functionalized microporous hybrid silica membranes. Journal of Materials Chemistry, 2012. 22(15): p. 7258-7264.

69. Delange, R.S.A., K. Keizer, and A.J. Burggraaf, Analysis And Theory Of Gas-Transport In Microporous Sol-Gel Derived Ceramic Membranes. Journal of Membrane Science, 1995. 104(1-2): p. 81-100.

70. Campaniello, J., et al., Long-term pervaporation performance of microporous methylated silica membranes. Chemical Communications, 2004(7): p. 834-835.

71. Castricum, H.L., et al., High-performance hybrid pervaporation membranes with superior hydrothermal and acid stability. Journal of Membrane Science, 2008. 324(1-2): p. 111-118.

72. Benes, N., A. Nijmeijer, and H. Verweij, Microporous silica membranes, in Membrane Science and Technology, N.K. Kanellopoulos, Editor 2000, Elsevier. p. 335-372.

73. Tsuru, T., et al., Preparation of hydrophobic nanoporous methylated $\mathrm{SiO}_{2}$ membranes and application to nanofiltration of hexane solutions. Journal of Membrane Science, 2011. 384(1-2): p. 149-156.

74. Castricum, H.L., et al., Hydrothermally stable molecular separation membranes from organically linked silica. Journal of Materials Chemistry, 2008. 18(18): p. 2150-2158.

75. Brinker, C.J., et al., Sol-gel strategies for controlled porosity inorganic materials. Journal of Membrane Science, 1994. 94(1): p. 85-102.

76. de Vos, R.M. and H. Verweij, High-selectivity, high-flux silica membranes for gas separation. Science, 1998. 279(5357): p. 1710-1711.

77. Abidi, N., et al., Surface modification of mesoporous membranes by fluoro-silane coupling reagent for CO2 separation. Journal of Membrane Science, 2006. 270(1-2): p. 101-107.

78. Bothun, G.D., K. Peay, and S. Ilias, Role of tail chemistry on liquid and gas transport through organosilane-modified mesoporous ceramic membranes. Journal of Membrane Science, 2007. 301(1-2): p. 162-170.

79. Javaid, A., et al., Solubility-based gas separation with oligomer-modified inorganic membranes. Journal of Membrane Science, 2001. 187(1-2): p. 141-150.

80. Leger, C., H.D. Lira, and R. Paterson, Preparation and properties of surface modified ceramic membranes .3. Gas permeation of $5 \mathrm{~nm}$ alumina membranes modified by trichlorooctadecylsilane. Journal of Membrane Science, 1996. 120(2): p. 187-195.

81. Sah, A., et al., Hydrophobic modification of $\gamma$-alumina membranes with organochlorosilanes. Journal of Membrane Science, 2004. 243(1-2): p. 125-132.

82. Tripp, C.P. and M.L. Hair, Reaction Of Methylsilanols With Hydrated Silica Surfaces - The Hydrolysis OfTrichloromethylsilanes, Dichloromethylsilanes, And Monochloromethylsilanes And The Effects Of Curing. Langmuir, 1995. 11(1): p. 149-155.

83. Van Gestel, $\mathrm{T}$., et al., Surface modification of $\mathrm{\gamma}-\mathrm{Al}_{2} \mathrm{O}_{3} / \mathrm{TiO}_{2}$ multilayer membranes for applications in non-polar organic solvents. Journal of Membrane Science, 2003. 224(1-2): p. 3-10.

84. Verrecht, B., et al., Chemical surface modification of gamma-Al2O3 $\mathrm{TiO} 2$ toplayer membranes for increased hydrophobicity. Desalination, 2006. 200(1-3): p. 385-386.

85. Yoshida, W., et al., Multilayer alkoxysilane silylation of oxide surfaces. Langmuir, 2001. 17(19): 
p. 5882-5888.

86. Younssi, S.A., et al., gamma alumina membranes grafting by organosilanes and its application to the separation of solvent mixtures by pervaporation. Separation and Purification Technology, 2003. 32(1-3): p. 175-179.

87. Wartmann, J. and H. Deuel, Organische Derivate Des Silikagels Mit Si-C-Bindung .2. Helvetica Chimica Acta, 1959. 42(4): p. 1166-1170.

88. Jou, J.D., W. Yoshida, and Y. Cohen, A novel ceramic-supported polymer membrane for pervaporation of dilute volatile organic compounds. Journal of Membrane Science, 1999. 162(1-2): p. 269-284.

89. Blitz, J.P., R.S.S. Murthy, and D.E. Leyden, The Role Of Amine Structure On Catalytic Activity For Silylation Reactions With Cab-O-Sil. Journal of Colloid and Interface Science, 1988. 126(2): p. 387-392.

90. McGovern, M.E., K.M.R. Kallury, and M. Thompson, Role Of Solvent On The Silanization Of Glass With Octadecyltrichlorosilane. Langmuir, 1994. 10(10): p. 3607-3614.

91. Murthy, R.S.S. and D.E. Leyden, Quantitative-Determination Of (3-Aminopropyl) Triethoxysilane On Silica-Gel Surface Using Diffuse Reflectance Infrared Fourier-Transform Spectrometry. Analytical Chemistry, 1986. 58(6): p. 1228-1233.

92. VanDerVoort, P. and E.F. Vansant, Silylation of the silica surface a review. Journal of Liquid Chromatography \& Related Technologies, 1996. 19(17-18): p. 2723-2752.

93. Vrancken, K.C., et al., Influence Of Water In The Reaction Of GammaAminopropyltriethoxysilane With Silica-Gel - A Fourier-Transform Infrared And CrossPolarization Magic-Angle-Spinning Nuclear-Magnetic-Resonance Study. Journal of the Chemical Society-Faraday Transactions, 1992. 88(21): p. 3197-3200.

94. Silberzan, P., et al., Silanation Of Silica Surfaces - A New Method Of Constructing Pure Or Mixed Monolayers. Langmuir, 1991. 7(8): p. 1647-1651.

95. Hair, M.L. and C.P. Tripp, Alkylchlorosilane Reactions At The Silica Surface. Colloids and Surfaces a-Physicochemical and Engineering Aspects, 1995. 105(1): p. 95-103.

96. Tripp, C.P. and M.L. Hair, An Infrared Study OfThe Reaction Of Octadecyltrichlorosilane With Silica. Langmuir, 1992. 8(4): p. 1120-1126.

97. Angst, D.L. and G.W. Simmons, Moisture Absorption Characteristics Of Organosiloxane SelfAssembled Monolayers. Langmuir, 1991. 7(10): p. 2236-2242.

98. Allara, D.L., A.N. Parikh, and F. Rondelez, Evidence For A Unique Chain Organization In LongChain Silane Monolayers Deposited On 2 Widely Different Solid Substrates. Langmuir, 1995. 11(7): p. 2357-2360.

99. Wasserman, S.R., Y.T. Tao, and G.M. Whitesides, Structure And Reactivity Of Alkylsiloxane Monolayers Formed By Reaction Of Alkyltrichlorosilanes On Silicon Substrates. Langmuir, 1989. 5(4): p. 1074-1087.

100. Simon, A., et al., Study of two grafting methods for obtaining a 3-aminopropyltriethoxysilane monolayer on silica surface. Journal of Colloid and Interface Science, 2002. 251 (2): p. 278283.

101. Tripp, C.P. and M.L. Hair, Chemical Attachment Of Chlorosilanes To Silica - A 2-Step AminePromoted Reaction. Journal of Physical Chemistry, 1993. 97(21): p. 5693-5698.

102. Child, M.J., et al., Infrared Studies Of The Adsorption Of Triethylamine On Silica At The Solid Vapor And Solid Liquid Interfaces. Journal of Colloid and Interface Science, 1982. 89(1): p. 202-208.

103. Feher, F.J. and D.A. Newman, Enhanced Silylation Reactivity Of A Model For Silica Surfaces. Journal of the American Chemical Society, 1990. 112(5): p. 1931-1936.

104. Luebke, D., C. Myers, and H. Pennline, Hybrid membranes for selective carbon dioxide separation from fuel gas. Energy \& Fuels, 2006. 20(5): p. 1906-1913.

105. Brzoska, J.B., I. Benazouz, and F. Rondelez, Silanization Of Solid Substrates - A Step Toward Reproducibility. Langmuir, 1994. 10(11): p. 4367-4373.

106. Heiney, P.A., et al., Structure and growth of chromophore-functionalized (3-aminopropyl) triethoxysilane self-assembled on silicon. Langmuir, 2000. 16(6): p. 2651-2657. 
107. White, L.D. and C.P. Tripp, Reaction of (3-aminopropyl)dimethylethoxysilane with amine catalysts on silica surfaces. Journal of Colloid and Interface Science, 2000. 232(2): p. 400407.

108. Duchet, J., et al., Influence of the deposition process on the structure of grafted alkylsilane layers. Langmuir, 1997. 13(8): p. 2271-2278.

109. Hertl, W., Mechanism Of Gaseous Siloxane Reaction With Silica .I. Journal of Physical Chemistry, 1968. 72(4): p. 1248.

110. Hertl, W., Mechanism Of Gaseous Siloxane Reaction With Silica. Journal of Physical Chemistry, 1968. 72(12): p. 3993.

111. Tedder, L.L., G.Q. Lu, and J.E. Crowell, Mechanistic Studies Of Dielectric Thin-Film Growth By Low-Pressure Chemical Vapor-Deposition - The Reaction Of Tetraethoxysilane With $\mathrm{SiO}_{2}$ Surfaces. Journal of Applied Physics, 1991. 69(10): p. 7037-7049.

112. Dubois, L.H. and B.R. Zegarski, Bonding Of Alkoxysilanes To Dehydroxylated Silica Surfaces - A New Adhesion Mechanism. Journal of Physical Chemistry, 1993. 97(8): p. 1665-1670.

113. Van Der Voort, P., K.C. Vrancken, and E.F. Vansant, Gas-phase chlorosilylation of silica gel: effectiveness, surface coverage and stoichiometry. Journal of the Chemical Society, Faraday Transactions, 1995. 91(2): p. 353-357.

114. Doppelt, P. and M. Stelzle, Selective metallization of silica surfaces by copper CVD using a chemical affinity pattern created by gas phase silylation and UV exposure. Microelectronic Engineering, 1997. 33(1-4): p. 15-23.

115. Daehler, A., et al., Postsynthesis vapor-phase functionalization of MCM-48 with hexamethyldisilazane and 3-aminopropyldimethylethoxylsilane for bioseparation applications. Journal of Physical Chemistry B, 2005. 109(34): p. 16263-16271.

116. Slavov, S.V., A.R. Sanger, and K.T. Chuang, Mechanism of silation of silica with hexamethyldisilazane. Journal of Physical Chemistry B, 2000. 104(5): p. 983-989.

117. Tripp, C.P. and M.L. Hair, Reaction Of Chloromethylsilanes With Silica - A Low-Frequency Infrared Study. Langmuir, 1991. 7(5): p. 923-927.

118. Caravajal, G.S., et al., Structural Characterization Of (3-Aminopropyl)TriethoxysilaneModified Silicas By Si-29 And C-13 Nuclear Magnetic-Resonance. Analytical Chemistry, 1988. 60(17): p. 1776-1786.

119. Culler, S.R., et al., Analytical And Spectroscopic Investigation OfThe Interaction Of CO With Amine Functional Silane Coupling Agents On Glass-Fibers. Journal of Colloid and Interface Science, 1983. 96(1): p. 69-79.

120. Culler, S.R., H. Ishida, and J.L. Koenig, Ft-Ir Characterization Of The Reaction At The Silane Matrix Resin Interphase Of Composite-Materials. Journal of Colloid and Interface Science, 1986. 109(1): p. 1-10.

121. Tada, H. and H. Nagayama, Chemical-Vapor Surface Modification Of Porous-Glass With Fluoroalkyl-Functional Silanes .1. Characterization Of The Molecular Layer. Langmuir, 1994. 10(5): p. 1472-1476.

122. Tada, H. and H. Nagayama, Chemical-Vapor Surface Modification Of Porous-Glass With Fluoroalkyl-Functionalized Silanes .2. Resistance To Water. Langmuir, 1995. 11(1): p. 136142.

123. Bhushan, B., D. Hansford, and K.K. Lee, Surface modification of silicon and polydimethylsiloxane surfaces with vapor-phase-deposited ultrathin fluorosilane films for biomedical nanodevices. Journal of Vacuum Science \& Technology A, 2006. 24(4): p. 11971202.

124. Salmio, H. and D. Bruhwiler, Distribution of amino groups on a mesoporous silica surface after submonolayer deposition of aminopropylsilanes from an anhydrous liquid phase. Journal of Physical Chemistry C, 2007. $111(2)$ : p. 923-929.

125. Chong, A.S.M., et al., Functionalization of large-pore mesoporous silicas with organosilanes by direct synthesis. Microporous and Mesoporous Materials, 2004 . 72(1-3): p. 33-42.

126. Mercier, L. and T.J. Pinnavaia, Direct synthesis of hybrid organic-inorganic nanoporous silica by a neutral amine assembly route: Structure-function control by stoichiometric incorporation of organosiloxane molecules. Chemistry of Materials, 2000. 12(1): p. 188-196. 
127. Chong, A.S.M. and X.S. Zhao, Functionalization of SBA-15 with APTES and characterization of functionalized materials. Journal of Physical Chemistry B, 2003. 107(46): p. 12650-12657.

128. Fadeev, A.Y. and T.J. McCarthy, Self-assembly is not the only reaction possible between alkyltrichlorosilanes and surfaces: Monomolecular and oligomeric covalently attached layers of dichloro- and trichloroalkylsilanes on silicon. Langmuir, 2000. 16(18): p. 7268-7274.

129. Fadeev, A.Y. and T.J. McCarthy, Trialkylsilane monolayers covalently attached to silicon surfaces: Wettability studies indicating that molecular topography contributes to contact angle hysteresis. Langmuir, 1999. 15(11): p. 3759-3766.

130. Hair, M.L. and W. Hertl, Reactions Of Chlorosilanes With Silica Surfaces. Journal of Physical Chemistry, 1969. 73(7): p. 2372.

131. Unger, K.K., N. Becker, and P. Roumeliotis, Recent Developments In Evaluation Of Chemically Bonded Silica Packings For Liquid-Chromatography. Journal of Chromatography, 1976. 125(1): p. 115-127.

132. Granier, M., et al., Improved strain relief of self-assembled monolayers from organohydridochlorosilanes grafted onto oxidized $(1,0,0)$ silicon wafers. Langmuir, 2003. 19(7): p. 2691-2695.

133. Alami-Younssi, S., et al., Grafting gamma alumina microporous membranes by organosilanes: Characterisation by pervaporation. Journal of Membrane Science, 1998. 143(1-2): p. 27-36.

134. Mercier, L. and T.J. Pinnavaia, Heavy metal lan adsorbents formed by the grafting of a thiol functionality to mesoporous silica molecular sieves: Factors affecting $\mathrm{Hg}(\mathrm{II})$ uptake. Environmental Science \& Technology, 1998. 32(18): p. 2749-2754.

135. Nam, K.H., S. Gomez-Salazar, and L.L. Tavlarides, Mercury(II) adsorption from wastewaters using a thiol functional adsorbent. Industrial \& Engineering Chemistry Research, 2003. 42(9): p. 1955-1964.

136. Hyun, S.H., S.Y. Jo, and B.S. Kang, Surface modification of gamma-alumina membranes by silane coupling for $\mathrm{CO}_{2}$ separation. Journal of Membrane Science, 1996. 120(2): p. 197-206.

137. Su, C.L., et al., Preparation and chiral selectivity of BSA-modified ceramic membrane. Chinese Chemical Letters, 2006. 17(5): p. 649-652.

138. Oh, S., et al., Preparation of novel ceramic membranes modified by mesoporous silica with 3 -aminopropyltriethoxysilane (APTES) and its application to $\mathrm{Cu}^{2+}$ separation in the aqueous phase. Journal of Membrane Science, 2007. 301(1-2): p. 118-125.

139. Liu, A.M., et al., A new class of hybrid mesoporous materials with functionalized organic monolayers for selective adsorption of heavy metal ions. Chemical Communications, 2000(13): p. 1145-1146.

140. Kinkel, J.N. and K.K. Unger, Role of solvent and base in the silanization reaction of silicas for reversed-phase high-performance liquid chromatography. Journal of Chromatography A, 1984. 316(0): p. 193-200.

141. Hozumi, A., et al., Fluoroalkylsilane monolayers formed by chemical vapor surface modification on hydroxylated oxide surfaces. Langmuir, 1999. 15(22): p. 7600-7604.

142. Gabino, F., et al., Evaluation of the cleaning of a new hydrophobic membrane for osmotic evaporation. Separation and Purification Technology, 2007. 55(2): p. 191-197.

143. Janknecht, P., et al., Ozone-water contacting by ceramic membranes. Separation and Purification Technology, 2001. 25(1-3): p. 341-346.

144. Krajewski, S.R., et al., Application of fluoroalkylsilanes (FAS) grafted ceramic membranes in membrane distillation process of $\mathrm{NaCl}$ solutions. Journal of Membrane Science, 2006. 281(1-2): p. 253-259.

145. Larbot, A., et al., Water desalination using ceramic membrane distillation. Desalination, 2004. 168(0): p. 367-372.

146. Hendren, Z.D., J. Brant, and M.R. Wiesner, Surface modification of nanostructured ceramic membranes for direct contact membrane distillation. Journal of Membrane Science, 2009. 331(1-2): p. 1-10.

147. Miller, J.R. and W.J. Koros, The Formation of Chemically Modified $y$-Alumina Microporous Membranes. Separation Science and Technology, 1990. 25(13-15): p. 1257-1280.

148. Mejean P., Collet A., Vigier M., Silvade.A, Bourret D., Larbot A., ICIM 5, Japan, 1998, p.176 
149. Javaid, A., et al., Nanocomposite membranes of chemisorbed and physisorbed molecules on porous alumina for environmentally important separations. Journal of Membrane Science, 2006. 275(1-2): p. 255-260.

150. Javaid, A. and D.M. Ford, Solubility-based gas separation with oligomer-modified inorganic membranes - Part II. Mixed gas permeation of $5 \mathrm{~nm}$ alumina membranes modified with octadecyltrichlorosilane. Journal of Membrane Science, 2003. 215(1-2): p. 157-168.

151. Javaid, A., D.A. Krapchetov, and D.M. Ford, Solubility-based gas separation with oligomermodified inorganic membranes - Part III. Effects of synthesis conditions. Journal of Membrane Science, 2005. 246(2): p. 181-191.

152. Singh, R.P., et al., Dual-surface-modified reverse-selective membranes. Industrial \& Engineering Chemistry Research, 2007. 46(22): p. 7246-7252.

153. McCarley, K.C. and J.D. Way, Development of a model surface flow membrane by modification of porous gamma-alumina with octadecyltrichlorosilane. Separation and Purification Technology, 2001. 25(1-3): p. 195-210.

154. Caro, J., M. Noack, and P. Kolsch, Chemically modified ceramic membranes. Microporous and Mesoporous Materials, 1998. 22(1-3): p. 321-332.

155. Tsuru, T., et al., Inorganic porous membranes for nanofiltration of nonaqueous solutions. Separation and Purification Technology, 2003. 32(1-3): p. 105-109.

156. Tsuru, T., et al., Permeation of nonaqueous solution through organic/Inorganic hybrid nanoporous membranes. AlChE Journal, 2004. 50(5): p. 1080-1087.

157. Tsuru T et al., Organic/inorganic Nanohybrid Membranes for Nanofiltration of Nonaqueous Solutions. MRS Proceedings, 752, 2002, AA8.8 doi:10.1557/PROC-752-AA8.8.

158. Castricum, H.L., et al., Hydrophobisation of mesoporous gamma-Al2O3 with organochlorosilanes - efficiency and structure. Microporous and Mesoporous Materials, 2005. 83(1-3): p. 1-9.

159. Eur. Pat. EP1603663, 2004

160. Voigt I, Ceramic nanofiltration membranes for applications in organic solvents, 9th Aachen Membrane Colloquium OP20-2 O 20P-11, Aachen, Germany, 2003

161. Gao, W. and L. Reven, Solid-State Nmr-Studies Of Self-Assembled Monolayers. Langmuir, 1995. 11(6): p. 1860-1863.

162. Van Alsten, J.G., Self-assembled monolayers on engineering metals: Structure, derivatization, and utility. Langmuir, 1999. 15(22): p. 7605-7614.

163. Gawalt, E.S., et al., Self-assembly and bonding of alkanephosphonic acids on the native oxide surface of titanium. Langmuir, 2001. 17(19): p. 5736-5738.

164. D'Andrea, S.C. and A.Y. Fadeev, Covalent surface modification of calcium hydroxyapatite using n-alkyl-and n-fluoroalkylphosphonic acids. Langmuir, 2003. 19(19): p. 7904-7910.

165. Lee, H., et al., Adsorption Of Ordered Zirconium Phosphonate Multilayer Films On Silicon And Gold Surfaces. Journal of Physical Chemistry, 1988. 92(9): p. 2597-2601.

166. P. H. Mutin, WO2004016630, 2004

167. Guerrero, G., P.H. Mutin, and A. Vioux, Anchoring of phosphonate and phosphinate coupling molecules on titania particles. Chemistry of Materials, 2001. 13(11): p. 4367-4373.

168. Nakatsuka, T., et al., Phosphate Coupling Agents For Calcium-Carbonate Filler. Journal of Applied Polymer Science, 1982. 27(1): p. 259-269.

169. Textor, M., et al., Structural chemistry of self-assembled monolayers of octadecylphosphoric acid on tantalum oxide surfaces. Langmuir, 2000. 16(7): p. 3257-3271.

170. Hofer, R., M. Textor, and N.D. Spencer, Alkyl phosphate monolayers, self-assembled from aqueous solution onto metal oxide surfaces. Langmuir, 2001. 17(13): p. 4014-4020.

171. Lukes, I., M. Borbaruah, and L.D. Quin, Direct Reaction Of Phosphorus-Acids With Hydroxy Of A Silanol And On The Silica-Gel Surface. Journal of the American Chemical Society, 1994. 116(5): p. 1737-1741.

172. Michel, R., et al., Selective molecular assembly patterning: A new approach to micro- and nanochemical patterning of surfaces for biological applications. Langmuir, 2002. 18(8): p. 3281-3287. 
173. Randon, J., P. Blanc, and R. Paterson, Modification Of Ceramic Membrane Surfaces Using Phosphoric-Acid And Alkyl Phosphonic-Acids And Its Effects On Ultrafiltration Of Bsa Protein. Journal of Membrane Science, 1995. 98(1-2): p. 119-129.

174. Guerrero, G., P.H. Mutin, and A. Vioux, Organically modified aluminas by grafting and sol-gel processes involving phosphonate derivatives. Journal of Materials Chemistry, 2001. 11(12): p. 3161-3165.

175. Vioux, A., et al., Hybrid organic-inorganic materials based on organophosphorus derivatives. New Aspects in Phosphorus Chemistry Iv, 2004. 232: p. 145-174.

176. Gao, W., et al., Self-assembled monolayers of alkylphosphonic acids on metal oxides. Langmuir, 1996. 12(26): p. 6429-6435.

177. Helmy, R. and A.Y. Fadeev, Self-assembled monolayers supported on TiO2: Comparison of $\mathrm{C}_{18} \mathrm{H}_{37} \mathrm{SiX}_{3}\left(\mathrm{X}=\mathrm{H}, \mathrm{Cl}, \mathrm{OCH}_{3} \mathrm{C}_{18} \mathrm{H}_{37} \mathrm{Si}\left(\mathrm{CH}_{3}\right)_{2} \mathrm{C}_{1}\right.$, and $\mathrm{C}_{18} \mathrm{H}_{37} \mathrm{PO}(\mathrm{OH})_{2}$. Langmuir, 2002. 18(23): $\mathrm{p}$. 8924-8928.

178. Knobler, C.M. and D.K. Schwartz, Langmuir and self-assembled monolayers. Current Opinion in Colloid \& Interface Science, 1999. 4(1): p. 46-51.

179. Pellerite, M.J., et al., Effects of fluorination on self-assembled monolayer formation from alkanephosphonic acids on aluminum: Kinetics and structure. Journal of Physical Chemistry B, 2003. 107(42): p. 11726-11736.

180. Allara, D.L. and R.G. Nuzzo, Spontaneously Organized Molecular Assemblies .1. Formation, Dynamics, And Physical-Properties Of Normal-Alkanoic Acids Adsorbed From Solution On An Oxidized Aluminum Surface. Langmuir, 1985. 1(1): p. 45-52.

181. Ulman, A., Formation and structure of self-assembled monolayers. Chemical Reviews, 1996. 96(4): p. 1533-1554.

182. Liakos, I.L., et al., Comparative study of self-assembly of a range of monofunctional aliphatic molecules on magnetron-sputtered aluminium. Surface and Interface Analysis, 2004. 36(4): p. 347-354.

183. Marcinko, S. and A.Y. Fadeev, Hydrolytic stability of organic monolayers supported on $\mathrm{TiO}_{2}$ and $\mathrm{ZrO}_{2}$. Langmuir, 2004. 20(6): p. 2270-2273.

184. Rigney, M.P., E.F. Funkenbusch, and P.W. Carr, Physical And Chemical Characterization Of Microporous Zirconia. Journal of Chromatography, 1990. 499: p. 291-304.

185. Mutin, P.H., G. Guerrero, and A. Vioux, Hybrid materials from organophosphorus coupling molecules. Journal of Materials Chemistry, 2005. 15(35-36): p. 3761-3768.

186. Zwahlen, M., et al., Orientation in methyl- and hydroxyl-terminated self-assembled alkanephosphate monolayers on titanium oxide surfaces investigated with soft X-ray absorption. Langmuir, 2002. 18(10): p. 3957-3962.

187. Pawsey, S., K. Yach, and L. Reven, Self-assembly of carboxyalkylphosphonic acids on metal oxide powders. Langmuir, 2002. 18(13): p. 5205-5212.

188. Pawsey, S., et al., H-1 fast MAS NMR studies of hydrogen-bonding interactions in selfassembled monolayers. Journal of the American Chemical Society, 2003. 125(14): p. 41744184.

189. Smalley, J.F., et al., An indirect laser-induced temperature jump determination of the surface pK(a) of 11-mercaptoundecanoic acid monolayers self-assembled on gold. Journal of Physical Chemistry B, 1999. 103(10): p. 1676-1685.

190. Schafer, W.A., et al., Physical And Chemical Characterization Of A Porous PhosphateModified Zirconia Substrate. Journal of Chromatography, 1991. 587(2): p. 137-147.

191. Dumon, S. and H. Barnier, Ultrafiltration Of Protein Solutions On $\mathrm{ZrO}_{2}$ Membranes - The Influence Of Surface-Chemistry And Solution Chemistry On Adsorption. Journal of Membrane Science, 1992. 74(3): p. 289-302.

192. Zou, H., S.S. Wu, and J. Shen, Polymer/silica nanocomposites: Preparation, characterization, properties, and applications. Chemical Reviews, 2008. 108(9): p. 3893-3957.

193. Aswal, D.K., et al., Self assembled monolayers on silicon for molecular electronics. Analytica Chimica Acta, 2006. 568(1-2): p. 84-108.

194. Wight, A.P. and M.E. Davis, Design and preparation of organic-inorganic hybrid catalysts. Chemical Reviews, 2002. 102(10): p. 3589-3613. 
195. DiBenedetto, A.T., Tailoring of interfaces in glass fiber reinforced polymer composites: a review. Materials Science and Engineering: A, 2001. 302(1): p. 74-82.

196. Nawrocki, J., et al., Part II. Chromatography using ultra-stable metal oxide-based stationary phases for HPLC. Journal of Chromatography A, 2004. 1028(1): p. 31-62.

197. Yoshinaga, K., Functionalization of inorganic colloidal particles by polymer modification. Bulletin of the Chemical Society of Japan, 2002. 75(11): p. 2349-2358.

198. Jia, X., et al., Preparation and properties of poly(vinyl alcohol)/silica nanocomposites derived from copolymerization of vinyl silica nanoparticles and vinyl acetate. European Polymer Journal, 2007. 43(4): p. 1123-1131.

199. Nguyen, V., W. Yoshida, and Y. Cohen, Graft polymerization of vinyl acetate onto silica. Journal of Applied Polymer Science, 2003. 87(2): p. 300-310.

200. Yamashita, S., et al., Preparation and physical properties of polybutadiene grafted onto silica. Journal of Applied Polymer Science, 1973. 17(10): p. 2935-2944.

201. Mo, T.C., et al., Synthesis and characterization of polyimide-silica nanocomposites using novel fluorine-modified silica nanoparticles. Journal of Applied Polymer Science, 2007. 104(2): p. 882-890.

202. Mo, T.-C., et al., Synthesis and characterization of polyimide-silica nanocomposites using novel fluorine-modified silica nanoparticles. Journal of Applied Polymer Science, 2007. 104(2): p. 882-890.

203. Takai, C., M. Fuji, and M. Takahashi, A novel surface designed technique to disperse silica nano particle into polymer. Colloids and Surfaces A: Physicochemical and Engineering Aspects, 2007. 292(1): p. 79-82.

204. Yang, F., Y.C. Ou, and Z.Z. Yu, Polyamide 6 silica nanocomposites prepared by in situ polymerization. Journal of Applied Polymer Science, 1998. 69(2): p. 355-361.

205. Reynaud, E., et al., Nanofillers in polymeric matrix: a study on silica reinforced PA6. Polymer, 2001. 42(21): p. 8759-8768.

206. Li, Y., J. Yu, and Z.-X. Guo, The influence of silane treatment on nylon 6/nano-SiO2in situ polymerization. Journal of Applied Polymer Science, 2002. 84(4): p. 827-834.

207. Yoshinaga, K., Y. Tani, and Y. Tanaka, Surface modification of fine colloidal silica with copolymer silane-coupling agents composed of maleic anhydride. Colloid and Polymer Science, 2002. 280(1): p. 85-89.

208. Zhao, J.H. and P.W. Carr, Synthesis and evaluation of an aromatic polymer-coated zirconia for reversed phase liquid chromatography. Analytical Chemistry, 1999. 71(22): p. 52175224.

209. Kingshott, P., et al., Covalent attachment of poly(ethylene glycol) to surfaces, critical for reducing bacterial adhesion. Langmuir, 2003. 19(17): p. 6912-6921.

210. Lee, S.W., et al., Transport and functional behaviour of poly(ethylene glycol)-modified nanoporous alumina membranes. Nanotechnology, 2005. 16(8): p. 1335-1340.

211. Zhu, Y.-I., et al., A ONE-STEP SURFACE MODIFICATION PROCEDURETO PEG-GRAFTED NANOTITANIA. Chinese Journal of Polymer Science, 2007. 25(03): p. 291-296.

212. Zhang, Z., et al., Synthesis of poly(ethylene glycol) (PEG)-grafted colloidal silica particles with improved stability in aqueous solvents. Journal of Colloid and Interface Science, 2007. 310(2): p. 446-455.

213. Li, P.F., et al., Thermo-responsive gating membranes with controllable length and density of poly(N-isopropylacrylamide) chains grafted by ATRP method. Journal of Membrane Science, 2009. 337(1-2): p. 310-317.

214. Nakatsuka, T., Polyacrylate-Graft Silica-Gel As A Support Of Lipase Interesterifying Triacylglycerol In Organic-Solvent. Journal of Applied Polymer Science, 1987. 34(6): p. 21252137.

215. Suzuki, K., et al., Modification of porous silica particles with poly(acrylic acid). Polymers for Advanced Technologies, 2000. 11(2): p. 92-97.

216. Cao, X.Z., et al., A novel hydrophilic polymer-ceramic composite membrane 1 acrylic acid grafting membrane. Journal of Membrane Science, 2008. 312(1-2): p. 15-22. 
217. Tsubokawa, N., et al., Graft-Polymerization Of Vinyl Monomers From Inorganic Ultrafine Particles Initiated By Azo Groups Introduced Onto The Surface. Polymer Journal, 1990. 22(9): p. 827-833.

218. Liu, Y.-L., C.-Y. Hsu, and K.-Y. Hsu, Poly(methylmethacrylate)-silica nanocomposites films from surface-functionalized silica nanoparticles. Polymer, 2005. 46(6): p. 1851-1856.

219. Liu, Y.-L., M.-C. Tseng, and M.-H. Fangchiang, Polymerization and nanocomposites properties of multifunctional methylmethacrylate POSS. Journal of Polymer Science Part A: Polymer Chemistry, 2008. 46(15): p. 5157-5166.

220. Ranade, S.V., X.Q. Xie, and A.T. Dibenedetto, Effect of interphase structure on the debonding of polycarbonate from S-2 glass fibers. Journal of Adhesion, 1997. 64(1-4): p. 7-+.

221. DiBenedetto, A.T., et al., Reactive coupling of fibers to engineering thermoplastics. Composite Structures, 1994. 27(1-2): p. 73-82.

222. Oréfice, R.L. and A. Brennan, Controlled modification of the structure of polymer surfaces by chemically grafting inorganic species. Materials Research, 1999. 2: p. 153-157.

223. Oréfice, R.L. and A. Brennan, Evaluation of the interactions between polymeric chains and surfaces with different structures performed by an atomic force microscope. Materials Research, 1998. 1: p. 19-28.

224. Punyacharoennon, P. and K. Srikulkit, Preparation of hyperbranched polyamidoamine polymer-ultrafine silica hybrid composite. Journal of Applied Polymer Science, 2008. 109(5): p. 3230-3237.

225. Yoshinaga, K. and T. Kobayashi, An effective cross linking of polymer layer on monodisperse, poly(maleic anhydride-styrene)-modified colloidal silica particles and properties of the composite. Colloid and Polymer Science, 1997. 275(12): p. 1115-1120.

226. Yoshinaga, K. and M. Teramoto, Bindings of a secondary polymer to monodisperse colloidal silica particles modified with poly(maleic anhydride-styrene) for controlling the surface polarity. Bulletin of the Chemical Society of Japan, 1996. 69(9): p. 2667-2672.

227. Gupta, S., P.C. Ramamurthy, and G. Madras, Covalent Grafting of Polydimethylsiloxane over Surface-Modified Alumina Nanoparticles. Industrial \& Engineering Chemistry Research, 2011. 50(11): p. 6585-6593.

228. Cinausero, N., et al., Influence of the surface modification of alumina nanoparticles on the thermal stability and fire reaction of PMMA composites. Polymers for Advanced Technologies, 2008. 19(6): p. 701-709.

229. Fadeev, A.Y. and Y.V. Kazakevich, Covalently attached monolayers of oligo(dimethylsiloxane) s on silica: A siloxane chemistry approach for surface modification. Langmuir, 2002. 18(7): p. 2665-2672.

230. Bachmann, S., et al., Synthesis and solid-state NMR investigations of radiation-immobilized polysiloxanes on bare, titanium-grafted, and zirconium-grafted silicas. Chemistry of Materials, 2001. 13(5): p. 1874-1879.

231. Faria, A.M., et al., Immobilized polymeric stationary phases using metalized silica supports. Journal of Separation Science, 2006. 29(6): p. 782-789.

232. US Pat. 5035803, 1991

233. Yoshida, W. and Y. Cohen, Removal of methyl tert-butyl ether from water by pervaporation using ceramic-supported polymer membranes. Journal of Membrane Science, 2004. 229(1-2): p. 27-32.

234. Y. Cohen, "Novel Ceramic-Polymer composite Membranes for the separation of liquid waste", U. S. Department of Energy, Project number 54926 (2000)

235. Tsubokawa, N. and H. Ishida, Graft-Polymerization Of Vinyl Monomers By Peroxyester Groups Introduced Onto The Surface Of Inorganic Ultrafine Particles. Polymer Journal, 1992. 24(8): p. 809-816.

236. Tsubokawa, N. and H. Ishida, Graft polymerization of methyl methacrylate from silica initiated by peroxide groups introduced onto the surface. Journal of Polymer Science Part A: Polymer Chemistry, 1992. 30(10): p. 2241-2246.

237. Tsubokawa, N. and A. Kogure, Cationic Graft-Polymerization From Ultrafine Silica Initiated By Acylium Perchlorate Groups Introduced Onto The Surface. Polymer Journal, 1993. 25(1): 
p. 83-89.

238. Kumar, P., et al., Polyethyleneimine-modified MCM-48 membranes: Effect of water vapor and feed concentration on $\mathrm{N}_{2} / \mathrm{CO}_{2}$ selectivity. Industrial \& Engineering Chemistry Research, 2008. 47(1): p. 201-208.

239. White, L.S., Transport properties of a polyimide solvent resistant nanofiltration membrane. Journal of Membrane Science, 2002. 205(1-2): p. 191-202.

240. White, L.S. and A.R. Nitsch, Solvent recovery from lube oil filtrates with a polyimide membrane. Journal of Membrane Science, 2000. 179(1-2): p. 267-274.

241. Scarpello, J.T., et al., The separation of homogeneous organometallic catalysts using solvent resistant nanofiltration. Journal of Membrane Science, 2002. 203(1-2): p. 71-85.

242. See Toh, Y.H., F.W. Lim, and A.G. Livingston, Polymeric membranes for nanofiltration in polar aprotic solvents. Journal of Membrane Science, 2007. 301(1-2): p. 3-10.

243. Vanherck, K., et al., A simplified diamine crosslinking method for PI nanofiltration membranes. Journal of Membrane Science, 2010. 353(1-2): p. 135-143.

244. Vanherck, K., et al., Cross-linked polyimide membranes for solvent resistant nanofiltration in aprotic solvents. Journal of Membrane Science, 2008. 320(1-2): p. 468-476.

245. Kita, $H_{\text {., }}$ et al., Effect of photocrosslinking on permeability and permselectivity of gases through benzophenone-containing polyimide. Journal of Membrane Science, 1994. 87(12): p. 139-147.

246. Liu, Y., R. Wang, and T.S. Chung, Chemical cross-linking modification of polyimide membranes for gas separation. Journal of Membrane Science, 2001. 189(2): p. 231-239.

247. Shao, L., et al., Transport properties of cross-linked polyimide membranes induced by different generations of diaminobutane (DAB) dendrimers. Journal of Membrane Science, 2004. 238(1-2): p. 153-163.

248. Tin, P.S., et al., Effects of cross-linking modification on gas separation performance of Matrimid membranes. Journal of Membrane Science, 2003. 225(1-2): p. 77-90.

249. Cheng, C.F., et al., Effect of reactive channel functional groups and nanoporosity of nanoscale mesoporous silica on properties of polyimide composite. Macromolecules, 2006. 39(22): p. 7583-7590.

250. Leu, C.M., Z.W. Wu, and K.H. Wei, Synthesis and properties of covalently bonded layered silicates/polyimide (BTDA-ODA) nanocomposites. Chemistry of Materials, 2002. 14(7): p. 3016-3021.

251. Zhang, Y.F., et al., Mixed-matrix membranes composed of Matrimid (R) and mesoporous ZSM-5 nanoparticles. Journal of Membrane Science, 2008. 325(1): p. 28-39.

252. Chung, T.S., et al., Mixed matrix membranes (MMMs) comprising organic polymers with dispersed inorganic fillers for gas separation. Progress in Polymer Science, 2007. 32(4): p. 483-507.

253. Mahajan, R. and W.J. Koros, Mixed matrix membrane materials with glassy polymers. Part 1. Polymer Engineering and Science, 2002. 42(7): p. 1420-1431.

254. Pechar, T.W., et al., Fabrication and characterization of polyimide-zeolite $L$ mixed matrix membranes for gas separations. Journal of Membrane Science, 2006. 277(1-2): p. 195-202.

255. II Kim, H. and S.S. Kim, Plasma treatment of polypropylene and polysulfone supports for thin film composite reverse osmosis membrane. Journal of Membrane Science, 2006. 286(1-2): p. 193-201.

256. Korikov, A.R., R. Kosaraju, and K.K. Sirkar, Interfacially polymerized hydrophilic microporous thin film composite membranes on porous polypropylene hollow fibers and flat films. Journal of Membrane Science, 2006. 279(1-2): p. 588-600.

257. Liu, L., M.H. Engelhard, and M. Yan, Surface and Interface Control on Photochemically Initiated Immobilization. Journal of the American Chemical Society, 2006. 128(43): p. 14067-14072.

258. Tsubokawa, N., et al., Grafting of 'dendrimer-like' highly branched polymer onto ultrafine silica surface. Reactive \& Functional Polymers, 1998. 37(1-3): p. 75-82. 
Polymer-grafted ceramic membranes 


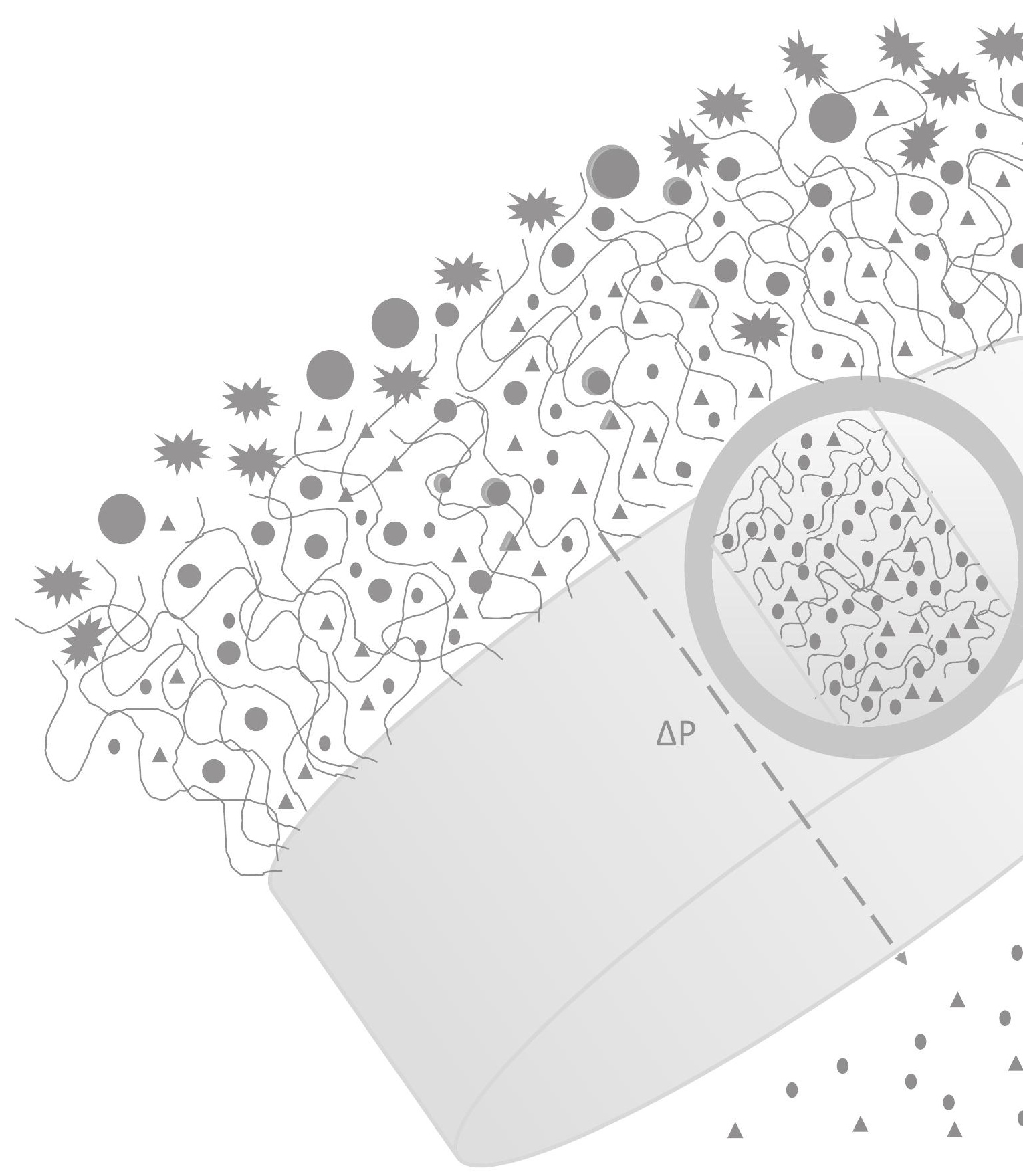


Chapter

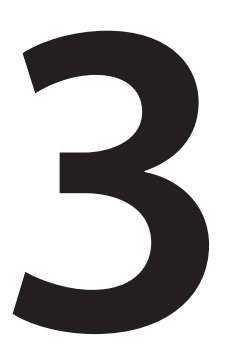

\title{
Effect of reaction conditions
}

\author{
and silane nature
}

on surface grafting

and pore filling

of titania

membranes

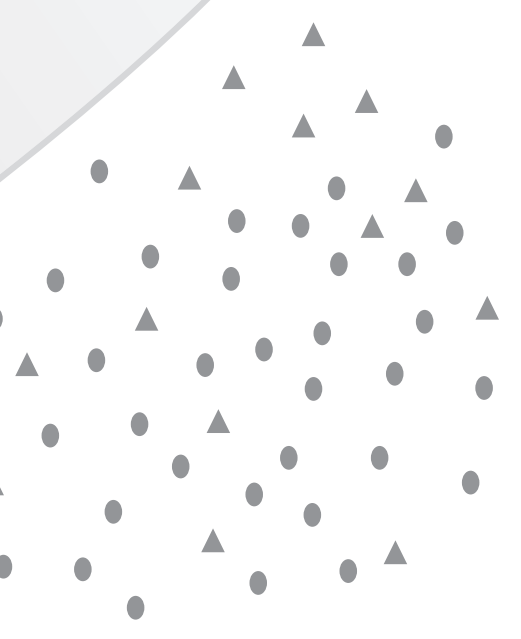




\section{Abstract}

This paper reports the fabrication and characteristics of titania powders and membranes, chemically modified (grafted) with several organo silanes. Trichloroalkyl silanes were examined with carbon chain lengths of $C_{1^{\prime}} C_{4^{\prime}} C_{8}$ and $C_{18^{\prime}}$ while for the methyl silanes the grafting of mono- and di-chloro precursors were studied as well. Grafting of the powders was proven by FTIR analysis. For $C_{18}$ the methylene chain was trans extended (or ordered) and almost perpendicular to the titania surface, while for $\mathrm{C}_{4}$ and $\mathrm{C}_{8}$ disordered alkyl chains are expected. Grafting of these silanes on titania membranes resulted in hydrophobic membranes. XPS analysis showed that not only the membrane surface but also pore walls were grafted with the silanes. Influence of precursor concentration and reaction conditions (temperature and time) are studied as well. Finally it is shown that these covalent bonds between the silanes and titania are stable during immersion in toluene or hexane for 14 days. 


\subsection{Introduction}

Over the last decades, there has been a growing interest in ceramic membranes due to their superior thermal, mechanical and chemical stability when compared with polymeric membranes. However, their low selectivity and hydrophilic character hampers their application for separations in non-aqueous systems. Special attention has been paid on the development of several methods for engineering the chemical (hydrophilicity/hydrophobicity) and physical properties (pore size, pore structure) of ceramic membranes. As a consequence the membrane performance (selectivity, permeability and fouling characteristics) can be altered. Surface engineering can either be achieved by physically adsorbing or chemically bonding polymer chains onto a substrate. Chemical bonding offers a unique opportunity to design membranes that simultaneously deliver the desired chemistry and the desired pore size/pore structure for specific applications. Furthermore, these hybrid membranes reduce swelling of the polymer due to the covalent bond, formed between the polymer and the rigid ceramic framework. Phosphoric acids derivatives [1], organosilanes, i.e. chloro- [1-8] and alkoxysilanes [9], fluorosilanes $[10,11]$ and even polysiloxanes [12] have been successfully grafted onto inorganic membranes. Van Gestel et al. [6] modified $\mathrm{\gamma}-\mathrm{Al}_{2} \mathrm{O}_{3}$ membranes with organosilanes and evaluated the effect of silane treatment on hexane and water permeability. They obtained hydrophobic membranes, showing permeation of hexane, when trichlorosilanes were grafted into the mesoporous pores and on the surface of the membrane. An increase in hexane permeability was also shown by Verrecht et al. [13] when a $\mathrm{\gamma}-\mathrm{Al}_{2} \mathrm{O}_{3}$ membrane was grafted with different chlorosilanes. By modifying the surface of a $3 \mathrm{~nm}$ zirconia membrane, using different coupling silanes, Voigt et al. [14] have shown an increase in toluene flux by a factor 2-3 as well as a decrease in the molecular weight cut off value of the membrane. Younssi et al. [9] showed that, when alkoxysilanes are used as grafting moiety, membrane properties like hydrophobicity, selectivity and membrane flux of different solvents clearly depend on grafting conditions and nature of the silanes.

Depending on the reaction conditions (e. g. temperature, nature of the solvent, time), the silane chemistry (e.g. number and type of reactive groups) and the amount of water adsorbed on the surface, different structures can be obtained [15]. The number of available surface reactive groups plays a crucial role in the final structure of the grafted layer. The formation of a monolayer on the ceramic surface 
is preferred for obtaining sufficient functional accessibility as well as reproducibility in fabrication. For monofunctional silanes, having only one hydrolysable group, a monolayer is always achieved. Meanwhile, a silane precursor with two or more hydrolysable groups will have more reactions routes. Difunctional silanes are capable to either form a covalent attachment to the surface or to form a 3-D surfaceinduced polycondensation product. Dichlorosilanes react with silica surfaces, yielding either covalently attached monolayers or polymeric layers, depending on reaction conditions. Similarly for trichlorosilanes, covalent attachment to the ceramic surface is not the only possible reaction. Along with covalent bonding, 2-D (self-assembly) and 3-D surface-induced polycondensation is possible.

In the case of alkyl-chlorosilanes covalent bonding occurs through the hydrolysis of the $\mathrm{Si}-\mathrm{Cl}$ bonds forming $\mathrm{Si}-\mathrm{OH}$ groups (equation 1) and only $\mathrm{HCl}$ as byproduct, which can easily be removed. The $\mathrm{Si}-\mathrm{OH}$ groups interact with the $\mathrm{OH}$ groups of the surface forming M-O-Si bonds to the substrate through condensation reactions (equation 2). Moreover, Si-O-Si bonds are also formed between adjacent silanols, available in the solution phase creating a polymer network.

$$
\begin{aligned}
& \left(\mathrm{C}_{n} \mathrm{H}_{2 n-1}\right)_{4-x} \mathrm{SiCl}+\mathrm{mH}_{2} \mathrm{O} \longrightarrow\left(\mathrm{C}_{\mathrm{n}} \mathrm{H}_{2 \mathrm{n}-1}\right)_{4-x} \mathrm{SiCl}_{(x-\mathrm{m})}(\mathrm{OH})_{m}+\mathrm{mHCl} \\
& \left(\mathrm{C}_{\mathrm{n}} \mathrm{H}_{2 n-1}\right)_{4-x} \mathrm{SiCl}(x-m) \\
& (\mathrm{OH})_{m}+\mathrm{HO}-\mathrm{M} \longrightarrow\left(\mathrm{C}_{\mathrm{n}} \mathrm{H}_{2 \mathrm{n}-1}\right)_{4-x} \mathrm{SiCl} \\
& (x-m)
\end{aligned}
$$

Where, $\mathrm{M}$ is the metal (in this work $\mathrm{Ti}$ ), $\mathrm{m}$ the number of hydrolyzed surface groups and $x$ the number of functional groups present in the silane.

The presence of a catalyst as water [16] or an amine [17] during hydrolysis (equation 1) is required for the condensation reaction. However, the presence of too much water causes polycondensation of the silanes leading to low surface and pore coverage and hence to a poor quality of the layer. Anhydrous silylation, which is the focus of this work, has shown to be an effective method of achieving a controlled degree of silylation and preventing polycondensation of the silanes in the bulk. A uniform layer and complete surface silylation coverage can be obtained in this way. In this paper grafting is reported of tri, di and mono chloro-alkylsilanes onto titania membranes with a pore size of $5 \mathrm{~nm}$ as well as on titania powders. In order to obtain a uniform and high surface coverage several reaction conditions (reaction temperature, reaction time and concentration of the precursor) are studied. Fourier transform infrared (FTIR) spectroscopy was used to prove if the silanes were successfully grafted. Furthermore, contact angle measurements on 
grafted membranes were performed to determine the hydrophobic character of the surface. XPS analysis was done and the $\mathrm{Si}$ and $\mathrm{C}$ depth profile was analyzed and the $\mathrm{Si}$ and $\mathrm{C}$ atomic concentration were determined. In order to check the feasibility of these systems in solvent filtration, stability tests in different solvents are performed.

\subsection{Experimental}

\subsubsection{Materials}

Trichloromethylsilane (TCMS: $\mathrm{CH}_{3} \mathrm{SiCl}_{3}=\mathrm{C}_{1}$ ), dichlorodimethylsilane (DCDMS: $\left.\left(\mathrm{CH}_{3}\right)_{2} \mathrm{SiCl}_{2}\right)$, chlorodimethylsilane (CDMS: $\left.\left(\mathrm{CH}_{3}\right)_{2} \mathrm{HSiCl}\right)$, butyltrichlorosilane (BuTCS: $\mathrm{C}_{4} \mathrm{H}_{9} \mathrm{SiCl}_{3}=\mathrm{C}_{4}$ ), octyltrichlorosilane (OcTS: $\mathrm{C}_{8} \mathrm{H}_{17} \mathrm{SiCl}_{3}=\mathrm{C}_{8}$ ) and octadecyl-trichlorosilane (OTS: $\mathrm{C}_{18} \mathrm{H}_{37} \mathrm{SiCl}_{3}=\mathrm{C}_{18}$ ) were obtained from Aldrich and used as received. Anhydrous toluene, anhydrous n-hexane, anhydrous isopropanol and hydrogen peroxide $\left(\mathrm{H}_{2} \mathrm{O}_{2}, 30\right.$ wt. \% in water) were obtained from Aldrich and used as received. The $\mathrm{TiO}_{2}$ coated a- $\mathrm{Al}_{2} \mathrm{O}_{3}$ supports, used in this work, were supplied by Hermsdorfer Intitut für Technische keramik e.v. (HTIK)/Inopor ultra. The flat supports had a diameter of 39 $\mathrm{mm}$, a thickness of $2 \mathrm{~mm}$, a porosity in the range of $30-55 \%$ and a mean pore size of $5 \mathrm{~nm}$ for $\mathrm{TiO}_{2}$ according to the information received from the provider.

The $\mathrm{TiO}_{2}$ powder (Hombikat UV 100) had an anatase structure and was supplied by Sachtleben Chemie $\mathrm{GmbH}$. The crystal structure of the $\mathrm{TiO}_{2}$ powder was verified by XRD. The BET surface area, as determined by $\mathrm{N}_{2}$ desorption/adsorption was $341 \mathrm{~m}^{2} \mathrm{~g}^{-1}$.

\subsubsection{Grafting procedure}

\section{Grafting titania powders}

Prior to grafting the powders were washed in an ethanol/water (2:1) solution for 24 hours at ambient temperature and dried in a vacuum oven for 30 minutes at $100^{\circ} \mathrm{C}$. Grafting of powders with organo chlorosilanes was done at various temperatures using silane concentrations of $25 \mathrm{mM}$ or $50 \mathrm{Mm}$ in anhydrous toluene.

For modifications performed at room temperature a typical procedure was as follows: (1) In a glove box under nitrogen atmosphere a $100 \mathrm{ml}$ toluene-silane solution, using silane concentrations of either 25 or $50 \mathrm{mM}$, was added to $0.5 \mathrm{~g}$ $\mathrm{TiO}_{2}$ powder in an Erlenmeyer flask and stirred for different reaction times (0.5 - 24 hours); (2) the mixture was removed from the glove box, filtrated and washed first with fresh toluene and then with a 2:1 ethanol/water solution for the removal of 
unbound silanes and afterwards dried at $100{ }^{\circ} \mathrm{C}$ for 24 hours in a vacuum oven to remove traces of solvents.

Two reactions for TCMS were performed at higher temperatures $\left(50\right.$ or $100{ }^{\circ} \mathrm{C}$ ) using an almost similar procedure. $\mathrm{TiO}_{2}$ powder $(0.5 \mathrm{~g})$ was added to a four-necked round flask, equipped with a reflux condenser, a water trap and a nitrogen inlet. A $100 \mathrm{ml}$ toluene-TCMS solution with a concentration of $50 \mathrm{mM}$, as prepared in a glove box, was slowly added by means of a dropping funnel to the $\mathrm{TiO}_{2}$ powder and refluxed for 24 hours under nitrogen. The suspension was then filtered, washed and finally dried as described above.

\section{Grafting titania membranes}

Prior to grafting the membranes were pre-treated to remove dust and to promote a suitable hydroxylation by soaking in an ethanol/water (2:1) solution for 24 hours at ambient temperature and dried in a vacuum oven for 30 minutes at $100{ }^{\circ} \mathrm{C}$. For promoting a higher hydroxylation degree, the ceramic membranes were subsequently subjected to first boiling in $\mathrm{H}_{2} \mathrm{O}_{2}$ and then in $\mathrm{H}_{2} \mathrm{O}$ (Millipore Q2) (1 hour for both cases). Finally, the membranes were dried under vacuum at $100{ }^{\circ} \mathrm{C}$ for 24 hours and stored under nitrogen atmosphere until further use. The grafting procedures used for flat membranes were similar to the ones used for powders. For reactions performed at room temperature a $100 \mathrm{ml}$ a silane-toluene solution (with concentrations varying from 25 - 100 mM) was first prepared in a beaker in a glove box under nitrogen atmosphere. Subsequently, a membrane was added and the solution was stirred for different reaction times ( $0.5-24$ hours). After the reaction the membranes were washed by soaking in toluene and subsequently in ethanol/water (2:1) and dried as described above.

For reactions at higher temperatures $\left(50\right.$ or $100{ }^{\circ} \mathrm{C}$ ), the membranes were placed in a five necked round flask equipped with a nitrogen inlet, a magnetic stirring, a water trap and a reflux condenser. A $100 \mathrm{ml} 50$ mM TCMS solution, as prepared in a glove box, was slowly added to the reactor vessel using a dropping funnel. The solution was stirred for 24 hours under nitrogen at 50 or $100{ }^{\circ} \mathrm{C}$. After the reaction was finished, the solution with the membrane was cooled down to room temperature and washed and dried as described before.

\subsubsection{Powders and membrane characterization Infrared spectroscopy}

The FTIR spectra of grafted powders were obtained with a TGA-IR Tensor 27 system 
spectrometer obtained from Bruker Optick GmbH, in the range 400-4000 $\mathrm{cm}^{-1}$, using a resolution of $4 \mathrm{~cm}^{-1}$ and 16 scans. Unmodified titania powders was used as background.

\section{Contact angle}

Static contact angle measurements were performed on grafted membranes using a video-based optical contact angle instrument (OCA 200) and a Hamilton Microliter syringe. A $5 \mu$ droplet of water (Millipore Q2) was injected at a speed of $1 \mu \mathrm{s} \mathrm{s}^{-1}$. Immediately hereafter a snapshot was taken and the contact angle was calculated using the static sessile drop method. The sessile drop method is measured by a contact angle goniometer using an optical subsystem to capture the profile of a pure liquid on a solid substrate. The angle formed between the liquid/solid interface and the liquid/vapor interface is the contact angle. The droplet is deposited by a syringe pointed vertically down onto the sample surface and a high resolution camera captures the image, which then is analyzed by image analysis software. The calculated contact angle value is an average of 5 drops.

\section{$X$-ray photoelectron spectroscopy (XPS)}

XPS was carried out on grafted $\mathrm{TiO}_{2}$ membranes using a PHI Quantera Scanning ESCA microprobe at a spatial resolution < $10 \mu \mathrm{m}$. Al-Ka monochromatic X-Rays $(1486.6 \mathrm{eV}$ ) have been generated at an accelerating voltage of $25 \mathrm{~V}$ and a $2.6 \mathrm{~mA}$ emission current. The atomic percentages of $\mathrm{Si}, \mathrm{Ti}, \mathrm{Al}$ and $\mathrm{C}$ were determined by taking into account the atomic concentrations calculated from the Si2p, Ti2p Al2p and C2p energy bands respectively. Atomic-concentration depth profiles were obtained by $\mathrm{Ar}^{+}$sputtering $(3.5 \mathrm{keV}$ ) on a $2 \times 2 \mathrm{~mm}$ area with an estimated sputter rate of $20 \mathrm{~nm} / \mathrm{min}$. Moreover, the $\mathrm{Si}$ concentration per unit area of titania membrane surface $\left(\mathrm{mol} \mathrm{m}^{-2}\right)$ was determined by taking into account the atomic concentrations of Si and Ti while for the titania layer a surface area of $73.0 \mathrm{~m}^{2} \mathrm{~g}^{-1}$ and a (theoretical) density of $3.84 \mathrm{~g} \mathrm{~cm}^{-3}$ was considered.

\section{Chemical stability tests}

In order to assess the stability of titania grafted systems several powders were soaked in various solvents: toluene, $\mathrm{n}$-hexane and isopropanol. Approximately $0.2 \mathrm{~g}$ of a titania grafted powder was soaked in $20 \mathrm{~g}$ of solvent and stirred for 7 to 14 days at room temperature. The powders were centrifuged at a speed of $1000 \mathrm{rpm}$ for 5 minutes and then washed and centrifuged with fresh solvent. This procedure was repeated three times; a total volume of $60 \mathrm{ml}$ of solvent was used per $0.2 \mathrm{~g}$ of 
powder. The powders were dried in air overnight and afterwards analyzed by FTIR, which results were compared with those of freshly grafted powders.

\subsection{Results and Discussion}

\subsubsection{General considerations}

Chemical pretreatment of the membrane prior to grafting has a crucial influence on the degree of silylation. Efficient hydroxylation by $\mathrm{H}_{2} \mathrm{O}_{2}$ can improve the amount of bonds between surface and silanes [7, 18]. The drying temperature is another important parameter as the presence of a surface water layer is required for the hydrolysis step. Tripp at al., have shown that no reaction occurs when TCMS is added to totally dehydrated silica at room temperature [19] It has been shown that an insufficient water layer is present when drying temperatures of more than $150^{\circ} \mathrm{C}$ are used [18]. Therefore in this work a drying temperature of $100{ }^{\circ} \mathrm{C}$ was selected. Control over process parameters like water content [20] and temperature during the silylation reaction is also crucial for preventing cross-polymerization of the silanes by the formation of Si-O-Si bonds prior to the formation of covalent bonds to the surface. In the case of silanes with two or more hydrolysable groups intermolecular condensation between adjacent molecules forming a cross-linked, fully packed polymerized silane layer can occur. The condensation reaction of the first hydroxyl group readily occurs, while the condensation of the second and third hydroxyl groups attached to the same silicon becomes increasingly more difficult [21] Therefore, an extra step is required, called baking or curing by heating the sample at temperatures 100 or $200{ }^{\circ} \mathrm{C}$. This completes the lateral condensation reactions with the formation of a lateral cross-linked silane layer.

\subsubsection{FTIR analysis of grafted powders}

In order to prove if the studied organosilanes were grafted onto titania powders and membranes FTIR spectroscopy is performed. In this section respectively the influence of alkyl chain length, the number of reactive groups and reaction conditions on grafting performance are discussed.

\section{Influence of alkyl chain length on grafting performance}

The FTIR spectra for unmodified titania andpowders modified with different trichloroalkylsilanes are presented in Figure 1. 

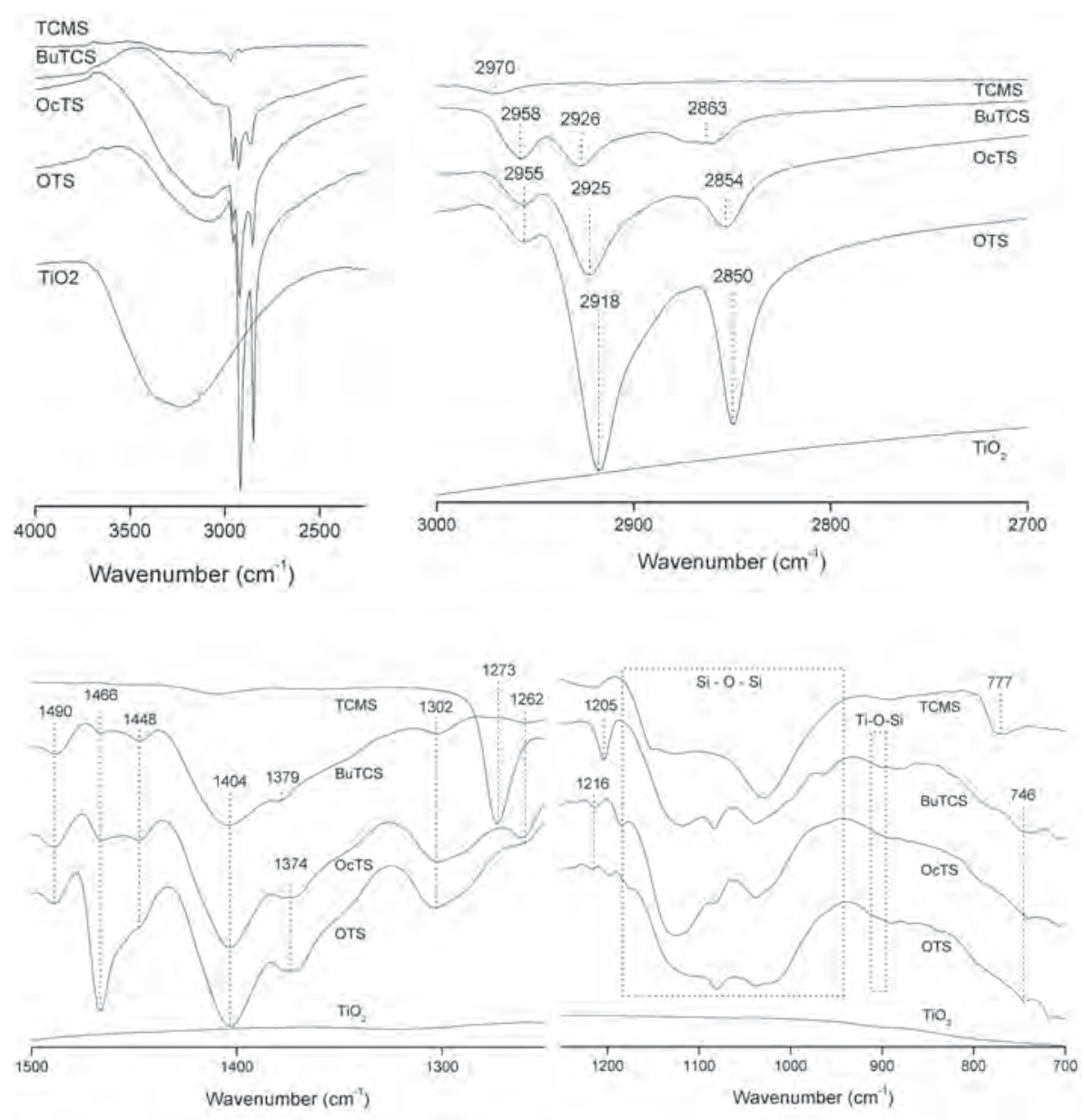

Figure 1:FTIRspectra oftitaniapowders (AF)and titania powders grafted with trichloromethylsilane (TCMS), butyltrichlorosilane (BuTCS), octyltrichlorosilane(OcTS), octadecyltrichlorosilane (OTS). The reactions were performed at RT for 24 hours with [silane] $=25 \mathrm{mM}$

For the unmodified titania a peak at $1640 \mathrm{~cm}^{-1}$ and a large hump between 3000 and $3600 \mathrm{~cm}^{-1}$ are observed, which are attributed to the $\mathrm{OH}$ groups, present in the powder.

Infrared spectroscopy has proven to be a suitable technique for assessing grafting of hydrocarbon chains on metal oxide surfaces, because C-H stretching bands (2800$3000 \mathrm{~cm}^{-1}$ ) can easily be detected. Furthermore, the position of the $\mathrm{CH}_{2}$ symmetric and asymmetric stretching peaks provide information about the conformational arrangement of the alkyl chains. For all trans extended (or ordered) methylene chains the IR frequencies are reported to be in the range of 2846 to $2850 \mathrm{~cm}^{-1}$ and 
2915 to $2920 \mathrm{~cm}^{-1}$ which corresponds to the bands of crystalline alkanes, while for highly disordered chains the frequencies are shifted to higher values close to those of liquid alkanes, near $2925 \mathrm{~cm}^{1}$ and $2856 \mathrm{~cm}^{-1}$ [22]. For C 18 (OTS) grafted on silicon [23] or aluminum [24] wafers it has been reported that highly-ordered, densely-packed OTS monolayers with chains close to perpendicular to the surface show methylene $\left(-\mathrm{CH}_{2}\right)$ symmetric and asymmetric bands at $2850 \mathrm{~cm}^{-1}$ and 2920 $\mathrm{cm}^{-1}$ respectively and methyl symmetric and asymmetric stretching at $2968 \mathrm{~cm}^{-1}$ and $2879 \mathrm{~cm}^{-1}$. In our case similar values were obtained for both methylene bands for octadecyltrichlorosilane $\left(\mathcal{C}_{18}\right)$ grafted onto a titania powder (Figure 1) indicating that alkyl chains with a high conformational degree were obtained after grafting OTS on titania powders. On the other hand, these authors showed that for silanes with shorter alkyl chains $(n<10)$ a shift towards higher wavenumbers for the methylene symmetric and asymmetric stretching was observed and can be ascribed to a disordered alkyl chain. This is in agreement with the values obtained for titania powders grafted with $\mathrm{C}_{4}$ and $\mathrm{C}_{8}$ (Figure 1).

After grafting the broad peak centered at $3450 \mathrm{~cm}^{-1}$ as presented in Figure 1 in the unmodified titania powder due to the stretching mode of the physically adsorbed water molecules almost disappears indicating that the silanes molecules have reacted with the surface water, confirming the silane grafting.

For all silanes several bands between 1600 and $1200 \mathrm{~cm}^{-1}$ can be observed attributed to the bending, twisting, rocking of the methyl and methylene groups. A strong band found around between $1466-1448 \mathrm{~cm}^{-1}$ is due to $\mathrm{CH}_{2}$ scissor $(\delta$ $\left.\mathrm{CH}_{2}\right)$ [25], while a peak around $1404 \mathrm{~cm}^{-1}$ is attributed to the bending mode of the methylene group adjacent to $\mathrm{Si}\left(\delta \mathrm{Si}-\mathrm{CH}_{2}\right)$ [25]. A weak peak around 1367 $\mathrm{cm}^{-1}$ is due to the symmetric bending mode of the methylene groups $\left(\delta \mathrm{CH}_{2}\right)$. As expected these peaks cannot be found for the TCMS, which contains only a methyl group as side group.

The signal around at 1302 and $1262 \mathrm{~cm}^{-1}$ is assigned to the $\mathrm{CH}_{2}$ wagging $\mathrm{CH}_{2}$ twistrock mode [25]. The strong band at $1272 \mathrm{~cm}^{-1}$ which is only observed for TCMS, is assigned to the $\mathrm{Si}-\mathrm{CH}_{3}$ deformation mode. As shown by the spectra in Figure $1 \mathrm{a}$ broad doublet band appears between 1180 and $1000 \mathrm{~cm}^{-1}$. This band is ascribed to the asymmetric and symmetric Si-O-Si stretching, indicating the formation of a Si-O bond and of Si-O-Si polycondensation $[17,26]$. The bands between700-800 $\mathrm{cm}^{-1}$ are due to the rocking modes of the $\mathrm{CH}_{3}$ group and to the Si-C stretching. Finally, 
the presence of a band attributed to the Ti-O-Si stretching band represented by a small shoulder in the region of $910 \mathrm{~cm}^{-1}$ allows us to conclude that silanes are grafted onto the titania powders. For the TCMS no shoulder could be observed.

\section{Influence of the number of reactive groups on grafting performance}

The effect of the number of reactive groups on grafting is studied as well. In Figure 2 the FTIR spectra are given for samples treated with tri-, di-, or monochlorosilanes (resp. TCMS, DCDMS and CDMS).

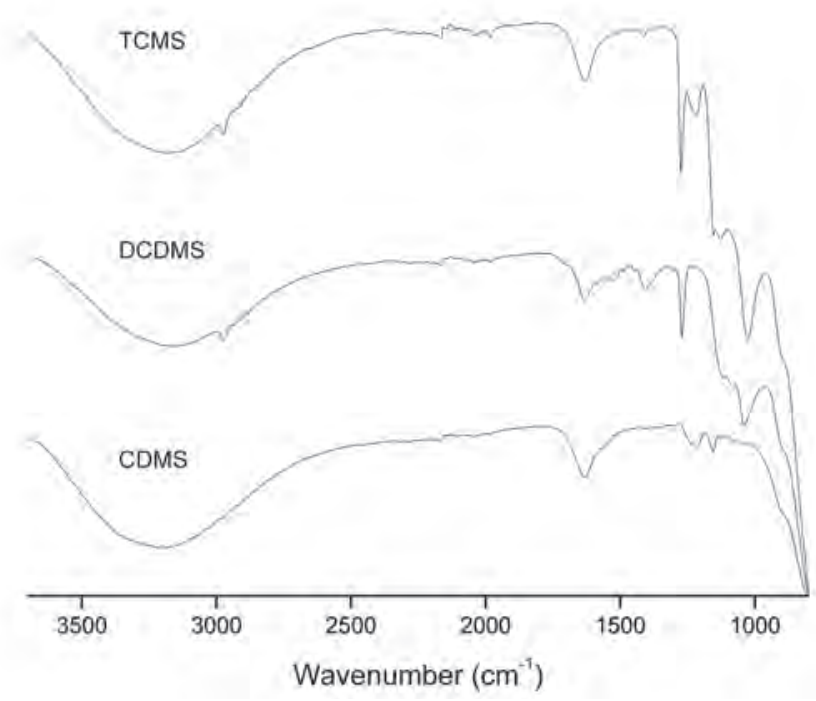

Figure 2: FTIR spectra of titania powder grafted with trichloromethylsilane (TCMS), dichlorodimethylsilane (DCDMS). The reactions were performed at RT for 24 hours with [silane] $=50 \mathrm{mM}$

It is well known that the tendency for condensation increases with the number of hydroxyl groups attached to the silicon atom (formed after hydrolysis). The degree of condensation therefore follows the order $\mathrm{RSi}(\mathrm{OH})_{3}>\mathrm{R}_{2} \mathrm{Si}(\mathrm{OH})_{2}>\mathrm{R}_{3} \mathrm{SiOH}$.

The presence of four characteristic bands for both TCMS and DCDMS allows us to conclude that here grafting is successful. These bands include a peak around 2960 $\mathrm{cm}^{-1}$ due to C-H vibration modes, a peak around $1272 \mathrm{~cm}^{-1}$, attributed to symmetric deformation of the $\mathrm{Si}-\mathrm{CH}_{3}$ group and finally a broad peak between 1136 and 1024 $\mathrm{cm}^{-1}$ due to Si-O-Si bond indicating some degree of polymerization on the powder surface. NMR [27], IR [28] and other methods [29] have shown that for trifunctional silanes 1:1 (one Si-O-M bond) as well as 1:2 (two Si-O-M bond) grafted structures 
are present on the surface, however structures 1:3 (three Si-O-M bonds) are not formed due to steric reasons [29]. In the latter case one of the three hydrolysable groups can condense with an adjacent silane, resulting in the formation of a siloxane bond indicated by the broad peak at $1180-930 \mathrm{~cm}^{-1}$. This confirms that a fully developed network was formed for the di- and trichlorosilanes. As expected, a more intense band for the siloxane bond formation is observed for the trichloro than for the dichloro system. These characteristics bands are not present for the monochlorosilane, or when they are present, they only exhibit at low intensities. The lack of reactivity of the monochlorosilane can be due to steric hindrance of the two additional methyl groups, limiting the access of $\mathrm{Si}-\mathrm{OH}$ to the hydroxyl groups of the titania powders. However, in the case of the dichlorosilane, the presence of these two methyl groups do not seem to affect grafting. A possible explanation is an additional reactive group for the dichlorosilane, which is available to either form a covalent bond with the surface or to react with an adjacent free silanol group. In conclusion, more strongly bonded layers with some degree of crosslinking can be achieved when di- and trifunctional silanes are used as a grafted moiety.

\section{Influence of reaction conditions on grafting performance}

Finally the effect of reaction conditions (time and temperature) on grafting performancewasstudied forthe trichloromethylsilaneand octadecyltrichlorosilane. Figure 3 presents FTIR spectra for these two silanes for a reaction time of 2 hours and 24 hours.

The characteristic bands for OTS- grafter titania powders are present after 2 hours of reaction; e.g.: the presence of $\mathrm{Si}-\mathrm{CH}_{2}$ at $1404 \mathrm{~cm}^{-1}, \mathrm{CH}_{2}$ in the hydrocarbon chain between 2920-2850 $\mathrm{cm}^{-1}$ and between 1466-1448 and, the $\mathrm{CH}_{3}$ groups at 2968 $\mathrm{cm}^{-1}$. The Si-O-Si peak due to polycondensation between the silane molecules at $1100-980 \mathrm{~cm}^{-1}$ and the presence of the peak around $910 \mathrm{~cm}^{-1}$ due to Ti-O-Si bond formation indicates that the bonding of the silanes to the surface is achieved after 2 hours of reaction, while an increased number of Si-O-Si bonds is formed for longer times, since a more intense band for the Si-O-Si can be seen after 24 hours of reaction. In the case of the TCMS, after 2 hours reaction, one could conclude that grafting of TCMS has occurred since the characteristic band for the $\mathrm{CH}_{3}$ at $2980 \mathrm{~cm}^{-1}$ and for the $\mathrm{Si}-\mathrm{CH}_{3}$ at $1272 \mathrm{~cm}^{-1}$, as well as the band due to the $\mathrm{Si}-\mathrm{O}-\mathrm{Si}$ bond formation at 1100-930 $\mathrm{cm}^{-1}$ are observed. These data are consistent with the appearance of alkyl groups on the surface. 
a)
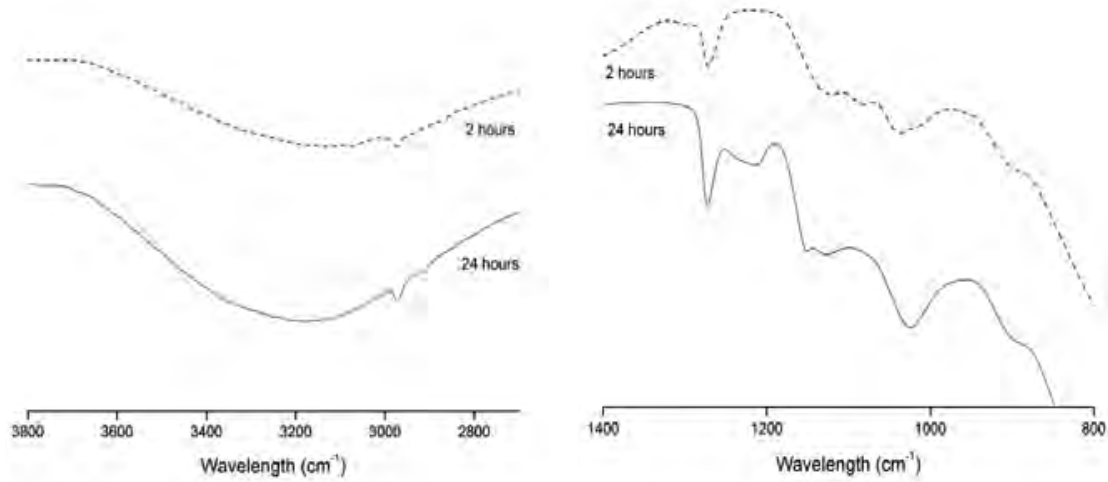

b)
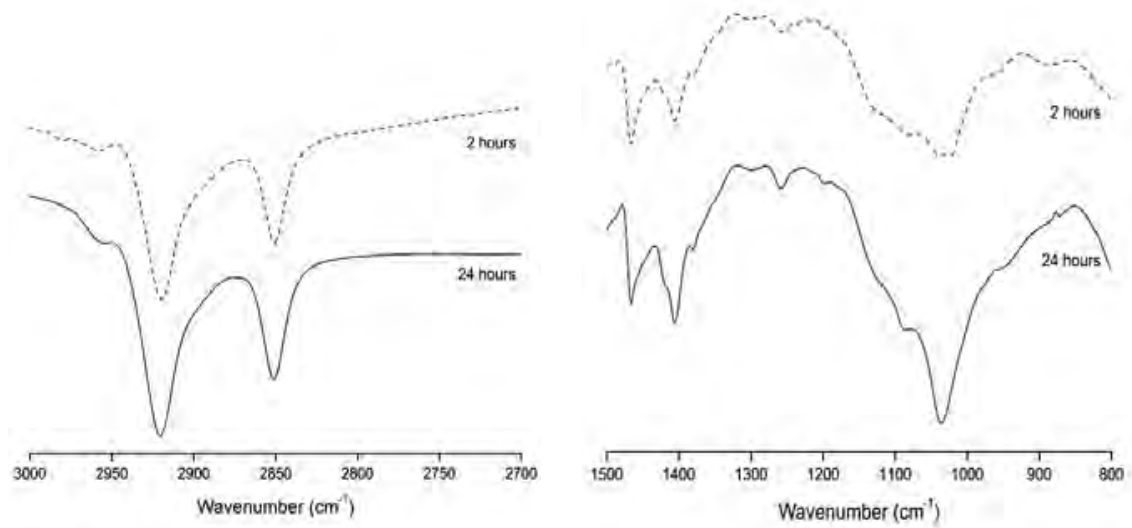

Figure 3: FTIR spectra of titania powder grafted with a) trichloromethylsilane (TCMS), b) octadecyltrichlorosilane (OTS). The reactions were performed at RT for 2 or 24 hours with [silane] $=25 \mathrm{mM}$.

\subsubsection{Hydrophobic character of the grafted membrane}

Since it was proven that modification of titania powders was possible by silylation, titania membranes were modified with different silylated agents. Due to their hydrocarbon side chains it is expected that hydrophobic surfaces are produced. In Figure 4 the contact angle for different silanes grafted onto a titania membrane are presented. 


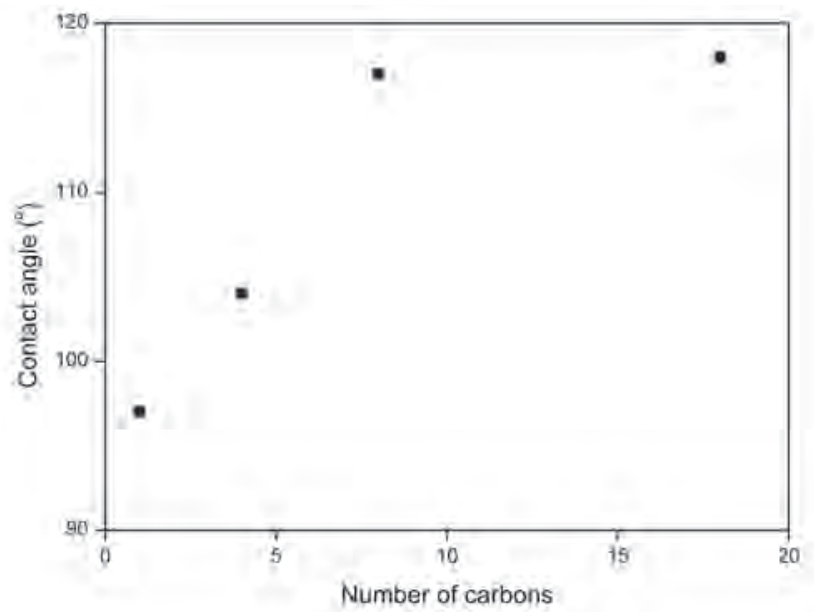

Figure 4: Water contact angle in degrees (deg) for titania membranes grafted with trichloromethylsilane, buthyltrichlorosilane, octyltrichloromethylsilane and octadecyltrichlorosilane. The reactions were performed 24 hours at RT with a [silane] $=25 \mathrm{mM}$.

All membranes were hydrophobised when trichloroalkylsilanes $\left(C_{1}, C_{4^{\prime}} C_{8}\right.$ and $\left.C_{18}\right)$ were used as grafting moiety. Furthermore it is shown that with increasing chain length, the contact angle increases, e.g. $97^{\circ}$ for TCMS and $116^{\circ}$ for OTS. A similar trend was observed by Fadeev at al. [15], who showed an increase in contact angle with chain length for mono-, di- and trichloroalkylsilanes grafted on silicon wafers. However, for OTS increases in the number of $\mathrm{CH}_{2}$ groups do not result in a signicficantly higher contact angle value, which might indicate certain degree of organization.

For di- and monochloroalkylsilanes (DCDMS and CDMS) lower contact angles were observed, $82^{\circ}$ for DCDMS and $74^{\circ}$ as for TCMS. Due to their short chain length (methyl) and a lower number of hydrolysable groups, a lower bonding density is expected for the di- and monochloro derived systems. Therefore, a fully hydrophobised surface and pore was not achieved in the latter case. Contrarily, in the case of all trichlorosilanes a fully hydrophobic surface was achieved.

As can be seen in Table 1, process parameters like reaction time, temperature and concentration have an influence on the degree of wettability. 
Table 1: Water contact angle for trichloromethylsilanes TCMS grafted on titania membranes at various silane concentrations, reaction times and reaction temperatures.

\begin{tabular}{cccc}
\hline $\begin{array}{c}{[\text { silane }]} \\
(\mathbf{m M})\end{array}$ & $\begin{array}{c}\text { Time } \\
(\mathbf{h})\end{array}$ & $\begin{array}{c}\text { Temperature } \\
\left({ }^{\circ} \mathrm{C}\right)\end{array}$ & $\begin{array}{c}\text { Contact angle } \\
\left({ }^{\circ}\right)\end{array}$ \\
\hline 25 & 24 & 22 & 97 \\
50 & 24 & 22 & 116 \\
100 & 24 & 22 & 126 \\
50 & 0.5 & 22 & 112 \\
50 & 1 & 22 & 113 \\
50 & 2 & 22 & 115 \\
50 & 24 & 50 & 128 \\
50 & 24 & 100 & 127 \\
\hline
\end{tabular}

With an increase in reaction time, temperature and concentration an increase in contact angle is observed. An increase in concentration can result in either the formation of more bonds to the surface and/or self polycondensation, forming a denser layer, which results in an increase in the contact angle due to poor infiltration of water in a denser methyl layer. A reaction time of 1 hour was sufficient to attain an hydrophobic surface, meaning that the reaction between the surface and the silane moiety occurs very fast. Moreover, as the reaction time increases, only a slight increase in contact angle is observed between 2 and 24 hours. Also from these results one can conclude that long reaction times are not required for the silylation reaction to be completed.

\subsubsection{XPS analysis on grafted membranes}

Contact angle results have shown that grafting of chlorosilanes is achieved on the surface of a titania membranes for all silanes. XPS analyses were performed in order to prove that grafting has occurred on both surface and pore walls of the membranes. Compositional information on the $\mathrm{Al}, \mathrm{Ti}, \mathrm{Si}, \mathrm{C}$ atomic concentrations as a function of depth were obtained by sputtering and subsequent XPS analysis. An XPS survey was done for all alkyl-titania grafted membranes. For all materials no XPS signals related to $\mathrm{Cl}$ were observed indicating the complete hydrolysis of the $\mathrm{Si}-\mathrm{Cl}$ bonds to yield silanols, the majority of which couple to form siloxanes as is consistent with F-TIR data. 


\section{Influence of precursor type on grafting performance}

Figure 5 shows XPS Si $2 p$ depth profiles for different trichloroalkylsilanes $\left(C_{1^{\prime}} C_{4^{\prime}} C_{8^{\prime}}\right.$ $C_{18} ;[$ silane $\left.]=25 \mathrm{mM}\right)$.

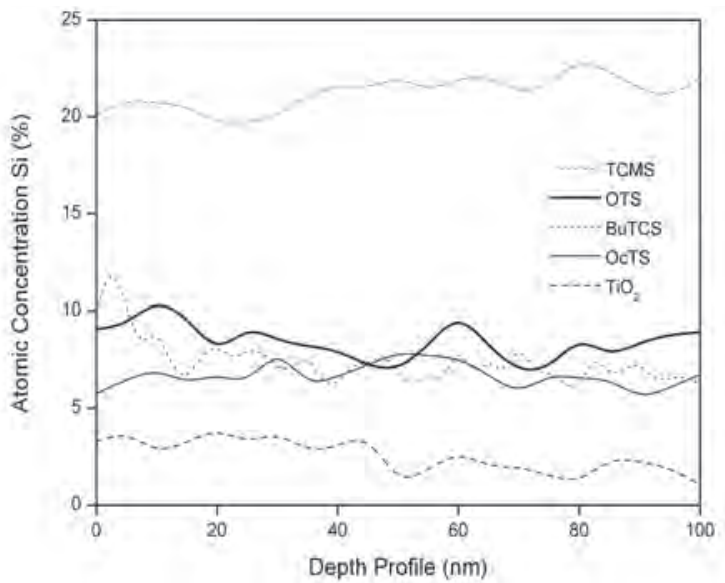

Figure 5: XPS Si depth profile for trichloromethylsilane (TCMS), butyltrichlorosilane (BuTCS), octyltrichlorosilane (OcTS), octadecyltrichlorosilane (OTS). The reactions were performed 24 hours at RT with a [silane] $=25 \mathrm{mM}$.

Table 2: Silicon concentration (per unit surface area of titania membrane) inside the mesopores calculated form XPS data at a sputtering depth of $100 \mathrm{~nm}$ for different precursors under various reaction conditions.

\begin{tabular}{cccccc}
\hline ID & Silane precursor & $\begin{array}{c}{[\text { silane }]} \\
(\mathbf{m M})\end{array}$ & $\begin{array}{c}\text { reaction time } \\
\text { (hours) }\end{array}$ & $\begin{array}{c}\text { Reaction } \\
\text { temp. }\left({ }^{\circ} \mathrm{C}\right)\end{array}$ & $\begin{array}{c}{[\mathrm{Si}]} \\
\mathbf{M o l ~ m}^{-2}\left(\mathbf{1 0 ^ { - 5 }}\right)\end{array}$ \\
\hline 1 & TCMS (C1) & 25 & 24 & 22 & 6.9 \\
2 & BuTCS (C4) & 25 & 24 & 22 & 2.0 \\
3 & OCTS (C8) & 25 & 24 & 22 & 2.0 \\
4 & OTS (C18) & 25 & 24 & 22 & 2.6 \\
5 & DCDMS & 50 & 24 & 22 & 1.6 \\
6 & TCMS & 50 & 24 & 22 & 9.0 \\
7 & TCMS & 100 & 24 & 22 & 10.1 \\
8 & TCMS & 50 & 24 & 50 & 10.5 \\
9 & TCMS & 50 & 24 & 100 & 11.1 \\
10 & TCMS & 50 & 0.5 & 22 & 4.3 \\
11 & TCMS & 50 & 1 & 22 & 5.7 \\
12 & TCMS & 50 & 2 & 22 & 7.0 \\
\hline
\end{tabular}

TCMS: Trichloromethylsilane, BuTCS: n-Butyltrichlorosilane, OcTS: Octyltrichlorosilane, OTS: Octadecyltrichlorosilane and DCDMS: Dicholorodimethylsilane. 
The profiles presented in figure 5 show an almost constant atomic concentration of Si up to a depth of $100 \mathrm{~nm}$. These results indicate that for all silanes both the internal mesopore surface as well as the external surface of the titania membranes were grafted. Table 2 list the silicon concentrations per unit surface area calculated from XPS data for different percursors and different reaction conditions.

As presented in Table 2, the $\mathrm{Si}$ atomic fraction at a depth of $100 \mathrm{~nm}$ is still significant around $7.0 \times 10^{-5} \mathrm{~mol} \mathrm{~m}^{-2}$ for $C_{1}, 2.0 \times 10^{-5} \mathrm{~mol} \mathrm{~m}^{-2}$ for $C_{4^{\prime}} 2.0 \times 10^{-5} \mathrm{~mol} \mathrm{~m}^{-2}$ $\mathrm{C}_{8}$ and $2.6 \times 10^{-5} \mathrm{~mol} \mathrm{~m}^{-2}$ for $\mathrm{C}_{18}$ (see Table 2). This is in agreement with the results of McCarley et al. [3], who observed the presence of Si till a depth of approximately $10 \mathrm{~nm}$ for porous anodized alumina ("anodiscs") treated at room temperature with octadecyltrichlorosilane $\left(C_{18}\right)$. Similar results were found by Lueke et al. [18], who detected the presence of a Si $2 p$ signal for room temperature $C_{4}$ treated anodiscs even after removing $100 \mathrm{~nm}$ of the material by sputtering. Besides the Si2p the C2p depth profile was analyzed as well. In Figure 6 the carbon atomic percentages at a sputtering depth of $100 \mathrm{~nm}$ are given for a pure titania membrane and membranes grafted by chlorosilanes with different alkyl chain lengths.

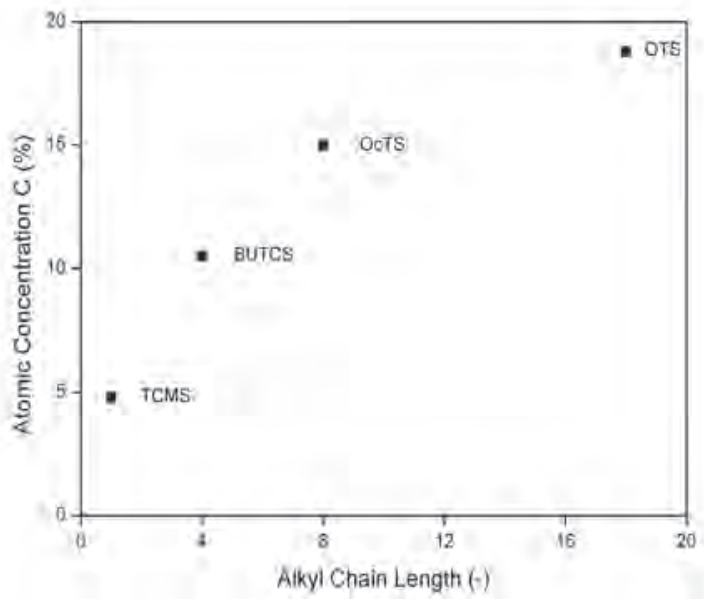

Figure 6: $C$ atomic concentration at a depth of $100 \mathrm{~nm}$ as determined by XPS for trichloromethylsilane (TCMS), butyltrichlorosilane (BuTCS), octyltrichlorosilane (OcTS), octadecyltrichlorosilane (OTS) at $100 \mathrm{~nm}$. The reactions were performed 24 hours at RT with a [silane] $=25 \mathrm{mM}$.

As expected, with the increase in chain length the carbon content inside the pores increases. The presence of carbon after removal of $100 \mathrm{~nm}$ by sputtering also confirms that the silanes are grafted inside the pores.

The influence of the number of reactive groups on grafting performance was 
studied by comparing trichloromethylsilane (TCMS) and dichlorodimethylsilane (DCDMS) grafted membranes. XPS analysis of the surface showed 5-6 times more Si for the TCMS-grafted membrane than for the DCDMS-grafted system. At a depth of $100 \mathrm{~nm}$ the surface coverage per titania membrane area $\left(\mathrm{mol} \mathrm{m}^{-2}\right)$ is for the TCMS-grafted system more than 4 times higher than for the DCDMS grafted membrane (compare sample ID 5 and 6 in Table 2). As expected, the trichloro system showed higher Si atomic concentration both on the surface and in the pores if compared with DCDMS, due to the higher reactivity of the first one. This is another explanation for the observed lower contact angle for DCDMS compared with the value for TCMS grafted membranes.

\section{Influence of reaction conditions on grafting performance}

AFM [30], ellipsometry [15], contact angle [15], TGA [31] and FTIR [32] results revealed that the grafting process is influenced by reaction parameters such as temperature [24], time, silane concentration and solvent. Therefore a more detailed study was performed, using $C_{1}$ as the precursor. The influence of several reaction parameters on surface/pore coverage was studied in order to achieve the most optimal grafted layer, meaning a densely grafted layer, but uniform over both surface and pore walls. In Figure 7 XPS depth profiles are given for the Si $2 p$ peak for $\mathrm{C}_{1}$ using reactant concentrations ranging from $25 \mathrm{mM}$ to $100 \mathrm{mM}$.

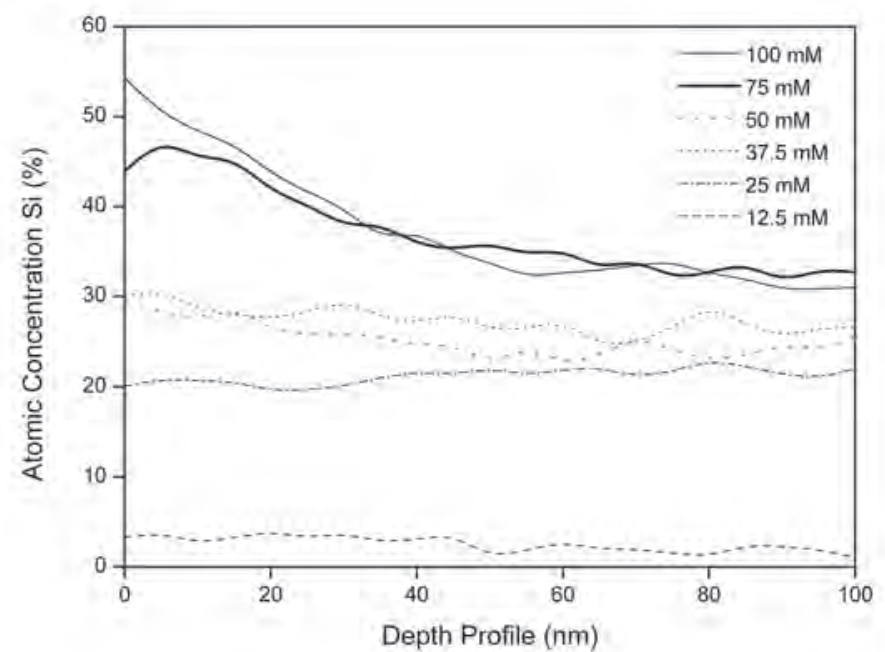

Figure 7: XPS Si depth of titania membranes grafted with for different concentrations of trichloromethylsilane (TCMS). The reactions were performed at RT for 24 hours under nitrogen atmosphere. 
At concentrations of $50 \mathrm{mM}$ or less grafting seems to be homogenous, meaning that the atomic concentration of $\mathrm{Si}$ in the outer and the inner surface are almost similar. At higher TCMS concentrations higher Si atomic concentrations are found on the surface, while inside the pores (at $100 \mathrm{~nm}$ ) almost identical values are obtained, around $7.0 \times 10^{-5} \mathrm{~mol} \mathrm{~m}^{-2}$ for $25 \mathrm{mM}$ and $10.1 \times 10^{-5} \mathrm{~mol} \mathrm{~m}^{-2}$ for $100 \mathrm{mM}$ (Table 2; resp. sample ID 1 and 7). This can be explained by the presence of three reactive groups per silane molecule, available for reaction both with the surface and with other silanes. At an excess of silanes, they easily form a thick multilayer resulting in a less uniform distribution as function of the pore depth (Figure 7). The higher surface concentration when using higher precursor concentration during reaction is in agreement with contact angle results (Table 1), where higher contact angles were found for higher concentrations. Based on all these results, $50 \mathrm{mM}$ was selected as the optimum concentration for further studies.

The reaction temperature also has an impact on structure and density of the grafted layer. The standard concentration of $50 \mathrm{mM}$ and reaction time of 24 hours was selected. The atomic concentrations of $\mathrm{Si}$ and $\mathrm{C}$ at $100 \mathrm{~nm}$ for different temperatures are given in Table 2 (sample ID 6, 8 and 9) and Table 3.

Table 3: Silicon and carbon atomic concentration on the outer titania surface (10 $\mathrm{nm}$ ) and inside mesopores (100 nm) for different temperatures. TCMS (C1 was used as precursor. A concentration of $50 \mathrm{mM}$ and a reaction time of 24 hours were selected.

\begin{tabular}{cccccc}
\hline ID & $\begin{array}{c}\text { Temperature } \\
\left({ }^{\circ} \mathrm{C}\right)\end{array}$ & $\begin{array}{c}\text { Si atomic concentration (\%) } \\
\text { Surface } \\
\text { concentration } \\
\mathbf{1 0 ~} \mathbf{~ n m}\end{array}$ & $\begin{array}{c}\text { Mesopore } \\
\text { concentration } \\
\mathbf{1 0 0 ~} \mathbf{~ m m}\end{array}$ & $\begin{array}{c}\text { C atomic concentration (\%) } \\
\text { concentration } \\
\mathbf{1 0} \mathbf{~ n m}\end{array}$ & $\begin{array}{c}\text { Mesopore } \\
\text { concentration } \\
\mathbf{1 0 0} \mathbf{~ n m}\end{array}$ \\
\hline 7 & 22 & 27.2 & 25.4 & 25.0 & 7.32 \\
8 & 50 & 42.4 & 30.3 & 32.9 & 7.53 \\
9 & 100 & 53.1 & 27.6 & 31.7 & 6,89 \\
\hline
\end{tabular}

The Si $2 p$ XPS depth profile of a $50 \mathrm{mM}$ system reacted at $50{ }^{\circ} \mathrm{C}$ or $100{ }^{\circ} \mathrm{C}$ is similar to the trend observed for high concentrations (75-100 mM) at room temperature, meaning a high concentration at the outer surface with increasing temperature and lower values at $100 \mathrm{~nm}$ (Table 3). This is an indication that at higher temperature as well as at higher concentrations a polymerized layer on the surface and/or at the entrance of the pores of the membrane is formed due to polycondensation of the silanes prior to attachment to the surface. These partially polymerized agglomerates will present reduced ability to migrate into the 
pores, forming most probably a multilayer with few attachments to the surface. Moreover, the presence of a Si-O-Si band on the FTIR spectra for all temperatures and concentrations considered confirms that polycondensation happens.

Brzoska et al.[33] [34], have demonstrated that the uniformity of grafted monolayers onto a silica wafer in the case of several $n$ - trichloroalkylsilanes ( $n=10$ 22) is influenced by the reaction temperature. A clear evidence for a near room temperature threshold temperature (Tc) is obtained, which is a/o determined by the alkyl-chain length of the grafted silane. At T $<$ Tc highly ordered densely packed islands are obtained, whereas above this critical temperature disordered and less dense layers are formed [35-37]. In order to understand this effect, we need to understand the monolayer formation process.

It is proposed that monolayers can be formed through an island-type growth [38] and/or a homogeneous disorder and incomplete monolayer growth [39], [40], [41]. In general the silanemolecules, as present in the reactive solution, are gradually adsorbed on the membrane surface and island formation begins due to an initial water layer present on the substrate. This physisorption process is followed by hydrolysis of the head group forming trisilanols. During this step drastic changes in the conformation of the alkyl chains occur. Under proper experimental conditions, a uniform densely packed monolayer is formed consisting of vertical chains, all in a trans-ordered conformation. At prolonged reaction covalent siloxane bonds are formed at the head group-substrate interface and a grafted layer is formed. Furthermore, intermolecular crosslinking can occur. Bierhaum et al. [42] observed for longer silanes (like $C_{18}$ ) island formation, while for smaller-chained silanes $(n<10)$, island formation was not observed. This phenomenon provides an explanation for the higher $\mathrm{Si}$ atomic concentration found for $C_{18}$ if compared with shorter silanes, like $C_{4}$ and $C_{8}$ (Table $2 ; I D 2,3,4$ ), since it is expected that $C_{18}$ can form more ordered and densely packed layers, while in the case of the other two silanes more disordered layers are expected and therefore lower surface coverage. In the case of the $C_{1}$, due to its small side chain, the steric hindrance effect is probably too low to have a large impact on grafting if compared with $C_{4}$ and $C_{8}$.

Finally the influence of reaction time on grafting performance will be treated. As discussed before the reaction between the silane and the surface $\mathrm{OH}$ groups seems to occur very fast. It was observed that after 30 minutes $\mathrm{Si}$ is present on the pore walls (Table 2; ID 10), indicating that the silanes have already diffused inside the pores. However, an increase is still observed after $1-2$ hours of reaction, from $4.3 \times 10^{-5} \mathrm{~mol} \mathrm{~m}^{-2}$ after 30 minutes to $5.7 \times 10^{-5} \mathrm{~mol} \mathrm{~m}^{-2}$ after 1 hour (Table 2; ID 11 
and 12). A comparison with a reaction time of 24 hours only showed a very small increase in Si atomic concentration, from $7.0 \times 10^{-5} \mathrm{~mol} \mathrm{~m}^{-2}$ after 2 hours to $9.0 \times 10^{-5}$ mol $\mathrm{m}^{-2}$ after 24 hours (Table 2; resp. ID 12 and 8) indicating that the hydrolysis and diffusion of the silanes into the pores is achieved after 2 hours of reaction. This confirms the FTIR results as given in Figure 3.

\subsubsection{Solvent stability tests}

In order to establish the stability of these systems in different solvents, grafted powders $\left(C_{1}, C_{4}, C_{8}\right.$ and $\left.C_{18}\right)$ were soaked in toluene or hexane. The FTIR spectra for the $C_{18}$ grafted powder before and after soaking in the selected solvents are presented in Figure 8.
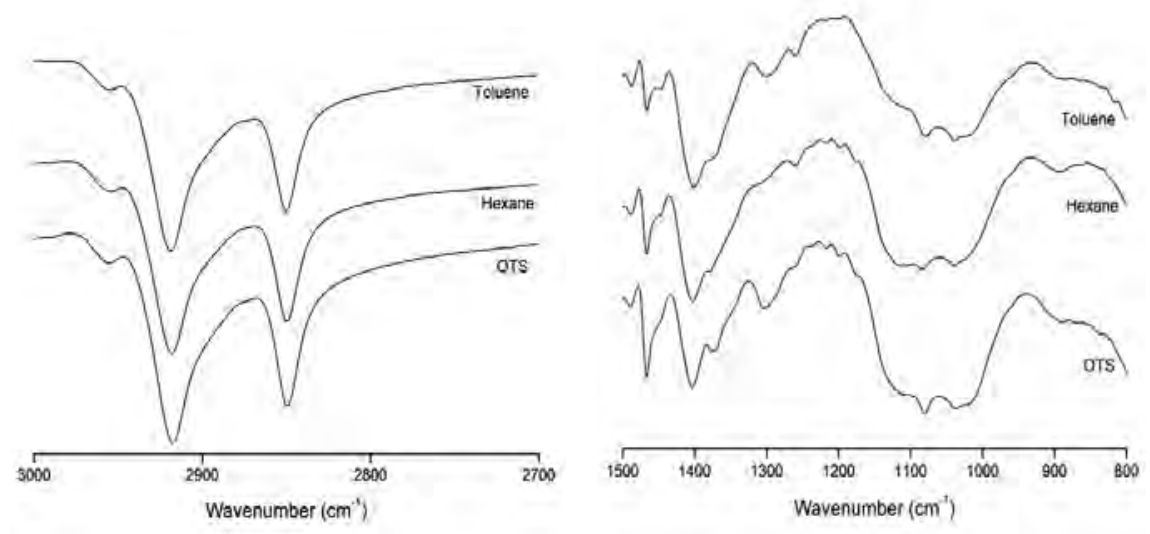

Figure 8: FTIR spectra of titania powder grafted with octadecyltrichlorosilane (OTS) after 14 days soaking in toluene and hexane.

As can be observed all bands present in the as-grafted powder before soaking are still present after soaking, meaning no degradation of the grafted systems has occurred and hence these grafted systems present a proper stability in organic solvents, as toluene and hexane. For $C_{1}, C_{8}$ and $C_{4}$ similar results were obtained, meaning $C_{1}, C_{4}$ and $C_{8}$ grafted powders were stable as well in both solvents. 


\subsection{Conclusions}

An experimental study was conducted on the silylation of different chlorosilanes onto titania powders and titania membranes with pores of $5 \mathrm{~nm}$, focusing on the effect of the reaction conditions (e.g. time, temperature and concentration) and the number of reactive groups of the silane on structural characteristics of the silylated layer formed. FTIR studies have proven that titania powders can be successfully grafted with both dichloro and trichlorosilanes at room temperature under an inert atmosphere.

Through the use of silanes with hydrocarbon end chains, hydrophobic membranes have been produced. This modification has not only occurred on the surface of the membrane, but also on the internal walls of the pores, as observed by XPS. Therefore, hydrophobic pores were obtained as well. Due to the presence of silanes along the pore walls, a decrease in pore size is expected compared with the unmodified membrane. A desirable uniform and packed layer was obtained, especially when mild conditions were used. Grafting at room temperature and concentrations less than $50 \mathrm{mM}$ are preferable, while reaction times of 24 hours are not really required, since after only 2 hours the silanes were successfully grafted onto the titania powders. Stability tests have shown that these systems show good stability in toluene and hexane for all silanes. Surface modification of inorganic membranes with silanes moieties can then render promising solvent resistant nanofiltration membranes.

\section{Acknowledgement}

This is an ISPT project (Institute for Sustainable Process Technology). 


\subsection{References}

1. Caro, J., M. Noack, and P. Kolsch, Chemically modified ceramic membranes. Microporous and Mesoporous Materials, 1998. 22(1-3): p. 321-332.

2. Sah, A., et al., Hydrophobic modification of gamma-alumina membranes with organochlorosilanes. Journal of Membrane Science, 2004. 243(1-2): p. 125-132.

3. McCarley, K.C. and J.D. Way, Development of a model surface flow membrane by modification of porous gamma-alumina with octadecyltrichlorosilane. Separation and Purification Technology, 2001. 25(1-3): p. 195-210.

4. Leger, C., H.D. Lira, and R. Paterson, Preparation and properties of surface modified ceramic membranes .3. Gas permeation of $5 \mathrm{~nm}$ alumina membranes modified by trichlorooctadecylsilane. Journal of Membrane Science, 1996. 120(2): p. 187-195.

5. Singh, R.P., J.D. Way, and S.F. Dec, Silane modified inorganic membranes: Effects of silane surface structure. Journal of Membrane Science, 2005. 259(1-2): p. 34-46.

6. Van Gestel, $\mathrm{T}_{\text {., }}$ et al., Surface modification of $\mathrm{y}-\mathrm{Al}_{2} \mathrm{O}_{3} / \mathrm{TiO}_{2}$ multilayer membranes for applications in non-polar organic solvents. Journal of Membrane Science, 2003. 224(1-2): p. 3-10.

7. Javaid, A. and D.M. Ford, Solubility-based gas separation with oligomer-modified inorganic membranes - Part II. Mixed gas permeation of $5 \mathrm{~nm}$ alumina membranes modified with octadecyltrichlorosilane. Journal of Membrane Science, 2003. 215(1-2): p. 157-168.

8. Fadeev, A.Y. and Y.V. Kazakevich, Covalently attached monolayers of oligo(dimethylsiloxane) s on silica: A siloxane chemistry approach for surface modification. Langmuir, 2002. 18(7): p. 2665-2672.

9. Younssi, S.A., et al., Gamma alumina membranes grafting by organosilanes and its application to the separation of solvent mixtures by pervaporation. Separation and Purification Technology, 2003. 32(1-3): p. 175-179.

10. Lu, J., et al., FAS grafted superhydrophobic ceramic membrane. Applied Surface Science, 2009. 255(22): p. 9092-9099.

11. Hendren, Z.D., J. Brant, and M.R. Wiesner, Surface modification of nanostructured ceramic membranes for direct contact membrane distillation. Journal of Membrane Science, 2009. 331(1-2): p. 1-10.

12. Leger, C., H.D. Lira, and R. Paterson, Preparation and properties of surface modified ceramic membranes .2. Gas and liquid permeabilities of $5 \mathrm{~nm}$ alumina membranes modified by a monolayer of bound polydimethylsiloxane (PDMS) silicone oil. Journal of Membrane Science, 1996. 120(1): p. 135-146.

13. Verrecht, $\mathrm{B}$., et al., Chemical surface modification of gamma- $\mathrm{Al}_{2} \mathrm{O}_{3} \mathrm{TiO}$, toplayer membranes for increased hydrophobicity. Desalination, 2006. 200(1-3): p. 385-386.

14. Voigt, l., Nanofiltration with ceramic membranes. Chemie Ingenieur Technik, 2005. 77(5): p. 559-564.

15. Fadeev, A.Y. and T.J. McCarthy, Self-assembly is not the only reaction possible between alkyltrichlorosilanes and surfaces: Monomolecular and oligomeric covalently attached layers of dichloro- and trichloroalkylsilanes on silicon. Langmuir, 2000. 16(18): p. 7268-7274.

16. Kallury, K.M.R., P.M. Macdonald, and M. Thompson, Effect Of Surface-Water And Base Catalysis On The Silanization Of Silica By (Aminopropyl)Alkoxysilanes Studied By X-Ray Photoelectron-Spectroscopy And C-13 Cross-Polarization Magic-Angle-Spinning NuclearMagnetic-Resonance. Langmuir, 1994. 10(2): p. 492-499.

17. Tripp, C.P. and M.L. Hair, Chemical Attachment Of Chlorosilanes To Silica - A 2-Step AminePromoted Reaction. Journal of Physical Chemistry, 1993. 97(21): p. 5693-5698.

18. Luebke, D., C. Myers, and H. Pennline, Hybrid membranes for selective carbon dioxide separation from fuel gas. Energy \& Fuels, 2006. 20(5): p. 1906-1913.

19. Tripp, C.P., Reaction of alkylchlorosilanes with silica at the solid/gas and solid/liquid interface, Langmuir, 1992. 8(8) p.1961-1967. 
20. Javaid, A., D.A. Krapchetov, and D.M. Ford, Solubility-based gas separation with oligomermodified inorganic membranes - Part III. Effects of synthesis conditions. Journal of Membrane Science, 2005. 246(2): p. 181-191.

21. Tripp C. P. et al., Reaction of Methylsilanols with Hydratate Silica Surfaces: The Hydrolysis of Trichloro-, Dichloro- and Monochloromethylsilanes and the effects of curing, 1995, 11, 149-150

22. Jeon, N.L., et al., Structure and stability of patterned self-assembled films of octadecyltrichlorosilane formed by contact printing. Langmuir, 1997. 13(13): p. 3382-3391.

23. Granier, M., et al., Improved strain relief of self-assembled monolayers from organohydridochlorosilanes grafted onto oxidized (1,0,0) silicon wafers. Langmuir, 2003. 19(7): p. 2691-2695.

24. Khatri, O.P. and S.K. Biswas, Thermal stability of octadecyltrichlorosilane self-assembled on a polycrystalline aluminium surface. Surface Science, 2004. 572(2-3): p. 228-238.

25. Snyder, R.G. and J.H. Schachtschneider, Vibrational Analysis Of The N-Paraffins .1. Assignments Of Infrared Bands In The Spectra Of $\mathrm{C}_{3} \mathrm{~h}_{8}$ Through N-C ${ }_{19} \mathrm{H}_{40}$. Spectrochimica Acta, 1963. 19(1): p. 85-116.

26. Schaefer, J.A. and W. Gopel, Initial-Stages Of Oxidation Of Si(100)(2X1) - A Combined Vibrational (Eels) And Electron-Binding Energy (Xps) Study. Surface Science, 1985. 155(2-3): p. 535-552.

27. Albert, K. and E. Bayer, Characterization Of Bonded Phases By Solid-State Nmr-Spectroscopy. Journal of Chromatography, 1991. 544(1-2): p. 345-370.

28. Hair, M.L. and C.P. Tripp, Alkylchlorosilane Reactions At The Silica Surface. Colloids and Surfaces a-Physicochemical and Engineering Aspects, 1995. 105(1): p. 95-103.

29. Roumeliotis, P. and K.K. Unger, Structure And Properties Of Normal-Alkyldimethylsilyl Bonded Silica Reversed-Phase Packings. Journal of Chromatography, 1978. 149(FEB): p. 211-224.

30. Mirji, S.A., Octadecyltrichlorosilane adsorption kinetics on $\left.\mathrm{Si}_{(100}\right) / \mathrm{SiO}_{2}$ surface: contact angle, AFM, FTIR and XPS analysis. Surface and Interface Analysis, 2006. 38(3): p. 158-165.

31. Matsuo, Y., et al., Preparation and characterization of silylated graphite oxide. Carbon, 2005. 43(14): p. 2875-2882.

32. Belyavskii, S.G., P.G. Mingalev, and G.V. Lisichkin, Chemical Modification of $\mathrm{Y}_{2} \mathrm{O}_{3}$; Surface with Aryl Silanes. Colloid Journal, 2004. 66(2): p. 128-136.

33. Brzoska, J.B., I. Benazouz, and F. Rondelez, Silanization Of Solid Substrates - A Step Toward Reproducibility. Langmuir, 1994. 10(11): p. 4367-4373.

34. Brzoska, J.B., N. Shahidzadeh, and F. Rondelez, Evidence Of A Transition-Temperature For The Optimum Deposition Of Grafted Monolayer Coatings. Nature, 1992. 360(6406): p. 719721.

35. Parikh, A.N., et al., An Intrinsic Relationship Between Molecular-Structure In Self-Assembled N-Alkylsiloxane Monolayers And Deposition Temperature. Journal of Physical Chemistry, 1994. 98(31): p. 7577-7590.

36. Glaser, A., et al., Low-temperature investigation of the growth mechanism of alkylsiloxane self-assembled monolayers. Analytical and Bioanalytical Chemistry, 2004. 379(4): p. 653657.

37. Carraro, C., et al., Observation of three growth mechanisms in self-assembled monolayers. Journal of Physical Chemistry B, 1998. 102(23): p. 4441-4445.

38. Maoz, R. and J. Sagiv, On the formation and structure of self-assembling monolayers. I. A comparative atr-wettability study of Langmuir--Blodgett and adsorbed films on flat substrates and glass microbeads. Journal of Colloid and Interface Science, 1984. 100(2): p. 465-496.

39. Tidswell, I.M., et al., X-ray specular reflection studies of silicon coated by organic monolayers (alkylsiloxanes). Physical Review B, 1990. 41(2): p. 1111.

40. Ohtake, T., N. Mino, and K. Ogawa, Effect Of Hydrocarbon Chain-Length On Arrangement Of Chemically Adsorbed Monolayers. Langmuir, 1992. 8(9): p. 2081-2083.

41. Mathauer, K. and C.W. Frank, Binary Self-Assembled Monolayers As Prepared By Successive 
Adsorption Of Alkyltrichlorosilanes. Langmuir, 1993. 9(12): p. 3446-3451.

42. Bierbaum, K., et al., Growth Of Self-Assembled N-Alkyltrichlorosilane Films On Si(100) Investigated By Atomic-Force Microscopy. Langmuir, 1995. 11 (6): p. 2143-2150. 


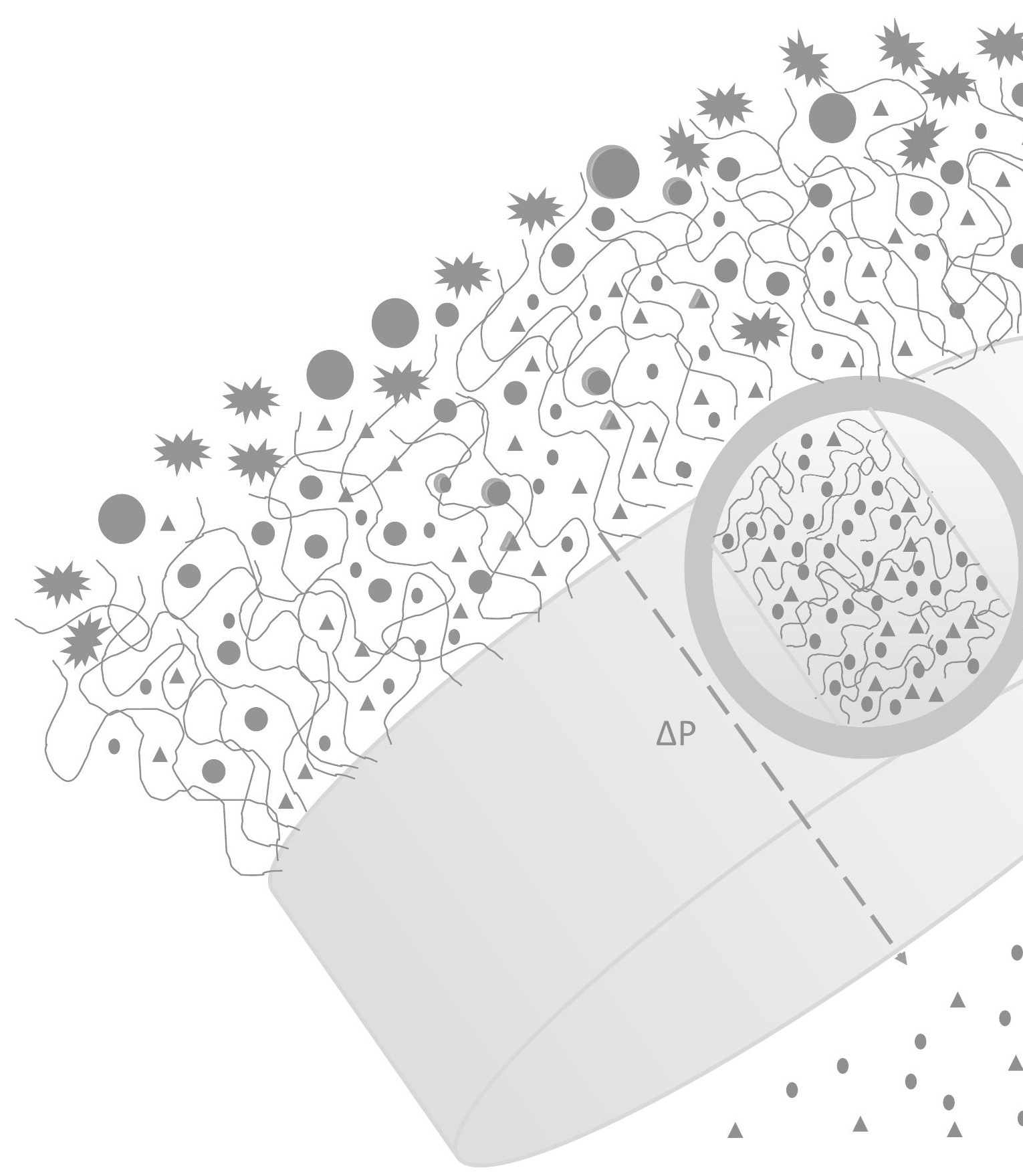


Chapter

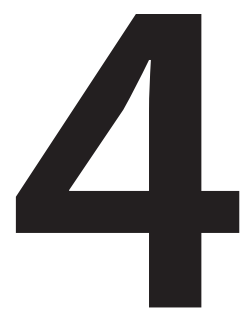

\section{Efficient pore grafting of}

siloxane moieties onto

gamma alumina flakes

$$
\begin{aligned}
& \Delta \stackrel{\Delta}{\Delta} \\
& { }^{-} \bullet^{\Delta} \bullet \bullet^{\bullet} \Delta
\end{aligned}
$$

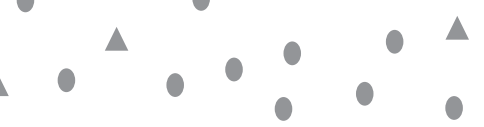

$$
\begin{aligned}
& \bullet \bullet \bullet \bullet \bullet \\
& \text { - }{ }^{\Delta}, 0^{\Delta}
\end{aligned}
$$




\section{Abstract}

Meso-porous (5 $\mathrm{nm}$ ) $\gamma$-alumina flakes were grafted with several alkyltrichlorosilanes or with a PDMS polymer. The systems were analyzed by FTIR, gas adsorption/desorption and TGA in order to gain more insight into the grafting on both surface and in pores of inorganic powders. In all cases grafting was proven, meaning a covalent bond between inorganic particle and organic moiety exists. A new method for PDMS grafting was developed which involved grafting of a linker (3-aminopropyltriethoxysilane: APTES) on alumina, either in the solution phase (SPD) or in the vapor phase (VPD), followed by PDMS grafting. It is proven that a more controlled, uniform mono layer of the APTES linker is grafted by the VPD deposition method, resulting in a more efficient grafting of PDMS onto the inner pore walls. Alumina, grafted with alkyl-trichlorosilanes, however showed a low chemical stability in protic solvents, which hampers their application where solvent resistance is required, whereas PDMS-grafted alumina is stable in a wide range of solvents. 


\subsection{Introduction}

Surface modification of metal oxide particles with organic moieties has typically been achieved by means of reactions between the surface hydroxyl groups of metal oxide particles (M-OH) and coupling reagents such as organosilane or organophosphorus compounds. This process is called grafting. In this process, a covalent bond is formed between the polymer matrix and the inorganic particle. For membrane applications, particularly for nanofiltration of non-aqueous systems, the use of hybrids is a new and promising strategy. Ceramic membranes present high thermal, mechanical and chemical stability. Unfortunately, their reduced selectivity and limited pore size availability combined with their hydrophilic character hampers their application. Grafting polymers on ceramic membranes offers the opportunity to tailor and manipulate interfacial properties, while retaining the mechanical strength and geometry of the supported material. Several types of molecules can be used the modification of inorganic unsupported and supported materials, for instance phosphate derivatives [1-3][4], chlorosilanes and alkoxysilane derivatives [5-7], triethoxysilane compounds [3], polydimethylsiloxane derivatives [8][9] and Grignard reactants [10]. Two general strategies can be pursued to bring about a hydrophobic modification of a hydrophilic inorganic powders/ membranes through the use of silicon-based organics. The strategy employed in this paper, is a post-modification of mesoporous inorganic powders/membranes by grafting the pores with organosilanes. These molecules contain one, two or three hydrolysable (alkoxy or chloro) groups, capable for covalent bonding with the surface $\mathrm{OH}$ groups, forming either a mono- or multi-layer structure.

Silanes can also be used as coupling agents and act as a bridge between the surface and the polymer to be grafted. In order to achieve this, the silanization agent should contain a hydrolysable group as well as a functional group (anchoring site), which can act as a linkage point for the attachment of other (e.g. polymer) molecules to the surface. In this work a mono-epoxy PDMS is selected as the polymer to be grafted. Due to their hydrophobic character, thermal and chemical stability and solubility in non-polar solvents PDMS-based membranes have been widely used as solvent resistant nanofiltration (SRNF) polymeric membranes. However, their swelling behavior, particularly in non-polar solvents hampers their applications. Since ceramic membranes present no swelling, the bonding of suitable polysiloxanes in the surface and pores is expected to reduce their swelling behavior. 
The morphology and structure of alkylchlorosilane- or aminosilane-modified surfaces strongly depends on (1) reaction conditions [11-18] (e.g. concentration, reaction temperature, type of solvent, time, phase of reaction, surface water or humidity) (2) type of silane [5, 19-21] (number and type of reactive groups, hydrophilic nature, size of the side chain), (3) curing conditions [22, 23] and (4) the properties of the inorganic support (pore size and shape, OH surface concentration). Surface-saturated layers of aminosilanes can be deposited under dry conditions, meaning in a dried organic solvent, or in the gas phase. Hydrolysis of alkoxy groups, hydrogen bonding of hydrolyzed alkoxy groups and further cross polymerization can be avoided in this way. However, an organic solvent still contains small amounts of water, resulting in multilayer formation. Because no solvents are needed in the gas phase, the presence of water can be excluded. Still modification of metal oxides with different kinds of organosilanes is mostly performed by solution phase methods [5, 11, 24-29]. In literature some studies are reported on gas-solid reactions of silanes $[13,18,21]$ onto metal oxide surfaces. Controlled hydrolysis of alkoxysilanes, solvent removal, washing procedures and others can be avoided when using gas-phase techniques. Furthermore, alkylsilane overlayers, deposited by a gas phase are better ordered, more uniform and more reproducible than layers deposited toluene solutions.

In this work we use $\gamma$-alumina flakes containing pores with a size of $5 \mathrm{~nm}$ treated with alkyltrichlorosilanes with different side chains or 3-aminopropyltriethoxysilane (APTES ) followed by PDMS grafting using two different APTES deposition methods, a solution phase method (SPD) and vapor phase method (VPD). In the first part of this paper the influence of the side chain of the alkyltrichlorosilanes on the microstructure and morphology of the grafted powder is analyzed. In the second part the influence of the phase deposition method on the structure of the aminosilane (APTES) layer and the impact on subsequent PDMS grafting is studied. In the third part a comparison in terms of thermal and chemical stability of these two systems is performed.

A combination of techniques, like FTIR spectroscopy, gas adsorption/desorption, thermogravimetrical analysis, are used to provide detailed information about the chemical nature of the incorporated organic moieties and their effect on the mesoporous structure of the alumina flakes. This work gives insight into the phenomenon of grafting occurring on both surface and in pores of inorganic powders. 


\subsection{Experimental}

\subsubsection{Materials}

Trichloromethylsilane (TCMS: $\mathrm{CH}_{3} \mathrm{SiCl}_{3^{\prime}} \mathrm{C}_{1}$ ), butyltrichlorosilane (BuTCS: $\mathrm{C}_{4} \mathrm{H}_{9} \mathrm{SiCl}_{3} \mathrm{C}_{4}$ ), octyltrichlorosilane (OcTS: $\mathrm{C}_{8} \mathrm{H}_{17} \mathrm{SiCl}_{3}, \mathrm{C}_{8}$ ), octadecyltrichlorosilane (OTS: $\mathrm{C}_{18} \mathrm{H}_{37} \mathrm{SiCl}_{3^{\prime}}$ $\mathrm{C}_{18}$ ) and 3-aminopropyltriethoxysilane (APTES) were obtained from Aldrich and used as received. The solvents (toluene, n-hexane, isopropanol, tetrahydrofuran, chloroform, methanol, dimethylformamide, 1-methy-2-pyrrolidone and butanol) were obtained from Aldrich and used as received. All solvents referred before were anhydrous. Acetone and ethanol were purchased from Aldrich and used as received. Mesoporous $\gamma$-alumina flakes were prepared from a boehmite sol. These flakes were dried and subsequently calcined at $625^{\circ} \mathrm{C}$ for 1 hour at a heating rate of $1{ }^{\circ} \mathrm{C} \mathrm{min}{ }^{-1}$, as described in detail in ref. [30]. The polysiloxane (mono(2,3-epoxy) polyetherterminated polydimethylsiloxane: PDMS) was obtained from ACBR. The polymer has a molecular weight of $1000 \mathrm{~g} \mathrm{~mol}^{-1}$ and a viscosity of 10-15 mPa s

\subsubsection{Grafting procedure}

\section{Pre-treatment of $\gamma$-alumina flakes}

Before grafting, the $\gamma$-alumina flakes were pre-treated by soaking in an ethanol/ water (2:1) solution for 24 hours at ambient temperature, dried in a vacuum oven at $100{ }^{\circ} \mathrm{C}$ for 24 hours and stored under nitrogen atmosphere until further use. This pre-treatment was done to remove dust and to promote a suitable degree of hydroxylation.

\section{Grafting of $\gamma$-alumina flakes with alkyltrichlorosilanes}

Grafting of $\gamma$-alumina flakes with chlorosilanes was done at room temperature in anhydrous toluene. A typical procedure was as follows: (1) In a glove box under nitrogen atmosphere a $100 \mathrm{~mL}$ toluene-silane solution, using a silane concentration of $25 \mathrm{mM}$, was added to $0.5 \mathrm{~g}$ of pre-treated $\mathrm{\gamma}$-alumina flakes in an Erlenmeyer flask and stirred for 24 hours, (2) the mixture was then removed from the glove box, filtrated and washed with fresh toluene and then with a 2:1 ethanol/water solution for the removal of unbound silanes and afterwards dried at $100{ }^{\circ} \mathrm{C}$ for 24 hours in a vacuum oven to remove traces of solvents.

\section{Grafting of $\gamma$-alumina flakes with APTES by solution phase deposition (SPD)}

The introduction of amino groups onto the alumina surface, i.e. the preparation 
of an "initiator site", was achieved by the treatment of the surface $\mathrm{OH}$ groups with APTES. A typical example is as follows: (1) in a glove box under nitrogen atmosphere a $100 \mathrm{ml} 50 \mathrm{mM}$ APTES-toluene solution was added to $600 \mathrm{mg}$ of $\gamma$-alumina flakes in a $250 \mathrm{ml}$ 4-necked round flask, (2) The mixture was then removed from the glove box, refluxed for 4 hours at $80{ }^{\circ} \mathrm{C}$ under a nitrogen flow. After this reaction the mixture was cooled to room temperature and centrifuged at $7500 \mathrm{rpm}$ for 20 min. This washing procedure was repeated 3 times with fresh solvent to remove any non-reacted silane. After that the modified flakes were washed in a mixture of 2:1 ethanol/water and centrifuged at $7500 \mathrm{rpm}$ for $10 \mathrm{~min}$. This procedure was again repeated 2 more times with a fresh solution. The solvent was removed and the modified flakes were dried at $100{ }^{\circ} \mathrm{C}$ under vacuum for 24 hours.

\section{Grafting of $\gamma$-alumina flakes with APTES by vapor phase deposition (VPD)}

A vapor phase method was used for grafting the APTES linker on $\gamma$-alumina flakes. This method implies that inside a glove box, under nitrogen atmosphere, a $100 \mathrm{ml}$ toluene-silane solution, using an APTES concentration of $25 \mathrm{mM}$, was added to a $250 \mathrm{ml}$ 2-necked round flask. In a second $250 \mathrm{ml}$ 2- necked round flask $600 \mathrm{mg}$ of alumina flakes were placed. Magnetic stirrers were added to both flasks. The flasks were then connected with a glass tube ("bridge") and the system was removed from the glove box, flushed with nitrogen and heated to $80^{\circ} \mathrm{C}$. After 4 hours both flasks were allowed to cool down and the modified flakes were washed and dried using the same procedure as described for the $\gamma$-alumina modified by the SPD method.

\section{Grafting of the APTES-grafted alumina flakes with PDMS}

The introduction of the siloxane-based polymer was achieved by the reaction between the grafted amino groups and the epoxy groups of the siloxane polymer (PDMS). A typical procedure is as follows: (1) In a glove box, under nitrogen atmosphere, a $100 \mathrm{ml}$ 2-isopropanol-PDMS solution, using an PDMS concentration of $25 \mathrm{mM}$, was added to $300 \mathrm{mg}$ of APTES-grafted alumina flakes, (2) the mixture was removed from the glove box, refluxed for 24 hours at $75^{\circ} \mathrm{C}$ under a nitrogen flow. After 3 hours the reaction vessel was cooled to room temperature and the solvent was removed by centrifuging at $7500 \mathrm{rpm}$ for $20 \mathrm{~min}$., washed with anhydrous 2-isopropanol and dried in the same way as described before. For both APTES-grafted alumina flakes modified by SPD or VPD the same procedure was followed. 


\subsubsection{Powder characterization Infrared spectroscopy}

FTIR spectra of the modified alumina flakes were obtained with a TGA-IRTensor 27 system spectrometer as described in chapter 3. An FTIR spectrum of unmodified $\gamma$-alumina flakes was used for background correction.

\section{Gas adsorption measurements}

Nitrogen adsorption/desorption isotherms were collected at $77 \mathrm{~K}$ using a Gemini system, VII version obtained from Micromeritics Instruments Corp. under nitrogen flow of $50 \mathrm{ml} \mathrm{min}{ }^{-1}$. Specific surface areas were calculated by using the multi-point Brunauer-Emmett-Teller (BET) method in the relative pressure range of $p / p_{0}=$ 0.05-0.2. Pore size distributions were evaluated from the desorption branches of the $\mathrm{N}_{2}$ isotherms by means of the Barrett-Halenda-Joyner (BHJ) model between relative pressures $p / p_{0}=0.35-0.9$ and the pore sizes were estimated from the peak positions of the $\mathrm{BHJ}$ pore size distribution curves. This method is based on Kelvin's equation, stating that condensation occurs in pores with radius $r_{k}$ at $p / p_{o}$ which for cylindrical pores is represented by:

$$
\ln \left(p / p_{0}\right)=-2 \gamma_{s} V_{\text {mol }} / R T_{K}
$$

with $\gamma_{s}$ the surface tension of the liquid-vapor interface $\left(8.85 \mathrm{MJ} / \mathrm{m}^{2}\right.$ for $\left.\mathrm{N}_{2}\right), V_{\text {mol }}$ the molar volume of the condensed $\mathrm{N}_{2}\left(34.7 \mathrm{~cm}^{3}\right), R$ the gas constant and $T$ the temperature. The pore volumes of these meso pores were obtained from the amount of nitrogen adsorbed at $p / p_{0}=0.95$. Before measurement each sample was vacuum-degassed at $200{ }^{\circ} \mathrm{C}$ for 12 hours.

\section{Thermo gravimetrical analysis}

Thermo gravimetrical analysis was conducted at a heating rate of $10{ }^{\circ} \mathrm{C} \mathrm{min}-1$ under $\mathrm{N}_{2}$ atmosphere. In all cases a run from room temperature till $1000{ }^{\circ} \mathrm{C}$ was performed and around $20 \mathrm{mg}$ of sample was used. Before the measurement, each sample was pre-treated from room temperature till $150{ }^{\circ} \mathrm{C}$ with a heating rate of $10{ }^{\circ} \mathrm{C} \mathrm{min}^{-1}$ to remove any adsorbed water.

\section{Chemical stability tests}

In order to assess the stability, $Y$-alumina flakes, grafted with different trichlorosilanes, were soaked in various solvents: toluene, $\mathrm{n}$-hexane and isopropanol. For PDMSgrafted systems, solvents as tetrahydrofuran, dichloromethane, acetone, 
chloroform, n-butanol, methanol, N,N'-dimethylformamide and 1-methyl-2pyrrolidone were used as well. Approximately $0.1 \mathrm{~g}$ of grafted yalumina flakes was soaked in $10 \mathrm{~g}$ of solvent and stirred for 7 days at room temperature. The powders were centrifuged at a speed of 7500 rpm for 5 minutes, 3-times washed with fresh solvent, centrifuged and air-dried overnight. The stability of the grafted flakes was analyzed by FTIR.

\subsection{Results and discussion}

\subsubsection{General considerations for alkyltrichlorosilanes}

Anhydrous silylation of trifunctional silanes occurs by means of hydrolysis between water molecules and chlorosilane molecules under formation of hydrolyzed species which then condense with the hydroxyl groups of the inorganic particles to form a covalent bond M (e.g. Al)-O-Si (eq. 2 and 3).

$\left(\mathrm{C}_{\mathrm{n}} \mathrm{H}_{2 \mathrm{n}+1}\right) \mathrm{SiCl}_{3}+\mathrm{mH}_{2} \mathrm{O} \longrightarrow\left(\mathrm{C}_{\mathrm{n}} \mathrm{H}_{2 \mathrm{n}+1}\right) \mathrm{SiCl}_{3-\mathrm{m}}(\mathrm{OH})_{m}+\mathrm{mHCl}$

$\left(\mathrm{C}_{\mathrm{n}} \mathrm{H}_{2 \mathrm{n}+1}\right) \mathrm{SiCl}_{3-\mathrm{m}}(\mathrm{OH})_{\mathrm{m}}+\mathrm{mOH}-\mathrm{M} \equiv \longrightarrow\left(\mathrm{C}_{\mathrm{n}} \mathrm{H}_{2 \mathrm{n}+1}\right) \mathrm{SiCl}_{3-\mathrm{m}}(\mathrm{OH})_{\mathrm{m}-1}-\mathrm{O}-\mathrm{M} \equiv+\mathrm{mH}_{2} \mathrm{O}$

Although the overall reaction between surface hydroxyl and chlorine molecules does not consume water, a covalent bond cannot occur in complete absence of water because of the catalytic role of water in this reaction [31]. Yoshida et al. have shown that at low surface water coverage the silylation is negligible but as the number of water monolayers (2-3) increases, a maximum of silane coverage is achieved both for silica and zirconia surfaces grafted with a vinyl silane (VTMS), followed by a decline at higher surface water content. The latter is due to the presence of a very thick silane layer, which can condense in the water layer without covalent attachment to the surface, particularly for hydrophobic silane precursors like alkyltrichlorosilanes [31].

After this first layer is formed (equation 2 and 3), multilayer reactions are expected. However, it is possible that multilayer and first layer silylation reactions occur simultaneously. These multilayer reactions proceed through the hydrolysis of the chlorine groups of the free silanes (equation 4) and a surface silane (equation 5) followed by a condensation reaction (equation 6) 


$$
\begin{aligned}
& \left(\mathrm{C}_{\mathrm{n}} \mathrm{H}_{2 \mathrm{n}+1}\right) \mathrm{SiCl} \mathrm{ml}_{1}+\mathrm{H}_{2} \mathrm{O} \longrightarrow\left(\mathrm{C}_{\mathrm{n}} \mathrm{H}_{2 \mathrm{n}+1}\right) \mathrm{SiCl}_{\mathrm{ml-1}}(\mathrm{OH})+\mathrm{HCl} \\
& \left(\mathrm{C}_{\mathrm{n}} \mathrm{H}_{2 \mathrm{n}+1}\right) \mathrm{SiCl}_{\mathrm{ml}-1}+\mathrm{H}_{2} \mathrm{O} \longrightarrow\left(\mathrm{C}_{\mathrm{n}} \mathrm{H}_{2 \mathrm{n}+1}\right) \mathrm{SiCl}_{\mathrm{m} 2-1}(\mathrm{OH})-\mathrm{M} \equiv+\mathrm{HCl} \\
& \left(\mathrm{C}_{\mathrm{n}} \mathrm{H}_{2 \mathrm{n}+1}\right) \mathrm{SiCl}_{3 \mathrm{ml-1}}-\mathrm{M} \equiv+\left(\mathrm{C}_{\mathrm{n}} \mathrm{H}_{2 \mathrm{n}+1}\right) \mathrm{SiCl}_{m 2-1}(\mathrm{OH})-\mathrm{M} \equiv \\
& \longrightarrow\left(\mathrm{C}_{\mathrm{n}} \mathrm{H}_{2 \mathrm{n}+1}\right) \mathrm{SiCl}{ }_{\mathrm{m1-1}} \mathrm{Si}-\mathrm{O}-\mathrm{Si}--\left(\mathrm{C}_{\mathrm{n}} \mathrm{H}_{2 \mathrm{n}+1}\right) \mathrm{Cl}_{\mathrm{m}-1}(-\mathrm{M} \equiv)+\mathrm{H}_{2} \mathrm{O}
\end{aligned}
$$

The water molecules required for the multilayer formation can be provided by the surface water, traces of water in the organic solvent or humidity during the curing step. Thus a proper sample pre-treatment is required as well as the use of anhydrous solvents and an inert atmosphere in order to control moisture.

\subsubsection{Principles of aminosilanes grafting}

For trialkoxysilanes, like aminosilanes, the silylation mechanism (equations 1-5) also applies. However, in the case of these silanes where the non-hydrolysable group, e.g. an amino group (- $\left.\mathrm{NH}_{2}\right)$, acts as the catalyst, equation 3-5 may not apply. The electron-rich amino group catalyzes the condensation of the silicon side of the molecule with a surface $\mathrm{OH}$ group forming a covalent siloxane bond [32]. Besides, hydrogen bonding or ionic interaction with surface $\mathrm{OH}$ groups or with other aminosilane molecules, that are not relevant for surface modification, are also possible reaction paths. This results in weakly attached layers. Vandenberg at al. [11] have shown that parameters as type of solvent (aqueous, organic, organic and anhydrous), reaction time and curing conditions have a direct effect on monolayer/multilayer formation and on aggregate formation. Reactions in dry solvents at room temperature for shorter times were shown to be preferable for monolayer formation with no aggregate formation.

\subsubsection{IR Analysis}

\section{Alkyltrichlorosilane grafting}

Figure 1 presents the FTIR spectra for unmodified and alumina flakes grafted with different alkyltrichlorosilanes. 

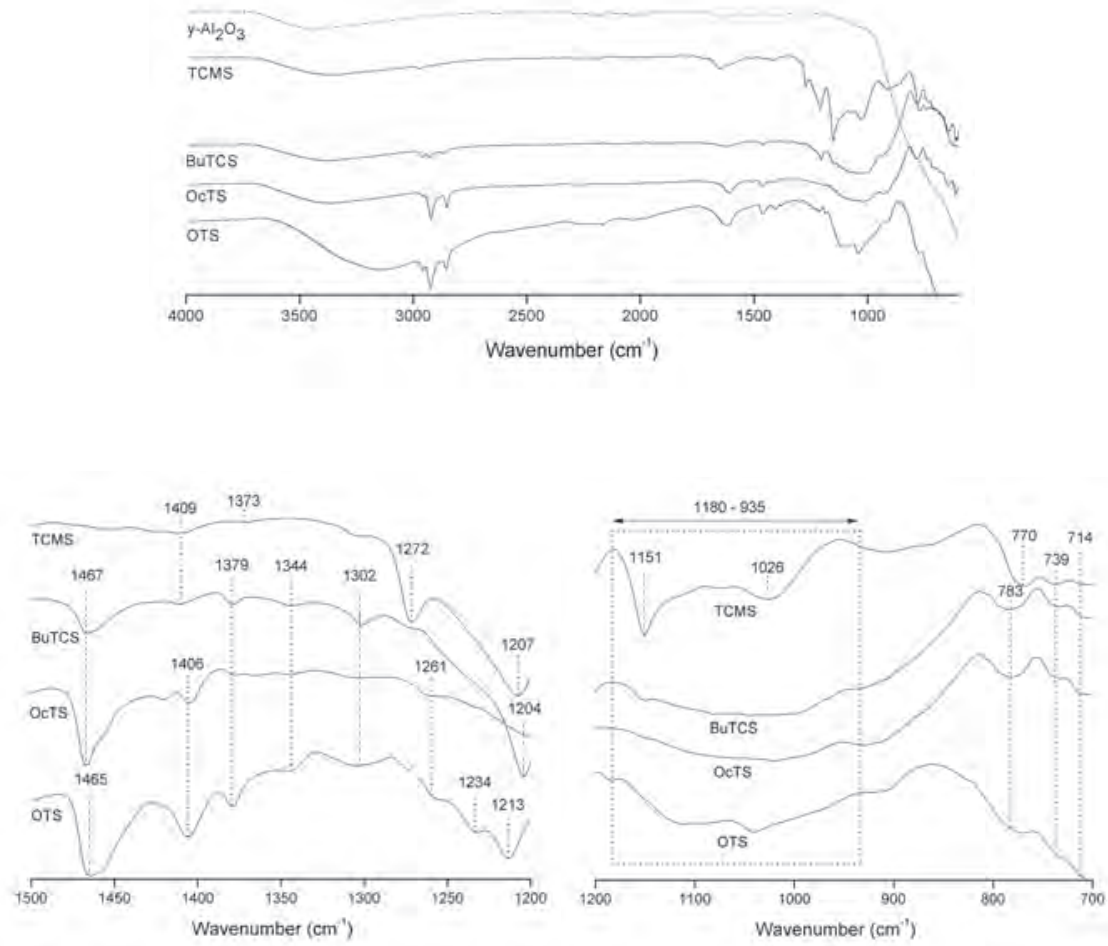

Figure 1:FTIRspectrafor pure $\gamma$-alumina flakes and for materials grafted with methyltrichlorosilane (TCMS), butyltrichlorosilane(BuTCS), octyltrichlorosilane(OcTS) and octadecyltrichlorosilane(OTS).

The frequencies and assignments of each vibrational mode are listed in Table 1. After the introduction of the alkyltrichlorosilanes new peaks can be seen, providing evidence of the attachment of these molecules on alumina. The region between $3000-2700 \mathrm{~cm}^{-1}$ is assigned to several C-H stretching modes from the methyl and methylene groups (Table 1). The appearance of these bands confirms the presence of the $\mathrm{CH}_{2}$ and/or $\mathrm{CH}_{3}$ groups from the hydrocarbon side chain present in all silanes. The structural organization of the grafted layer can be determined by the positions of these methylene stretching modes. For highly ordered and densely-packed grafted molecules with close to perpendicular chain axis orientation, methylene stretching modes at around 2920 and $2950 \mathrm{~cm}^{-1}$ are expected, as well as a methyl stretching mode at $2968 \mathrm{~cm}^{-1}[33,34]$. Similar wavenumber values are found for both OTS and OcTS (Table 1), indicating that an all trans OTS and OcTS layer might have been formed. The absorption signals due to $-\mathrm{CH}_{2}$ - stretching broaden and shift to higher wavenumbers when the degree of disorder increases [33, 34]. For BuTCS 
the deviation towards higher wavenumbers indicates a more disordered and less densely packed structure with more gauche defects. The region at $1500-1100 \mathrm{~cm}^{-1}$ and $900-650 \mathrm{~cm}^{-1}$ is dominated by several bands assigned to methyl $\left(\mathrm{CH}_{3}\right)$ and methylene $\left(\mathrm{CH}_{2}\right)$ deformation (bending, rocking, twisting, stretching) due to the hydrocarbon side chain present in all alkyltrichlorosilanes (Table 1). This confirms the successful incorporation of the silanes onto the alumina flakes in all cases. The broad band between 1100 and $980 \mathrm{~cm}^{-1}$ is assigned to symmetric and asymmetric stretching of the Si-O-Si band due to the formation of a polymerized layer through a condensation reaction between adjacent silanes, which results in the formation of siloxane bonds [35]. However, due to this broad band, the peak attributed to the Al-O-Si stretching mode, expected at $960 \mathrm{~cm}^{-1}$, could not be resolved. The presence of all these characteristics bands for alkyltrichlorosilanes on the FTIR spectra of the modified flakes proves that the surface was modified.

Table 1: FTIR wavenumbers (in $\mathrm{cm}^{-1}$ ) assignments of the main bands for different alkyltrichlorosilanes as grafted on $\gamma$-alumina flakes

\begin{tabular}{|c|c|c|c|c|c|}
\hline OTS & OCTS & BuTCS & TCMS & Assignment & Ref. \\
\hline 2964 & 2964 & 2962 & 2964 & $\mathrm{CH}_{3}$ symmetric stretching $\left(\mathrm{V}_{\mathrm{s}} \mathrm{CH}_{3}\right)$ & {$[33,34]$} \\
\hline 2920 & 2920 & 2965 & - & $\mathrm{CH}_{2}$ symmetric stretching $\left(\mathrm{V}_{\mathrm{s}} \mathrm{CH}_{2}\right)$ & {$[33,34]$} \\
\hline 2850 & 2848 & 2858 & & $\mathrm{CH}_{2}$ asymmetric stretching $\left(\mathrm{V}_{\text {as }} \mathrm{CH}_{2}\right)$ & {$[33,34]$} \\
\hline 1465 & 1467 & 1467 & - & $\mathrm{CH}_{2}$ bending (scissoring) $\left(\mathrm{CCH}_{2}\right)$ & {$[36,37]$} \\
\hline 1406 & 1406 & 1409 & & Bending mode of the $\left(\mathrm{CH}_{2}\right) \mathrm{Si}\left(\delta \mathrm{CH}_{2}\right)$ & {$[36,38]$} \\
\hline 1379 & 1379 & 1379 & 1373 & $\mathrm{CH}_{3}$ bending (symmetric) mode $\left(\delta \mathrm{CH}_{3}\right)$ & {$[37,38]$} \\
\hline 1344 & 1344 & 1344 & & $\mathrm{CH}_{2}$ bending $\left(\delta \mathrm{CH}_{2}\right)$ & \\
\hline 1302 & 1302 & 1302 & - & $\begin{array}{c}\mathrm{CH}_{2} \text { twist-rock deformation }\left(\mathrm{T}_{\mathrm{CH}}\right) \\
\text { and } \mathrm{CH}_{2} \text { wagging }\left(\omega \mathrm{CH}_{2}\right)\end{array}$ & {$[36,39]$} \\
\hline- & - & - & 1272 & $\mathrm{CH}_{3}$ bending mode of the $\mathrm{Si}-\mathrm{CH}_{3}\left(\delta \mathrm{CH}_{3}\right)$ & {$[5,36]$} \\
\hline 1261 & 1261 & 1261 & & $\begin{array}{c}\left(\mathrm{CH}_{2}\right) \text { Si wagging }\left(\omega \mathrm{CH}_{2}\right) \\
\text { and } \mathrm{C}\left(\mathrm{CH}_{2}\right) \text { twisting }\left(\mathrm{TCH}_{2}\right)\end{array}$ & $\begin{array}{c}{[36,38,} \\
39]\end{array}$ \\
\hline 1213 & 1204 & 1204 & & $\left(\mathrm{CH}_{2}\right) \mathrm{Si}$ wagging $\left(\omega \mathrm{CH}_{2}\right)$ & {$[36,39]$} \\
\hline $1180-935$ & $1180-935$ & $1180-935$ & 1180-935 & Si-O-Si stretch (vs/as Si-O-Si) & $\begin{array}{c}{[5,36,} \\
37]\end{array}$ \\
\hline 783 & 783 & 783 & 770 & $\mathrm{CH}_{3} \operatorname{rock}\left(\mathrm{TCH}_{3}\right)$ & {$[37-40]$} \\
\hline 739 & 739 & 739 & 739 & $\begin{array}{l}\left(\mathrm{CH}_{2}\right) \mathrm{C} \text { rock }\left(\mathrm{T} \mathrm{CH}_{2}\right) \\
\text { and } \mathrm{Si}-\mathrm{C} \text { stretching mode }(\mathrm{V} \mathrm{Si}-\mathrm{C})\end{array}$ & {$[39,40]$} \\
\hline 714 & 714 & 714 & 714 & $\mathrm{CH}_{2}$ rocking $\left(\mathrm{\tau}_{\mathrm{CH}}\right)$ & \\
\hline
\end{tabular}




\section{Grafting of PDMS - Influence of the APTES deposition method}

Figure 2 shows the FTIR spectra of the alumina flakes grafted with 3-aminopropyltriethoxysilane (APTES) by solution phase deposition (SPD) and vapor phase deposition (VPD).
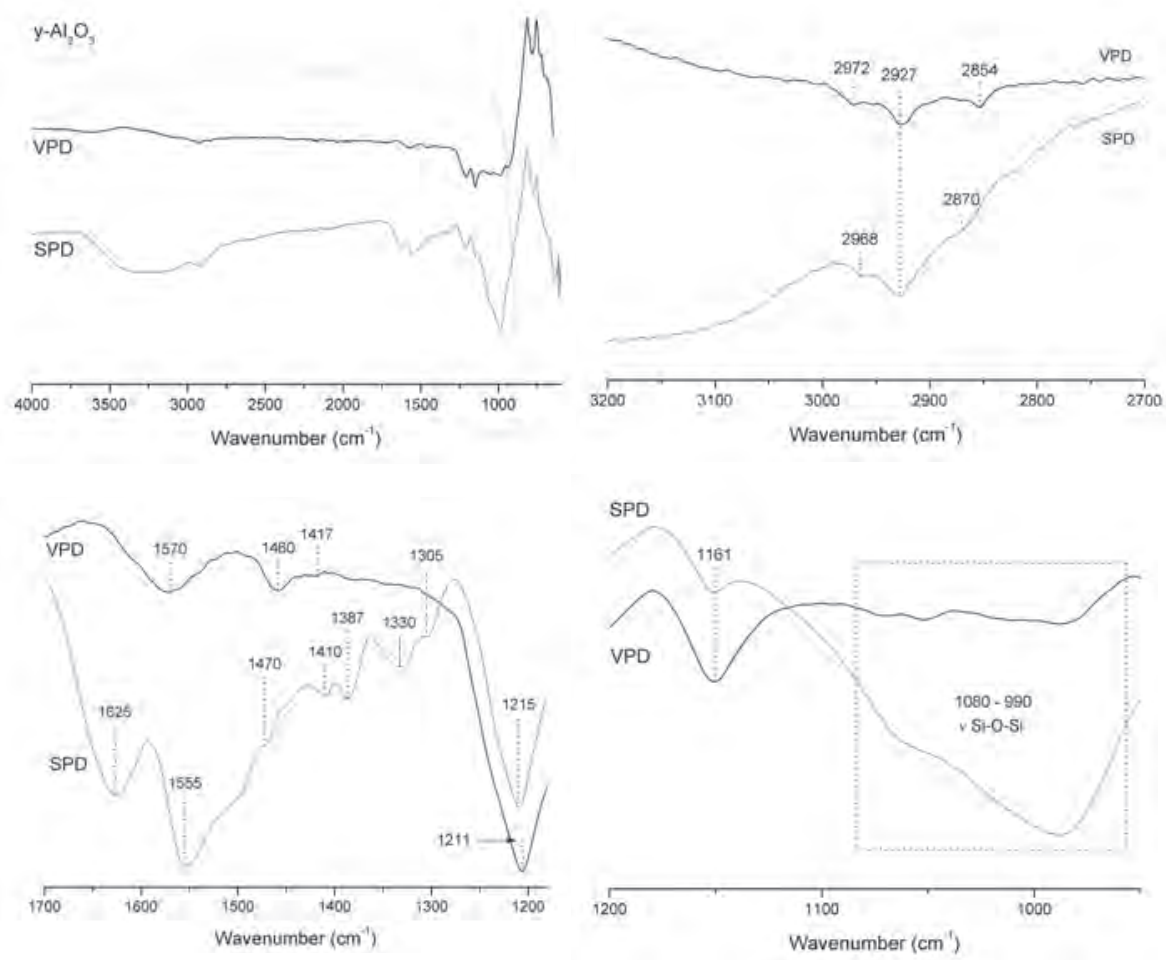

Figure 2: FTIR spectra for $\gamma$-alumina flakes modified with 3-aminopropyltriethoxysilane (APTES) by solution phase deposition (SPD) and by vapor phase deposition (VPD)

The frequencies and assignments of each vibrational mode are listed in Table 2. For the unmodified alumina flakes the broad peak between $3600-3000 \mathrm{~cm}^{-1} \mathrm{can}$ be assigned to the stretching modes of the various types of surface hydroxyl groups $(\mathrm{M}-\mathrm{OH})$ of alumina, while the peak at $1640 \mathrm{~cm}^{-1}$ can be attributed to the bending mode of residual intra-molecular water $(\delta \mathrm{OH})$. After APTES grafting new characteristic peaks, consistent with the incorporation of APTES, were formed. The peaks in the range 3000-2700 $\mathrm{cm}^{-1}$, due to the methyl and methylene stretches (Table 2) confirms the presence of the propyl chain of APTES. However, for the SPD method the presence of the weak peaks at 2968, 2870, $1387 \mathrm{~cm}^{-1}$, due to the different vibrations modes of the methyl group present in the ethoxy group, 
indicate that not all ethoxy groups were efficiently hydrolyzed. This means that either an incomplete siloxane hydrolysis has occurred or physically adsorbed nonhydrolyzed APTES was not effectively removed. For the VPD method only one of these bands, with lower intensity, can be observed $\left(2972 \mathrm{~cm}^{-1}\right)$, indicating that for VPD the majority of the alkoxy groups have reacted by hydrolysis and condensation reactions.

Table 2: FTIR wavenumbers $\left(\mathrm{cm}^{-1}\right)$ assignments of the main bands for APTES as grafted on $\gamma$-alumina flakes by solution phase deposition (SPD) and vapor phase deposition (VPD).

\begin{tabular}{|c|c|c|c|}
\hline APTES SPD & APTES VPD & Assignment & Ref. \\
\hline 2968 & 2972 & $\mathrm{CH}_{3}$ asymmetric stretching $\left(\mathrm{V}_{\mathrm{s}} \mathrm{CH}_{3}\right)$ & {$[13,21,29]$} \\
\hline 2927 & 2927 & $\mathrm{CH}_{2}$ asymmetric stretching $\left(\mathrm{V}_{\mathrm{as}} \mathrm{CH}_{2}\right)$ & {$[13,21,29]$} \\
\hline- & 2854 & $\mathrm{CH}_{2}$ symmetric stretching $\left(\mathrm{V}_{\mathrm{s}} \mathrm{CH}_{2}\right)$ & {$[13,21,29]$} \\
\hline 2870 & - & $\mathrm{CH}_{3}$ symmetric stretching $\left(\mathrm{V}_{\mathrm{s}} \mathrm{CH}_{3}\right)$ & {$[21,29]$} \\
\hline 1625 & - & Al-OH........ $\mathrm{NH}_{2}$ bending $\left(\delta \mathrm{NH}_{2}\right.$ hydrogen bonded $)$ & {$[14,42]$} \\
\hline 1555 & 1570 & $\mathrm{NH}_{2}$ bending (scissoring) $\left(\delta \mathrm{NH}_{2}\right)$ & {$[11,21,43]$} \\
\hline 1470 & 1460 & $\begin{array}{l}\mathrm{CH}_{2} \text { bending (scissoring) }\left(\delta \mathrm{CH}_{2}\right) \\
\text { and } \mathrm{CH}_{3} \text { (ethoxy) bending }\left(\mathrm{CH}_{3^{\prime}} \text { only for SPD) }\right.\end{array}$ & {$[13,29,43]$} \\
\hline 1410 & 1417 & Bending mode of $\mathrm{CH}_{2}$ directly attached to $\mathrm{Si}\left(\delta \mathrm{CH}_{2}\right)$ & {$[13,29,43]$} \\
\hline 1387 & - & $\mathrm{CH}_{3}$ (ethoxy) symmetric deformation $\left(\delta \mathrm{CH}_{3}\right)$ & {$[13,29]$} \\
\hline 1330 & - & $\mathrm{C}\left(\mathrm{CH}_{2}\right)$ deformation (wagging) $\left(\delta \mathrm{CH}_{2}\right)$ & [39] \\
\hline 1305 & - & $\mathrm{CH}_{2}$ twist-rock deformation $\left(\mathrm{TCH}_{2}\right)$ & [13] \\
\hline 1215 & 1211 & $\mathrm{Si}\left(\mathrm{CH}_{2}\right)$ wagging $\left(\omega \mathrm{CH}_{2}\right)$ & [43] \\
\hline 1161 & 1161 & $\mathrm{CH}_{2}$ twisting $\left(\mathrm{TCH}_{2}\right)$ & {$[43]$} \\
\hline $1070-990$ & 1080-990 & Si-O in-plane stretching (u Si-O-Si) & {$[13,29]$} \\
\hline 775 & 775 & Si- $C$ stretch (vSi-C) & \\
\hline 730 & 730 & $\mathrm{CH}_{2}$ rock-twist $\left(\mathrm{TCH}_{2}\right)$ & [39] \\
\hline
\end{tabular}

The presence of the propyl side chain of APTES is also confirmed by the appearance of peaks between $1500-1200 \mathrm{~cm}^{-1}$ and $800-700 \mathrm{~cm}^{-1}$. These regions are characterized by the bending, twisting, rocking and wagging vibration modes of the methylene group, as assigned in Table 2. The presence of a broad band centered at 1560-1550 $\mathrm{cm}^{-1}$ due to the bending of $\mathrm{NH}_{2}$ groups is a clear evidence for the presence of amine groups, proving the incorporation of the APTES onto the alumina flakes. In the case of SPD grafting another peak at $1625 \mathrm{~cm}^{-1}$ is present as well. Several authors have attributed this peak to the oxidation of the amine to form a bicarbonate salt in a reaction with atmospheric $\mathrm{CO}_{2}$, particularly when the samples were reacted and dried in air. However, in our case the reactions were performed under nitrogen and subsequently dried under nitrogen. Culler et al. [14, 
$41,42]$ have attributed this peak to the formation of a hydrogen-bonded coupling structure, formed between the Al-OH groups of the surface and/or with free silanol groups ( $\mathrm{Si}-\mathrm{OH})$ and the amine groups of the coupling agent. Therefore, the presence of this band might indicate the presence of hydrogen bonded species. Another, possible explanation is due to the presence of impurities as adsorption of some water molecules in the surface/thick siloxane network, capable of hydrogen bonding with $\mathrm{OH}$ surface groups that have not reacted with APTES, or/and with the amino group of the APTES molecules. This can lead to a band around $1630 \mathrm{~cm}^{-1}$. However given the intensity of this band and the absence in the FTIR for the APTES VPD grafted flakes (Figure 2) this does not seem to be a plausible explanation.

a)

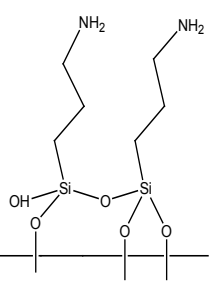

b)

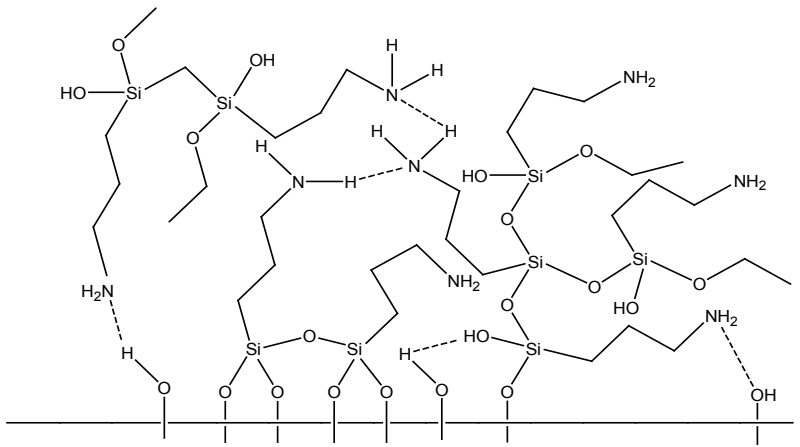

Figure 3: Possible types of bonding/interaction between aminopropyltriethoxysilane molecules and alumina substrates (a) horizontal polymerization (b) horizontal and vertical polymerization combined with hydrogen bonding between adjacent amino groups and with surface $\mathrm{OH}$ groups.

For the VPD system less intense bands are observed, especially the ones attributed to the methylene group and amino group, most probably due to a lower loading of the linker since one monolayer is expected in this case, whereas for the SPD a thick multilayer is expected. This is also confirmed by the broad and intense band observed for the SPD IR spectrum between 1100-900 $\mathrm{cm}^{-1}$ due to the Si-OSi stretching modes (symmetric and asymmetric) when compared with the VPD spectra (1080-1022 cm $)$. A possible explanation for the stronger appearance of $\mathrm{Si-O}-\mathrm{Si}$ stretching modes is that the deposition of silane from the liquid phase suffers from the deposition of aggregated alkylsilane molecules while in the vapor-phase method aggregate formation is prevented. Vertical polymerization (Figure 3) is avoided in the VPD case since oligomeric precursors in solution have a low vapor pressure and rarely vaporize [16]. For VPD only condensation reactions between adjacent silanes, bound to the surface, are possible (horizontal 
polymerization) resulting in a thin layer, whereas a thicker and more loosely bound layer is obtained by SPD (Figure 3). In solution-phase reactions APTES molecules can either covalently bond to the surface $\mathrm{OH}$ or/and with adjacent silanol groups, but the amino groups can also form hydrogen bonds with other amino or silanol groups of adjacent silanes and/or with the surface $\mathrm{OH}$ as illustrated in figure 3 . In conclusion, the presence of all the characteristic bands described above allows us to conclude that modified amino silalyted $\gamma$-alumina flakes were successfully obtained.

\section{Polydimethylsiloxane grafting}

By means of the successful grafting of APTES anchoring amine groups $\left(\mathrm{NH}_{2}\right)$ are introduced on the surface and pore wall of the alumina flakes. A PDMS grafted alumina flake can be obtained through a nucleophilic substitution reaction between these amine groups and the epoxy groups present on the polysiloxane polymer. This is achieved by epoxy ring opening.

The polysiloxane (mono(2,3-epoxy) polyetherterminated polydimethylsiloxane was chosen because of its low viscosity. A low viscosity polymer is preferable for a more efficient pore infiltration since the diffusion will be easier for such a system. The use of a monofunctional PDMS results in only one bond formation to the surface through the amino anchoring groups allowing the chain to stretch far from the surface, as desired. 
a)
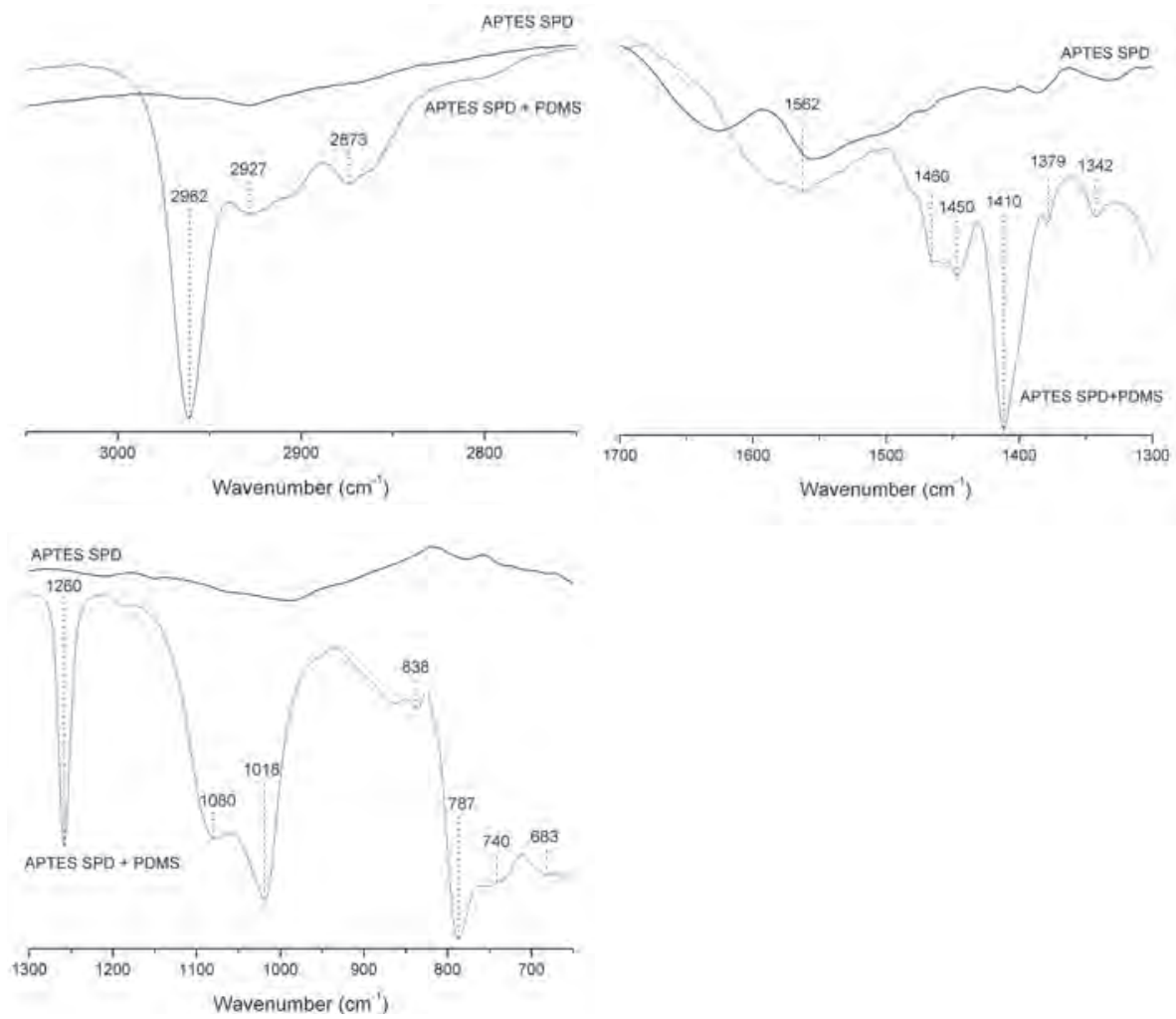

b)
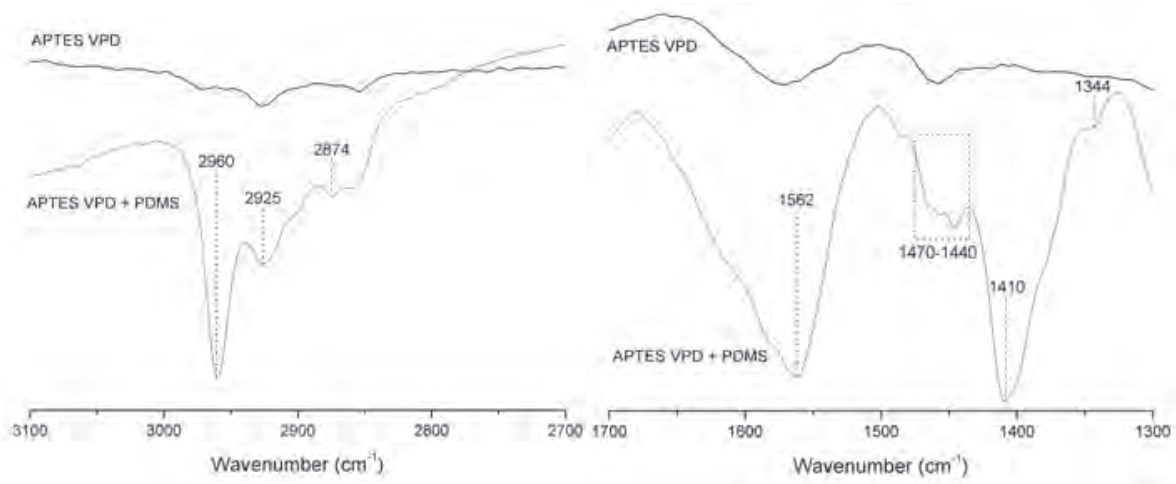


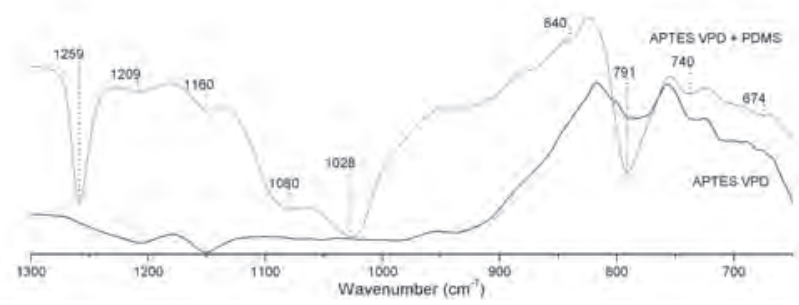

Figure 4: FTIR spectra for $\gamma$-alumina flakes modified with 3-aminopropyltriethoxysilane (APTES) by solution phase deposition (SPD) and by vapor phase deposition (VPD) and subsequently with mono (2,3-epoxy) polyether terminated polydimethylsiloxane for APTES modified by (a) SPD and (b) VPD.

Figure $4 \mathrm{a}$ and $\mathrm{b}$ display the FTIR results of PDMS grafted on alumina modified with APTES by SPD and VPD respectively. The wavenumbers and assignments of each vibrational mode are listed in Table 3. Due to PDMS grafting, new peaks appear between 3000-2800 $\mathrm{cm}^{-1}$, which confirms the presence of $\left(\mathrm{Si}-\mathrm{CH}_{3}\right)_{2}$ and $\mathrm{CH}_{2}$ and $\left(\mathrm{CH}_{2}\right)_{3}$ groups. In the region between 1500-800 $\mathrm{cm}^{-1}$ more intense bands are observed when compared with the linker IR spectra (Figure 2). This IR region corresponds to vibration modes for both methyl and methylene groups including a band at 1470-1440 $\mathrm{cm}^{-1}$ due to the $\mathrm{CH}_{2}$ scissoring mode and [37], a peak at 1410 $\mathrm{cm}^{-1}$ due to the asymmetric bending mode $\left(\delta_{\mathrm{as}} \mathrm{CH}_{3}\right)$ [44], a band at 1340-1330 $\mathrm{cm}^{-1}$ due to the twisting deformation mode of the methylene group $\left(\mathrm{\tau}_{\mathrm{CH}}\right)$ and finally three new peaks at $1260-1259 \mathrm{~cm}^{-1}, 840-838 \mathrm{~cm}^{-1}$ and $790 \mathrm{~cm}^{-1}$ due to the symmetric bending of the methyl groups connected to the silicon atom $\left(\delta_{\mathrm{s}} \mathrm{Si}-\right.$ $\left.\mathrm{CH}_{3}\right)$ [45]. The presence of all these bands proves the incorporation of the polymer on the flakes. As discussed before the VPD process results in the formation of an APTES monolayer. Less PDMS is expected to be grafted and therefore less intense bands were observed in the PDMS VPD IR spectra when compared with the PDMS SPD IR spectra as is confirmed by a more intense band at around 1200-1000 cm-1, due to the Si-O-Si stretch, for SPD when compared with VPD. Due to the presence of this broad band, the peak corresponding to the $\mathrm{C}-\mathrm{O}$ stretching band of the $\mathrm{CH}_{2}$ $\mathrm{O}-\mathrm{CH}_{2}$ bond in the polymer structure, expected at $1113 \mathrm{~cm}^{-1}$ is not observed [46]. The chemical modification through the reaction with the epoxy ring results in the formation of a secondary amine (figure 5), which is confirmed by FTIR through the deformation mode of the N-H group at around 1570-1560 $\mathrm{cm}^{-1}$ (Table 3). The PDMS grafting is proven by the absence of the anti-symmetric stretching vibration of the cyclic ether at around $910 \mathrm{~cm}^{-1}$ and the peak at $1289 \mathrm{~cm}^{-1}$ due to the symmetric stretching vibration of the cyclic ether. 


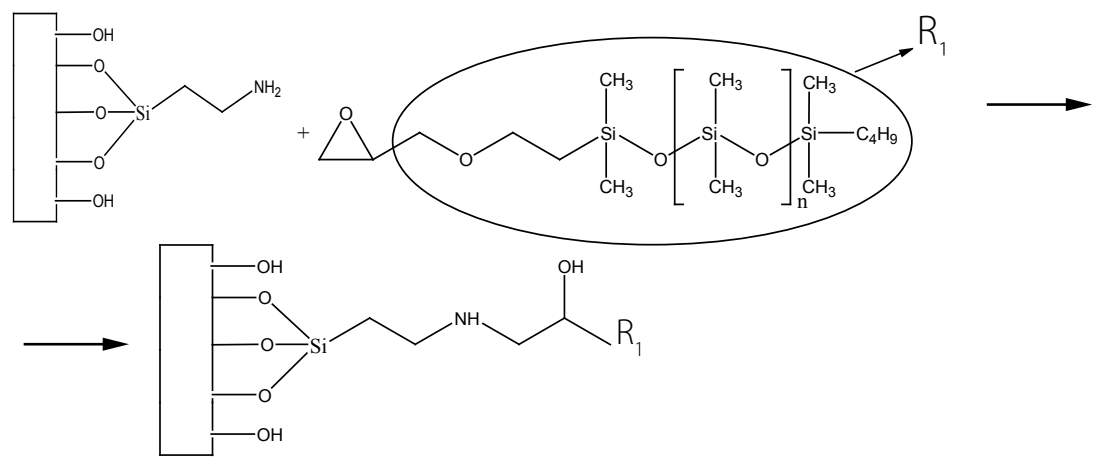

Figure 5: Schematic reaction between of 3-aminopropyltriethoxysilane (APTES) and the mono(2,3-epoxy) polyetherterminated polydimethylsiloxane (PDMS) on a $\gamma$-alumina surface.

From these IR data it can be concluded that all epoxy rings of PDMS have reacted completely with the amine group of the APTES via a covalent bonding $[35,46]$, resulting in a successful grafting of PDMS on APTES modified $\gamma$-alumina flakes.

Table 3: FTIR wavenumbers $\left(\mathrm{cm}^{-1}\right)$ assignments of the main bands for PDMS as grafted on Y-alumina flakes modified with APTES by solution phase deposition (SPD) and vapour phase deposition (VPD).

\begin{tabular}{|c|c|c|c|}
\hline PDMS SPD & PDMS VPD & Assignment & Ref. \\
\hline 2962 & 2960 & $\mathrm{CH}_{3}$ asymmetric stretching $\left(\mathrm{V}_{\text {as }} \mathrm{CH}_{3}\right)$ & {$[44,45]$} \\
\hline 2927 & 2925 & C-H stretch (v C-H) & {$[44,45]$} \\
\hline 2873 & 2874 & $\mathrm{CH}_{2}$ asymmetric stretching $\left(\mathrm{\delta} \mathrm{CH}_{2}\right)$ & {$[47]$} \\
\hline 1562 & 1562 & $\mathrm{NH}$ bending (scissoring) $(\mathrm{\delta} \mathrm{NH})$ & [45] \\
\hline $1460-1450$ & $1470-1440$ & $\mathrm{CH}_{2}$ bending (scissoring) $\left(\delta \mathrm{CH}_{2}\right)$ & {$[48]$} \\
\hline 1410 & 1410 & $\mathrm{CH}_{3}$ asymmetric bending mode of the $\mathrm{Si}-\mathrm{CH}_{3}\left(\delta \mathrm{C}-\mathrm{H}_{3}\right)$ & {$[44,48]$} \\
\hline 1342 & 1344 & $\mathrm{C}\left(\mathrm{CH}_{2}\right)$ wagging mode $\left(\omega \mathrm{CH}_{2}\right)$ & \\
\hline 1260 & 1259 & $\mathrm{CH}_{3}$ symmetric bending of the $\mathrm{Si}-\mathrm{CH}_{3}\left(\delta \mathrm{C}-\mathrm{H}_{3}\right)$ & {$[44,48]$} \\
\hline 1080 & 1080 & Si-O-Si symmetric stretching $\left(\mathrm{U}_{\mathrm{s}^{\prime}} \mathrm{u}_{\mathrm{s}} \mathrm{Si}-\mathrm{O}-\mathrm{Si}\right)$ & {$[45]$} \\
\hline 1018 & 1028 & Si-O-Si asymmetric stretching $\left.\left(\mathrm{U}_{\mathrm{as}} \cup_{\mathrm{as}} \mathrm{Si}-\mathrm{O}-\mathrm{Si}\right)\right)$ & \\
\hline 838 & 840 & $\mathrm{CH}_{3}$ rocking of the $\mathrm{Si}-\mathrm{CH}_{3}\left(\delta \mathrm{C}-\mathrm{H}_{3}\right)$ & [48] \\
\hline 787 & 791 & Si- $C$ stretch $(v S i-C)$ & \\
\hline 740 & 740 & $\mathrm{CH}_{3}$ rocking $\left(\delta \mathrm{CH}_{3}\right)+\mathrm{CH}_{2}$ rock-twist $\left(\mathrm{T}_{2}\right)$ & [44] \\
\hline 683 & 674 & Si- $C$ stretch $(v S i-C)$ & [44] \\
\hline
\end{tabular}

\subsubsection{Pore microstructure of grafted alumina flakes}

In order to evaluate the effect of different grafting moieties [24, 25] (e.g. nature, steric hindrance, hydrophobicity) and deposition methods [18, 24] on the morphology and structure of pores of the $\mathrm{y}$-alumina flakes, nitrogen adsorption/ 
desorption measurements were performed. Other parameters as texture of the porous flakes (i.e. the size and shape of the pores), the number of reactive sites, the silane concentration $[20,25]$ and the steric hindrance of the precursor molecules can also determine the amount of species grafted till saturation and have a direct impact on the structure and morphology of the modified material.

\section{Alkyl chain length}

Figure 6a shows the $\mathrm{N}_{2}$ adsorption-desorption isotherms of alumina flakes grafted with alkyltrichlorosilanes. For all samples the isotherms are characteristic for monolayer-multilayer adsorption followed by capillary condensation at $\mathrm{P} / \mathrm{P}_{0}=0.76$. This is typically for a type IV isotherm with an $\mathrm{H} 1$ hysteresis loop, associated with mesoporous materials with narrow necks and a relative low level of pore connectivity [17]. In addition the relative sharp increase in volume adsorbed at $\mathrm{P} / \mathrm{P}_{0}=0.76$ is indicative for the presence of uniform mesopores, resulting in a uniform pore size distribution, as calculated by the $\mathrm{BJH}$ method based on the desorption branch [49] (Figure 6b).

a

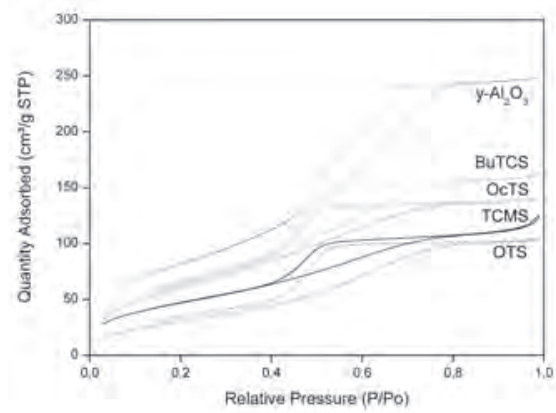

b

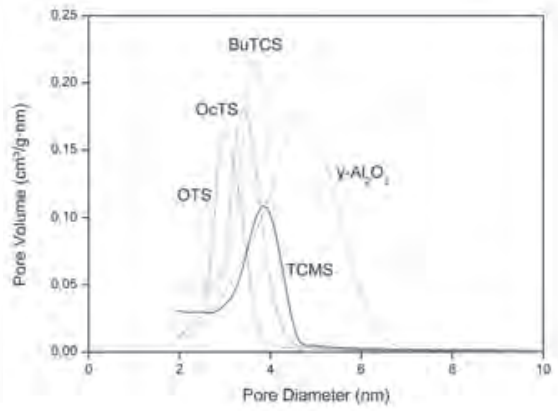

Figure 6: (a) $N_{2}$ physisorption isotherms for pure $\gamma$-alumina flakes and for materials modified with methyltrichlorosilane (TCMS), buthyltrichlorosilane (BuTCS), octyltrichlorosilane (OCTS) and octadecyltrichlorosilane (OTS) (b) Pore size distribution for pure $\gamma$-alumina flakes (A) and for materials modified with (B) buthyltrichlorosilane (BuTCS) (C) methyltrichlorosilane (TCMS), (D) octyltrichlorosilane (OcTS), (E) octadecyltrichlorosilane (OTS).

The mean pore diameter $\left(\mathrm{d}_{\mathrm{p}}\right)$, pore volume $\left(\mathrm{V}_{\mathrm{p}}\right)$ and BET surface area $\left(\mathrm{S}_{\mathrm{BET}}\right)$ values are included in Table 4. In all cases, after modification with alkylchlorosilanes, both BET surface area, mean pore diameter $\left(d_{p}\right)$ and pore volume $\left(V_{p}\right)$ values decrease if compared with the unmodified flakes, meaning that not only the surface of the alumina flakes but also the inner pore walls were grafted. 
Table 4: Mean mesopore diameter (Mean $d_{p}$ ), from BJH fit, pore volume $\left(V_{p}\right)$ and surface area $A$ for pure $\gamma$-alumina flakes (AF) and materials modified with methyltrichlorosilane (TCMS), buthyltrichlorosilane (BuTCS), octyltrichlorosilane (OcTS) and octadecyltrichlorosilane (OTS).

\begin{tabular}{lccc}
\hline & $\begin{array}{c}\text { Mean } \mathbf{d}_{\mathbf{p}} \\
(\mathbf{n m})\end{array}$ & $\begin{array}{c}\boldsymbol{V}_{\mathbf{p}} \\
\left(\mathbf{c m}^{\mathbf{3}} \mathbf{g}^{-1}\right)\end{array}$ & $\begin{array}{c}\boldsymbol{A}\left(\mathbf{N}_{\mathbf{2}}\right) \\
\left(\mathbf{m}^{2} \mathbf{g}^{-1}\right)\end{array}$ \\
\hline AF & 4.7 & 0.39 & 280 \\
AF+TCMS & 3.9 & 0.17 & 121 \\
AF+BuTCS & 3.7 & 0.29 & 249 \\
AF+OCTS & 3.4 & 0.23 & 234 \\
AF+OTS & 2.9 & 0.19 & 102 \\
\hline
\end{tabular}

As expected, with increasing hydrocarbon side chain length a larger reduction in pore volume, pore size and surface area is observed in the order of $C_{4}$ (BUTCS), via $C_{8}$ (OCTS) to $\mathrm{C}_{6}$ (OTS). However, for the TCMS $\left(C_{1}\right)$, which contains only one methyl groups as side chain, the some of the lowest values are attained for both pore volume and surface area, being $0.17 \mathrm{~cm}^{3} \mathrm{~g}^{-1}$ and $121 \mathrm{~m}^{2} \mathrm{~g}^{-1}$, respectively. A possible explanation for this is the formation of a polymerized network or multilayer deposition. The presence of traces of water present in the solvent (even though an anhydrous solvent was used) and of three chlorine groups on TCMS easily results in condensation reactions between adjacent silanes prior to surface reaction resulting and subsequently a higher degree of pore filling. The formation of these multilayer systems is confirmed for all cases by the Si-O-Si asymmetric and symmetric stretching band in the FTIR spectrum (Figure 1). Furthermore, as expected OTS $\left(C_{18}\right)$ presents the highest reduction on both surface area, pore size and pore volume when compared with smaller silanes as OcTS $\left(C_{8}\right)$ and BuTCS $\left(C_{4}\right)$ These results are in agreement with the results reported by Pinheiro et al. [50], where $\mathrm{TiO}_{2}$ membranes with a pore size of $4 \mathrm{~nm}$ were modified with different trichlorosilanes using the same reaction conditions. XPS measurements showed 3 - 4 times higher Si atomic concentration from the surface till $100 \mathrm{~nm}$ inside the porous structure for TCMS $\left(6.9 \times 10^{-5} \mathrm{~mol} \mathrm{~m}^{-2}\right)$ if compared with BuTCS, OcTS and OTS. Furthermore, in this reference it is shown that a uniform modification could be achieved along the pores.

\section{APTES linker deposition}

The $\mathrm{N}_{2}$ adsorption-desorption isotherms of alumina flakes grafted with 3-aminopropyltriethoxysilane (APTES) via solution phase deposition (SPD) and vapor phase deposition are presented in Figure 7a and Figure 8a, respectively. 
a

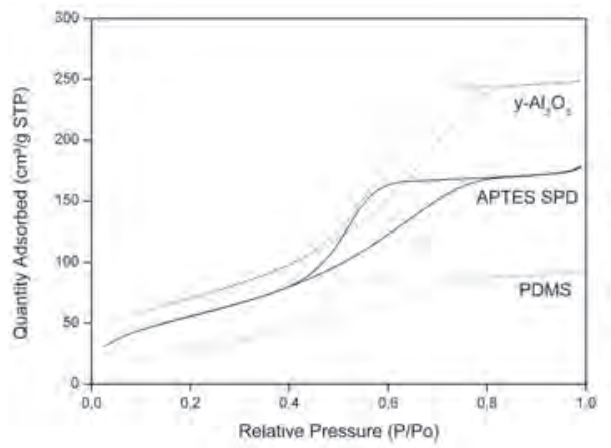

b

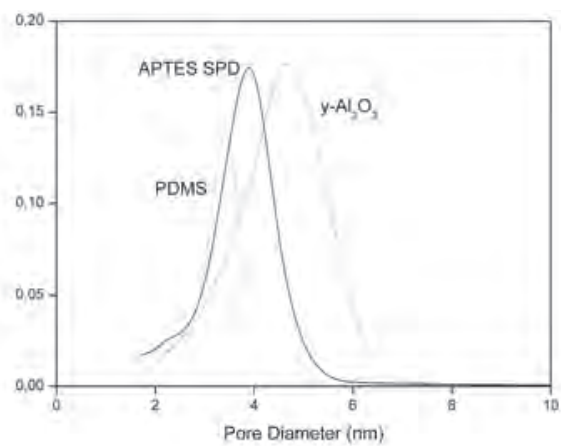

Figure 7: (a) $\mathrm{N}_{2}$ physisorption isotherms and (b) Pore size distribution curves for pure $\gamma$-alumina flakes and for materials modified with 3-aminopropyltriethoxysilane (APTES) via solution phase deposition (SPD) and subsequently with PDMS, by using APTES as a linker for PDMS grafting.

a

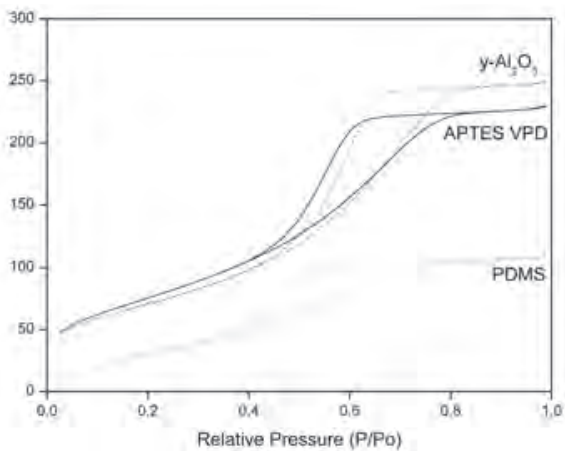

b

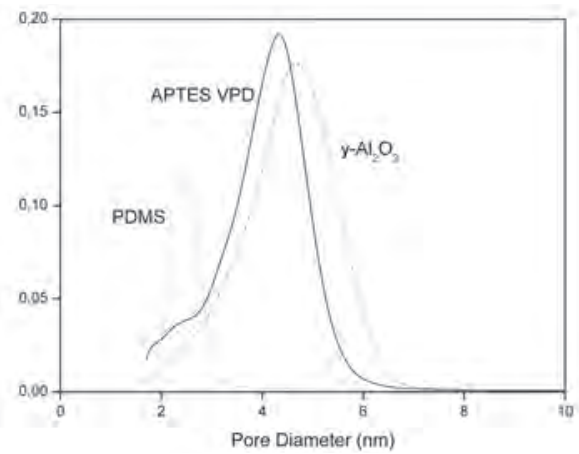

Figure 8: (a) $\mathrm{N}_{2}$ physisorption isotherms (b) Pore size distribution for pure $\gamma$-alumina flakes and for materials modified with 3-aminopropyltriethoxysilane (APTES) via vapor phase deposition (VPD) and subsequently with PDMS, by using APTES as a linker for PDMS grafting.

It can be seen that for both systems a type IV isotherm with an $\mathrm{H} 1$ hysteresis loop was obtained, indicating the presence of mesopores. The pore size distribution curves show for both methods a uniform and sharp pore size distribution (Figure $7 \mathrm{~b}$ and $8 \mathrm{~b})$. The BET surface area $\left(\mathrm{S}_{\mathrm{BET}}\right)$, mesopore volume $\left(\mathrm{V}_{\mathrm{p}}\right)$ and mean pore size $\left(d_{p}\right)$ values are given in Table 5.

For the SPD and VPD method a decrease in pore size is observed of $0.9 \mathrm{~nm}$ and 0.4 $\mathrm{nm}$ respectively if compared with the unmodified alumina flakes. A reduction in pore volume and surface area of around $28 \%$ and $18 \%$ is respectively attained in the case of SPD, whereas for VPD a less pronounced reduction of $5 \%$ for pore volume and 2 $\%$ for surface area is obtained. All these results are an indication that the pores within 
the alumina flakes become more densely filled with ATPTES by using SPD due to the possible formation of a multilayer system whereas with VPD only a monolayer might be formed. The presence of a multilayer APTES system is also confirmed by the SPD FTIR spectra (Figure 2) showing a broad Si-O-Si stretching band, due to polycondensation reactions between adjacent silanes. Here the three hydrolysable ethoxy groups can react, in the presence of traces of water, either with the surface hydroxyl groups and/or with adjacent silanes, forming a thick polymeric network and thus a strong reduction in pore size and pore volume. Ritter et al. [18] have shown that, while the water content has no effect on surface silane loading, a strong pore blocking is promoted in the presence of water due to cross-linking of silane molecules. On the other hand, the tendency towards aggregation (island formation) is expected to be less pronounced in the vapor phase deposition, as discussed before [51]. A monolayer can more easily be achieved for VPD, resulting in a lower decrease in pore volume, pore size and surface area when compared with SPD methods.

Table 5: Mean mesopore diameter (Mean $\left.d_{p}\right)$ from BJH fit $\left(d_{p} B J H\right)$, pore volume $\left(v_{p}\right)$ and surface area $(A)$ for pure $\gamma$-alumina flakes and flakes modified with 3-aminopropyltriethoxysilane (APTES) via solution phase deposition (SPD) and by vapor phase deposition (VPD) and subsequently with PDMS, by using the APTES as a linker for PDMS grafting.

\begin{tabular}{lccc}
\hline & $\begin{array}{c}\text { Mean } \mathbf{d}_{\mathbf{p}} \\
(\mathbf{n m})\end{array}$ & $\begin{array}{c}\mathbf{V}_{\mathbf{p}} \\
\left(\mathbf{c m}^{\mathbf{3}^{-1}} \mathbf{\mathbf { g } ^ { - 1 }}\right.\end{array}$ & $\begin{array}{c}\mathbf{A}\left(\mathbf{N}_{\mathbf{2}}\right) \\
\left(\mathbf{m}^{2} \mathbf{g}^{-1}\right)\end{array}$ \\
\hline AF (Alumina Flakes) & 4.8 & 0.39 & 256 \\
AF+APTES SPD & 3.8 & 0.28 & 211 \\
AF+APTES SPD +PDMS & 3.5 & 0.18 & 120 \\
AF+APTES VPD & 4.2 & 0.37 & 252 \\
AF+APTES VPD +PDMS & 2.2 & 0.12 & 106 \\
\hline
\end{tabular}

\section{Polydimethylsiloxane grafting}

The adsorption/desorption isotherms for PDMS grafted on alumina flakes modified by APTES with VPD and SPD are presented in Figure 7a and 8a, respectively. For both methods a type IV isotherm is still obtained. A clear reduction in pore volume is observed when the polymer is grafted onto the linker modified surface, $36 \%$ for SPD and $68 \%$ for VPD, indicating that modification has indeed occurred inside the pores and that the modification was uniform in a sense that the pore structure remained intact and no microporosity was observed.

In addition, for both cases, a decrease in pore size was achieved (see Table 5 and 
Figures $7 \mathrm{~b}$ and $8 \mathrm{~b}$ ), also confirming the presence of PDMS inside the pores. For the VPD system a stronger reduction in pore size is achieved than for the SPD system. Due the formation of an APTES monolayer more space is available for the diffusion of the polymer inside the pores for VPD while the multilayer deposition of APTES by SPD hampers diffusion of PDMS into the pores. In conclusion, the gas adsorption/ desorption results on PDMS grafted membranes show that a deposition of the linker through a VPD method is preferable for obtaining well-grafted PDMS systems.

\subsubsection{Thermal stability of the grafted alumina systems}

In Figure 9a thermogravimetric analysis (TGA) results are presented for alumina flakes grafted with different alkyltrichlorosilanes.

a

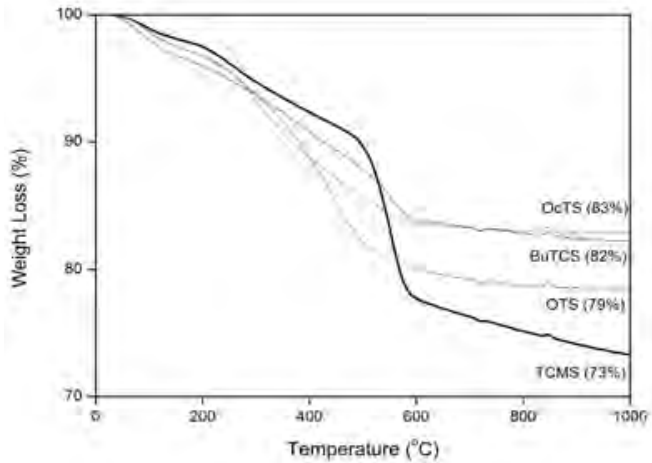

b

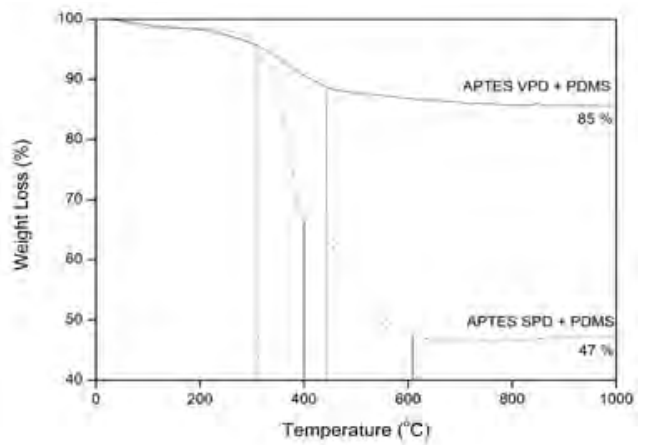

Figure 9: TGA of $\gamma$-alumina flakes modified with a) different trichlorosilanes as octadecyltrichlorosilane (OTS), octyltrichlorosilane (OcTS), buthyltrichlorosilane (BUTCS) and methyltrichlorosilane (TCMS), b) with 3-aminopropyltriethoxysilane (APTES) by solution phase deposition (SPD) and vapor phase deposition (VPD) followed by grafting with PDMS. 
All flakes show a constant, slight weight loss up to $200{ }^{\circ} \mathrm{C}$ that can be assigned to absorbed water on the surface and inside the mesopores of the material. Above this temperature, larger silanes, like OTS, OcTS and BuTCS, show a weight loss of around $20 \%$ for OTS, $16 \%$ for OCTS and $17 \%$ for BUTCS in the temperature range of 280 to $600{ }^{\circ} \mathrm{C}$. Similar results were obtained by Fadeev at al. [52]. However, for TCMS, the maximum decrease in weight is shifted towards higher temperatures, showing the most significant weight loss in the range of 470 to $600{ }^{\circ} \mathrm{C}$. For the TCMS-grafted system it is also remarkable that a total weight loss of almost $25 \%$ is observed. This larger weight loss for the TCMS system is in agreement with the stronger formation of a polymerized network or multilayer deposition for TCMS if compared with the higher alkyl chains as confirmed by FTIR and $\mathrm{N}_{2}$-adsoroption/ desorption.

Figure 9b shows TGA results for $\gamma$-alumina flakes modified with APTES and subsequently PDMS. For both types of grafted powders (VPD and SPD) a small weight loss of $4 \%$ up to $340{ }^{\circ} \mathrm{C}$ is observed that can be related to adsorbed water of the modified $\gamma$-alumina surface, trapped ethanol and partial decomposition of unreacted APTES and/or PDMS. These TGA results indicate that the $\gamma$-alumina flakes modified by VPD and SPD are thermally stable up till $340{ }^{\circ} \mathrm{C}$. The decomposition temperatures as observed in this work (around $340{ }^{\circ} \mathrm{C}$ ) is higher than the boiling points of the individual liquids (APTES, b.p. $=217^{\circ} \mathrm{C}$ and PDMS, b.p. $=205^{\circ} \mathrm{C}$ ). Therefore, an increase in thermal stability is observed after modification. This supports that the aminopropyl and siloxane groups are chemically bonded to the alumina flakes.

For alumina flakes, modified with APTES by VPD and subsequently with PDMS, a second stage of mass loss is observed between 340 till $500{ }^{\circ} \mathrm{C}$ accounts around 12 $\%$. This weight loss represents the degradation of the organic groups. After heating up to $1000{ }^{\circ} \mathrm{C}$ an overall weight loss of $15 \%$ for VPD is observed, though most of the weight loss was observed up till $600{ }^{\circ} \mathrm{C}$.

For flakes modified by SPD two distinct stages of significant weight loss can be seen above $340{ }^{\circ} \mathrm{C}$. The first one is observed at around $400{ }^{\circ} \mathrm{C}$ with a total weight loss of $34 \%$. After heating up to about $600{ }^{\circ} \mathrm{C}$, the overall weight loss is $43 \%$ for SPD, while for VPD only $15 \%$ is observed. The much stronger decrease in weight for SPD modified flakes compared to the VPD ones cannot be explained by the decomposition of the polymer as grafted in the mesopores. It is assumed that the $\gamma$-alumina flakes are agglomerated in such a way that they enclose the mesopores as observed by $\mathrm{N}_{2}$ adsorption/desorption. During the grafting procedure not only 
the internal pores are grafted but also the outer surface of the agglomerates. For the SPD-derived flakes it is obvious that multilayer formation on the outer surface of APTES is much more pronounced than for VPD-derived flakes, which explains the much stronger weight decrease for the SPD-derived systems. As was shown by FTIR (Figure 4a) a more intense band is obtained for the Si-O-Si stretching mode due to polycondensation reactions.

\subsubsection{Chemical Stability}

The grafted materials were soaked in different solvents for seven days in order to access if the systems are stable under harsh conditions. FTIR was performed and the disappearance of the main characteristic bands for the grafted systems or the presence of new bands was assigned as possible degradation of the grafted flakes. For the alkyltrichlorosilanes, toluene, hexane and isopropanol were used. For toluene all the characteristics bands were present (results not shown). Powders soaked in isopropanol and hexane showed degradation of some of the bands. FTIR spectra before and after soaking of the PDMS grafted $\gamma$-alumina powders in different solvents are presented in Figure 10, which include hexane, toluene, isopropanol and dichloromethane.

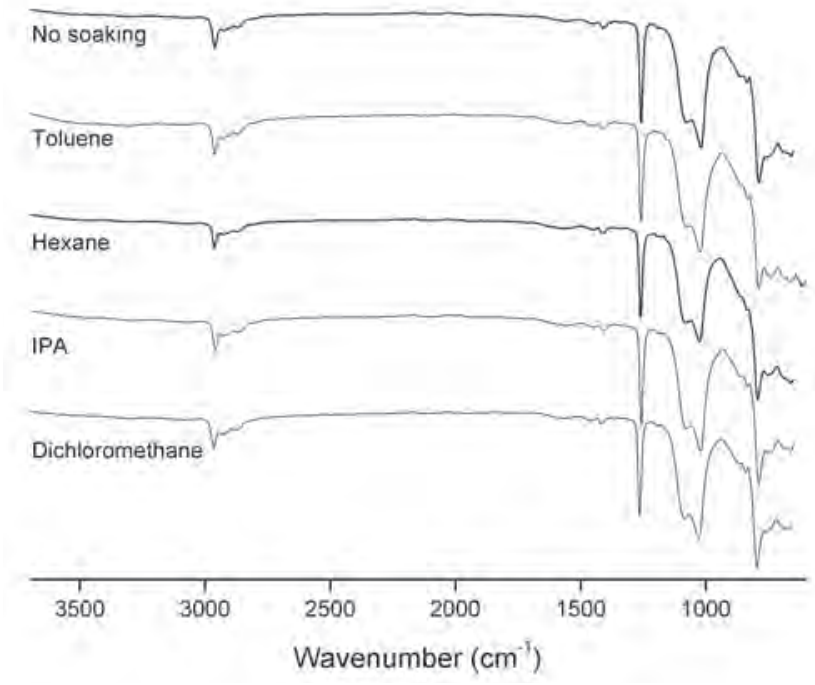

Figure 10: FTIR spectra for $\gamma$-alumina dense powders modified with PDMS by using APTES as the linker before and after 7 days soaking in several organic solvents as: toluene, hexane, isopropanol, dichloromethane. In Table 6 a complete list of all the solvents tested and the respective stability is presented. 
Table 6: Stability tests for $Y$-alumina flakes modified with mono(2,3-epoxy)polyether terminated polydimethylsiloxane (A) methyltrichlorosilane (B), buthyltrichlorosilane (C), octyltrichlorosilane (D), and octadecyltrichlorosilane (E) after 7 days soaking in different solvents. $+=$ stable, $+/$ - = some degree of degradation, - = degradation (not stable)

\begin{tabular}{|c|c|c|c|c|c|c|c|c|c|c|}
\hline & Chloroform & THF & Acetone & $\mathrm{MeOH}$ & ButOH & NMP & DMF & Toluene & Hexane & IPA \\
\hline A & + & + & + & + & + & $+/-$ & + & + & + & + \\
\hline B & & & Stability & not tested & & & & + & + & - \\
\hline C & & & Stability & not tested & & & & + & $+/-$ & - \\
\hline D & & & Stability & not tested & & & & + & $+/-$ & - \\
\hline E & & & Stability & not tested & & & & + & + & $+/$ \\
\hline
\end{tabular}

In all solvents, the characteristic bands attributed to the successful incorporation of both APTES and PDMS are present. Therefore, this PDMS surface modification presents a promising grafting route for the preparation of solvent resistance nanofiltration membranes. The alkylchlorosilane-grafted systems are less stable in protic solvents like IPA, but show no degradation in toluene. The latter observation is again a prove that alkyltrichlorosilanes are grafted on alumina as toluene is used for dissolving the precursors during the grafting reaction.

\subsection{Conclusions}

In this study grafting through silylation of alumina flakes has proven to be a suitable approach for engineering both surface chemistry and pore size. In the first grafting route, $Y$-Alumina flakes were grafted with alkyltrichlorosilanes with different chain lengths at room temperature. Both the pores and the surface were grafted, however their low stability in organic protic solvents hampers their application where solvent resistance is a requirement. Therefore, another grafting route was designed. This involved the use of an aminosilane as a linker (APTES) followed by the attachment of PDMS. The final product was a PDMS grafted flake. PDMS grafted alumina flakes are attained through a two-step grafting method using APTES as linker, applied by either vapor phase deposition or solution phase deposition and subsequent with a mono-epoxy PDMS. By using these methods PDMS was grafted on both the external surface walls and the internal pore wall. Through the use of a vapor phase deposition technique for linker deposition a more controlled deposition can be achieved when compared to the solution phase method. The vapor phase deposition method resulted in a thinner and more uniform layer of the linker and thus more free space for efficient diffusion 
of the PDMS polymer into the pores. Alumina flakes grafted with PDMS by either applying the SPD or VPD method for the linker, were stable at temperatures up to $380^{\circ} \mathrm{C}$. Stability tests show that the PDMS grafted alumina powders are stable in a wide range of solvents, even though for a harsh solvent as NMP some degradation could be observed. Therefore, this approach of PDMS grafting shows a promising way for solvent filtration, particularly in the nanofiltration range, where hydrophobic surfaces and solvent resistant systems are required.

\section{Acknowledgement}

This is an ISPT project (Institute for Sustainable Process Technology). 


\subsection{References}

1. Randon, J. and R. Paterson, Preliminary studies on the potential for gas separation by mesoporous ceramic oxide membranes surface modified by alkyl phosphonic acids. Journal of Membrane Science, 1997. 134(2): p. 219-223.

2. Randon, J., P. Blanc, and R. Paterson, Modification Of Ceramic Membrane Surfaces Using Phosphoric-Acid And Alkyl Phosphonic-Acids And Its Effects On Ultrafiltration Of Bsa Protein. Journal of Membrane Science, 1995. 98(1-2): p. 119-129.

3. Caro, J., M. Noack, and P. Kolsch, Chemically modified ceramic membranes. Microporous and Mesoporous Materials, 1998. 22(1-3): p. 321-332.

4. Vioux, A., et al., Hybrid Organic-Inorganic Materials Based on Organophosphorus Derivatives, New Aspects in Phosphorus Chemistry IV, J-P. Majoral Editor, 2004, Springer Berlin/Heidelberg, p145-174

5. Sah, A., et al., Hydrophobic modification of gamma-alumina membranes with organochlorosilanes. Journal of Membrane Science, 2004. 243(1-2): p. 125-132.

6. Younssi, S.A., et al., gamma alumina membranes grafting by organosilanes and its application to the separation of solvent mixtures by pervaporation. Separation and Purification Technology, 2003. 32(1-3): p. 175-179.

7. Leger, C., H.D. Lira, and R. Paterson, Preparation and properties of surface modified ceramic membranes .3. Gas permeation of $5 \mathrm{~nm}$ alumina membranes modified by trichlorooctadecylsilane. Journal of Membrane Science, 1996. 120(2): p. 187-195.

8. Leger, C., H.D. Lira, and R. Paterson, Preparation and properties of surface modified ceramic membranes .2. Gas and liquid permeabilities of $5 \mathrm{~nm}$ alumina membranes modified by a monolayer of bound polydimethylsiloxane (PDMS) silicone oil. Journal of Membrane Science, 1996. 120(1): p. 135-146.

9. Zengin, A., at al., Formation and Properties of Surface-Anchored Amine-Terminated Poly(dimethylsiloxane) Assemblies with Tunable Physico-Chemical Characteristics, Thin Solid Films, 2011, 519, p. 3135-3140

10. Eur. Pat., EP053616, 2010

11. Vandenberg, E.T., et al., Structure Of 3-Aminopropyl Triethoxy Silane On Silicon-Oxide. Journal of Colloid and Interface Science, 1991. 147(1): p. 103-118.

12. Cain, J.F. and E. Sacher, Auger-Electron Spectroscopy Of Deposited Silane Layers. Journal of Colloid and Interface Science, 1978. 67(3): p. 538-540.

13. Kurth, D.G. and T. Bein, Thin-Films Of (3-Aminopropyl)Triethoxysilane On Aluminum-Oxide And Gold Substrates. Langmuir, 1995. 11(8): p. 3061-3067.

14. Culler, S.R., H. Ishida, and J.L. Koenig, Structure Of Silane Coupling Agents Adsorbed On Silicon Powder. Journal of Colloid and Interface Science, 1985. 106(2): p. 334-346.

15. Brzoska, J.B., I. Benazouz, and F. Rondelez, Silanization Of Solid Substrates - A Step Toward Reproducibility. Langmuir, 1994. 10(11): p. 4367-4373.

16. Haller, I., Covalently Attached Organic Monolayers On Semiconductor Surfaces. Journal of the American Chemical Society, 1978. 100(26): p. 8050-8055.

17. Sing, K.S.W., et al., Reporting Physisorption Data For Gas Solid Systems With Special Reference To The Determination Of Surface-Area And Porosity (Recommendations 1984). Pure and Applied Chemistry, 1985. 57(4): p. 603-619.

18. Ritter, H., et al., A comparative study of the functionalization of mesoporous silica MCM-41 by deposition of 3-aminopropyltrimethoxysilane from toluene and from the vapor phase. Microporous and Mesoporous Materials, 2009. 121(1-3): p. 79-83.

19. Fadeev, A.Y. and T.J. McCarthy, Self-assembly is not the only reaction possible between alkyltrichlorosilanes and surfaces: Monomolecular and oligomeric covalently attached layers of dichloro- and trichloroalkylsilanes on silicon. Langmuir, 2000. 16(18): p. 7268-7274.

20. Luan, Z.H., et al., Preparation and characterization of (3-aminopropyl)triethoxysilanemodified mesoporous SBA-15 silica molecular sieves. Microporous and Mesoporous 
Materials, 2005. 83(1-3): p. 150-158.

21. Ek, S., E.I. liskola, and L. Niinisto, Gas-phase deposition of aminopropylalkoxysilanes on porous silica. Langmuir, 2003. 19(8): p. 3461-3471.

22. Vrancken,K.C.,etal.,Influence ofwaterinthereaction of [gamma]-aminopropyltriethoxysilane with silica gel. A Fourier-transform infrared and cross-polarisation magic-angle-spinning nuclear magnetic resonance study. Journal of the Chemical Society, Faraday Transactions, 1992. 88(21).

23. Chiang, C.H., N.I. Liu, and J.L. Koenig, Magic-Angle Cross-Polarization C-13 Nmr-Study Of Aminosilane Coupling Agents On Silica Surfaces. Journal of Colloid and Interface Science, 1982. 86(1): p. 26-34.

24. Salmio, H. and D. Bruhwiler, Distribution of amino groups on a mesoporous silica surface after submonolayer deposition of aminopropylsilanes from an anhydrous liquid phase. Journal of Physical Chemistry C, 2007. 111(2): p. 923-929.

25. Chong, A.S.M., et al., Functionalization of large-pore mesoporous silicas with organosilanes by direct synthesis. Microporous and Mesoporous Materials, 2004. 72(1-3): p. 33-42.

26. Alami-Younssi, S., et al., Grafting gamma alumina microporous membranes by organosilanes: Characterisation by pervaporation. Journal of Membrane Science, 1998. 143(1-2): p. 27-36.

27. Chiang, C.H. and J.L. Koenig, Fourier-Transform Infrared Spectroscopic Study Of The Adsorption Of Multiple Amino Silane Coupling Agents On Glass Surfaces. Journal of Colloid and Interface Science, 1981. 83(2): p. 361-370.

28. Boerio, F.J., L.H. Schoenlein, and J.E. Greivenkamp, Adsorption Of GammaAminopropyltriethoxysilane Onto Bulk Iron From Aqueous-Solutions. Journal of Applied Polymer Science, 1978. 22(1): p. 203-213.

29. Chiang, C.H.,H. Ishida, and J.L. Koenig, The Structure Of Gamma-Aminopropyltriethoxysilane On Glass Surfaces. Journal of Colloid and Interface Science, 1980. 74(2): p. 396-404.

30. N. Benes, A. Nijmeijer, H. verweij in : N. K. Kanellopoulos (Ed. ), Recent Advences In Gas Separation by Microporous Ceramic Membranes, Elsevier, Amsterdam, 2000, p. 335

31. Yoshida, W., et al., Multilayer alkoxysilane silylation of oxide surfaces. Langmuir, 2001. 17(19): p. 5882-5888.

32. Kanan, S.A., W.T.Y. Tze, and C.P. Tripp, Method to double the surface concentration and control the orientation of adsorbed (3-aminopropyl)dimethylethoxysilane on silica powders and glass slides. Langmuir, 2002. 18(17): p. 6623-6627.

33. Snyder, R.G., H.L. Strauss, and C.A. Elliger, C-H Stretching Modes And The Structure Of Normal-Alkyl Chains .1. Long, Disordered Chains. Journal of Physical Chemistry, 1982. 86(26): p. 5145-5150.

34. Macphail, R.A., et al., C-H Stretching Modes And The Structure Of Normal-Alkyl Chains .2. Long, All-Trans Chains. Journal of Physical Chemistry, 1984. 88(3): p. 334-341.

35. A.Lee, S., Infrared spectra-structure correlations for organosilicon compounds. Spectrochimica Acta, 1960. 16(1-2): p. 87-105.

36. Wang, R.W., G. Baran, and S.L. Wunder, Packing and thermal stability of polyoctadecylsiloxane compared with octadecylsilane monolayers. Langmuir, 2000. 16(15): p. 6298-6305.

37. Choi, J., N.S. Wang, and V. Reipa, Electrochemical Reduction Synthesis of Photoluminescent Silicon Nanocrystals. Langmuir, 2009. 25(12): p. 7097-7102.

38. Snyder, R.G. and J.H. Schachtschneider, Vibrational Analysis Of The N-Paraffins .1. Assignments Of Infrared Bands In The Spectra Of $\mathrm{C}_{3} \mathrm{H}_{8}$ Through N-C ${ }_{19} \mathrm{H}_{40}$. Spectrochimica Acta, 1963. 19(1): p. 85-116.

39. Murata, H., et al., Vibrational-Spectra, Normal Vibrations And Rotational-Isomerism Of Alkylsilanes .1. Propylsilane, Butylsilane And Their Si-Perdeuterium Compounds. Journal of Molecular Structure, 1979. 52(1): p. 1-11.

40. Tripp, C.P. and M.L. Hair, Reaction Of Chloromethylsilanes With Silica - A Low-Frequency Infrared Study. Langmuir, 1991. 7(5): p. 923-927.

41. Culler, S.R., et al., Analytical And Spectroscopic Investigation OfThe Interaction Of $\mathrm{CO}_{2}$ With Amine Functional Silane Coupling Agents On Glass-Fibers. Journal of Colloid and Interface Science, 1983. 96(1): p. 69-79. 
42. Culler, S.R., H. Ishida, and J.L. Koenig, Ft-Ir Characterization Of The Reaction At The Silane Matrix Resin Interphase Of Composite-Materials. Journal of Colloid and Interface Science, 1986. 109(1): p. 1-10.

43. Weigel, C. and R. Kellner, Ftir-Atr-Spectroscopic Investigation Of The Silanization Of Germanium Surfaces With 3-Aminopropyltriethoxysilane. Fresenius Zeitschrift Fur Analytische Chemie, 1989. 335(7): p. 663-668.

44. Leites, L.A., et al., Vibrational And Electronic-Spectra And The Structure Of Crystalline Poly(Dimethylsilane). Macromolecules, 1992. 25(11): p. 2991-2993.

45. Enescu, D., et al., Polydimethylsiloxane-modified chitosan I. Synthesis and structural characterisation of graft and crosslinked copolymers. Journal of Polymer Research, 2009. 16(1): p. 73-80.

46. Enescu, D., et al., Polydimethylsiloxane modified chitosan. Part III: Preparation and characterization of hybrid membranes. Carbohydrate Polymers, 2009. 76(2): p. 268-278.

47. Durdureanu-Angheluta, A., et al., Synthesis and characterization of magnetite particles covered with alpha-trietoxysilil-polydimethylsiloxane. Journal of Magnetism and Magnetic Materials, 2010. 322(19): p. 2956-2968.

48. Fadeev, A.Y. and Y.V. Kazakevich, Covalently Attached Monolayers of Oligo(dimethylsiloxane) s on Silica: A Siloxane Chemistry Approach for Surface Modification. Langmuir, 2002. 18(7): p. 2665-2672.

49. Barrett, E.P., L.G. Joyner, and P.P. Halenda, The Determination Of Pore Volume And Area Distributions In Porous Substances .1. Computations From Nitrogen Isotherms. Journal of the American Chemical Society, 1951.73(1): p. 373-380.

50. Pinheiro, F.M. Ana, Chapter 3.

51. Sharma, K.K., et al., Toward efficient nanoporous catalysts: Controlling site-isolation and concentration of grafted catalytic sites on nanoporous materials with solvents and colorimetric elucidation of their site-isolation. Journal of the American Chemical Society, 2008. 130(1): p. 218-228.

52. Fadeev, A.Y., R. Helmy, and S. Marcinko, Self-assembled monolayers of organosilicon hydrides supported on titanium, zirconium, and hafnium dioxides. Langmuir, 2002. 18(20): p. 7521-7529. 



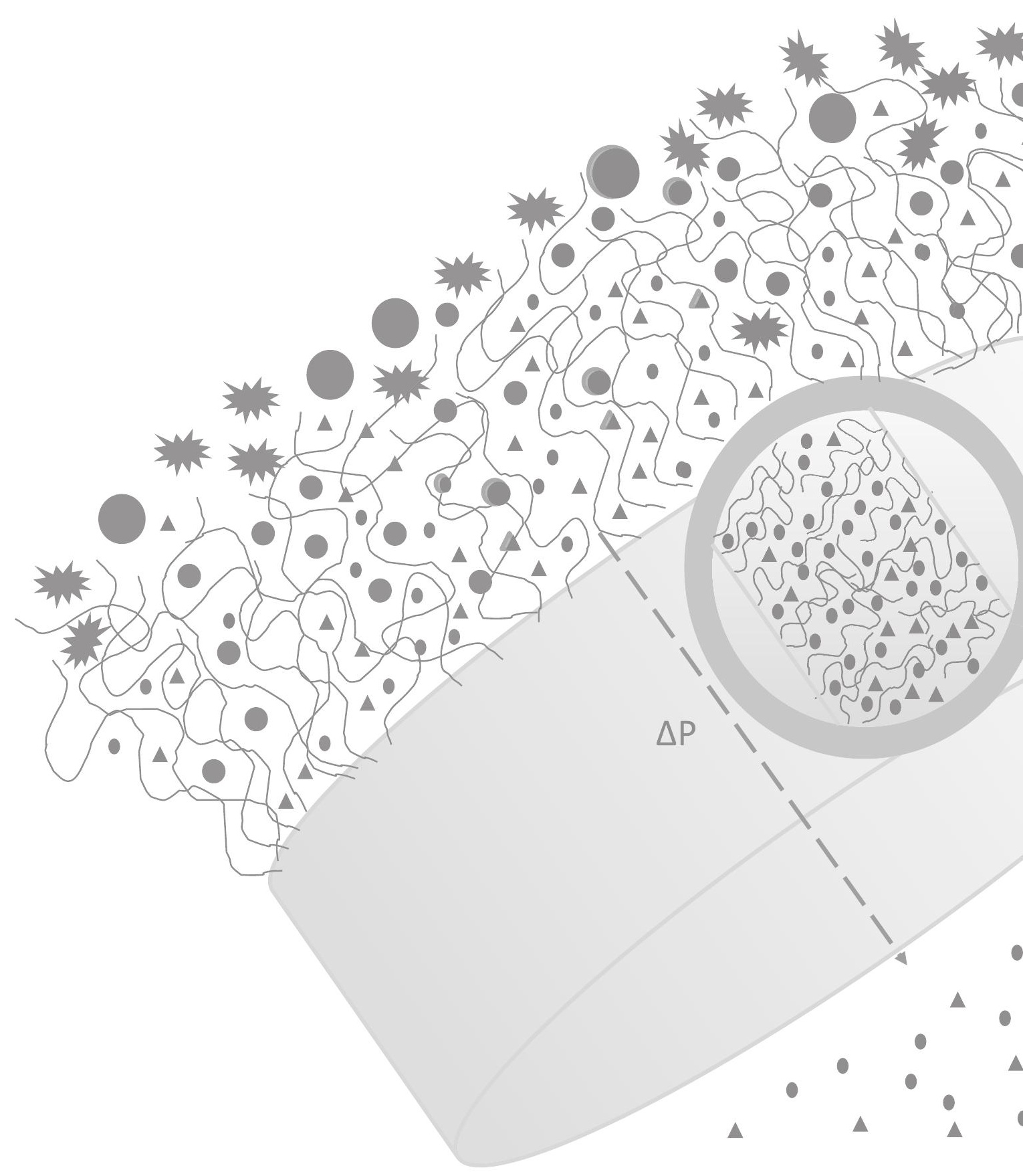


Chapter

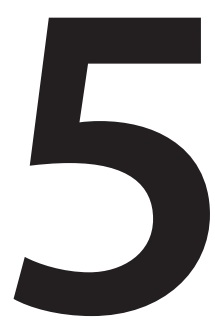

\section{Development}

of a PDMS-grafted

alumina membrane

and its evolution as

a solvent resistant

nanofiltration

membrane

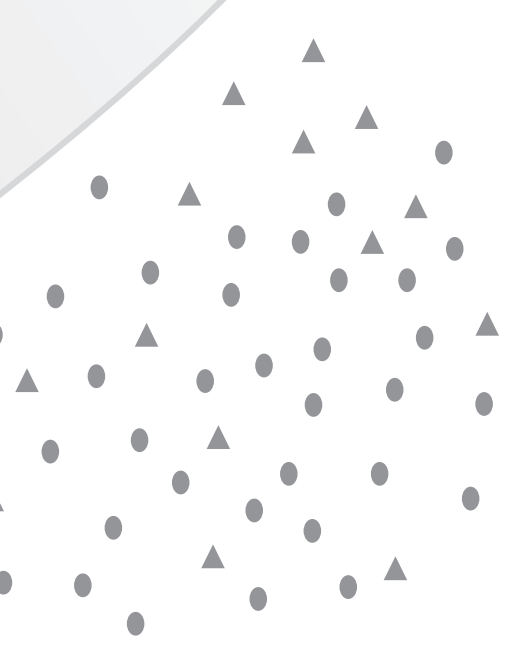




\section{Abstract}

A new solvent resistant nanofiltration (SRNF) membrane is developed by grafting a PDMS polymer into the pores of a $5 \mathrm{~nm} \gamma$-alumina ceramic membrane. These PDMS grafted $\gamma$-alumina membranes were attained through a two-step synthesis which initially involved grafting of the linker, APTES, by a vapor phase deposition (VPD) or a solution phase deposition (SPD) method, followed by grafting of an epoxy terminated PDMS. Through this route one is able to tune pore size and to engineer surface chemistry (e.g. hydrophobicity) of membranes in favor of nonpolar organic solvent permeation. Reproducible results were obtained for filtration experiments with hexane, toluene and isopropyl alcohol (IPA). As expected, higher permeances were found for non-polar solvents than for more polar solvents (resp. $4.8 \pm 0.1 \mathrm{I} \mathrm{m}^{-2} \mathrm{hr}^{-1} \mathrm{bar}^{-1}$ for hexane, $3.1 \pm 0.5 \mathrm{I} \mathrm{m}^{-2} \mathrm{hr}^{-1} \mathrm{bar}^{-1}$ for toluene and $0.54 \pm 0.04$ $1 \mathrm{~m}^{2} \mathrm{hr}^{1}$ bar $^{-1}$ for IPA). A Molecular Weight Cut Off (MWCO) of $500 \pm 10$ Da was determined. Stability tests in hexane, toluene and IPA have shown that these newly developed membranes were stable in all these solvents during testing periods of up to 170 days. 


\subsection{Introduction}

Solvent resistant nanofiltration (SRNF) has gained increasing interest, as it is an effective and energy-saving technology in several strategic fields, such as pharmaceutical industry, fine chemistry and petrochemistry. In these applications state-of-theart NF membranes for aqueous applications are not suitable and solvent-resistant nanofiltration (SRNF) membranes are required. In general, nanofiltration membranes can be divided into two major groups according to their material properties: organic polymeric membranes and inorganic ceramic membranes.

Today, polymeric membranes are commercially available and have found multiple applications in fields like recovery of organometallic catalysts from organic solutions [1] and the de-acidification of vegetable oils [2]. However, these membranes tend to swell in solvents, which reduce their potential for separation, in particular involving non-polar solvents [3-5]. For non-polar solvents Tarleton et al. [6] observed 80\% swelling of the initial thickness at ambient pressure for a $2 \mu \mathrm{m}$ thick PDMS separating layer coated on a PAN support. Another drawback is their limited chemical stability with respect to aggressive solvents, e.g. NMP and DMF [7].

In contrast to polymeric membranes, ceramic membranes are characterized by no swelling behavior and a very high chemical, thermal and mechanical stability in all types of polar and non-polar organic solvents [8, 9]. However, conventional ceramic membranes are hydrophilic due to the presence of surface hydroxyl groups, which leads to low fluxes for non-polar solvents [10-12].

Therefore, much focus is on developing new classes of chemically modified membranes for improving the filtration performance of SRNF membranes, i.e. enhancing chemical and mechanical stability and reduced swelling effects of polymeric membranes and enhancing solvent affinity of ceramic membranes.

Polysiloxane-based polymers, like PDMS, are normally used as polymeric SRNF membranes. PDMS displays a unique combination of characteristics which include high free volume, flexibility of the siloxane backbone, thermal and chemical stability, hydrophobicity and solubility in non-polar solvents. However, their swelling behavior, particularly in non-polar solvents hampers its application. The use of strongly swelling solvents like hexane will result in an increase in free space between the polymer chains and consequently in a less selective convective solute transport. In literature several solutions are proposed to overcome or to reduce this swelling behavior [13-15]. Gevers et al. [16] incorporated fillers as zeolites onto a silicon-based membrane via further crosslinking which resulted in a decrease 
in membrane swelling by non-polar solvents $[6,17]$. Dutczak et al. [18] prepared a SRNF a-Alumina/PDMS hollow fiber composite membrane by coating a PDMS layer on an a-Alumina ceramic support.

An alternative approach is the introduction of a covalent bond between a polymer and the ceramic surface resulting in a ceramic grafted polymer membrane. This is expected to reduce polymer swelling, since the polymer is immobilized inside the pore. An increase in membrane performance is expected as well through a reduction in pore size and an enhancement of specific interaction/affinity between the membrane and the permeating molecules.

To our knowledge the only reported PDMS (as silicon oil) grafted membrane by using a ceramic as support was by Leger at al. [19]. They evaluated this system for both gas permeation and pervaporation of pure organic solvents. This membrane was chemically and thermally stable, unaffected by organic solvents as toluene, THF and acetone, but it degrades in high and low pH media.

In this paper a new grafting route was designed for grafting PDMS on an alumina ceramic membrane. The surface modification strategy employed is based on the formation of an aminosilane monolayer on a hydroxyl-terminated substrate and subsequent reaction of the amine group with epoxy-terminated PDMS, having a low molecular weight and viscosity, enabling the formation of a PDMS grafted layer in the pores.

As already mentioned, grafting PDMS alters the pore size and solvent affinity of the $\gamma$-alumina membrane. It has been shown that for hydrophilic membranes the permeability for polar solvents (methanol, ethanol and propanol) was higher than for non-polar solvents (pentane, hexane, octane). On the contrary, for hydrophobic membranes, permeability for non-polar solvents was higher than for polar solvents [20-22]. The wide range of polarities, viscosities, surface tensions between the different solvents and solvent mixtures complicates a unified approach to describe the transport mechanism of these solvents through the membrane [20, 23-25]. Several authors have shown that the transport mechanism will always be a competition between the pore flow and the solution-diffusion transport mechanism in non-aqueous applications, especially for PDMS polymeric membranes [20, 21, 26-30]. However, few studies are focused on the transport mechanisms through inorganic or hybrid membranes for non-aqueous systems [31-34]. Therefore, one of the aims of this work is an elucidation about the transport mechanism through a PDMS- $\gamma$-alumina grafted membrane by studying the permeation performance of solvents with different polarities, molecule sizes and 
viscosities. The influence of membrane properties like swelling and compaction effects is also taken into account.

In this paper a supported $\gamma$-alumina membrane (pore size $5 \mathrm{~nm}$ ) was grafted with a polysiloxane (mono(2,3-epoxy) polyetherterminated polydimethylsiloxane: PDMS). Two different linker deposition methods (solution or vapor phase) were used in order to evaluate the effect of linker deposition on PDMS grafting. Contact angle and permporometry measurements were used to access the extension of the modification. In order to evaluate the effect of the PDMS treatment on the membrane performance, toluene, hexane and IPA permeabilities of the membranes were determined. To further characterize the membrane the Molecular Weight Cut Off (MWCO) was also determined. Finally silica wafers were grafted in order to study the swelling of the polymer used and to evaluate its effect on the membrane performance for different solvents.

\subsection{Experimental}

\subsubsection{Materials}

As ceramic support $\gamma$-alumina supported a-Alumina was used. Flat disc-shaped a-alumina supports with a diameter of $39 \mathrm{~mm}$, a thickness of $2.0 \mathrm{~mm}$ and a pore size of $70 \mathrm{~nm}$ were purchased from Pervatech (Enter, the Netherlands). These supports were coated with a $300 \mathrm{~nm} \gamma$-alumina layer by dip-coating the supports in a boehmite sol followed by drying and calcining at $650^{\circ} \mathrm{C}$ (heating and cooling rates: $1^{\circ} \mathrm{C} \mathrm{min}^{-1}$; hold: 1 hour). The deposition /calcination cycle was carried out twice. A pore size of 5-5.5 nm for the mesoporous $\gamma$-Alumina layer was measured by permporometry. Anhydrous toluene, n-hexane, isopropanol and 3-aminopropyltriethoxysilane (APTES) were obtained from Aldrich and used as received. The polysiloxane, mono(2,3-epoxy)polyetherterminated polydimethylsiloxane, was obtained from ABCR. The polymer has a molecular weight of $1000 \mathrm{~g} \mathrm{~mol}^{-1}$ and a viscosity of 10-15 mPa s.

\subsubsection{Grafting procedure}

\section{Pre-treatment of $\gamma$-alumina membranes}

Prior to grafting, the $\gamma$-alumina membranes were pre-treated to remove any impurities and to promote a suitable hydroxylation and hydration degree by soaking in an ethanol/water (2:1) solution for 24 hours at ambient temperature 
and subsequent drying in a vacuum oven at $100{ }^{\circ} \mathrm{C}$ for 24 hours. The membranes were then stored under nitrogen atmosphere until further use.

\section{Grafting of $\gamma$-Alumina membranes with APTES by solution phase deposition (SPD)}

The introduction of amino groups onto the alumina surface, as an "initiator site", was achieved by treatment of the surface hydroxyl groups with APTES. The procedure was as follows: (1) inside a glove box under nitrogen atmosphere, a $100 \mathrm{ml}$ tolueneAPTES solution, using APTES concentrations of 12.5 or $25 \mathrm{mM}$, was added to a 500 ml 5 necked round flask fitted with a sample holder on which the membrane was placed, which is submersed in the reaction mixture and a magnetic stirrer. (2) The flask containing the mixture was removed from the glove box and refluxed for 4 hours at $80{ }^{\circ} \mathrm{C}$ under a nitrogen flow. After the refluxing step the membrane was retrieved from the reaction solution and washed with fresh toluene $(20 \mathrm{ml})$, soaked overnight in toluene to remove any physical adsorbed silane and washed with ethanol afterwards followed by drying at $100{ }^{\circ} \mathrm{C}$ under vacuum for 24 hours.

\section{Grafting of $\gamma$-Alumina membranes with APTES by vapor phase deposition (VPD)} Grafting $Y$-alumina membranes with APTES by VPD is based on the method as described in [35] for grafting $Y$-alumina flakes with APTES. Inside a glove box under nitrogen atmosphere, a $100 \mathrm{ml}$ toluene-silane solution, using an APTES concentration of 12.5 or $25 \mathrm{mM}$ was added to a $500 \mathrm{ml}$-necked round flask, fitted with a magnetic stirrer. The vessel was removed from the glove box and a cleaned membrane was placed (with the mesoporous layer facing to the APTEStoluene solution) in a sample holder a few centimeters above the solvent surface. The sample holder was placed inside a glass tube that was connected to both the vessel containing the solution and a condenser connected to a water trap. A thermocouple was placed and a nitrogen flow was applied to saturate the vessel with nitrogen. The reaction was performed by refluxing for 4 hours at $80^{\circ} \mathrm{C}$. Subsequently the membrane was soaked, washed and dried as described above for the SPD deposition method.

\section{Grafting of APTES-grafted $\gamma$-Alumina membranes with PDMS}

The introduction of the siloxane-based polymer was achieved by the reaction between the amino group of the grafted APTES molecule and the epoxy groups of the siloxane polymer. A mono(2,3-epoxy)polyether-terminated polydimethylsiloxane (PDMS) was used. 
The procedure was as follows: (1) a $100 \mathrm{ml}$ isopropanol-PDMS solution, using a PDMS concentration of 12.5 or $25 \mathrm{mM}$, was added to an APTES-grafted $\gamma$-alumina membrane placed in a sample holder submersed in the reaction mixture in a $500 \mathrm{ml} 5$ necked round flask, inside a glove box; (2) the flask was removed from the glove box and refluxed for 24 hours at $75^{\circ} \mathrm{C}$ under a nitrogen flow. After 24 hours the reaction mixture was allowed to cool down and the membrane was soaked overnight in isopropanol $(20 \mathrm{ml})$ to remove any physical adsorbed silane and afterwards washed with ethanol and acetone. The modified membrane was placed in a glass petri dish and dried at $100{ }^{\circ} \mathrm{C}$ under vacuum for 24 hours.

\subsubsection{Membrane Characterization}

\section{Contact angle}

Static contact angle measurements were performed on the grafted as described in chapter 3 on the grafted membranes. A droplet of $5 \mu \mathrm{L}$ of water (Millipore Q2) was injected at a speed of $1 \mu \mathrm{l} \mathrm{s-1}$. The calculated contact angle values were an average of 5 drops.

\section{Permporometry}

Permporometry was employed to determine the pore size distribution of the modified and unmodified membrane layers. Permporometry is based on the stepwise blocking of pores by capillary condensation of a vapor and simultaneous measurement of the diffusional flux of a non-condensable gas through the remaining open pores [36]. Cyclohexane $\left(T=70^{\circ} \mathrm{C}\right)$ was used as the condensable vapor (blocking vapor) as it has a high evaporation rate and is inert to the membranes to be characterized. Oxygen and nitrogen are used as non-condensable gases. A permporometry measurement is started at low relative vapor pressures where all pores are open because in this case the vapor molecules only adsorb to the pore walls. As the relative vapor pressure increases, a multi-molecular layer starts to form, the so-called t-layer. When the relative vapor pressure rises further, the adsorption process is followed by capillary condensation till all pores are completely filled. When adsorption is completed the desorption process starts, which consists of stepwise decreasing of the relative vapor pressure. In the beginning, the liquid in the larger pores evaporates, while by further reducing the relative vapor pressure also smaller pores open. The pore size can be calculated by the Kelvin equation (equation 1): 


$$
\ln P_{\mathrm{rel}}=\left(-\gamma_{\mathrm{s}} \mathrm{Vm} / \mathrm{R} T\right)\left(1 / r_{\mathrm{k} 1}+1 / \mathrm{r}_{\mathrm{k} 2}\right) \cos \theta
$$

where $P_{\text {rel }}$ is the relative vapor pressure of the condensable vapor, $Y_{s}$ the surface tension of the liquid-vapor interface $\left(\mathrm{N} \mathrm{m}^{-1}\right), \mathrm{V}_{\text {mol }}$ the molar volume of the condensable vapor $\left(\mathrm{m}^{3} / \mathrm{mol}\right)$, $R$ the gas constant $\left(\mathrm{J} \mathrm{mol}^{-1} \mathrm{~K}^{-1}\right)$, T the temperature $(\mathrm{K})$, $\theta$ the contact angle which the liquid makes with the pore wall and $r_{k 1}$ and $r_{k 2}$ the Kelvin radii $(m)$ which are the radii of curvature of the vapor-liquid interface under consideration. The contact angle $\theta=0$ when it is assumed that the condensable vapor completely wets the membrane.

\section{Solvent permeation experiments}

Steady state solvent flux analyses were carried out on unmodified and PDMS modified membranes using a stainless steel dead-end filtration set-up. Figure 1 shows a schematic drawing and a picture of the set-up. An active membrane area of $6.6 \times 10^{-4} \mathrm{~m}^{2}$ was used. The feed solution was poured into the cell and pressurized with helium to the desired pressure at room temperature. A trans membrane pressure (TMP) range of 1-11 bar was used.

\section{Solvents}

The solvents used in this study were anhydrous n-hexane, toluene and isopropanol (IPA) supplied by Sigma-Aldrich Ltd. These solvents have been chosen to cover a wide range of organic solvents, from aromatic (toluene) to linear alkane (n-hexane) and an alcohol (isopropanol, IPA), showing different properties like polarity and solubility behavior in polymers, which are important properties with respect to nanofiltration. N-hexane is the most hydrophobic solvent followed by toluene and IPA. Other solvent properties are listed in Table 1. Effective solvent diameters are determined taking into account the molecular structure, the chemical bond length and the bonding angles of the molecules. Accordingly the effective diameter is not considered as an absolute diameter of the molecule but as a relative measure of the molecular size. 

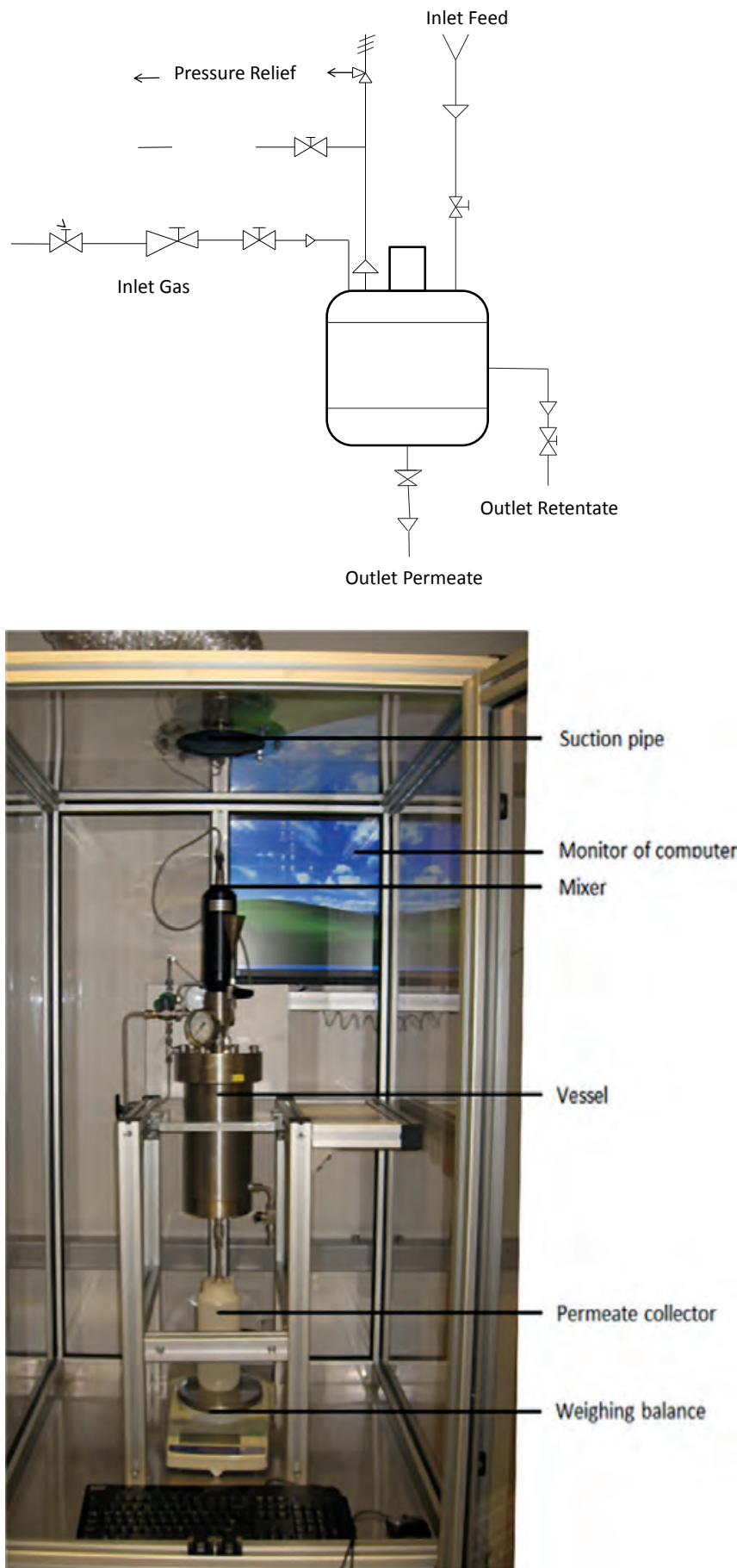

Figure 1: A scheme and a photo of the dead-end filtration set-up. 
Table 1: Solvent characteristics.

\begin{tabular}{lllllllll}
\hline Solvent & Formula & $\begin{array}{l}\text { Molecular } \\
\text { weight } \\
{\left[\mathbf{g ~ m o l}^{-1}\right]}\end{array}$ & $\begin{array}{l}\text { Density } \\
{\left[\mathrm{g} \mathrm{cm}^{-3}\right]}\end{array}$ & $\begin{array}{l}\text { Viscosity } \\
{[\mathrm{mPa} \text { s] }}\end{array}$ & $\begin{array}{l}\text { Surface } \\
\text { tension } \\
{\left[\mathrm{mN} \mathrm{m}^{-1}\right]}\end{array}$ & $\begin{array}{l}\text { Dipole } \\
\text { moment } \\
{[\mathrm{D}]}\end{array}$ & $\begin{array}{l}\text { Effec- } \\
\text { tive } \\
\text { solvent } \\
\text { diame- } \\
\text { ter [nm] }\end{array}$ & $\begin{array}{l}\text { Kinetic } \\
\text { diameter } \\
\text { [nm] }\end{array}$ \\
\hline n-hexane & $\mathrm{C}_{6} \mathrm{H}_{14}$ & 86.2 & 0.6594 & 0.307 & 18.396 & 0.09 & 0.46 & 0.43 \\
toluene & $\mathrm{C}_{6} \mathrm{H}_{5} \mathrm{CH}_{3}$ & 92.1 & 0.8667 & 0.590 & 28.522 & 0.32 & 0.50 & 0.59 \\
IPA & $\mathrm{C}_{3} \mathrm{H}_{7} \mathrm{OH}$ & 60.1 & 0.7869 & 2.381 & 21.322 & 1.66 & 0.39 & 0.47 \\
\hline
\end{tabular}

Liquid permeation experiments were carried out in a sequence that started with the most hydrophobic (hexane) to the most hydrophilic (IPA). Prior to the experiments the membranes were soaked overnight in the solvent to be measured. After each measurement, the membrane was washed and dried for 24 hours at $100{ }^{\circ} \mathrm{C}$ to remove any water and solvent adsorbed in the membrane micropores.

\section{Molecular Weight Cut Off measurements}

The molecular weight cut off (MWCO) was determined by filtration experiments with a solution of polyisobutylenes (PIB's) with different molecular masses. PIB's (Glissopal') of 550, 1000, 1300 and $2300 \mathrm{~g} \mathrm{~mol}^{-1}$ were provided by BASF (Germany) and PIB of $350 \mathrm{~g} \mathrm{~mol}^{-1}$ by Janes S.A. (Switzerland). All chemicals were used as supplied without additional purification. These five PIB's, all having a broad MW distribution, were used to create a mixture in toluene of equal weight ratios of the respective PIB's at a total polymer concentration of $0.3 \%(\mathrm{w} / \mathrm{w})$ resulting in molecular weights ranging from 200 to $20,000 \mathrm{~g} \mathrm{~mol}^{-1}$. The MWCO measurements were performed by filtration of the PIB mixture through a membrane using the dead-end filtration set-up (Figure 1) for 90 minutes at 10 bar trans membrane pressure under continuous stirring (250 rpm) to prevent oligomer deposition on top of the membrane.

In order to determine the retention of the membrane the feed, permeate and retentate were analyzed by gel permeation chromatography (GPC). This analysis gives the fraction of molecules permeated through the membrane as a function of the molecular mass. By plotting these retentions against the Molecular Weight (MW), the MWCO is determined at $90 \%$ retention.

A GPC-analyzer, "Agilient Technologies 1200 Series" equipped with a refractive index "Shodex-RI-7", was used. The columns used for separation of PIB oligomers was a tandem of Polymer Standards services GmbH PSS SDV $100 \AA$ and PSS SDV $1000 \AA$ (injection volume $=100 \mu \mathrm{l}$, flow rate $=1 \mathrm{ml} \mathrm{min} \mathrm{m}^{-1}$, temperature: RT). Analytical grade THF was used as a mobile phase. Chromatographs were analyzed using software of PDD (WinGPC scientific V6.20). 


\section{Ellipsometry}

Ellipsometry experiments are performed with a J.A. Woollan Co., Inc M-2000X spectroscopic ellipsometer for measuring layer thickness and swelling. Swelling is determined by comparing the layer thickness in liquid (toluene and hexane) and dry environment. These experiments are performed on APTES and PDMS grafted on a silica wafer since the surface of the porous alumina supports are too rough for accurate ellipsometry studies. It is assumed PDMS grafted on a silica wafer presents a similar layer thickness as when grafted on the surface of the alumina support. During ellipsometry measurements the polarization of the light changes when light reflects or transmits from a material. The change in polarization $(\rho)$ is represented as an amplitude ratio $(\psi)$ and a phase difference $(\Delta)$ as given in equation 2 :

$$
\rho=\tan (\psi) e^{i \Delta}
$$

The optical constants (refractive index) must be known or determined to analyze the correct layer thickness from an optical measurement. The optical constants are known for dense PDMS polymers and are assumed to be equal to those of the PDMS grafted on silicon wafer. The used refractive index has a value of 1.402 at a wavelength of $632.8 \mathrm{~nm}$.

\subsection{Results and discussion}

A series of membranes, which were prepared via the two different deposition methods for the APTES linker were characterized by contact angle, permporometry and filtration experiments. Two different precursor concentrations were chosen: 12.5 and $25 \mathrm{mM}$, while the linking molecule (APTES) was either applied by a solution phase or by a vapor phase deposition method (resp. SPD and VPD). A previous FTIR study by these authors [35] has proven that $\gamma$-alumina flakes could be grafted with APTES as a linker and subsequently with a mono-epoxy terminated PDMS. Therefore, exactly the same reaction conditions and materials were used in this study.

\subsubsection{Contact angle}

In order to confirm the attachment of APTES and PDMS static contact angles were determined. Table 2 shows water contact angle data for $\gamma$-alumina membranes 
modified with APTES by SPD as well as VPD and subsequently grafted with PDMS.

Table 2: Water contact angle data (in degrees) for APTES and PDMS grafted on alumina membranes by different methods (SPD and VPD) and linker concentrations.

\begin{tabular}{|c|c|c|c|c|c|c|}
\hline \multirow[t]{2}{*}{ ID } & \multirow[t]{2}{*}{ Sample } & \multirow[t]{2}{*}{ Method } & \multicolumn{2}{|c|}{ Precursor Concentration (mM) } & \multirow{2}{*}{\multicolumn{2}{|c|}{$\begin{array}{c}\text { Contact angle } \\
\left({ }^{\circ}\right)\end{array}$}} \\
\hline & & & APTES & PDMS & & \\
\hline 1 & Alumina + APTES & SPD & 25 & - & $67 \pm 3$ & \\
\hline 2 & Alumina + APTES & VPD & 25 & - & $32 \pm 2$ & \\
\hline $3(\mathrm{C})$ & Alumina + APTES + PDMS & VPD & 12.5 & 12.5 & $\begin{array}{l}72 \pm 1 \\
86 \pm 3 \\
72 \pm 3\end{array}$ & (C1) (C2) (C3) \\
\hline $4(A)$ & Alumina + APTES +PDMS & VPD & 25 & 25 & $\begin{array}{l}94 \pm 1 \\
97 \pm 1 \\
91 \pm 1\end{array}$ & $(\mathrm{~A} 1)(\mathrm{A} 2)(\mathrm{A} 3)$ \\
\hline 5 (B) & Alumina + APTES +PDMS & SPD & 12.5 & 12.5 & $101 \pm 2$ & (B1) \\
\hline $6(\mathrm{D})$ & Alumina + APTES +PDMS & SPD & 25 & 25 & $113 \pm 2$ & (D1) \\
\hline
\end{tabular}

For unmodified membranes no water contact angle could be measured, which was expected because of the hydrophilic character of the surface $\mathrm{OH}$ groups.

An increase in contact angle can be observed by modifying the $\gamma$-alumina membrane with APTES using either the SPD or VPD method (Table 2). The wetting behavior of APTES is a result of several contributions including the hydrophilic amino group and the hydrophobic propyl group. APTES grafted membranes still show a hydrophilic character, due to the exposed amino functionality. In general, for the SPD system higher values were obtained when compared with the VPD system. For APTES the electron rich amine group can catalyze the condensation reaction of the ethoxy group with a surface $\mathrm{OH}$ group of alumina, forming a covalent bond. However hydrogen bonding or ionic interaction with surface $\mathrm{OH}$ groups and/or covalent crosslinking with hydroxyl groups of other aminosilane molecules are also possible reaction paths. Consequently the morphology of $\gamma$-alumina surfaces modified with APTES tends to be complex [22, 37-43]. The surface coverage and structure of the grafted layer depends on reaction parameters like reaction time [40], temperature [44], choice of solvent and water content of the solvent [22, 41, 44, 45], silane concentration [46] and reaction phase (liquid or vapor) $[22,37,43,44]$. The degree of crosslinking can also influence the contact angle values. A higher degree of crosslinking (silane cross-polymerization) is expected to result in higher contact angle values. The formation of a monolayer system is expected for theVPD reaction while for the SPD system a multilayer can easily be formed. Pinheiro et al. [35] have modified $y$-alumina flakes with a pore size of $5 \mathrm{~nm}$ with APTES through both VPD and SPD and subsequently with PDMS by using similar 
experimental conditions as described in this paper. These authors have shown that for SPD a multilayer system is achieved whereas for VPD a monolayer of APTES is formed. This confirms the higher contact angles attained for SPD.

\subsubsection{Permporometry}

Permporometry experiments were carried out on unmodified and grafted $\gamma$-Alumina membranes in order to assess if the pores walls were grafted and to what extent. Figure 2 shows the accumulated oxygen flux through open pores versus the relative vapor pressure of cyclohexane, while Figure 3 displays the pore size distribution as calculated from the data given in Figure 2, for both unmodified and grafted $\gamma$-Alumina membranes.

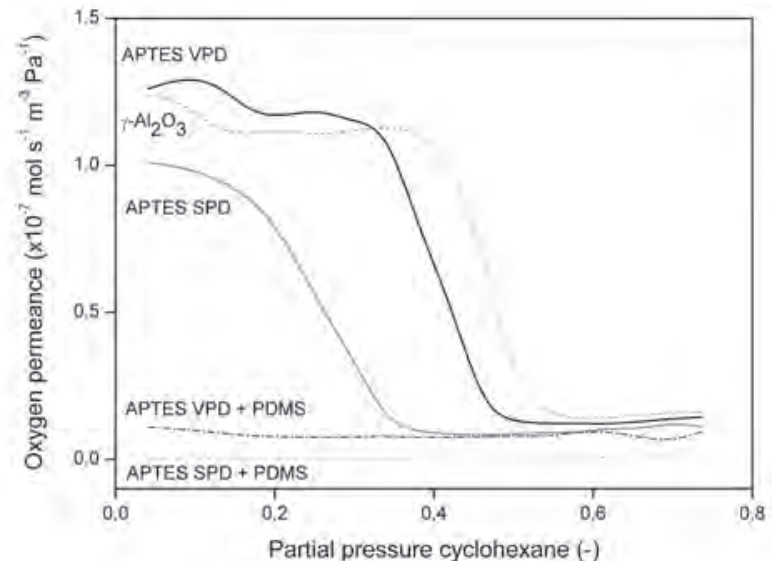

Figure 2: Accumulated oxygen permeation vs relative cyclohexane vapor pressure at $15{ }^{\circ} \mathrm{C}$ for $\gamma$-alumina membranes grafted with APTES by solution phase deposition (SPD) and vapour phase deposition (VPD) and futher on with PDMS. [APTES] and [PDMS]: $25 \mathrm{mM}$.

A reduction in mean Kelvin radius is observed from $2.7 \mathrm{~nm}$ for the unmodified membrane to $2.2 \mathrm{~nm}$ for the membrane modified with APTES by VPD and to 1.5 $\mathrm{nm}$ for the membrane modified by SPD. The higher reduction in pore size for the SPD-derived system can be attributed to the formation of a multilayer, whereas for VPD a monolayer is expected as discussed before. Since the theoretical length of an APTES grafted bonded molecule to the $\mathrm{OH}$ surface group is $0.53 \mathrm{~nm}$, assuming a completely stretched molecule and bond angles of $109^{\circ}$, the observed decrease in pore radius of $0.5 \mathrm{~nm}$ for VPD is due to monolayer formation, while for SPD at least two layers can be formed. This was also supported by the results reported by Pinheiro at al. [35], where $\gamma$-alumina flakes, having a pore diameter of $5 \mathrm{~nm}$, were 
modified with APTES using identical reaction conditions. In that work nitrogen gas adsorption/desorption measurements showed a more pronounced reduction in pore volume, pore size and surface area for SPD when compared to VPD, indicating a multilayer formation in the case of SPD. Haller et al. [47] showed that the tendency of aggregate formation is reduced when silylation is performed in the vapor phase due to the low vapor pressure of aggregates present in the precursor solution, which will not migrate towards the membrane surface but remain in the precursor solution.

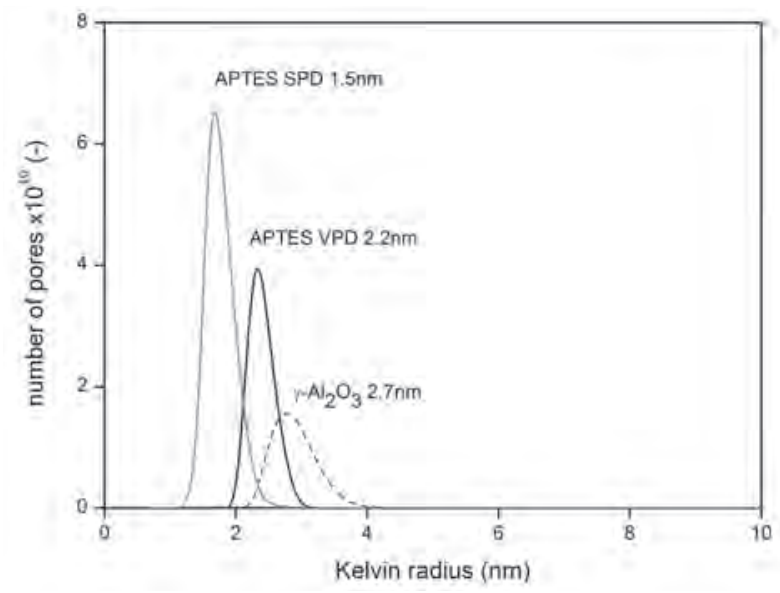

Figure 3: Pore size distribution, calculated from permporometry data, of unmodified $y$-alumina membranes, membranes grafted with APTES by solution phase deposition (SPD) or vapour phase deposition (VPD). During VPD or SPD reaction a concentration of $25 \mathrm{mM}$ was used.

After PDMS grafting a change in pore size was observed for both cases and as the pores remained closed at very low cyclohexane relative partial pressure, a microporous or dense membrane is assumed (Figure 3), which might indicate that the PDMS was successfully grafted not only on the surface but also in the pores of the mesoporous alumina membrane. A theoretical (maximum) length of $3.0 \mathrm{~nm}$ was calculated for the PDMS polymer itself, whereas for the APTES-PDMS bonded to the $\gamma$-alumina surface a length of 3.6 was estimated. The pore diameter of the unmodified $\gamma$-alumina measured is $5.4 \mathrm{~nm}$, after the APTES is grafted by SPD and VPD a pore diameter of 3 and $4.4 \mathrm{~nm}$ is measured, respectively. Thus a pore diameter less than $1.4 \mathrm{~nm}$ can be expected after PDMS grafting for the VPD system (if assumed that only one of the pore walls are grafted), which is below the detection limit of the permporometry analysis as used in this work. For the SPD, the pore is probably too small for allowing the diffusion of PDMS inside the pore and thus for grafting the PDMS. 


\subsubsection{Permeation performance}

The influence of both APTES deposition methods and concentration of the linker and polymer (PDMS) on membrane performance (flux, permeability, MWCO and stability) was investigated.

First the results are discussed for the $25 \mathrm{mM}$ PDMS-alumina grafted membranes where the APTES was grafted by the vapor phase deposition (VPD) method (= $25 \mathrm{mM}-\mathrm{VPD})$.

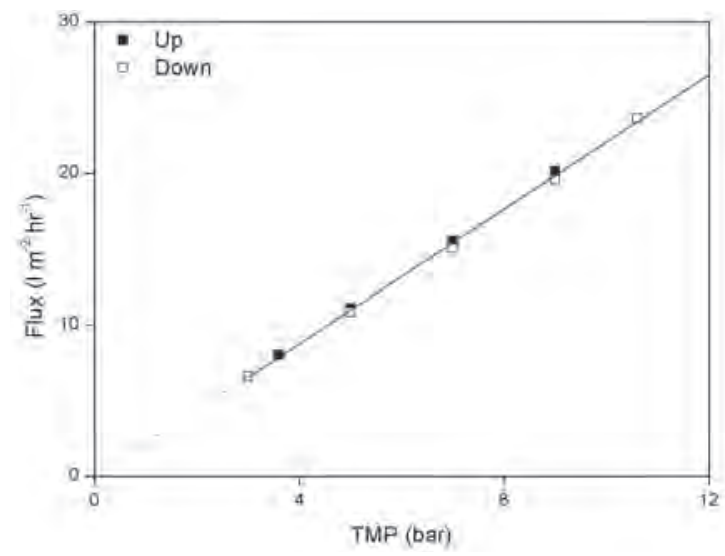

Figure 4: Solvent flux in toluene versus trans membrane pressure (TMP) of a 25 mM APTES (VPD) plus PDMS-grafted membrane. TMP is first stepwise increased from 4 till 11 bar and subsequently stepwise decreased until 3.5 bar.

In Figure 4 the flux - trans membrane pressure (TMP) relationship is shown for pure toluene through a $25 \mathrm{mM}-\mathrm{VPD}-\mathrm{PDMS}$ membrane. The results, generated by stepwise increasing and subsequent decreasing the pressure, clearly show a linear relation and by extrapolating these results a zero flux is observed at zero pressure as expected for pure solvents. No hysteresis between up and down is noticeable, meaning that in the applied pressure range no plastic deformation of the grafted polymer and the support has occurred 


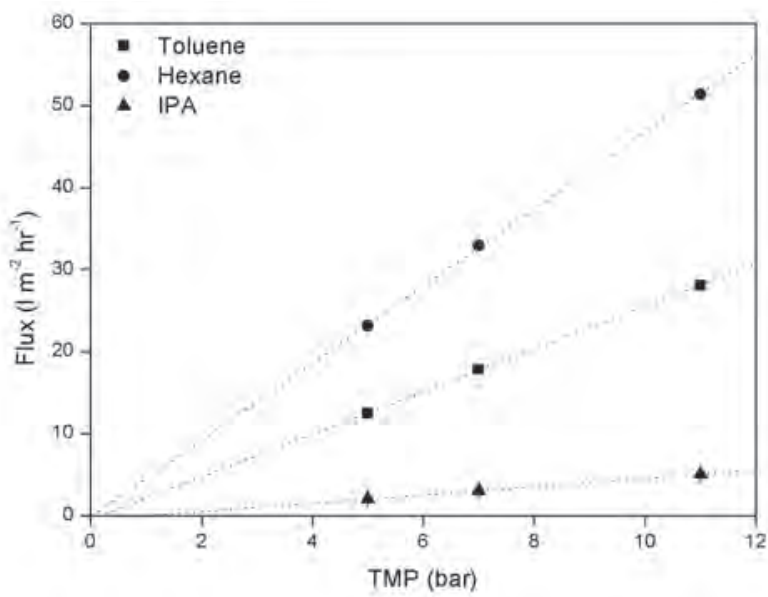

Figure 5: Isopropanol (IPA), n-hexane and toluene flux versus trans membrane pressure (TMP) for a 25 mM APTES (VPD)PDMS-grafted alumina membrane (A1).

Figure 5 shows the steady state toluene, hexane and isopropanol fluxes as a function of the trans membrane pressure through a $25 \mathrm{mM}$ PDMS-grafted membrane by VPD. These results are obtained with freshly grafted membranes, which were soaked in the respective solvents for 1 day prior to the filtration experiment. Hexane presents the highest flux, followed by respectively toluene and IPA. Similar results as in Figure 5 were obtained for a commercial radiation cross-linked PDMS $(2 \mu \mathrm{m})$-polyacrylonitrile (PAN) composite membrane, where linear alkanes e.g. hexane and cyclic/aromatic compounds e.g. cyclohexane and xylene, presented fluxes of around two orders of magnitude higher than alcohols [26]. However, 1.5-2 times higher fluxes were reported for all solvents by these authors when compared with our results. As shown in Figure 5 , in all cases the fluxTMP relationship is clearly linear and obeys Darcy's law, stating the TMP $(\triangle P)$ is the driving force in solvent permeation:

$$
J=\left(K_{m} / \eta\right) \cdot \Delta P
$$

The slope of flux, J, versus TMP is equal to the permeance according to Darcy's law which contains the solvent viscosity $(\eta)$ and a constant $K_{m^{\prime}}$ which is the membrane permeability coefficient and for a single membrane layer with a pore radius $r$, can be expressed as:

$$
K_{m}=\left(\varepsilon . r^{2}\right) /(8 T L)
$$


where $\varepsilon$ is the porosity of the membrane material, $\tau$ the tortuosity of the membrane layer, and $L$ the membrane layer thickness.

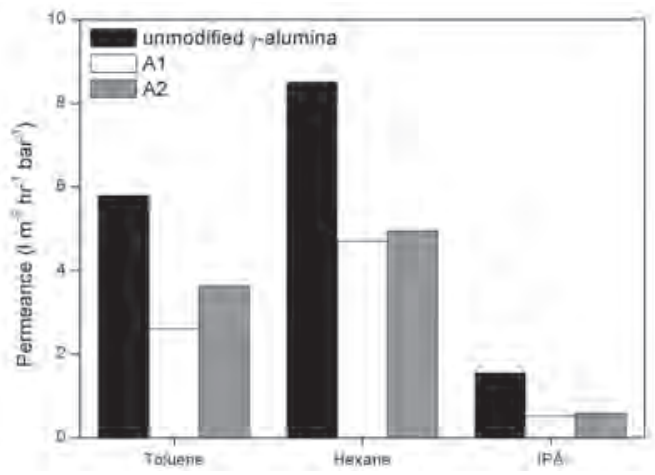

Figure 6: Permeances for toluene, hexane and IPA of 25 mM VPD PDMS grafted membranes (A1 and $\mathrm{A} 2$ ) and an unmodified $\gamma$-alumina.

Figure 6 shows the permeance for each solvent for the unmodified and PDMS grafted membranes. Between the two grafted membranes (A1 and A2) the deviation in permeance for each solvent is small, with the largest deviation for toluene. Overall it can be said that the results for these membranes are reproducible. Permeances of the modified membranes are lower than the $\gamma$-alumina membrane, supporting the reduction in pore size observed by permporometry and proving that grafting has occurred successfully.

In general flux and permeance performance can be explained by using either the pore-flow (hydraulic) or the solution-diffusion (chemical) model. Both theories will now be discussed for the results obtained in this work. In the solution-diffusion model chemical transport is dominating the permeance. For pore-flow transport Darcy's law is obeyed and the Hagen-Poiseuille model can be applied. If flux obeys this law then the flux is dependent on trans membrane pressure as well as on structural properties of the membrane material (like porosity and pore size) and solvent viscosity but not on other physical and chemical properties of membrane and permeating solvent.

Figure 7 illustrates this flux dependency according to Darcy's law (equation 3) by showing a linear relation between flux and TMP/ $\eta$. For unmodified $\gamma$-alumina membranes, such a linear fit of the solvent data could not be obtained, meaning that the mechanism of permeation through these membranes does not obey the pore flow model. Similar observations were reported by Tsuru et al. [48] showing that for unmodified $\mathrm{SiO}_{2}-\mathrm{TiO}_{2}$ membranes pore flow did not apply whereas for 
hydrophobic membranes, obtained by modifying the ceramic membranes with trichloromethylsilane (TCMS), the transport mechanism was found to obey the pore flow model.

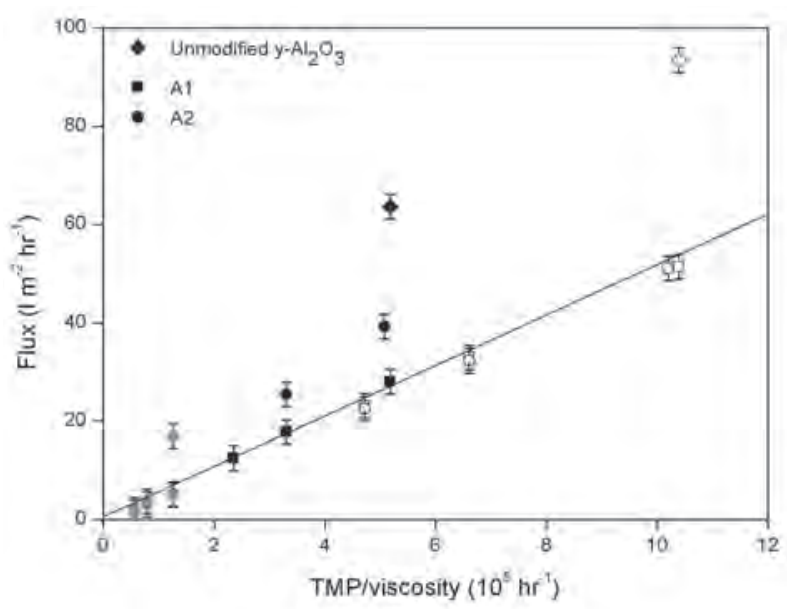

Figure 7: Flux as function of the trans membrane pressure divided by the viscosity for two different $25 \mathrm{mM}$ VPD PDMS grafted $\gamma$-alumina membranes. The grey symbols represent the measurements IPA, the black symbols toluene and the open ones hexane. The line is the average slope of the data points.

A linear fit of the data for the grafted membrane (Figure 7) yields a value of $\mathrm{K}_{\mathrm{m}}$ $=5.14 \mathrm{~m}$, which is defined as the viscosity corrected permeance (VCP). All data points are close to a straight line even though some values for the toluene flux present a slight deviation from the general trend. It can therefore be stated that the modified membrane obeys the Hagen-Poiseuille model for all solvents in the pressure range considered, meaning that transport is dominated by pore flow transport mechanism. Some literature references also indicate that this pore flow mechanism explains the solvent flux behavior in polymeric PDMS membranes $[21,25]$. However, other researchers found that chemical transport via a solutiondiffusion mechanism is prevalent for these systems, as non-polar solvents are expected to have affinity towards PDMS [23, 24]. In general, the hydrophobic character of the PDMS membrane leads to a preferential chemical interaction towards non-polar solvents [49]. This preferential interaction can also be attributed to comparable values for the solubility coefficients of these solvents and PDMS [26]. The Hildebrand solubility parameter ( $\delta$ ) provides a numerical estimate for the degree of interaction between materials and can be a good indication for 
interaction between solvent and membrane material, particularly for non-polar materials like several polymers. The Hildebrand solubility parameter is a reflection of the van der Waals force and is derived from the cohesive energy, which in turn is derived from the heat of vaporization $\left(\Delta \mathrm{H}_{\text {vap }}\right)$. The square root of this cohesive energy equals the Hildebrand solubility parameter:

$$
\delta=\sqrt{\frac{\Delta \mathrm{H}_{\mathrm{vap}}-\mathrm{RT}}{\mathrm{V}_{\mathrm{m}}}}=\sqrt{\frac{\mathrm{E}_{\mathrm{coh}}}{\mathrm{V}_{\mathrm{m}}}}
$$

Where $E_{\text {coh }}$ is the cohesive energy, $R$ is the gas constant, $T$ is the temperature and $V_{m}$ is the molar volume. Materials are miscible when they have similar cohesive energy densities and thus similar Hildebrand solubility parameters. For solvents the values for $\Delta H_{\text {vap }}$ and $V_{m}$ are easily obtained from literature, but for polymeric and ceramic materials this is more problematic. For the determination of Hildebrand solubility parameters for these kind of materials the group contribution method as proposed by Fedors et al. [50] is used. In this method the cohesive energies and molar volumes of the different groups are summed and then the Hildebrand solubility parameter ( $\delta$ ) can be calculated by equation 5 . In this way for PDMS a $\delta$ value of $15 \mathrm{MPa}^{1 / 2}$ is calculated. In Figure 8 solvent permeances as function of their Hildebrand solubility $(\delta)$ parameter are shown.

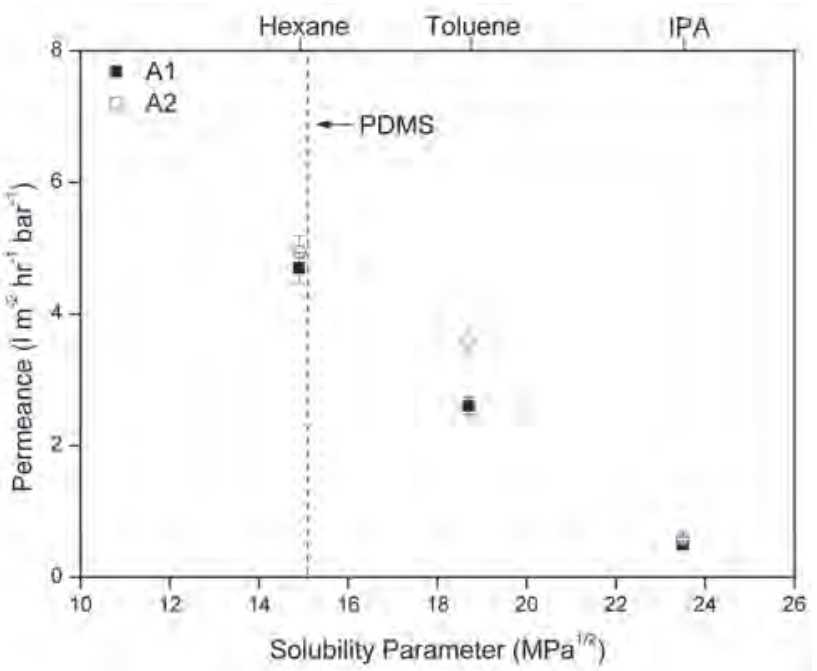

Figure 8: Permeance of 25 mM VPD PDMS grafted membranes as a function of the Hildebrand solubility parameter. The dotted line represents the solubility parameter of PDMS. 
A solubility parameter of the solvent close to the $\delta$-value of PDMS, means a higher affinity between solvent and polymer and consequently a higher permeance can be expected if transport is determined by chemical affinity. Since the solubility parameter of hexane is closer to the value of PDMS than those for toluene and IPA, it is expected that hexane shows the highest permeance as can be deduced from the permeance results in Figure 8.

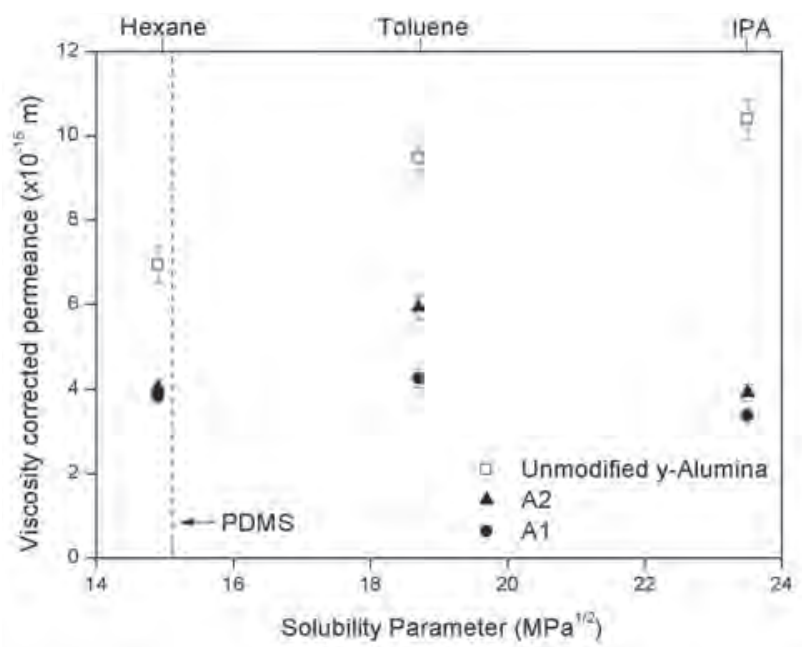

Figure 9: Viscosity-corrected permeance (VCP) as a function of the Hildebrand solubility parameter for the unmodified and 25 Mm VPD PDMS grafted membranes (A1 and A2). The dotted line represents the solubility parameter of PDMS.

However, in this work the influence of viscosity by means of the Hagen-Poiseuille model for pore flow mechanism is also discussed (see e.g. Figure 7). In order to identify the influence of affinity (solution-diffusion model) versus the influence of viscosity (pore flow model) on solvent transport through these membranes, the viscosity-corrected permeance $(=\mathrm{VCP})$ is plotted against the Hildebrand solubility parameter (see Figure 9). The VCP values were determined by the slope of an individual set of data points belonging to one membrane and one type of solvent. For the unmodified membrane IPA presents the highest VCP value, followed by toluene and hexane. The Hildebrand solubility parameter of $\gamma$-alumina is expected to be closer to IPA (polar), followed by toluene and hexane (both non-polar) due to the formation of a hydrogen bridge between the polar groups of the solvent and the surface hydrophilic hydroxyl groups of $\gamma$-alumina. The VCP of the $\gamma$-alumina membranes will therefore increase with solubility parameter of the solvents studied when the chemical transport mechanism is playing an important role. 
In contrast with the $\gamma$-alumina membrane, the Hildebrand solubility parameter of PDMS is closest to the value of hexane, followed by toluene and then IPA indicating that there is affinity towards the solvents in the same order. Hexane, a linear molecule presents the highest affinity with PDMS but shows a lower VCP than toluene, a cyclic molecule, which in turn shows a lower affinity (Figure 9). This contradiction with the "Hildebrand-solubility parameter theory" is also observed by Robinson et al. [26], where higher permeability values were obtained for cyclic alkanes, e.g. cyclohexane and aromatics e.g. xylene when compared with n-alkanes.

An effect of chemical interactions between solvent and polymeric membranes is swelling of the polymer. Even though, it is expected that pore confinement in the ceramic membrane restricts swelling of the PDMS network due to the rigidity of the support matrix. It is expected that the degree of swelling is the highest for the best matching solubility parameters between solvent and membrane material. In the case of PDMS more solvent sorption results in a more stretched/ swelled polymeric structure. For that reason the swelling behavior was studied on PDMS grafted on a silica wafer by means of ellipsometry. Through this method it was found that the layer thickness (APTES+PDMS) increased with a factor 1.5 after immersing in toluene and with a factor 2.3 after immersing in hexane. Swelling could not be determined accurately in IPA because of similar refractive indexes for IPA and PDMS. A stronger swelling of PDMS in hexane than in toluene confirms the validity of the solubility parameter used for grafted APTES+PDMS implying a higher affinity for PDMS and hexane than for PDMS and toluene and hence a better chemical transport for hexane is expected when applying this model.

For grafted porous membranes it seems feasible that pores can be more confined by more swelling in hexane resulting in smaller pores and hence less pore flow transport, with respect to toluene. However, for dense PDMS systems Robinson et al. [19] obtained similar permeation results as described in this paper, implying that in our case the grafted PDMS membrane is also dense and has completely confined pores for both hexane and toluene. A dense membrane suggests that pore flow transport is similar for hexane and toluene. Nevertheless higher VCP values are found for toluene. Considering Darcy's law (equation 3), the only parameter able to explain these observations is the viscosity. A plausible explanation can be related to the molecular shape of the molecules considered. Speculations are that straight-chain hydrocarbons, such as hexane become more ordered under compression and hence increase their viscosity while the cyclic 
shape of toluene makes the molecule rigid and not as compressible as hexane [26]. An increase of pressure from 1 to 12 bar will increase the hexane viscosity by $1.2 \%$ [51] and toluene viscosity by $0.8 \%$ [52] which is not sufficient to fully explain the difference in VCP values. An increase in hexane viscosity of $10.5 \%$ (for membrane A1) is necessary to obtain equal VCP values for toluene and hexane. The values used for the viscosity (Table 1) represent the macroscopic viscosity of the bulk liquid. A liquid confined inside the membrane only consists of a few molecules which are affected more by the PDMS present in these pores. It is imaginable that this confinement increases the resistance for the fluid to flow and as a result the "microscopic" viscosity (if compared with the normal "macroscopic" one) increases more for the more flexible hexane than for the rigid toluene molecule. However, it is unclear what the value of the microscopic viscosity might be and therefore also to what extent there is chemical transport.

Finally, for flux-TMP plots higher positive intercepts for $n$-alkanes than for aromatic (2.5 vs. $1-2 \mid \mathrm{m}^{-2} \mathrm{hr}^{-1}$ ) were found by Robinson et al. [26] confirming higher affinity towards hexane than toluene. Due to the similarity of Robinson's results and our results there might be a slightly stronger chemical transport supporting pore flow for hexane than for toluene in a grafted PDMS system. However in our work not enough data points at different pressures were taken, necessary to give accurate intercepts.

\subsubsection{Permeation of membranes grafted with PDMS using a SPD- grafted APTES linker}

For $\gamma$-Alumina membranes modified with APTES by a solution phase deposition (SPD) method and subsequently grafted with PDMS by using the same reaction condition as discussed before (reaction time, temperature and concentration) no flux was measured for any of the solvents. Three membranes were tested. This is most likely due to complete pore blocking caused by the formation of a dense polymerized PDMS network on the APTES linker. As shown in Figure 3, when APTES is grafted by SPD a reduction in pore radius from $2.7 \mathrm{~nm}$ to $1.5 \mathrm{~nm}$ has occurred indicating multilayer formation and thus a less uniform, thick and high density layer of anchoring amino groups is expected. This can lead to some degree of pore blocking, particularly in the entrance of the pores. Asefa et al. [53] showed that the deposition of APTMS from a toluene solution produced aggregated grafted groups onto a MCM-41 silica support, while Ritter et al. [44] indicated that the tendency towards aggregation and external surface grafting is less pronounced 
for VPD systems. Yokoi et al. [54] found that the surface-bonded amino groups were concentrated near the pore entrance and on the external surface. It can be expected that for the SPD system in our work the linker deposition will restrict the diffusion of the PDMS inside of the pores when compared with the VPD-grafted APTES. For the SPD-grafted APTES membranes PDMS is preferable grafted at the surface and pore entrance of the ceramic membrane, which results in strong pore blocking and consequently no flux for any of the solvents tested. A decrease in the concentration of the APTES linker to $12.5 \mathrm{mM}$ resulted in low toluene fluxes for pressures as high as 11 bar $\left(2.2 \mathrm{I} \mathrm{m}^{-2} \mathrm{hr}^{-1} \mathrm{bar}^{-1}\right)$ and no flux or a negligible flux for low pressures like 6 or 8 bar.

From these results it can be concluded that applying APTES by VPD is the preferred modification method for obtaining reproducible membranes with good flux values for the tested solvents.

\subsubsection{Influence of the polymer loading on membrane performance}

In order to assess the influence of linker and subsequent polymer loading on membrane performance, two different concentrations (12.5 and $25 \mathrm{mM}$ ) of linker and polymer were used during membrane fabrication. These samples have respectively the ID code $D$ and $A$ in Table 2 . The solvent permeation behavior of membrane with code A (25 mM APTES applied by VPD + 25 mM PDMS) is described in detail before.

In Figure 12 the permeance for all three solvents for unmodified and modified membranes, using a linker and polymer concentrations of $12.5 \mathrm{mM}$, are presented. As expected, the membrane presents similar behavior as the membranes grafted with $25 \mathrm{mM}$ of linker and polymer (Figure 6), meaning a reduction in permeance for all solvents when compared to unmodified membranes. This is an indication that grafting has occurred. As expected, for all membranes hexane shows the highest permeance and IPA the lowest. However, if compared e.g. with the $25 \mathrm{mM}$ samples (A), a larger variation in permeances for each solvent is observed for all three membranes, indicating that fabrication of the $12.5 \mathrm{mM}$ membranes is less reproducible. A possible explanation can be an incomplete coverage of the surface with the linker (APTES) and subsequently with the polymer (PDMS). Contact angle measurements show for all of membranes hydrophilic contact angles $\left(C 1=72 \pm 1^{\circ}\right.$, $C 2=86 \pm 3^{\circ}$ and $C 3=72 \pm 3^{\circ}$ ). This supports a less complete coverage with PDMS, at least on the surface. 


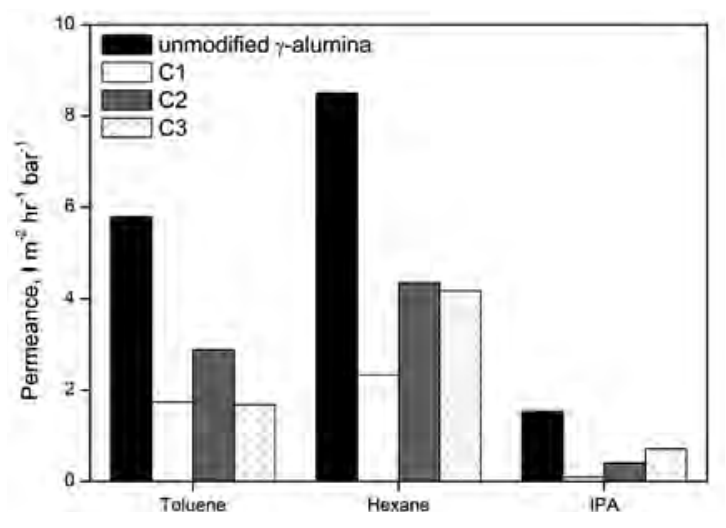

Figure 10: Permeance for toluene, hexane and IPA of 12.5 mM VPD PDMS grafted membranes (C1, C2 and C3) and unmodified $y$-alumina.

\subsubsection{Chemical stability}

Since for all membranes the 25 mM VPD APTES-PDMS- $\gamma$-alumina membrane was the only one delivering reproducible permeance values, stability tests in toluene, hexane and IPA were performed on these membranes (A1, A2, A3). Membrane A1 was used for the stability in hexane, A2 for toluene and A3 for IPA. Filtration experiments for stability were performed at 11 bar TMP, while the membrane remained soaked in the selected solvent during the testing period. A few times solvents were exchanged for a certain period.

Figure 11 shows the stability in hexane. After the initial permeation measurements, as discussed before, a MWCO measurement (Time = 0 days) was performed. After 21 days the solvent was changed to toluene for 4 days, after which the membrane was cleaned, dried and soaked again in hexane. Overall, the permeance in hexane was stable for at least 35 days while the solvent change did not seem to have any influence. Contact angle measurements were performed at 0 days and after 33 days. A shift from $94 \pm 1^{\circ}$ to $93 \pm 1^{\circ}$ was measured, indicating that no degradation or removal of the PDMS from the membrane after hexane soaking was observed, which supports the stable permeation data. 


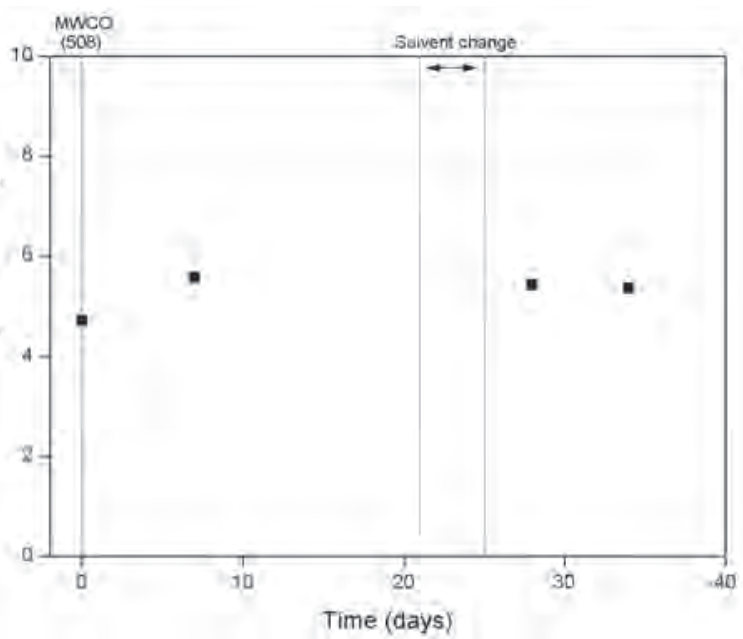

Figure 11: n-Hexane permeance of a 25 mM PDMS membrane (A1) as function of time. Filtration experiments were conducted at 11 bar TMP and room temperature.

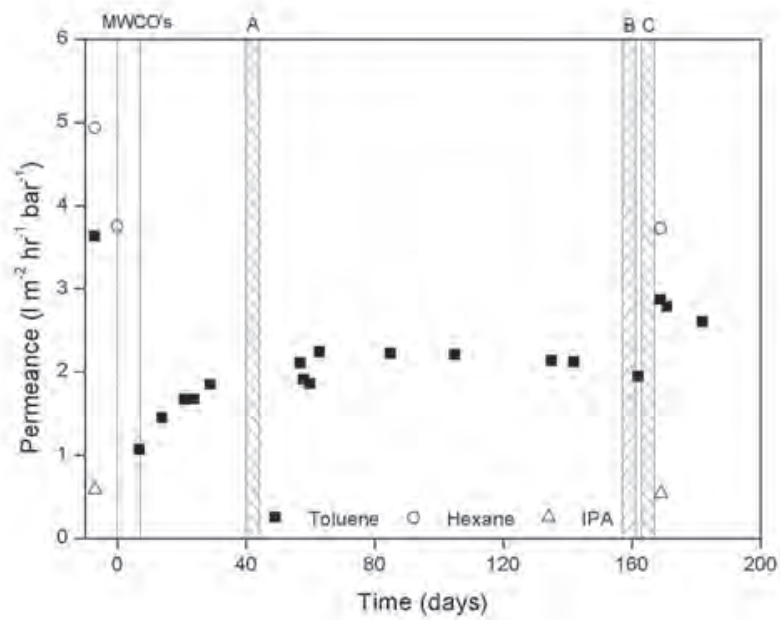

Figure 12: Toluene permeance for a $25 \mathrm{mM}$ PDMS membrane (A2) as function of time. In period $\mathrm{A}$ the solvent was changed to hexane and after 4 days back to toluene. In period $\mathrm{B}$ the membrane was treated in toluene at $80^{\circ} \mathrm{C}$ for 4 days and in period $\mathrm{C}$ in IPA at $75^{\circ} \mathrm{C}$ for 5 days. The permeance data at Time $<0$ days represent initial experiments as given in Figure 6 and 8 .

A more elaborate study on membrane stability has been performed in toluene. These results are summarized in Figure 12. Prior to these stability tests (i.e. prior to Time $=0$ days in Figure 12) the membrane permeance was measured in toluene, hexane and IPA (so-called initial tests, which results are e.g. given in Figure 6) and subsequently soaked for 7 days in hexane where upon the molecular weight cut off (MWCO) was 
determined (Time $=0$ days). Subsequently, the membrane was soaked in toluene for another 7 days and again the MWCO was determined. After that the membrane was maintained in toluene till the solvent was exchanged to hexane at day 40 , followed by drying and soaking in toluene. All these experiments were performed at room temperature. In order to determine the stability in a boiling solvent and thus to simulate the APTES and PDMS reaction conditions, the membranes were soaked in boiling IPA and toluene i.e. at day 157 the membrane was soaked in toluene at $80^{\circ} \mathrm{C}$ for 4 days and at day 163 in IPA at $75^{\circ} \mathrm{C}$ in IPA for 4 days.

A decrease in toluene permeance from 3.8 to $2.1 \mathrm{I} \mathrm{m}^{-2} \mathrm{hr}^{-1} \mathrm{bar}^{-1}$ is observed between the initial experiment (Time $=-7$ days) and the moment the system is stabilized (Time $\sim 29$ days), while the contact angle shows a small decrease from an initial value of $97 \pm 1^{\circ}$ till $92 \pm 2^{\circ}$ (Time $=60$ days). A decrease in permeance is often attributed to starting-up effects which are usually related to some traces of water or organic impurities in the membrane as e.g. reported by Chowdhury et al. [47], who analyzed hexane and toluene fluxes using hydrophilic $\gamma$-alumina membranes with different pore sizes $(3.5-5.9 \mathrm{~nm})$. In their work the decrease in solvent permeance was attributed to a possible on-going capillary condensation of water in the membrane pores, which is present in the solvents in small amounts. A comparable decrease in permeance in long-term experiments is also observed by Sah et al. [55] where pervaporation experiments with a n-butanol / water mixture (97.5/2.5 wt.\%) were performed using (hydrophobic) hybrid silica membranes. The authors ascribed this phenomenon to initial interaction of the solvent mixture with the hybrid silica network in the early stages of operation as well as to a structural rearrangement of the polymeric network by the applied pressure. However, since it is assumed that in our case the grafted PDMS layer is completely confined in the pores, structural rearrangements will most probably not be the case. Capillary condensation of water seems to be the most probably source for the permeation behaviour of hydrophilic membranes used by Chowdhury et al. [47], but (hydrophobic) PDMS-grafted membranes as ours have a much lower tendency for capillary condensation of water, though other organic impurities might give similar effects.

In the period between the initial experiments (Time $=0$ days) and the time stability in permeance is reached (Time $\sim 29$ days) a drop in permeance is observed from 3.8 to $1.1 \mathrm{I} \mathrm{m}^{-2} \mathrm{hr}^{-1} \mathrm{bar}^{-1}$. This can be ascribed to some (larger) PIB molecules which remained inside the membrane after the (two) MWCO measurements. The most feasible explanation is that flushing time and pressure were not sufficient 
for complete removal of the PIB molecules from the membrane. After the two MWCO measurements the permeance slowly increased until probably all the PIB molecules were released from the membrane.

No significant change in permeance occurred after a change from toluene to hexane at day 40. Eventually the permeance is constant and it can be stated that the membrane is stable for at least 130 days in toluene.

During grafting of the APTES linker the toluene-APTES solution is kept at a temperature of $80^{\circ} \mathrm{C}$, allowing the formation of a vapor, which reacts with the $\mathrm{OH}$ groups of the membrane surface. PDMS is subsequently grafted to the modified membrane in IPA at $75^{\circ} \mathrm{C}$. In order to investigate the stability of a $25 \mathrm{mM}$ PDMS grafted membrane (A2) under more extreme conditions, the membrane was soaked after 157 days in toluene at $80^{\circ} \mathrm{C}$. As presented in Figure 12 , the toluene permeance remained constant as it is still within the error range, which was determined from the data points around 60 days. Here an error of $0.4 \mathrm{I} \mathrm{m}^{-2} \mathrm{hr}^{-1} \mathrm{bar}^{-1}$ was determined. After this experiment in boiling toluene the membrane was dried and soaked for 4 days in IPA at $75^{\circ} \mathrm{C}$ and subsequently the permeance in IPA, toluene and hexane was measured. Between each measurement the membrane was dried and soaked overnight in the respective solvent. As shown in Figure 12, a slight increase in toluene permeance was observed after this latter treatment. A possible explanation is degradation of the PDMS layer. Contact angle measurements show a decrease from $92 \pm 2^{\circ}$ (Time $=60$ days) to $82 \pm 2^{\circ}$ (Time $=170$ days) which can be an indication of some detachment of PDMS molecules. Another explanation is related to the removal of impurities present inside the membrane, combined with changes in morphology of the grafted layer due to multiple swelling and compaction cycles that occurred during the soaking and drying steps. Degradation of the PDMS layer does not seem to be plausible in this case, since a lower value of toluene (Figure 12, after period C) permeance is measured when compared to the initial value.

The permeances of hexane, toluene and IPA at the end of the stability tests (Figure 12, after period C), are presented in Figure 15 as viscosity corrected permeance (VCP) values versus the Hildebrand solubility parameter.

A comparison between these values and the ones determined before stability tests shows a slight, almost negligible, decrease in permeance but a similar trend (Figure 9), meaning that toluene still presents the highest VCP value whereas for hexane and IPA identical values for VCP are found. Therefore, the unexpected higherVCP for toluene when compared with hexane cannot be explained by startup effects. 


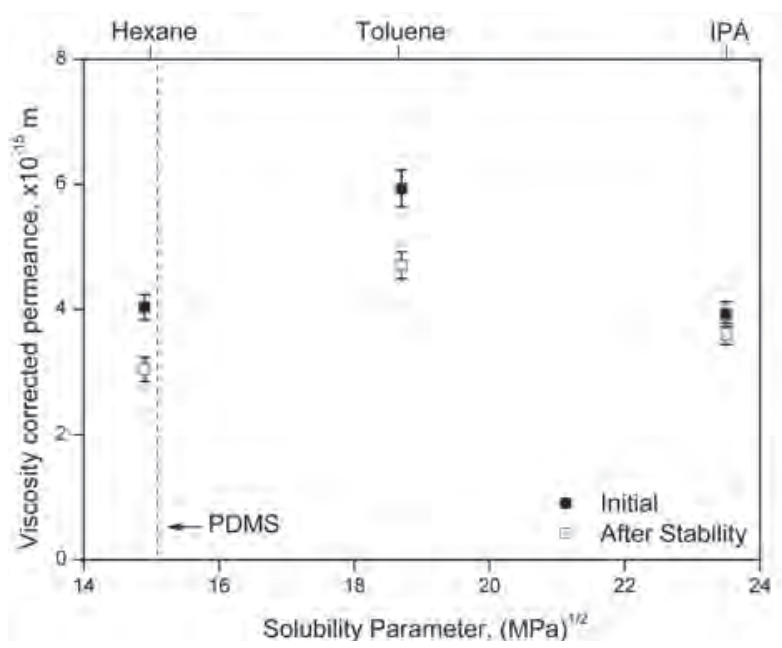

Figure 13: Viscosity corrected permeance (VCP) versus the Hildebrand solubility parameter of a $25 \mathrm{Mm}$ PDMS grafted membrane (A2) before and after stability tests

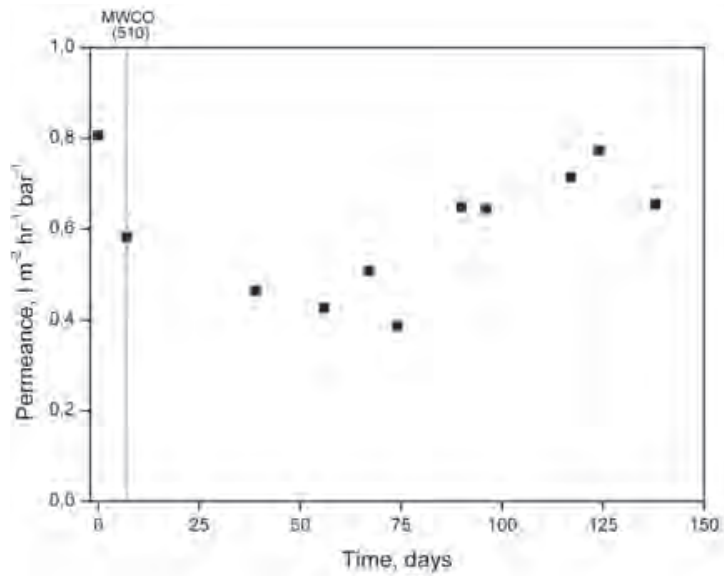

Figure 14: Stability of a 25 mM PDMS (A3) membrane in IPA. Filtrations were conducted at 11 bar TMP and room temperature.

Figure 14 shows the stability in IPA. After 7 days the MWCO is measured. The permeance values for IPA are in the range of 0.4-0.8 $1 \mathrm{~m}^{-2} \mathrm{hr}^{-1} \mathrm{bar}^{-1}$ and are within the experimental error $\left(0.4 \mathrm{I} \mathrm{m}^{-2} \mathrm{hr}^{-1} \mathrm{bar}^{-1}\right)$. For IPA permeance values at the end of the stability testing period are comparable to the initial value and thus the membrane can be considered stable in IPA for at least 130 days. An initial contact angle value of $91 \pm 1^{\circ}$ is measured, while after 73 days to a contact angle is $73 \pm 4^{\circ}$. This decrease in hydrophobicity seems not to influence the permeance performance.

In conclusion, it can be stated that PDMS grafted membranes are stable in hexane 
(Figure 11), toluene (Figure 12) and in IPA (Figure 14). Furthermore, changing solvents seems to have a non-damaging effect on flux of the different solvents.

\subsubsection{MWCO measurements}

Several methods have been proposed in literature for the determination of the MWCO for SRNF membranes, however till so far no universal protocol is available. The complexity arises from pronounced effects of process conditions (e.g. concentration polymerization phenomenon), inherent properties of the membrane and solute (shape and flexibility), and solvent-solute-membrane interactions [56]. A promising method is the filtration of a mixture of different MW fractions of styrenes or isobutylene oligomers dissolved in toluene or hexane as proposed by different authors [57][58]. In this work a 0.3\% (w/w) solution of polyisobutylene (PIB) in toluene was used.

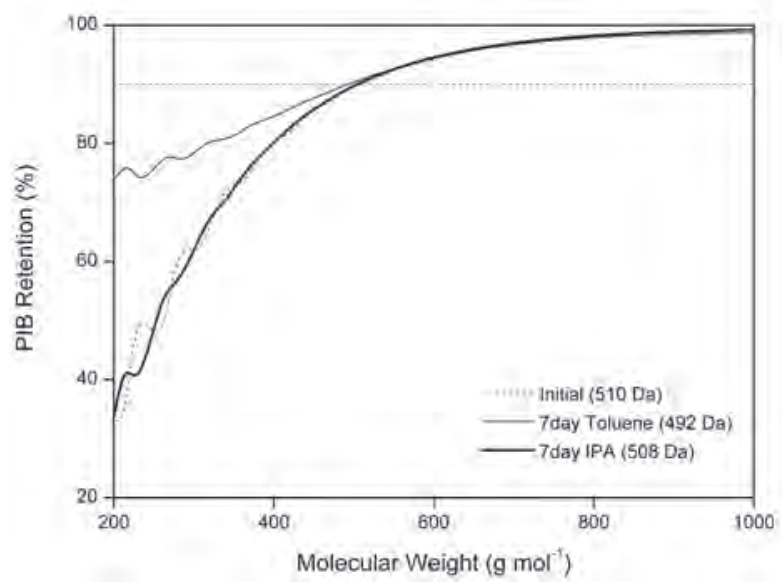

Figure 15: PIB retention curves for a 25 mM VPD modified membranes ( $\mathrm{A} 1$ ) before and after treatment for 7 days in toluene (A2), or for 7 days in IPA (A3).

Figure 15 shows PIB retentions as performed on 3 different membranes (A1, A2, $A 3)$, synthesized under identical conditions. For membrane A1 the MWCO of the $\mathrm{PIB} /$ toluene solution was determined on a freshly prepared membrane, while for membranes $\mathrm{A} 2$ and $\mathrm{A} 3$ the $\mathrm{MWCO}$ of a PIB/toluene solution was determined after the membranes were soaked for 7 days in respectively toluene and IPA. The MWCO's of the modified membranes are significantly lower than the MWCO of the unmodified membrane $(2500 \mathrm{Da})$. As the maximum retention of the membranes was $100 \%$ (for MW > $900 \mathrm{Da}$ ) it is clear that no defects or cracks are present. In 
all cases the polyisobutylene retention curves for the $25 \mathrm{mM}$ VPD PDMS grafted $\gamma$-alumina membranes intersect at $90 \%$ retention with a MW of around $500 \mathrm{Da}$. By using lower precursor concentrations during grafting, like $12.5 \mathrm{mM}$ for a VPD modified membrane, MWCO values between 800-2000 Da were obtained. The wide range for MWCO values confirms and supports the lack of reproducibility for pure solvent fluxes as shown in Figure 10. This is another proof that in our case only APTES and PDMS concentrations of $25 \mathrm{mM}$ are suitable for making reproducible membranes.

Table 3: Toluene and hexane permeance and MWCO values for several membranes reported in the literature.

\begin{tabular}{|c|c|c|c|c|c|}
\hline & $\begin{array}{l}\text { Toluene } \\
\text { permeance } \\
\left(\mathrm{I} \mathrm{m}^{-2} \mathrm{hr}^{-1} \text { bar }^{-1}\right)\end{array}$ & $\begin{array}{l}\text { Hexane } \\
\text { permeance } \\
\left(\mathrm{I} \mathrm{m}^{-2} \mathrm{hr}^{-1} \text { bar }^{-1}\right)\end{array}$ & $\begin{array}{l}\text { IPA permeance } \\
\left(\mathrm{I} \mathrm{m}^{-2} \mathrm{hr}^{-1} \text { bar }^{-1}\right)\end{array}$ & $\begin{array}{l}\text { MWCO } \\
\text { (Da) }\end{array}$ & Ref. \\
\hline $\begin{array}{l}\text { PDMS grafted Alumina } \\
\text { (This work) }\end{array}$ & $3.1 \pm 0.5$ & $4.8 \pm 0.1$ & $0.54 \pm 0.04$ & 500 & - \\
\hline $\begin{array}{l}\text { MPF-50 (Koch, Silicon } \\
\text { based NF membrane) } \\
\text { (Suffers from compac- } \\
\text { tion) }\end{array}$ & 1.3 & 1.52 & 0.15 & $700^{a)}$ & {$[20,21,25]$} \\
\hline $\begin{array}{l}\text { Membrane D (Osmonics) } \\
\text { Composite dimethylsili- } \\
\text { cone NF }\end{array}$ & 2.44 & 1.6 & 0.2 & $807^{b)}$ & {$[21,30]$} \\
\hline $\begin{array}{l}\text { PAN-PE/PDMS }( \pm 1 \mu \mathrm{m}) \\
\text { Plasma treated }\end{array}$ & 1.2 & - & 0.2 & $1000^{c)}$ & [27] \\
\hline $\begin{array}{l}\text { PAN/PDMS cross-linked } \\
\text { by irradiation }(2 \mu \mathrm{m})\end{array}$ & - & 8.41 & - & $350-400^{d)}$ & {$[26,59]$} \\
\hline PAN/PDMS $(2 \mu \mathrm{m})$ & $2.0 \pm 0.4$ & $3.0 \pm 0.4$ & & $1200-1250^{f)}$ & [17] \\
\hline $\begin{array}{l}\text { a-Alumina Tubular shape } \\
(20 \mathrm{~nm}) / \text { PDMS coated } \\
\text { membrane } \\
(7.3 \pm 3 \mu \mathrm{m})\end{array}$ & $1.6 \pm 0.1$ & - & - & $500^{g)}$ & [18] \\
\hline
\end{tabular}

a) Determined in a mixture of Sudan IV/ ethylacetate, b) Determine in a mixture of tripalmitin/ hexane c) Determine in a Rose bengal/IPA solution, d) Determine with a mixture of Iron (III) naphtalene/xylene, f) Determine in a PIB/hexane solution

\subsubsection{Comparison with literature}

For $25 \mathrm{mMVPD}$ grafted membrane a toluene permeance of $3.1 \mathrm{I} \mathrm{m}^{-2} \mathrm{hr}^{-1} \mathrm{bar}^{-1}$ (Figure 8) and a MWCO of $500 \mathrm{Da}$ are obtained. Table 3 presents the values for toluene, hexane and IPA permeances and MWCO values for several membranes reported in 
the literature. A comparison in terms of toluene and hexane permeances reveals in all case the highest values for membranes prepared in this work. This holds as well for laboratory-made membranes as reported by Dutczak et al. [18], Vankelecom et al. [27] and Stafie et al. [17], as well as two commercial available membranes, the MPF-50 and membrane D [21,30]. Most of these membranes present similar or higher MWCO values if compared with the systems, described in this work. Only the PAN-PDMS composite membrane of Robinson et al. [26] shows the highest hexane permeance and the lowest MWCO value [9].

In conclusion, the membranes, developed in this work, can be a suitable membrane for SRNF, since it presents relative good fluxes when compared with others, good stability in organic solvents, a suitable MWCO range and reproducible membranes can be attained.

\subsection{Conclusions}

In this study it is shown that modifying a porous ceramic support by polymer grafting allows us to tune the pore size and engineer the surface chemistry (e.g. hydrophobicity) of membranes, which play a crucial role in the membrane performance. PDMS grafted $\gamma$-alumina membranes were attained through a twostep synthesis which initially involves a silylation step with APTES and followed by a ring opening reaction with an epoxy terminated PDMS. In this work the linker was deposited using two different methods, a vapor phase method (VPD) and a solution phase method (SPD). Through both methods the linker was successfully grafted, and subsequently the PDMS. After grafting the linker on the membrane a reduction in pore radius was observed for both methods and thus proving that the pore walls were successfully modified. However, a clear difference in the thickness and structure of the APTES linker grafted layer was attained. For VPD, a monolayerlike structure was observed, whereas for SPD a multilayer system was obtained. Further reduction in pore size was observed after PDMS grafting, indicating that the PDMS successfully modified the pores. The incorporation of polymeric material by grafting allows us to engineer the properties of the $\gamma$-Alumina membrane as proven by the increase in contact angle towards a more hydrophobic membrane. A concentration of $25 \mathrm{mM}$ was found to be efficient to promote a suitable hydrophobicity $\left(94^{\circ}\right)$ and pore size reduction towards a microporous or dense material. 
Permeation at room temperature was examined for three solvents with different viscosities, shapes and polarities, i.e. hexane, toluene and IPA. As expected, nonpolar solvents showed higher permeances than more polar ones $\left(4.8 \pm 0.1 \mathrm{I} \mathrm{m}^{-2}\right.$ $\mathrm{hr}^{-1}$ bar ${ }^{-1}$ for hexane, $3.1 \pm 0.5 \mathrm{I} \mathrm{m}^{-2} \mathrm{hr}^{-1}$ bar $^{-1}$ for toluene vs. $0.54 \pm 0.04 \mathrm{I} \mathrm{m}^{-2} \mathrm{hr}^{-1} \mathrm{bar}^{-1}$ for IPA). Similar values were obtained for a set of 3 membranes using the same experimental conditions.

In conclusion, reproducible membranes were synthesized and a MWCO of a $500 \mathrm{Da}$ was measured. Therefore, a nanofiltration membrane was synthesized. Moreover, stability tests performed in hexane, toluene and IPA at room temperature have shown that these membranes were stable in all solvents during testing periods of up to 170 days. The membrane was also soaked in toluene and IPA at higher temperatures in order to simulate the reaction conditions during membrane fabrication. No change in toluene permeance was observed after this treatment, indicating that these membranes are stable under the conditions, used during fabrication of the membranes. Correcting the flux-pressure relationships for viscosity shows that for all solvents the transport is mainly controlled by pore flow and that solution/diffusion is less significant. Higher viscosity corrected permeances (VCPs) are observed for toluene than for hexane and IPA. However, according to the Hildebrand solubility model, hexane is expected to present the highest VCP, followed by toluene and IPA. Similar behavior for dense polymeric PDMS membranes suggests that our grafted PDMS is dense as well. Swelling experiments have indicated that more swelling was observed for hexane. The apperent viscosity of the liquid, if confined inside the membrane, may differ from the macroscopic/bulk viscosity of a solvent due to interaction between solvent and membrane. This confined viscosity effect is more pronounced for hexane than for toluene, almost certainly caused by the flexibility of hexane and the rigidity of toluene. However, no actual value could be determined for the microscopic viscosity. Therefore, further studies are needed in order to clarify the role of chemical transport and how the microscopic viscosity influences the transport in dense systems as the one study.

\section{Acknowledgement}

Marcel Boerrigter is acknowledged for performing the Gas Permeation Chromatography measurements. This is an ISPT project (Institute for Sustainable Process Technology). 


\subsection{References}

1. Scarpello, J.T., et al., The separation of homogeneous organometallic catalysts using solvent resistant nanofiltration. Journal of Membrane Science, 2002. 203(1-2): p. 71-85.

2. Zwijnenberg, H.J., et al., Acetone-stable nanofiltration membranes in deacidifying vegetable oil. Journal of the American Oil Chemists Society, 1999. 76(1): p. 83-87.

3. Geens, J., et al., Polymeric nanofiltration of binary water-alcohol mixtures: Influence of feed composition and membrane properties on permeability and rejection. Journal of Membrane Science, 2005. 255(1-2): p. 255-264.

4. Geens, J., B. Van der Bruggen, and C. Vandecasteele, Characterisation of the solvent stability of polymeric nanofiltration membranes by measurement of contact angles and swelling. Chemical Engineering Science, 2004. 59(5): p. 1161-1164.

5. Van der Bruggen, B., J. Geens, and C. Vandecasteele, Fluxes and rejections for nanofiltration with solvent stable polymeric membranes in water, ethanol and n-hexane. Chemical Engineering Science, 2002. 57(13): p. 2511-2518.

6. Tarleton, E.S., J.P. Robinson, and M. Salman, Solvent-induced swelling of membranes Measurements and influence in nanofiltration. Journal of Membrane Science, 2006. 280(12): p. 442-451.

7. Beerlage, M.A.M., Polyimide ultrafiltration membranes for non-aqueous systems, PhD Thesis, 1994, University of Twente, Enschede.

8. Tsuru, T., et al., Inorganic porous membranes for nanofiltration of nonaqueous solutions. Separation and Purification Technology, 2003. 32(1-3): p. 105-109.

9. Geens, J., et al., Modelling of solute transport in non-aqueous nanofiltration. Journal of Membrane Science, 2006. 281(1-2): p. 139-148.

10. Verrecht, B., et al., Chemical surface modification of gamma-Alumina $\mathrm{TiO}_{\text {, }}$ toplayer membranes for increased hydrophobicity. Desalination, 2006. 200(1-3): p. 385-386.

11. Van Gestel, T., et al., Surface modification of $\gamma$-Alumina/ $/ \mathrm{TiO}_{2}$ multilayer membranes for applications in non-polar organic solvents. Journal of Membrane Science, 2003. 224(1-2): p. 3-10.

12. Sah, A., et al., Hydrophobic modification of $y$-alumina membranes with organochlorosilanes. Journal of Membrane Science, 2004. 243(1-2): p. 125-132.

13. Vankelecom, I.F.J., et al., Parameters Influencing Zeolite Incorporation In Pdms Membranes. Journal of Physical Chemistry, 1994. 98(47): p. 12390-12396.

14. Vankelecom, I.F.J., S. DeBeukelaer, and J.B. Uytterhoeven, Sorption and pervaporation of aroma compounds using zeolite-filled PDMS membranes. Journal of Physical Chemistry B, 1997. 101(26): p. 5186-5190.

15. Litvinov, V.M. and H.W. Spiess, H- Nmr-Study Of Molecular Motions In Polydimethylsiloxane And Its Mixtures With Aerosils. Makromolekulare Chemie-Macromolecular Chemistry and Physics, 1991. 192(12): p. 3005-3019.

16. Gevers, L.E.M., I.F.J. Vankelecom, and P.A. Jacobs, Solvent-resistant nanofiltration with filled polydimethylsiloxane (PDMS) membranes. Journal of Membrane Science, 2006. 278(1-2): p. 199-204.

17. Stafie, N., D.F. Stamatialis, and M. Wessling, Effect of PDMS cross-linking degree on the permeation performance of PAN/PDMS composite nanofiltration membranes. Separation and Purification Technology, 2005. 45(3): p. 220-231.

18. Dutczak, S.M., et al., Composite capillary membrane for solvent resistant nanofiltration. Journal of Membrane Science, 2011. 372(1-2): p. 182-190.

19. Leger, C., H.D.L. Lira, and R. Paterson, Preparation and properties of surface modified ceramic membranes. Part II. Gas and liquid permeabilities of $5 \mathrm{~nm}$ alumina membranes modified by a monolayer of bound polydimethylsiloxane (PDMS) silicone oil. Journal of Membrane Science, 1996. 120(1): p. 135-146.

20. Machado, D.R., D. Hasson, and R. Semiat, Effect of solvent properties on permeate flow 
through nanofiltration membranes. Part I: investigation of parameters affecting solvent flux. Journal of Membrane Science, 1999. 163(1): p. 93-102.

21. Bhanushali, D., et al., Performance of solvent-resistant membranes for non-aqueous systems: solvent permeation results and modeling. Journal of Membrane Science, 2001. 189(1): p. 1-21.

22. Bhanushali, D., S. Kloos, and D. Bhattacharyya, Solute transport in solvent-resistant nanofiltration membranes for non-aqueous systems: experimental results and the role of solute-solvent coupling. Journal of Membrane Science, 2002. 208(1-2): p. 343-359.

23. Paul, D.R. and Kebralim.O.M, Pressure-Induced Diffusion Of Organic Liquids Through Highly Swollen Polymer Membranes. Journal of Applied Polymer Science, 1970. 14(9): p. 2201.

24. Paul, D.R., J.D. Paciotti, and O.M. Ebralima, Hydraulic Permeation Of Liquids Through Swollen Polymeric Networks .2. Liquid-Mixtures. Journal of Applied Polymer Science, 1975. 19(7): p. 1837-1845.

25. Machado, D.R., D. Hasson, and R. Semiat, Effect of solvent properties on permeate flow through nanofiltration membranes - Part II. Transport model. Journal of Membrane Science, 2000. 166(1): p. 63-69.

26. Robinson, J.P., et al., Solvent flux through dense polymeric nanofiltration membranes. Journal of Membrane Science, 2004. 230(1-2): p. 29-37.

27. Vankelecom, I.F.J., et al., Physico-chemical interpretation of the SRNF transport mechanism for solvents through dense silicone membranes. Journal of Membrane Science, 2004. 231(1-2): p. 99-108.

28. Gevers, L.E.M., et al., Physico-chemical interpretation of the SRNF transport mechanism for solutes through dense silicone membranes. Journal of Membrane Science, 2006. 274(1-2): p. 173-182.

29. Gevers, L.E.M., et al., Optimisation of a lab-scale method for preparation of composite membranes with a filled dense top-layer. Journal of Membrane Science, 2006. 281(1-2): p. 741-746.

30. Bhanushali, D. and D. Bhattacharyya, Advances in solvent-resistant nanofiltration membranes - Experimental observations and applications, in Advanced Membrane Technology, N.N. Li, et al., Editors. 2003, New York Acad Sciences: New York. p. 159-177.

31. Dobrak, A., et al., Solvent flux behavior and rejection characteristics of hydrophilic and hydrophobic mesoporous and microporous $\mathrm{TiO}_{2}$ and $\mathrm{ZrO}_{2}$ membranes. Journal of Membrane Science, 2010. 346(2): p. 344-352.

32. Tsuru, T., et al., Permeation of Liquids through Inorganic Nanofiltration Membranes. Journal of Colloid and Interface Science, 2000. 228(2): p. 292-296.

33. Tsuru, T., et al., Characterization of sol-gel derived membranes and zeolite membranes by nanopermporometry. Separation and Purification Technology, 2003. 32(1-3): p. 23-27.

34. Tsuru, T., et al., Preparation of hydrophobic nanoporous methylated $\mathrm{SiO}_{2}$ membranes and application to nanofiltration of hexane solutions. Journal of Membrane Science, 2011. 384(1-2): p. 149-156.

35. Ana F.M. Pinheiro, Efficient pore grafting of siloxane moieties onto $\gamma$-alumina flakes (this thesis: chapter4)

36. Cao, G.Z., et al., Permporometry study on the size distribution of active pores in porous ceramic membranes. Journal of Membrane Science, 1993. 83(2): p. 221-235.

37. Vandenberg, E., et al., Protein immobilization of 3-aminopropyl triethoxy silane glutaraldehyde surfaces: Characterization by detergent washing. Journal of Colloid and Interface Science, 1991. 143(2): p. 327-335.

38. White, L.D. and C.P. Tripp, Reaction of (3-Aminopropyl)dimethylethoxysilane with Amine Catalysts on Silica Surfaces. Journal of Colloid and Interface Science, 2000. 232(2): p. 400407.

39. Kurth, D.G. and T. Bein, Thin Films of 3-Aminopropyltriethoxysilane on Aluminum Oxide and Gold Substrates. Langmuir, 1995. 11(8): p. 3061-3067.

40. Heiney, P.A., et al., Structure and Growth of Chromophore-Functionalized 3-Aminopropyltriethoxysilane Self-Assembled on Silicon. Langmuir, 2000. 16(6): p. 2651-2657. 
41. Trens, P. and R. Denoyel, Adsorption of $Y$-Aminopropyltriethoxysilane and Related Molecules at the Silica/Heptane Interface. Langmuir, 1996. 12(11): p. 2781-2784.

42. Kallury, K.M.R., P.M. Macdonald, and M. Thompson, Effect of Surface Water and Base Catalysis on the Silanization of Silica by Aminopropylalkoxysilanes Studied by X-ray Photoelectron Spectroscopy and 13C Cross-Polarization/Magic Angle Spinning Nuclear Magnetic Resonance. Langmuir, 1994. 10(2): p. 492-499.

43. Raman, L.P., M. Cheryan, and N. Rajagopalan, Solvent recovery and partial deacidification of vegetable oils by membrane technology. Fett-Lipid, 1996. 98(1): p. 10-14.

44. Ritter, $\mathrm{H}_{\text {., }}$ et al., A comparative study of the functionalization of mesoporous silica MCM-41 by deposition of 3-aminopropyltrimethoxysilane from toluene and from the vapor phase. Microporous and Mesoporous Materials, 2009. 121(1-3): p. 79-83.

45. Vandezande, P., L.E.M. Gevers, and I.F.J. Vankelecom, Solvent resistant nanofiltration: separating on a molecular level. Chemical Society Reviews, 2008. 37(2): p. 365-405.

46. Kang, H.J. and F.D. Blum, Structure and dynamics of amino functional silanes adsorbed on silica surfaces. The Journal of Physical Chemistry, 1991. 95(23): p. 9391-9396.

47. Chowdhury, S.R., et al., Effect of trace amounts of water on organic solvent transport through gamma-alumina membranes with varying pore sizes. Langmuir, 2004. 20(11): p. 4548-4552.

48. Tsuru, T., et al., Permeation of nonaqueous solution through organic/Inorganic hybrid nanoporous membranes. AIChE Journal, 2004. 50(5): p. 1080-1087.

49. Stafie N., Poly(dimethylsiloxane)-base Composite Nanofiltration Membrane for Nonaqueous Applications, PhD thesis,2004, University of Twente, Enschede, The Netherlands

50. Van Properties of Polymers: Their Correlation with Chemical Structure; Their Numerical Estimation and Prediction from Additive Group Contributions

51. Kiran, E. and Y.L. Sen, High-Pressure Viscosity And Density Of Normal-Alkanes. International Journal of Thermophysics, 1992. 13(3): p. 411-442.

52. Dymond, J.H., et al., The Viscosity Of Liquid Toluene At Elevated Pressures. International Journal of Thermophysics, 1995. 16(4): p. 877-882.

53. Sharma, K.K., et al., Toward efficient nanoporous catalysts: Controlling site-isolation and concentration of grafted catalytic sites on nanoporous materials with solvents and colorimetric elucidation of their site-isolation. Journal of the American Chemical Society, 2008. 130(1): p. 218-228.

54. Yokoi, T., H. Yoshitake, and T. Tatsumi, Synthesis of amino-functionalized MCM-41 via direct co-condensation and post-synthesis grafting methods using mono-, di- and tri-aminoorganoalkoxysilanes. Journal of Materials Chemistry, 2004. 14(6): p. 951-957.

55. Sah, A., Chemically modified ceramic membranes-study of structural and transport properties, PhD thesis, 2006, Enschede, The Netherlands.

56. Zwijnenberg, H.J., et al., Important factors influencing molecular weight cut-off determination of membranes in organic solvents. Journal of Membrane Science, 2012. 390-391(0): p. 211-217.

57. I Voigt, Ceramic Nanofiltration Membranes for Applications in Organic Solvents, in: 9th Aachen Membrane Colloquium, Aachen, Germany, 2003, pp. pOP 20-21-OP 20-21.

58. Toh, Y.H.S., et al., In search of a standard method for the characterisation of organic solvent nanofiltration membranes. Journal of Membrane Science, 2007. 291(1-2): p. 120-125.

59. Tarleton, E.S., et al., Non-aqueous nanofiltration: solute rejection in low-polarity binary systems. Journal of Membrane Science, 2005. 252(1-2): p. 123-131. 


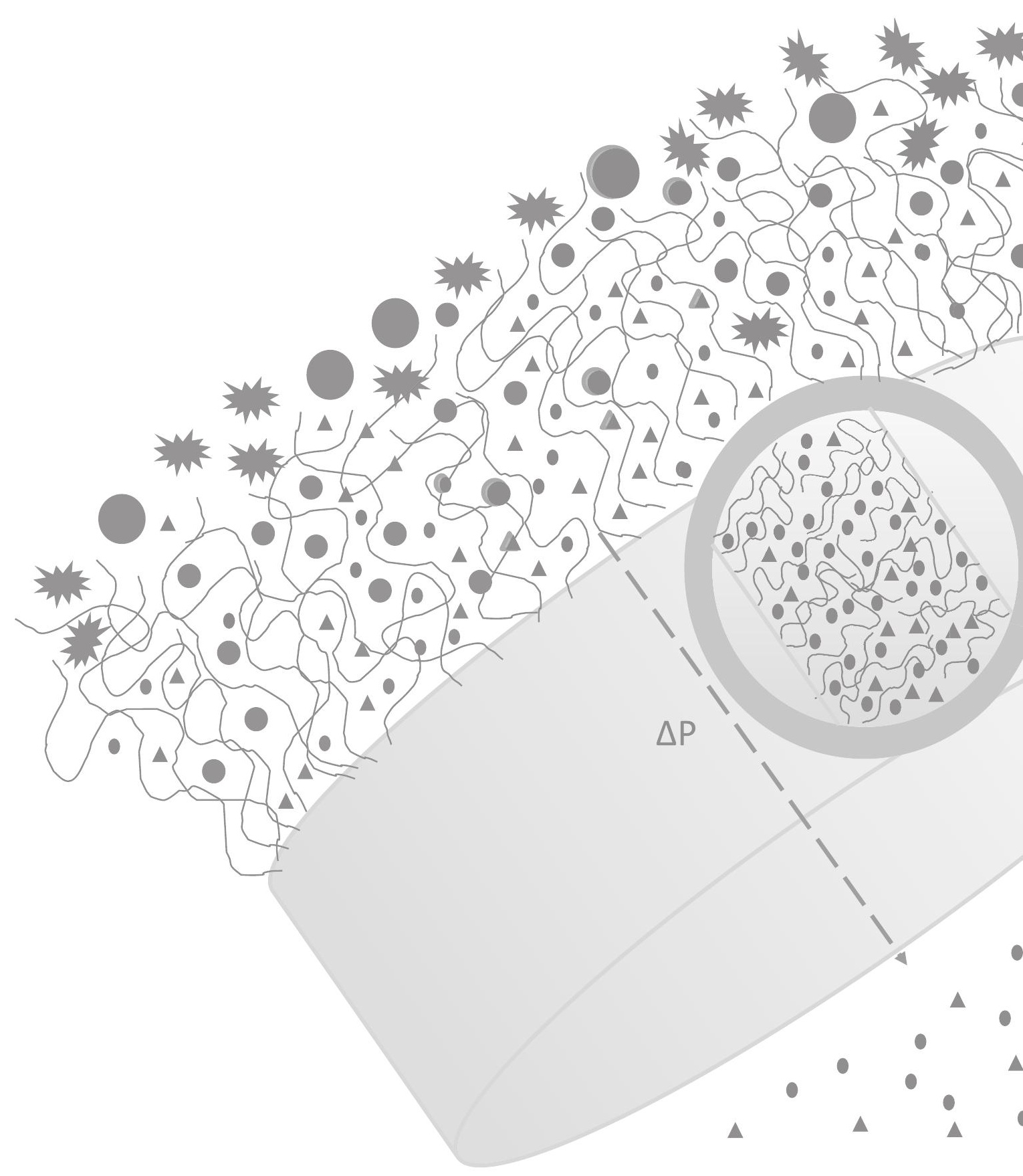


Chapter

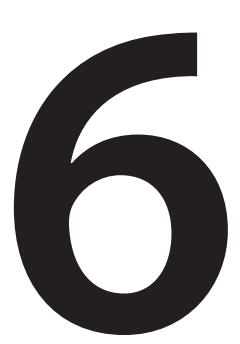

\section{BTDA-ODA imide grafting} of ceramic membranes:

Fabrication, microstructure and solvent permeation

$$
\begin{aligned}
& \Delta_{\Delta}^{\Delta} \\
& \bullet_{0}^{\Delta} \bullet_{0}^{\bullet} \bullet^{\Delta}
\end{aligned}
$$

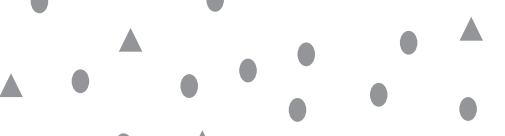

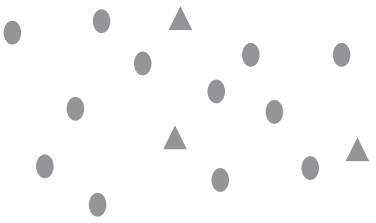




\section{Abstract}

Hydrophilic nanofiltration membranes are developed by grafting a polyimidebased polymer (BTDA-ODA) into the pores of 5 or $9 \mathrm{~nm} \gamma$-alumina membranes. Polyimide grafted membranes were prepared through a two-step synthesis which involved grafting of the linker (APTES), using a vapor phase (VPD) or a solution phase deposition method (SPD), followed by grafting of the dianhydride (BTDA) monomer and subsequently the diamine (ODA) by applying either an in-situ polymerization or a layer by layer method. Grafting (covalently bonding) of the subsequent monomers on alumina was proven by FTIR. Filtration experiments showed that grafting method and ceramic membrane pore size directly influence membrane performance. For membranes prepared by in-situ polymerization no detectable solvent flux could be measured, whilst for a porous $9 \mathrm{~nm}$ grafted membrane grafted by a layer by layer method reproducible toluene $\left(1.7 / \mathrm{m}^{-2} \mathrm{hr}^{-1}\right.$ $\mathrm{bar}^{-1}$ ) and hexane permeances $\left(3.9 \mathrm{I} \mathrm{m}^{-2} \mathrm{hr}^{-1} \mathrm{bar}^{-1}\right)$ were attained. A Molecular Weight Cut Off (MWCO) of 830 Da was determined. Stability tests in toluene and hexane show that these polyimide grafted membranes were stable in toluene during a period of up to 29 days, however for hexane on going capillary condensation of water resulted in a drastic decrease in hexane permeance. It is demonstrated that layer by layer method results in better control over membrane pore size and solvent performance. 


\subsection{Introduction}

Separation and purification of organic-organic mixtures are a major problem in the chemical industry. Membrane technology has the potential to answer to these demands. Solvent Resistant Nanofiltration Membranes (SRNF) allow economic (reduction in energy costs) and efficient (reduction of waste by recycling) separation of molecules in the in the molecular weight range of 200-1000 $\mathrm{g} \mathrm{mol}^{-1}$. Several examples are available in the petrochemical [1-3], food [4-6], chemical synthesis $[7,8]$ and pharmaceutical industry $[9,10]$ e.g. recovering of dewaxing solvents from lubricant oil filtrates [11] and recovering of organometallic complexes from organic solvents [12]. Despite all these advantages, the limit in choice of robust membranes hampers the application of SRNF membranes. The development of membranes with improved chemical resistance, long term stability and separation performance is crucial.

Many polymeric membranes used for organic solvent nanofiltration (OSN) are composites based on a polydimethylsiloxane (PDMS) separating layer on a polyacrilonitrile (PAN) support [13-18]. Although PAN shows good solvent resistance, the PDMS separation layer suffers from swelling in many solvents resulting in limited solvent stability and poor performance [18-21].

Another very important class of advanced polymers as membrane materials are aromatic polyimides. Polyimide SRNF membranes are usually integrally skinned asymmetric membranes. Some examples are the BTDA based Lenzing P84 [22][23] and the BTDA based Matrimid ${ }^{\varpi}$, the PMDA based Kapton $^{\mathrm{TM}}$ and the polyetherimide Ultrem 100. These polymers show an excellent thermal and mechanical stability due to their stiff aromatic backbone. Prolonged use of polyimides (PI) is possible at temperatures up to $200^{\circ} \mathrm{C}$, and for short-term applications at temperatures up to $400{ }^{\circ} \mathrm{C}$ [24]. They are also resistant at room temperature to a number of solvents such as aromatics, aliphatics and ketones, esters, alcohols and concentrated acids [22] [25]. However, PI membranes can become instable in certain classes of solvents such as amines (DMAc and DMSO) as well as chlorinated and protic solvents (NMP, THF, DMF) which are common solvents for polyimides synthesis [26].

In order to solve this problem the polymer chains are usually crossslinked. A PI membrane can be crosslinked by thermal or UV irradiation $[27,28]$ or by chemical reactions [29-31]. Crosslinking promotes resistance to chemical attack and reduces the mobility of the polymer chains (swelling effects) [32-35]. Chemical crosslinking of $\mathrm{Pl}$ with diamines in an imide ring-opening reaction is the most commonly used 
method. Toh et al.[34] crosslinked a PI-Lenzing P84 based SRNF membrane by immersion of the preformed membrane into a bath of an aliphatic diamine. The resulting membrane showed to be stable in protic solvents, e.g. DMF while a MWCO of 250-420 $\mathrm{g} \mathrm{mol}^{-1}$ was achieved. A Matrimid'-based PI membrane, crosslinked with aromatic diamines, was reported by Vanherck et al. [33]. The membrane displayed good stability in DMAc, DMSO, NMP and DMF.

Another approach is the use of inorganic membranes as a support, since, in contrast with polymeric membranes, these ceramic materials present a high mechanical and thermal stability, no swelling effects and are inert to virtually all organic solvents, making them excellent candidates for use as membrane support $[20,33,36]$. Through a grafting technique one can covalently bond a polymeric layer, in this case a polyimide, to an inorganic membrane support. This covalent bonding prevents detachment of the polyimide, even in solvents in which most polyimides are soluble, which can result in increased chemical and mechanical stability.

In this work grafting of an alumina membrane with a polyimide-based polymer by a two-step process is described. First, the alumina oxide support is grafted with a functionalized amino silane (linker) which provides anchoring groups for subsequent grafting of the dianhydride and diamine monomers resulting in a polyimide grafted alumina membrane.

Polyimides are usually the product of a reaction between a dianhydride and a diamine to produce a soluble polyamic acid, which is thermally or chemically converted to a polyamide by the loss of water. For the dianhydride we used the 3,3'-4,4'-benzophenonetetracarboxylic dianhydride (BTDA) and oxydianiline (ODA) was selected as the diamine (Figure 1). Both monomers are commercially available. The influence of the pore size of the ceramic membrane support, linker grafting method, monomer grafting method to the membrane on membrane struture and filtration performance is evaluated. The molecular structure and morphology of the grafted-polyimides were characterized by FTIR, gas adsorption and thermogravimetrical analysis on grafted alumina powders/flakes, whereas the membrane structure and wettability were characterized by permporometry and contact angle. Furthermore, liquid permeation and MWCO measurements were done to evaluate the membrane performance for nanofiltration. 
<smiles>O=C(c1ccc2c(c1)C(=O)OC2=O)c1ccc2c(c1)C(=O)OC2=O</smiles>

BTDA<smiles>Nc1ccc(Oc2ccc(N)cc2)cc1</smiles>

ODA

Figure 1: Chemical structures of the monomers used for generating the correspondent polyimide: the dianhydride benzophenonetetracarboxylic dianhydride (BTDA) and the diamine, 3,3'-diaminodiphenyl ether (ODA).

\subsection{Experimental}

\subsubsection{Materials}

All chemicals were used as received. The diamine, 3,3'-diaminodiphenyl ether (ODA), the dianhydride 3,3'4,4'-benzophenonetetracarboxylic dianhydride (BTDA) and the linking agent 3-aminopropyltriethoxysilane (APTES) were supplied by Aldrich. The solvents (toluene, $\mathrm{n}$-hexane, isopropanol, dimethylacetamide) were anhydrous and obtained from Aldrich. Acetone and ethanol were purchased from Aldrich. Mesoporous $\gamma$-alumina flakes were prepared from a boehmite sol. These flakes were dried and subsequently calcined at $650{ }^{\circ} \mathrm{C}$ or $825^{\circ} \mathrm{C}$ for 1 hour at a heating rate of $1{ }^{\circ} \mathrm{C} \mathrm{min}^{-1}$, as described in detail in [37]. The ceramic membranes consisted of a mesoporous $\gamma$-alumina top layer on a macroporous a-alumina support. The a-alumina supports were obtained from Pervatech. Flat discs with diameter $39 \mathrm{~mm}$, thickness $2.0 \mathrm{~mm}$ and a pore size of $70 \mathrm{~nm}$ were used. These supports were then coated with a $\gamma$-alumina layer of $300 \mathrm{~nm}$ thickness by dipcoating. The membranes were dried and subsequently calcined at $650{ }^{\circ} \mathrm{C}$ or $825^{\circ} \mathrm{C}$ for 1 hour using a heating rate of $1^{\circ} \mathrm{C} \mathrm{min}^{-1}$.

\subsubsection{Grafting procedure}

\subsubsection{1. $\gamma$-alumina flakes}

\section{Pre-treatment of $\gamma$-alumina flakes}

Before grafting, the $\gamma$-alumina flakes were pre-treated by soaking in an ethanol/ water (2:1) solution for 24 hours at ambient temperature, dried in a vacuum oven at $100{ }^{\circ} \mathrm{C}$ for 24 hours and stored under nitrogen atmosphere until further use. This 
was done to remove impurities and to promote a suitable degree of hydroxylation and hydratation.

\section{Grafting of $\gamma$-alumina flakes with APTES by solution phase deposition (SPD)}

The introduction of amino groups onto the $\gamma$-alumina flakes, i.e. the preparation of an "initiator site", was achieved by a reaction of the surface OH groups with APTES as described in a previous work [40] (chapter 4). In this work a $100 \mathrm{ml} 50 \mathrm{mM}$ APTES-toluene solution was used.

\section{Grafting of APTES-grafted $\gamma$-alumina flakes with polyimide: BTDA-ODA}

A two-step synthesis was employed. In a first stage, a poly(amic acid) was formed and subsequently a polyimide is formed through a thermal imidization process. Two methods were used to introduce the monomers:

1) In-situ polymerization: A reaction between the amino group of APTES and the anhydride group of BTDA (4,4'-benzophenonetetracarboxylic dianhydride), followed by a subsequent reaction between the anhydride and the amino group of diamine, 3'- diaminodiphenyl ether (ODA).

2) Layer by layer grafting: after the reaction with a monomer the product was washed and thermally imidized before the reaction with the next monomer.

A typical procedure for the in-situ polymerization method is as follows: (1) To a solution of $300 \mathrm{mg}$ of APTES-grafted $\gamma$-alumina $\mathrm{Al}_{2} \mathrm{O}_{3}$ in dimethylacetamide (DMAc) $(100 \mathrm{~mL})$ BTDA was added $(4.8 \mathrm{~g}, 150 \mathrm{mmol})$, (2) the mixture was stirred for 3 hours at $75^{\circ} \mathrm{C}$, (3) subsequently the diamine ODA (1.5g, $100 \mathrm{mmol}$ ) was added, (4) the mixture was stirred for 3 hours at $75^{\circ} \mathrm{C}$ and finally the reaction mixture was refluxed for 24 hours at $150{ }^{\circ} \mathrm{C}$. After the reaction was completed, the mixture was allowed to cool down and centrifuged with $20 \mathrm{ml}$ of fresh DMAc at $7500 \mathrm{rpm}$ for 20 min. This was repeated 2 more times with fresh DMAc to remove any nonbonded polymer. Immediately after the modified flakes were thermal imidized by stepwise heating the modified flakes for 1 hour at 100, 150, 200, 250 and finally at $300{ }^{\circ} \mathrm{C}$ with an intermediate heating rate of $1^{\circ} \mathrm{C} \mathrm{min}^{-1}$ and then cooled down at $1{ }^{\circ} \mathrm{C}$ min 1 till room temperature.

For the layer by layer method the reaction was stopped before addition of the diamine, ODA. After reaction with BTDA, the APTES-grafted flakes were washed and thermal imidized as described above for the whole polymer. For the reaction with the second monomer, ODA, the same procedure was used as for grafting BTDA, followed again by a thermal imidization treatment. For this layer by layer method 
an excess of dianhydride was not required and therefore identical concentrations of monomers were used: BTDA $50 \mathrm{mmol}(1.6 \mathrm{~g})$ and ODA $50 \mathrm{mmol}(1.0 \mathrm{~g})$.

\subsubsection{Membranes}

\section{Pre-treatment of $\gamma$-alumina membranes}

Before grafting, the $\gamma$-alumina membranes were pre-treated to remove any impurities and to promote a suitable degree of hydroxylation and hydration by soaking in an ethanol/water (2:1) solution for 24 hours at ambient temperature and drying in a vacuum oven at $100{ }^{\circ} \mathrm{C}$ for 24 hours. The membranes were then stored under nitrogen atmosphere until further use.

\section{Grafting of $\gamma$-alumina membranes with APTES by solution phase deposition (SPD)} The introduction of amino groups onto the $\gamma$-alumina membrane was achieved by the reaction of the surface hydroxyl groups with APTES as described in chapter 5 [38]. In this work a $100 \mathrm{ml}$ toluene-silane solution, with a silane concentration of $50 \mathrm{mM}$, was used.

\section{Grafting of $\gamma$-alumina membrane with APTES by vapor phase deposition (VPD)} APTES was grafted on a $\gamma$-alumina membrane as described in chapter 5 [38]. In this work a $100 \mathrm{ml}$ toluene-silane solution with an APTES concentration of $50 \mathrm{mM}$ was used.

\section{Grafting of APTES-grafted $\gamma$-alumina membranes with BTDA-ODA}

A typical procedure for the in-situ polymerization method is as follows: (1) An APTES-Al $\mathrm{O}_{3}$ grafted membrane was placed in a sample holder in a 5 necked round flask, (2) $100 \mathrm{ml}$ of DMAc and $4.8 \mathrm{~g}$ (150 mmol) BTDA were added to the round bottom flask, (2) The mixture was stirred for 3 hours at $75^{\circ} \mathrm{C}$ and after 3 hours 1.5 g ODA (100 mmol) was added, (3) The mixture was stirred for 3 hours at $75^{\circ} \mathrm{C}$ and finally the reaction is reflux for 24 hours at $150^{\circ} \mathrm{C}$. After the reaction was complete, the membrane was washed and soaked in fresh DMAc to remove any non-bonded polymer. Immediately after, the modified membranes was thermally imidized at $300{ }^{\circ} \mathrm{C}$ using an identical thermal procedure as described for the $\gamma$-alumina flakes. In the layer by layer polymerization method the reaction was first stopped after reaction with BTDA by means of thermal imidization before addition of the diamine, ODA. The second monomer (ODA) was added using the same procedure as for grafting BTDA followed again by a thermal imidization. For the layer by 
layer method an excess of dianhydride was not required and therefore identical concentrations of the monomers were used: BTDA $50 \mathrm{mmol}(1.6 \mathrm{~g})$ and ODA 50 mmol (1.0 g).

\subsubsection{Characterization}

\section{Infrared spectroscopy}

FTIR spectra of the modified alumina flakes were obtained with a TGA-IRTensor 27 system spectrometer in the range $400-4000 \mathrm{~cm}^{-1}$. An FTIR spectrum of unmodified $\gamma$-alumina flakes was used for background correction. For further details see chapter 3 of this thesis.

\section{Gas adsorption measurements}

Nitrogen adsorption/desorption isotherms were collected at $77 \mathrm{~K}$ using a Gemini system, VII version (Micromeritics Instruments Corp.). Before each measurement the samples were vacuum-degassed at $200{ }^{\circ} \mathrm{C}$ for 12 hours. Pore size distribution, surface area and pore volume were determined. A detailed description of the method can be found in chapter 4 .

\section{Thermo gravimetrical analysis}

Thermo gravimetrical analysis was conducted at a heating rate of $10^{\circ} \mathrm{C} \mathrm{min}^{-1}$ under $\mathrm{N}_{2}$ atmosphere from room temperature till $1000{ }^{\circ} \mathrm{C}$ was performed and around 20 mg of sample was used. Before each measurement the samples were pre-treated from room temperature till $150^{\circ} \mathrm{C}$ with a heating rate of $10{ }^{\circ} \mathrm{C} \mathrm{min}-1$ to remove any adsorbed water.

\section{Contact angle}

Static contact angle measurements were performed on the grafted as described in chapter 3 on the grafted membranes. A droplet of $5 \mu \mathrm{L}$ of water (Millipore Q2) was injected at a speed of $1 \mu \mathrm{s} \mathrm{s}^{-1}$. The calculated contact angle values were an average of 5 drops.

\section{Permporometry}

Permporometry was employed to determine the pore size distribution of the modified and unmodified membrane layers [39]. A detailed description is given in chapter 5 . 


\section{Solvent permeation experiments}

Steady-state solvent flux analyses of toluene and $\mathrm{n}$-hexane at room temperature were carried out on unmodified and BTDA-ODA modified alumina membranes in a stainless steel dead-end nanofiltration set-up pressurized with helium to the desired pressure. A trans membrane pressure (TMP) of 1-11 bar was used. A more detailed description can be found in chapter 5 .

\section{Molecular weight cut-off measurements}

The molecular weight cut off was determined by filtration experiments with a $0.3 \%(\mathrm{w} / \mathrm{w})$ solution of polyisobutylenes (PIB's) in toluene with different molecular masses, using a dead-end filtration set-up, as described before in chapter 5 . The MWCO measurements were performed for 90 minutes at a TMP of 10 bar with continuously stirring (250 rpm). The feed, permeate and retentate were then analyzed by gel permeation chromatography (GPC).

\subsection{Results and discussion}

In order to graft each monomer, and consequently the resulting polyimide to $\gamma$-alumina flakes or membranes first a linker was grafted. By means of a silylation step APTES was grafted on $\gamma$-alumina, generating amino anchoring groups as illustrated in Figure 2a). The next step is the polyimide synthesis. Polyimides are in general either prepared by a one-step or by a two-step method. In the onestep method no intermediate poly(amic acid) is formed and the final polyimide is soluble in organic solvents like phenol. In this work a two-step method was employed, involving the formation of a poly(amic acid) intermediate by a reaction between an aromatic dianhydride (BTDA) and an aromatic diamine (ODA) in a protic solvent, e.g. DMAc. This was followed by an imidization or cyclodehydration step of this poly(amic acid) to yield the final polyimide. The final polyimide is insoluble in organic solvents.

In this work two different methods in the two-step approach were used, as illustrated in Figure $2 \mathrm{~b}$ ) and $2 \mathrm{c}$ ) and its influence in the membrane performance was evaluated. In the first method, "in-situ polymerization", as illustrated in Figure 2b), the BTDA-DMAc solution was added to the APTES-grafted flake/membrane and allowed to react, subsequently the diamine (ODA) was added after which the resulting poly(amic acid) was thermally imidizated into its polyimide form. 
a) Grafting the linker (APTES)
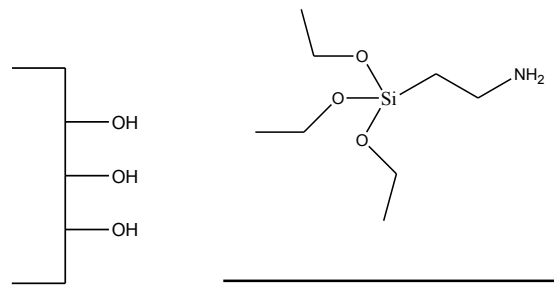

Toluene, $4 \mathrm{hr}, 80{ }^{\circ} \mathrm{C}$

b) In-situ graft polymerization method (1:3:2)
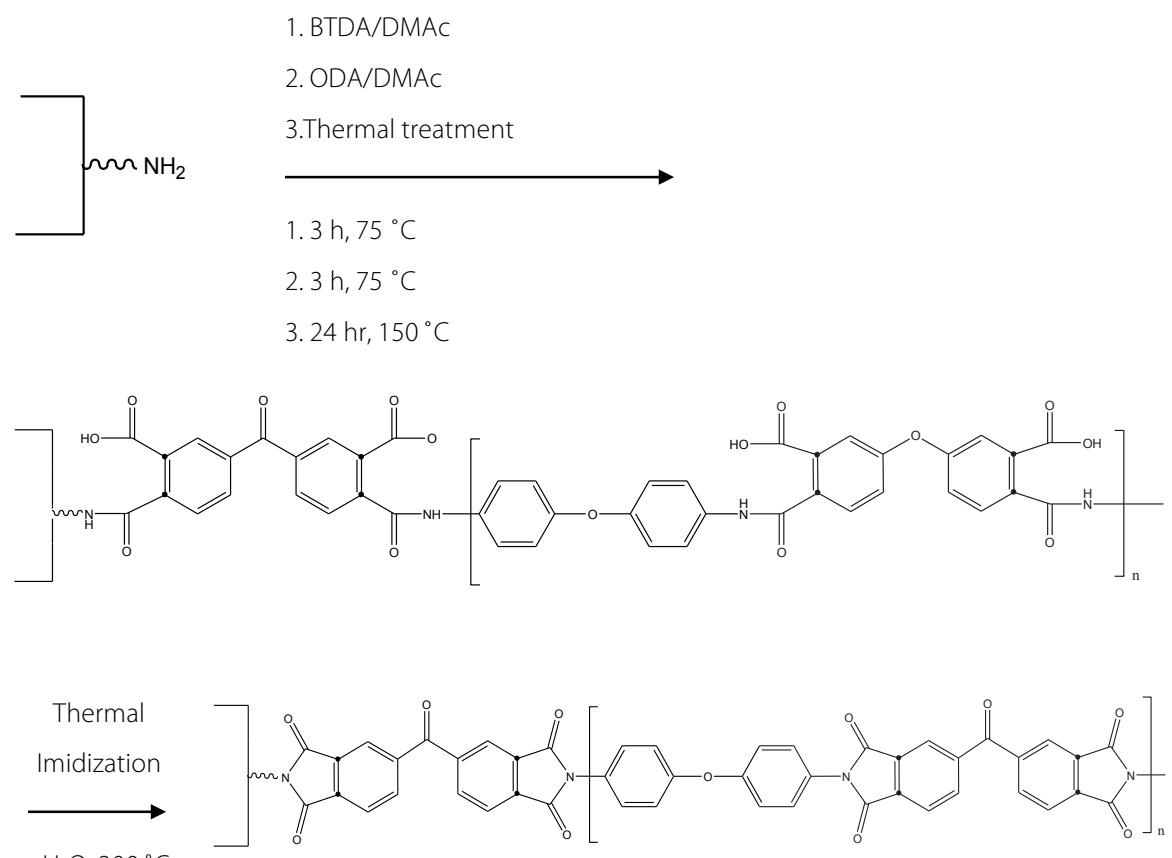

$-\mathrm{H}_{2} \mathrm{O}, 300^{\circ} \mathrm{C}$
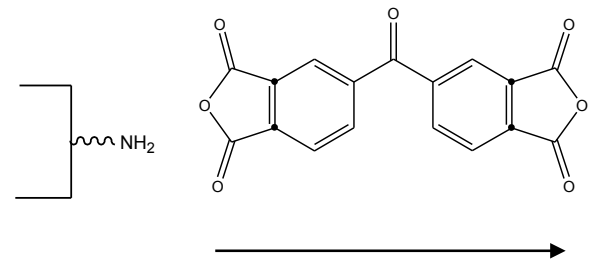

DMAc, $3 \mathrm{hr}, 80^{\circ} \mathrm{C}$<smiles>CCC(CC)NC(=O)c1cc(C(=O)c2ccc3c(c2)C(=O)OC3=O)ccc1C(=O)O</smiles> 


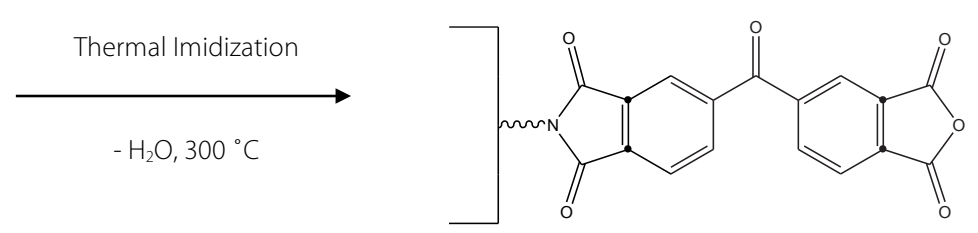

2. Grafting ODA (M2)

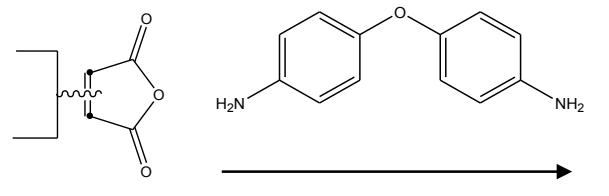

DMAc, $3 \mathrm{hr}, 80^{\circ} \mathrm{C}$

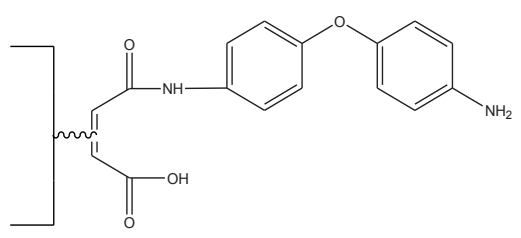

Thermal Imidization

$-\mathrm{H}_{2} \mathrm{O}, 300^{\circ} \mathrm{C}$

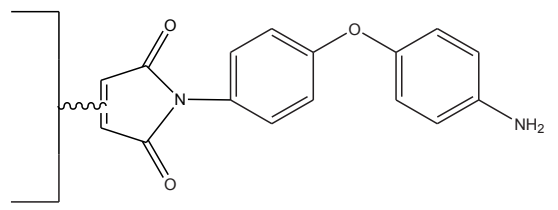

Figure 2: Scheme for the synthesis of a $\gamma$-aluminaflake/ membrane with (a) 3-aminopropyltriethoxysilane (APTES) and subsequently with both 4,4'-benzophenonetetracarboxylic dianhydride (BTDA) and 3'- diaminodiphenyl ether (ODA) by (b) in-situ polymerization method or (c) a layer by layer method.

A second method was developed to achieve a better controlled deposition and growth of the polymer and to prevent possible pore blocking in the membrane. This route is referred to as the "layer by layer" route and is schematically presented in Figure 2c). The BTDAIDMAc solution was added to the vessel containing the APTES grafted flake/membrane and the dianhydride was allowed to react at $75^{\circ} \mathrm{C}$, after which the reaction mixture was cooled to room temperature and the flakes/ membranes were washed and thermally imidized at $300{ }^{\circ} \mathrm{C}$. Subsequently, the ODA/DMAc was added and after 3 hours the reaction was stopped, the mixture washed and thermally imidized again.

\subsubsection{Grafting of $\gamma$-alumina flakes with APTES/ BTDA-ODA}

Figure 3 and 4 show the FT-IR spectra of unmodified and modified flakes with APTES linker and the BTDA-ODA polyimide, respectively. Here the linker was grafted by using a solution phase method. In a previous study it was proven that APTES-grafted $\gamma$-alumina flakes/membranes can be obtained by applying either an SPD or a VPD method [40] (chapter 4). 
The flakes, modified with APTES, show the characteristic peaks attributed to APTES. These include the peaks between $3000-2800 \mathrm{~cm}^{-1}$ due to the $\mathrm{C}-\mathrm{H}$ stretching modes $\left(2964,2929,2883 \mathrm{~cm}^{-1}\right)$ indicating the presence of both methyl and methylene bands. The bands between 1500-1200 $\mathrm{cm}^{-1}$ and $800-700 \mathrm{~cm}^{-1}$ are assigned to bending, twisting, rocking and wagging vibrations of the methylene groups confirming the incorporation of the propyl groups. The presence of the amino group can be confirmed by the peak at $1588 \mathrm{~cm}^{-1}$. Finally, the incorporation of APTES is confirmed by the presence of a broad band attributed to the symmetric and anti-symmetric Si-O-Si stretching mode due to the formation of siloxane bonds between adjacent silanes, which leads to multilayer formation when SPD is used as grafting method. Similar results were obtained in a previous study. All these FTIR results agree with the data as given in [40], in which paper a more detailed discussion on the FTIR data is given.

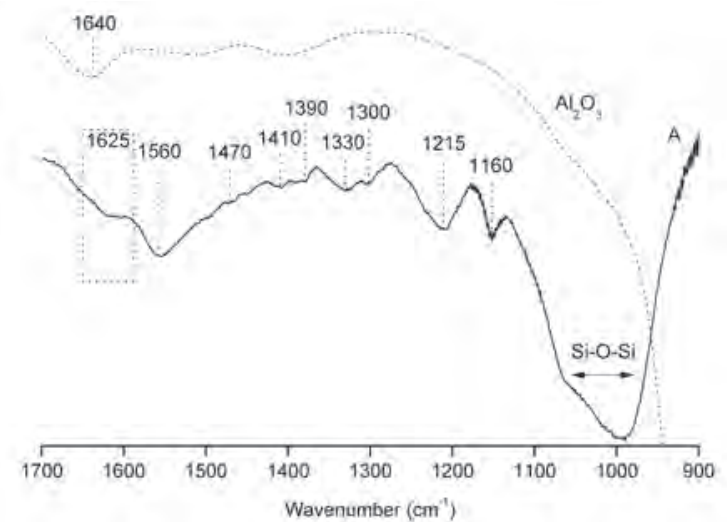

Figure 3: FTIR spectra for pure $\gamma$-alumina flakes calcined at $650{ }^{\circ} \mathrm{C}$ and for materials modified with (A) 3-aminopropyltriethoxysilane (APTES) via solution phase deposition.

After APTES grafting was confirmed, the first monomer was added. Figure 4 presents the FTIR spectra of they-alumina flakes grafted with BTDA and subsequently with ODA. The reaction of the BTDA monomer with the APTES modified $y$-alumina flakes involves a nucleophile attack of the amino group to the carbonyl carbon of the anhydride ring, followed by opening of the anhydride ring. In order to study the reaction step by step the reaction was stopped by thermal imidization at this stage as presented schematically in Figure $2 \mathrm{c}$ ). Since the sample was thermally treated, one expects ring closure. This will lead to the formation of imide bonds between BTDA and APTES proving that the dianhydride is covalently bonded to the APTES and consequently grafted onto the flakes. 


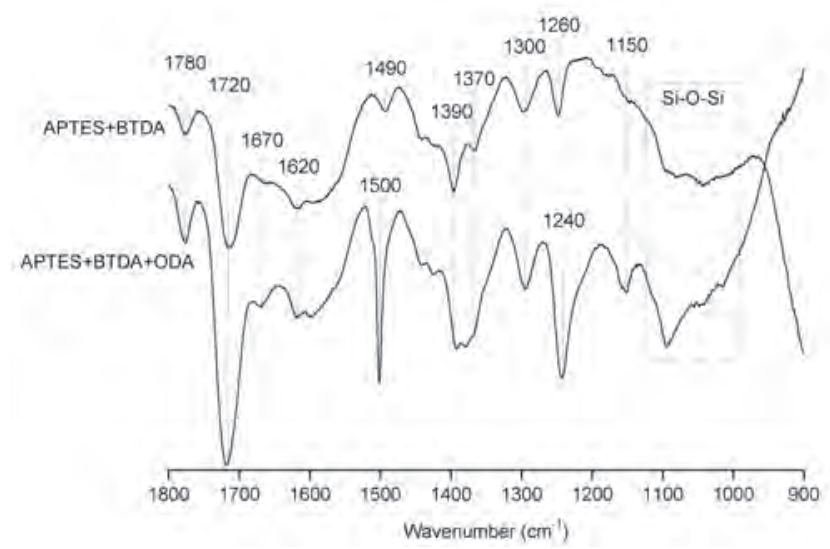

Figure 4: FTIR spectra for unmodified $\gamma$-alumina flakes, calcined at $650^{\circ} \mathrm{C}$ (pore size $5 \mathrm{~nm}$ ) and for materials modified with the linker 3-aminopropyltriethoxysilane (APTES) and followed by grafting with 3,3'4,4'benzophenonetetracarboxylic dianhydride (BTDA) (A) and 3,3'-diaminodiphenyl ether (ODA) (B).

The presence of characteristic imide bands like the duplet band at 1780 and 1720 $\mathrm{cm}^{-1}$ and the band at $1370 \mathrm{~cm}^{-1}$, attributed to the $\mathrm{C}=\mathrm{O}$ asymmetric stretching, $\mathrm{C}=\mathrm{O}$ symmetric stretching and to the $\mathrm{C}-\mathrm{N}$ stretching $\left(\mathrm{U}_{\mathrm{C}-\mathrm{N}-\mathrm{C}}\right)[41-44]$, suggesting the conversion of the amide groups into imide groups, proves that grafting of the imide groups of BTDA was successful. Furthermore, the absence of the bands related with the amide bands at $1660-1650 \mathrm{~cm}^{-1}$ due to stretching of the amide I ( $\cup \mathrm{C}=\mathrm{O}$ stretching of the CONH group) and a band at 1530-1550 $\mathrm{cm}^{-1}$ due to stretching of the amide II (coupling $\cup \mathrm{C}-\mathrm{N}$ and $\delta \mathrm{N}-\mathrm{H}$ of the C-NH group) $[42,43$, 45] supports that BTDA was successfully grafted and imidized.

The presence of the bands ascribed to different stretching and bending modes of the carbon - carbon double bond of the aromatic ring of the BTDA between 1620$1300 \mathrm{~cm}^{-1}\left(1620,1490\right.$ and $\left.1390 \mathrm{~cm}^{-1}\right)[43,44,46]$ and the other bands between 1450-1300 $\mathrm{cm}^{-1}$, due to the different stretching and bending modes of the $\mathrm{C}-\mathrm{H}$ bonds [47], support the grafting of BTDA onto alumina flakes. The band at $1670 \mathrm{~cm}^{1}$, to be ascribed to the carbonyl stretching $(\cup \mathrm{C}=\mathrm{O})$ of the benzophenone unit of the BTDA [48, 49], confirms that the BTDA was incorporated onto alumina flakes.

Since the BTDA possesses two dianhydride rings and only one is expected to react with the amino group of the APTES to form an imide, the band at $1780 \mathrm{~cm}^{-1}$ can be attributed to the $\mathrm{C}=\mathrm{O}$ stretching of those dianhydride groups that have not reacted with APTES and are available for further reaction with a diamine in a subsequent step. This latter is also confirmed by the presence of a band at 1260 
$\mathrm{cm}^{-1}$, attributed to the stretching mode of the $\mathrm{C}=\mathrm{O}$ of the dianhydride group. After the reaction with the dianhydride (BTDA), the diamine (ODA) was added to the reaction mixture containing BTDA/DMAc. In this in-situ polymerization case the reaction was not stopped after the reaction with BTDA was completed. The amino group from the aromatic diamine ODA reacted with the anhydride ring through a nucleophilic acyl substitution of one of the carbonyl carbons of the phthalic anhydride unit, followed by a polymerization reaction forming the correspondent poly(amic acid) (Figure 2b). Through a thermal (imidization) treatment at $300{ }^{\circ} \mathrm{C}$ the poly(amic acid) was transformed into its polyimide form by ring closure forming again an imide bond. An FTIR spectrum of the product formed is given in Figure 4. The formation of the APTES+BTDA+ODA bond is confirmed by the increase of the characteristic bands for the imide group as discussed above $\left(1780,1720,1370 \mathrm{~cm}^{-1}\right)$. The absence of the amide bands at $1660-1650 \mathrm{~cm}^{1}$ and at $1530-1550 \mathrm{~cm}^{-1}$ supports the conversion of the amide bonds into imide, resulting into the respective polyimide. Also an increase in intensity is observed for the bands attributed to the stretching and bending modes of the $\mathrm{C}=\mathrm{C}$ of the aromatic rings present in BTDA as well as in ODA (e.g. 1620, 1500-1490 and $1300 \mathrm{~cm}^{-1}$ ). The asymmetric stretching of the -C-O-C- (originating from aromaticO-aromatic) of the 3,4-ODA unit is clearly visible at $1240 \mathrm{~cm}^{-1}[45,47]$. In this final stage of the grafting process the linker, APTES, is till grafted onto the alumina flakes as can be seen by the presence a broad band between $1100-1000 \mathrm{~cm}^{-1}$, assigned to the Si-O-Si stretching modes due to siloxane bond formation and thus polyimide grafted $\gamma$-alumina flakes were successfully grafted.

The FTIR results described above concern grafting of $\gamma$-alumina flakes calcined at $650{ }^{\circ} \mathrm{C}$. For the $\gamma$-alumina flakes calcined at $825^{\circ} \mathrm{C}$ (enclosing pores with size of $9 \mathrm{~nm}$ ) all the characteristic bands were observed in the infrared spectra as well (results not shown). This confirms that APTES was successfully grafted on alumina and both BTDA and ODA were covalently bonded to this linker and thus to the alumina flakes.

\subsubsection{Structural characterization of $\gamma$-alumina grafted with APTES/ BTDA-ODA}

Figure $5 \mathrm{a}$ and $6 \mathrm{a}$ presents the $\mathrm{N}_{2}$ adsorption/desorption isotherms curves for unmodified $\gamma$-alumina flakes, calcined at $650{ }^{\circ} \mathrm{C}$ or $825{ }^{\circ} \mathrm{C}$ respectively, and modified with APTES by solution phase deposition, followed by a reaction with 3,3'4,4'-benzophenonetetracarboxylic dianhydride (BTDA) and subsequently with 3,3'-diaminodiphenyl ether (ODA).

Figure 5 a shows for all systems a type IV isotherm with a $\mathrm{H} 2$ hysteresis, generally 
associated with mesoporous materials with narrow necks and a relative low level of pore connectivity [50]. The BET surface area $\left(S_{B E T}\right)$, pore volume $\left(v_{p}\right)$ and mean pore size $\left(d_{p}\right)$ values are given in Table 1.

a

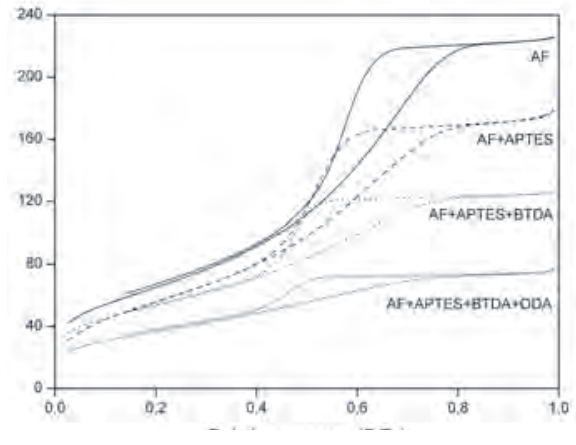

b

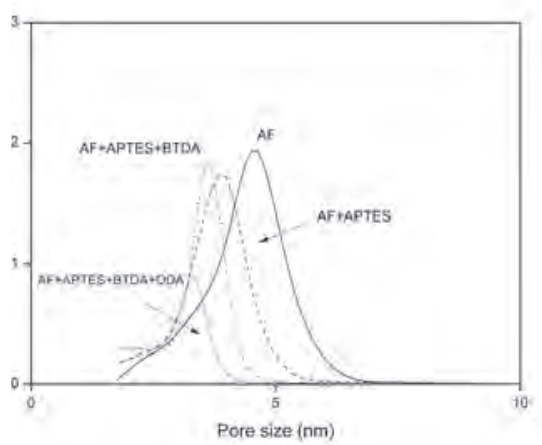

Figure 5: (a) $\mathrm{N}_{2}$ physisorption isotherms (b) Pore size distribution curves for pure $\gamma$-alumina flakes calcined at $650{ }^{\circ} \mathrm{C}$ and for materials modified with 3-aminopropyltriethoxysilane (APTES) via solution phase deposition (SPD) followed by grafting of 3,3',4,4'-benzophenonetetracarboxylic dianhydride (BTDA) and subsequently with 3,3'-diaminodiphenyl ether (ODA).

Table 1: BET Surface area $\left(S_{\text {BET }}\left(N_{2}\right)\right)$, mean mesopore pore diameter from fits $\left(d_{p} B J H\right)$ and pore volume $\left(v_{\mathrm{p}}\right)$ for pure $\gamma$-alumina flakes calcined at $650{ }^{\circ} \mathrm{C}$ and $825^{\circ} \mathrm{C}$ and materials modified with 3,3',4,4'-benzophenonetetracarboxylic dianhydride (BTDA) and subsequently with 3,3'diaminodiphenyl ether (ODA).

\begin{tabular}{|c|c|c|c|}
\hline & $\begin{array}{c}\text { Mean } d_{p} \\
(n m)\end{array}$ & $\begin{array}{c}v_{p} \\
\left(\mathrm{~cm}^{3} \mathrm{~g}^{-1}\right)\end{array}$ & $\begin{array}{l}S_{B E T}\left(N_{2}\right) \\
\left(m^{2} g^{-1}\right)\end{array}$ \\
\hline $\operatorname{AF}\left(650^{\circ} \mathrm{C}\right)$ & 4.7 & 0.35 & 240 \\
\hline AF $\left(650^{\circ} \mathrm{C}\right)+\operatorname{APTES} S P D$ & 3.9 & 0.26 & 203 \\
\hline $\operatorname{AF}\left(650^{\circ} \mathrm{C}\right)+\mathrm{APTES} S P D+B T D A$ & 3.6 & 0.20 & 169 \\
\hline AF $\left(650^{\circ} \mathrm{C}\right)+$ APTES SPD+BTDA+ODA & 3.4 & 0.15 & 134 \\
\hline $\operatorname{AF}\left(825^{\circ} \mathrm{C}\right)$ & 10 & 0.30 & 94,3 \\
\hline $\operatorname{AF}\left(825^{\circ} \mathrm{C}\right)+\mathrm{APTES} S P D$ & 9.1 & 0.24 & 86.1 \\
\hline $\mathrm{AF}\left(825^{\circ} \mathrm{C}\right)+\mathrm{APTES} S \mathrm{SP}+\mathrm{BTDA}$ & 8.3 & 0.20 & 80.6 \\
\hline $\mathrm{AF}\left(825^{\circ} \mathrm{C}\right)+\mathrm{APTES} S \mathrm{SP}+\mathrm{BTDA}+\mathrm{ODA}$ & 5.8 & 0.11 & 74.3 \\
\hline
\end{tabular}

For all modified flakes a sequential decrease in pore size, pore volume and surface area can be observed by increasing the number of organic moieties, demonstrating 
a sequential filling of the pores after each grafting step. In combination with the FTIR results discussed above (Figure 3 and 4), these adsorption/desorption results indicate that grafting has not only occurred on the surface but also within the pores. The pore size distribution curves shown in Figure $4 \mathrm{~b}$ were calculated by the BJH method [51] based on the desorption branch. The degree of pore wall grafting will now be discussed. For the monomers BTDA and ODA a molecular size of respectively $1 \mathrm{~nm}$ and $0.8 \mathrm{~nm}$ is determined assuming an angle of $109.5^{\circ}$ between the $\mathrm{C}$-atoms and a complete stretched structure. Taking into account this values a decrease in pore diameter of 1.8-1.9 nm is expected if one mono layer of each of the monomers is grafted on the pore wall. However, after the addition of BTDA and subsequently with ODA a decrease in pore size was observed of only $0.3 \mathrm{~nm}$ and 0.2 $\mathrm{nm}$ respectively for the $650^{\circ} \mathrm{C}$ calcined $\gamma$-alumina flakes (Table 1). A pore size of 3.9 $\mathrm{nm}$ remains after grafting these $\gamma$-alumina flakes with APTES by the SPD method. In theory one can expect that the available pore is large enough for the BTDA and ODA monomers to diffuse inside and to react with the linker. However, this is not the case assuming that grafting only occurred at the pore entrance and the surface of the flakes. A possible reason is the rigid and bulky shape of the molecules BTDA and ODA which can hamper diffusion in such small pores.

a

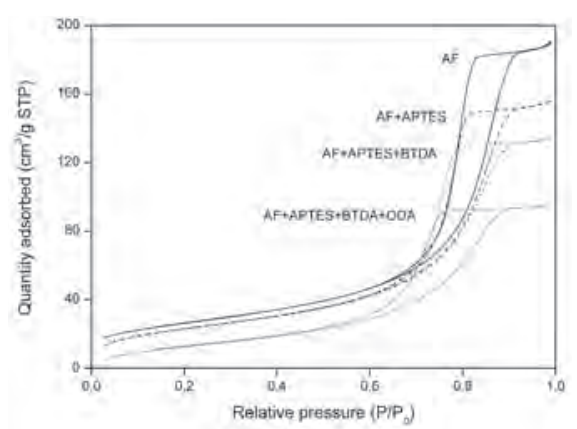

b

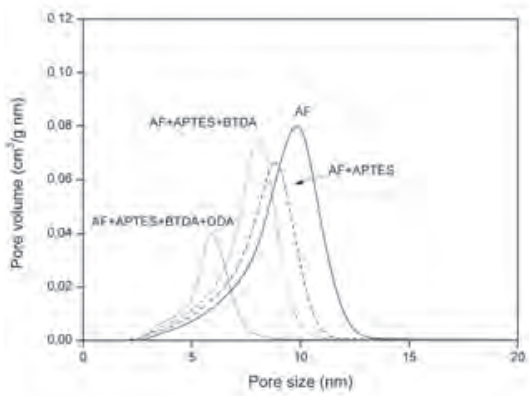

Figure 6: (a) $\mathrm{N}_{2}$ physisorption isotherms (b) pore size distribution curve for pure $\gamma$-alumina flakes calcined at $825^{\circ} \mathrm{C}$ and for materials modified with 3-aminopropyltriethoxysilane (APTES) via solution phase deposition followed by grafting of 3,3,4,4'-benzophenonetetracarboxylic dianhydride (BTDA) and subsequently with 3,3'-diaminodiphenyl ether (ODA).

Therefore, $\gamma$-alumina flakes with bigger pore sizes were grafted as well. In Figure 6a the isotherms for $9 \mathrm{~nm}$-alumina $\left(825^{\circ} \mathrm{C}\right.$ calcined) unmodified and modified flakes are presented. As already observed in Figure 5 a, before and after grafting a type IV isotherm is observed indicating the presence of a mesoporous system. In addition, the relative sharp increase in volume adsorbed at $P / P_{0}=0.7$ is indicative for the 
presence of uniform mesopores, resulting in a uniform pore size distribution, as observed in Figure 6b). As shown in table 1, a sequential decrease in both surface area, pore volume and pore size is attained, agreeing with successful filling of the pores. A similar decrease in both pore size and pore volume after grafting the APTES is shown (Table 1) for each flake type (650 and $825^{\circ} \mathrm{C}$ calcined). However, for the $10 \mathrm{~nm}$ flakes, the available space for further grafting of the monomers is two times more. In the case of the $10 \mathrm{~nm} \gamma$-alumina, a reduction in pore size of $1.7 \mathrm{~nm}$ is observed after APTES+BTDA grafting and a further reduction of around $2.5 \mathrm{~nm}$ is attained after the addition of the diamine, ODA. This total reduction of $4.2 \mathrm{~nm}$ indicates that at least two layers of BTDA and one layer of ODA is grafted within the pores. Therefore, by increasing the pore size of the $\gamma$-alumina flakes the polyimide was grafted onto the inner pore walls, even when the linker was deposited by using a solution phase method (SPD). Grafting by a vapor phase technique (VPD) results in a thin monolayer of APTES will in turn render more space for the diffusion of each monomer and subsequently for the polymerization reaction, as demonstrated in a previous study [40] on PDMS grafted alumina systems.

\subsubsection{Thermal stability of $\gamma$-alumina flakes grafted with APTES/ BTDA-ODA}

Figure 7 shows TGA results for the $10 \mathrm{~nm}$ modified $\gamma$-alumina flakes with APTES/ BTDA-ODA. Up to about $540{ }^{\circ} \mathrm{C}$ no clear change in weight is observed, while after this temperature the sample weight decreased $45 \%$ by heating to $1000{ }^{\circ} \mathrm{C}$. This weight loss represents the degradation of organic groups. From these results, it is concluded that the grafted $\gamma$-alumina flakes are thermally stable up to $540{ }^{\circ} \mathrm{C}$. The decomposition temperature observed in this work (around $540{ }^{\circ} \mathrm{C}$ or more) is higher than the boiling points (b.p.) of the individual precursors (APTES b.p. $=$ $223^{\circ} \mathrm{C}$, BTDA b.p. $=452^{\circ} \mathrm{C}$ and ODA b.p. $=219^{\circ} \mathrm{C}$ ). Therefore, an increase in thermal stability is assumed after modification. This again confirms that the aminopropyl and polyimide groups are chemically bonded to the $\gamma$-alumina flakes. 


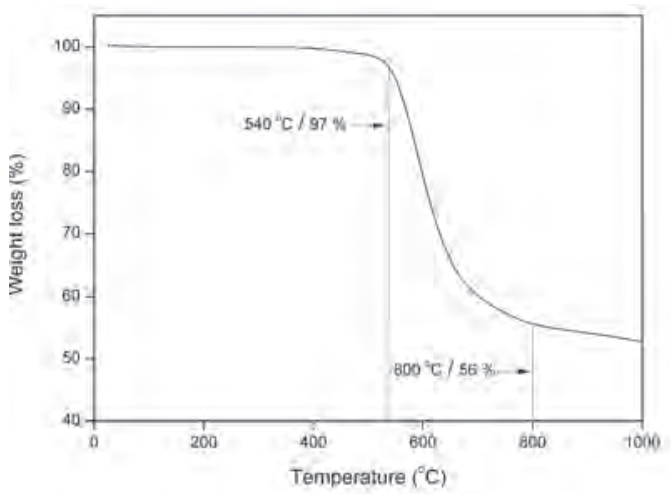

Figure 7: TGA curve for $\gamma$-alumina flakes calcined at $825^{\circ} \mathrm{C}$, grafted with APTES and subsequently with BTDA and ODA.

\subsubsection{Structural characterization and membrane performance}

A series of membranes were synthesized by using two different deposition methods of the APTES linker, a solution and a vapor phase method (SPD and VPD respectively). $\gamma$-alumina membranes with a pore size of $5 \mathrm{~nm}\left(650^{\circ} \mathrm{C}\right)$ and $9 \mathrm{~nm}$ $\left(825^{\circ} \mathrm{C}\right)$ were used as supports for modification.

In the case of the $\gamma$-alumina with a pore size of $9 \mathrm{~nm}$, the deposition of both monomers BTDA-ODA was conducted by the in-situ polymerization as well as by the layer by layer method, while for the $\gamma$-alumina membranes with a pore size of $5 \mathrm{~nm}$ only the in-situ polymerization method was used for grafting the monomers. Contact angle, permporometry and liquid filtrations measurements were conducted to elucidate both membrane structure and performance.

\section{Influence of the pore size of the $\gamma$-alumina layer on the grafting performance}

Table 2 lists the contact angle values measured for unmodified (for both 5 and $9 \mathrm{~nm}$ ) and $\gamma$-alumina membranes modified with APTES/BTDA-ODA. Different deposition methods of the linker (SPD and VPD) were used. In both cases, in-situ polymerization was selected for grafting BTDA-ODA.

For both unmodified membranes (Table 2, ID A and B) no contact angle could be measured due to the presence of $\mathrm{OH}$ hydrophilic groups. After modification an increase in contact angle is observed, however the membrane is still hydrophilic, as expected. Both monomers used possess hydrophilic groups like carbonyl groups present in the dianhydride unit of BTDA and amino groups from ODA (Figure 1). The increase in contact angle confirms that grafting has occurred. This is in agreement with FT-IR, gas adsorption and TGA results for modified $y$-alumina flakes as discussed before. 
Table 2: Contact angles $(\theta)$ for unmodified $\gamma$-alumina membranes with a pore size of 5 and $9 \mathrm{~nm}$, respectively and $\gamma$-alumina membranes modified with APTES/BTDA-ODA. The linker is deposited by two different methods a solution phase (SPD) and a vapor phase (VPD) method. The addition of the BTDA and ODA is performed by the "in-situ polymerization" method.

\begin{tabular}{|c|c|c|}
\hline Membrane & Linker Deposition & $\theta$ \\
\hline $\mathrm{Y}-\mathrm{Al}_{2} \mathrm{O}_{3}\left(650^{\circ} \mathrm{C}\right) 5 \mathrm{~nm}(\mathrm{~A})$ & - & $\sim 0$ \\
\hline $\mathrm{Y}-\mathrm{Al}_{2} \mathrm{O}_{3}\left(825^{\circ} \mathrm{C}\right) 9 \mathrm{~nm}(\mathrm{~B})$ & - & $\sim 0$ \\
\hline $\mathrm{Y}-\mathrm{Al}_{2} \mathrm{O}_{3}(5 \mathrm{~nm})+\mathrm{APTES} / \mathrm{BTDA}-\mathrm{ODA}(\mathrm{C})$ & SPD & $67 \pm 5$ \\
\hline $\mathrm{Y}-\mathrm{Al}_{2} \mathrm{O}_{3}(5 \mathrm{~nm})+\mathrm{APTES} / \mathrm{BTDA}-\mathrm{ODA}(\mathrm{D})$ & VPD & $60 \pm 2$ \\
\hline$\gamma-\mathrm{Al}_{2} \mathrm{O}_{3}(9 \mathrm{~nm})+\mathrm{APTES} / \mathrm{BTDA}-\mathrm{ODA}(\mathrm{E})$ & SPD & $65 \pm 4$ \\
\hline $\mathrm{Y}-\mathrm{Al}_{2} \mathrm{O}_{3}(9 \mathrm{~nm})+\mathrm{APTES} / \mathrm{BTDA}-\mathrm{ODA}(\mathrm{F})$ & VPD & $59 \pm 3$ \\
\hline
\end{tabular}

In order to show whether grafting has occurred inside the pores, permporometry measurements were performed for both unmodified membranes (Table 2, ID A and B) and membranes, modified by in-situ polymerization (Table 2, ID D, E, F). Figure 8 presents the oxygen permeance as function of the cyclohexane partial pressure. For all grafted systems no detectable transition was observed stating that the structure is dense or micro porous with pores smaller than a radius of $1.5 \mathrm{~nm}$. As a consequence, no pores could be detected by means of permporometry for these grafted membranes, because the invalidity of the Kelvin equation for micro porous and dense systems.

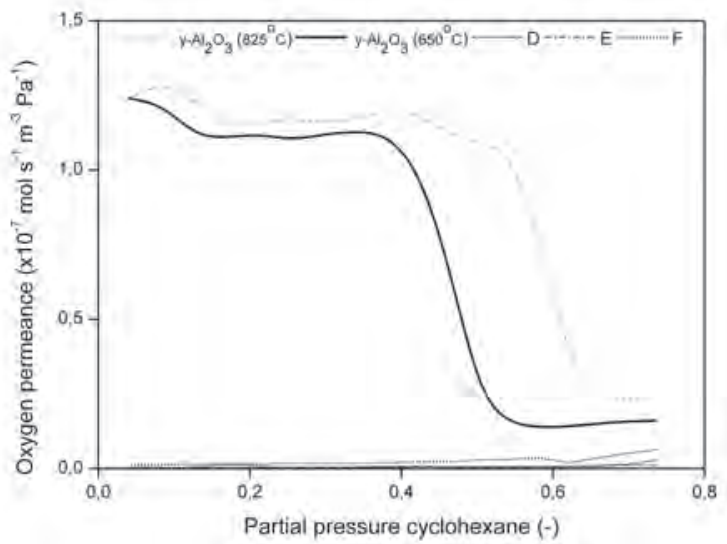

Figure 8: Oxygen permeation as function of the cyclohexane vapor pressure at $15{ }^{\circ} \mathrm{C}$ for the unmodified membranes with a pore size of $5 \mathrm{~nm}\left(650^{\circ} \mathrm{C}\right)$ and $9 \mathrm{~nm}\left(825^{\circ} \mathrm{C}\right)$. (D) a $5 \mathrm{~nm}$ $\gamma$-alumina membrane modified with APTES by VPD and subsequently with BTDA-ODA. (E) and (F) a $9 \mathrm{~nm}$-alumina membrane modified with APTES by SPD and VPD and subsequently with BTDA-ODA, respectively. All membranes were prepared by "in-situ polymerization". 
Toluene and hexane fluxes were analyzed for both unmodified 5 and $9 \mathrm{~nm}$ (Table 2 ID A and B, respectively) and modified membranes with APTES/BTDA-ODA by in-situ polymerization (Table 2, ID C, D, E, F). For the $5 \mathrm{~nm} \gamma$-alumina membrane a toluene permeance of $5.6 \mathrm{I} \mathrm{m}^{-2} \mathrm{~h}^{-1} \mathrm{bar}^{-1}$ and a hexane permeance of $8.51 \mathrm{Im}^{-2} \mathrm{hr}^{-1} \mathrm{bar}^{-1}$ was measured, whereas for the $9 \mathrm{~nm} \gamma$-alumina membrane a toluene permeance of $8.51 \mathrm{~m}^{-2} \mathrm{hr}^{-1} \mathrm{bar}^{-1}$ and a hexane permeance of $10.8 \mathrm{I} \mathrm{m}^{-2} \mathrm{hr}^{-1} \mathrm{bar}^{-1}$ was obtained. After modification by in-situ polymerization no detectable flux for any of the solvents was measured for any of the membranes. An absence of permeance indicates that grafting was successful but it resulted in a dense membrane for organic solvent filtration.

\section{Influence of the monomer deposition method}

As discussed in the previous section, polyimides grafted by in-situ polymerization result in dense membranes for solvent filtration. In order to overcome this issue a new method was employed: a layer by layer deposition (Figure 2c). In a sequantial form being $L=A P T E S, M 1=B T D A$ and $M 2=O D A$, a general struture of a layer by layer grafted polyimide is:

$$
\mathrm{Al}_{2} \mathrm{O}_{3}-\mathrm{L}-\mathrm{M} 1-\mathrm{M} 2
$$

In this work after the linker (L) was grafted only one layer of BTDA (M1) and one layer of ODA (M2) were applied.

In order to check if this method resulted in a porous system, permporometry measurments were performed after grafting each layer (APTES, BTDA and ODA), as presented in Figure 9 and 10.

In Figure 9 for both unmodified and membranes modified by the a layer by layer deposition a clear increase in oxygen permeation is observed when the cyclohexane partial pressure decreases, indicating a transition between capillary condensation and adsorption on pore walls, and thus the presence of a porous struture. Contrarilary, this is not observed when the grafted membrane is produced by in-situ polymerization (polymerized) meaning that the membrane is dense or microporous, as discussed before. In conclusion, the sequential layer by layer grafting renders a sequential decrease in pore size as seen in Figure 10. 


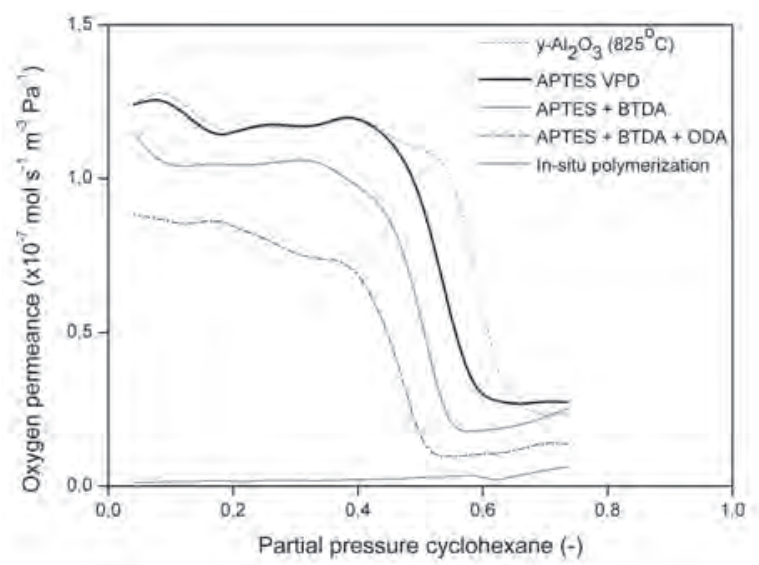

Figure 9: Accumulated oxygen permeation as function of the cyclohexane vapor pressure at $15^{\circ} \mathrm{C}$ for the $9 \mathrm{~nm}$ unmodified $\gamma$-alumina membrane $\left(825^{\circ} \mathrm{C}\right)$ and a $\gamma$-alumina membrane modified with APTES by VPD and subsequently with BTDA-ODA prepared by "in-situ polymerization and" membranes modified with APTES by VPD (APTES VPD), followed by a "layer by layer" reaction with BTDA (APTES +BTDA) and subsequently with ODA (APTES+BTDA+ODA).

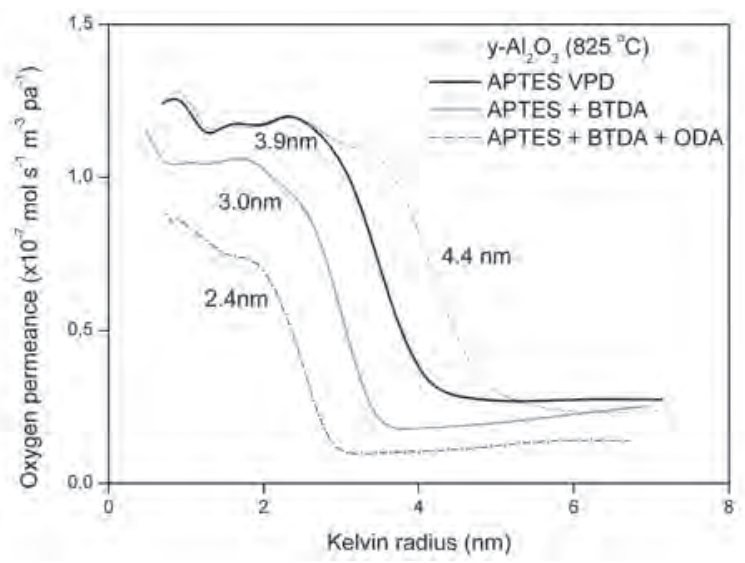

Figure 10: Cumulative Kelvin radius calculated from data given in Figure 9 for the $9 \mathrm{~nm}$ unmodified $\gamma$-alumina membrane and $\gamma$-alumina membranes modified with APTES/BTDA-ODA prepared by the "layer by layer" method.

As expected, a decrease of around $0.5 \mathrm{~nm}$ is observed when the linker (APTES) was grafted by vapor phase deposition (VPD) [52]. A further reduction in pore radius of $0.8 \mathrm{~nm}$ was observed after BTDA grafting matching the theorical calculated length of this molecule. Finally, grafting of the diamine ODA renders a further decrease of $0.6 \mathrm{~nm}$ which is aproximatly the theorical calculated length $(0.70 .8 \mathrm{~nm})$. Therefore, one can conclude that a $y$-alumina membrane is obtained of which the pore walls are grafted with APTES/BTDA-ODA. 
Table 3: Contact angles for unmodified $\gamma$-alumina membranes with a pore size of $9 \mathrm{~nm}$, respectively and modified with APTES/BTDA-ODA. The linker is deposited by a vapor phase (VPD) method. Different methods are described in this table as:"in-situ polymerization" and "layer by layer".

\begin{tabular}{lccc}
\hline Membrane & Linker Deposition & Monomer Deposition & $\theta$ \\
\hline$\gamma-\mathrm{Al}_{2} \mathrm{O}_{3}\left(825^{\circ} \mathrm{C}\right) 9 \mathrm{~nm}(\mathrm{~B})$ & - & - & $\sim 0$ \\
$\gamma-\mathrm{Al}_{2} \mathrm{O} 3(9 \mathrm{~nm})+\mathrm{APTES} / \mathrm{BTDA}-\mathrm{ODA}(\mathrm{E})$ & $\mathrm{VPD}$ & in-situ polymerization & $59 \pm 3^{\circ}$ \\
$\mathrm{\gamma}-\mathrm{Al}_{2} \mathrm{O}_{3}(9 \mathrm{~nm})+\mathrm{APTES} / \mathrm{BTDA}(\mathrm{G})$ & $\mathrm{VPD}$ & Layer by layer & $39 \pm 1^{\circ}$ \\
$\mathrm{\gamma}-\mathrm{Al}_{2} \mathrm{O}_{3}(9 \mathrm{~nm})+\mathrm{APTES} / \mathrm{BTDA}-\mathrm{ODA}(\mathrm{H} 1, \mathrm{H} 2)$ & $\mathrm{VPD}$ & Layer by layer & $46 \pm 1^{\circ}$ \\
\hline
\end{tabular}

\section{Membrane performance}

Toluene and hexane fluxes at different trans membrane pressures (TMP) were determined on 3 membranes (ID G, H1 and H2). Membrane G was grafted with APTES+BTDA. After permeance analysis membrane $G$ (the permeance was only measured at a TMP of 11 bar) was cleaned and dried, after which ODA was grafted (Membrane ID H1). In the case of the membrane $\mathrm{H} 2$, no filtration experiments were conducted after grafting BTDA, instead ODA was directly grafted.

Toluene and hexane flux-pressure relationships of two grafted APTES/BTDA-ODA membranes (Table 3 ID H1 and H2) for pure toluene and hexane are shown in Figure 11.

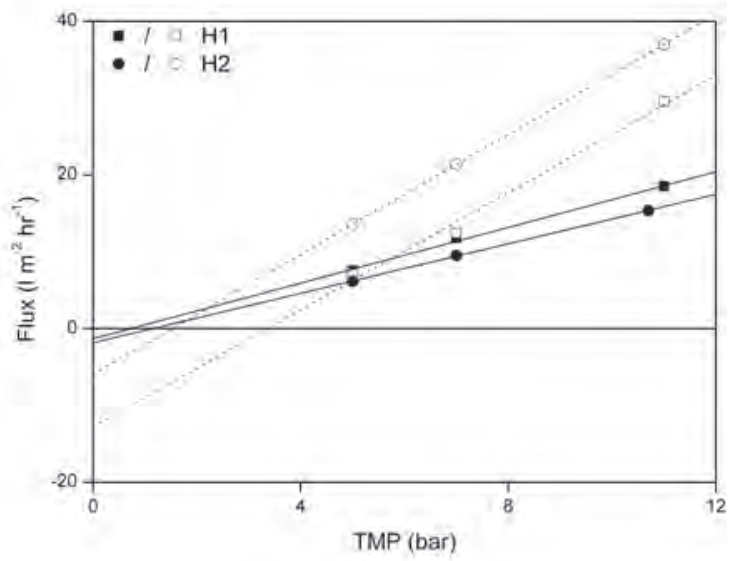

Figure 11: The flux pressure relationship for $\gamma$-alumina membranes modified with APTES/BTDA$\mathrm{ODA}(\mathrm{H} 1$ and $\mathrm{H} 2)$. The filled symbols represent toluene and the open ones hexane.

As observed in Figure 10, the flux (J)-pressure (TMP) relationships show a linear behavior and it can be assumed both toluene and hexane obey Darcy's law, stating that the trans membrane pressure (TMP) is the driving force in solvent permeation: 


$$
J=(k m / \eta) T M P
$$

where $J$ is the flux $\left(I \mathrm{~m}^{-2} \mathrm{hr}^{-1}\right), \mathrm{Km}$ a constant $(\mathrm{m}), \eta$ the solvent viscosity (Pa.s) and TMP the trans membrane pressure (bar).

The slope of flux $\left(\mathrm{m}^{-2} \mathrm{hr}^{-1}\right)$ versus the TMP (bar) is equal to the permeance, which contains a constant, $\mathrm{Km}$ and solvent viscosity, $\eta$ (Darcy's Law, equation 1). A comparison for toluene and hexane permeances between unmodified $\gamma$-alumina and the modified membranes with BTDA and BTDA-ODA are presented in Figure 12.

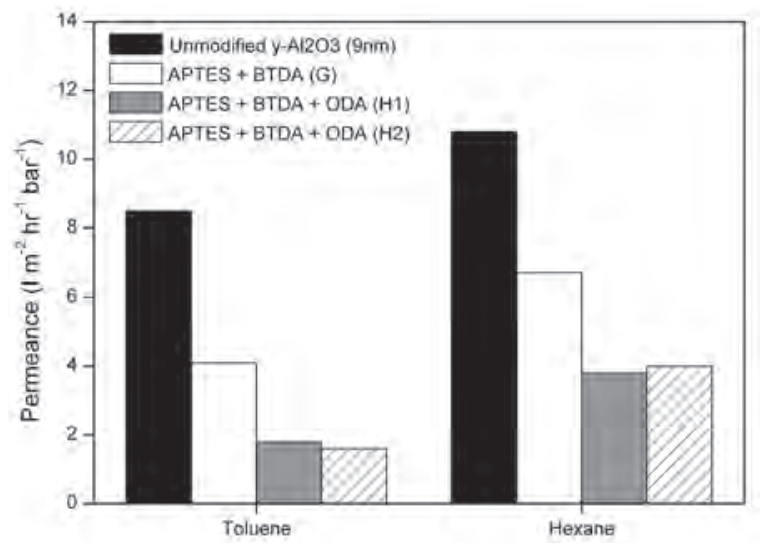

Figure 12: Toluene and hexane permeances for unmodified $9 \mathrm{~nm}$-alumina membranes and modifications with BTDA and ODA ( $\mathrm{G}, \mathrm{H} 1$ and $\mathrm{H} 2)$.

A sequential decrease in permeance is observed for both solvents as the membrane is grafted with more and more monomers, supporting that all grafting steps were successful, and that the pore walls were grafted with both monomers. This is in agreement with the reduction in pore size as measured by permporometry (Figure 10). For both APTES/BTDA-ODA grafted membranes presented in Figure $12(\mathrm{H} 1$, and $\mathrm{H} 2$ ), the difference in permeance for each solvent is small. Therefore, it can be concluded that the results for these membrane are reproducible and that solvent permeation experiments after grafting of the first monomer, BTDA, does not degrade the grafted layer and has no influence on the reaction of the second monomer, ODA (compare $\mathrm{H} 1$ and $\mathrm{H} 2$ ).

Generally, flux-pressure relationships for pure solvents go through the origin, but this is not observed for both BTDA-ODA grafted membranes, as presented in Figure 11. Negative intercepts with the $y$-axis (flux) are observed for both 
hexane and toluene but the values are clearly larger for hexane than for toluene. This effect can be ascribed to the presence of chemical transport assisting poreflow transport [13]. During pore-flow transport Darcy's law (equation 1) is obeyed and the Hagen-Poissuelle model can be applied. The solution diffusion model is often favored when chemical transport is the dominant transport mechanism. However, when chemical transport is playing a significant role a positive intercept is expected in the TMP versus flux curve [13]. A negative intercept may probably represent the opposite of chemical transport, meaning solvent repulsion, meaning that a minimal pressure is required for the solvent to start permeating. The two membranes ( $\mathrm{H} 1$ and $\mathrm{H}_{2}$ ) show comparable repulsion towards toluene, but a slightly higher deviation is observed for hexane. The stronger repulsion towards hexane than to toluene is in agreement with the calculated Hildebrand solubility parameter presented in Table 4. The difference in Hildebrand solubility parameters (see Table 4) between the solvent and the polymer (BTDA-ODA), which acts as an indication for the relative solvency behavior of a solvent or polymer, can be a measure for affinity (chemical transport) of a solvent through BTDA-ODA. The solubility parameter of BTDA-ODA is a bit closer to toluene than to hexane, which might indicate that affinity towards toluene is higher than to hexane. Assuming this is correct and taken the less negative intercept for toluene into account, one would expect a higher permeance for toluene. Instead, a higher permeance for hexane is observed (Figure 12, membranes $\mathrm{H} 1$ and $\mathrm{H} 2$ ).

Table 4: Hildebrand solubility parameters for the monomers and polymer used. A list of different solvents is also included.

\begin{tabular}{lc}
\hline & $\Delta, \mathrm{MPa}^{1 / 2}$ \\
\hline Hexane & 15 \\
Toluene & 19 \\
IPA & 24 \\
Water & 48 \\
BTDA & 33 \\
ODA & 27 \\
BTDA-ODA & 31 \\
\hline
\end{tabular}

To identify the influence of affinity (chemical transport) versus the influence of the viscosity (pore-flow transport) the viscosity corrected permeance (VCP) (for the macroscopic viscosity) is plotted against the Hildebrand solubility parameter in Figure 13.

A higher VCP for toluene than hexane is observed for the unmodified membrane 
as expected. Contrarily, for the modified membranes $(\mathrm{H} 1$ and $\mathrm{H} 2)$ similar VCPs are observed for initial filtration measurements indicating that the transport mechanism is solely based on pore-flow transport. Therefore, the VCP is primarily dependent on material properties of the membrane and not on the solvents considered.

Stability tests were carried out in both toluene and hexane using the same membrane $(\mathrm{H} 2)$ and are presented in Figure 14. The membrane is cleaned and dried before switching to the other solvent.

The membrane is initially soaked in toluene for 24 hours (Time = day 1 ) and the permeance is measured. After this, the membrane is soaked in hexane for 24 hours (Time $=$ day 2) and the permeance is measured. The membrane is subsequently soaked in toluene (Time = day 3 till day 9 ) followed by a soaking in hexane for 32 days (Time = day 10 till day 41) and finally in toluene for another 19 days (Time = day 42 till day 61$)$.

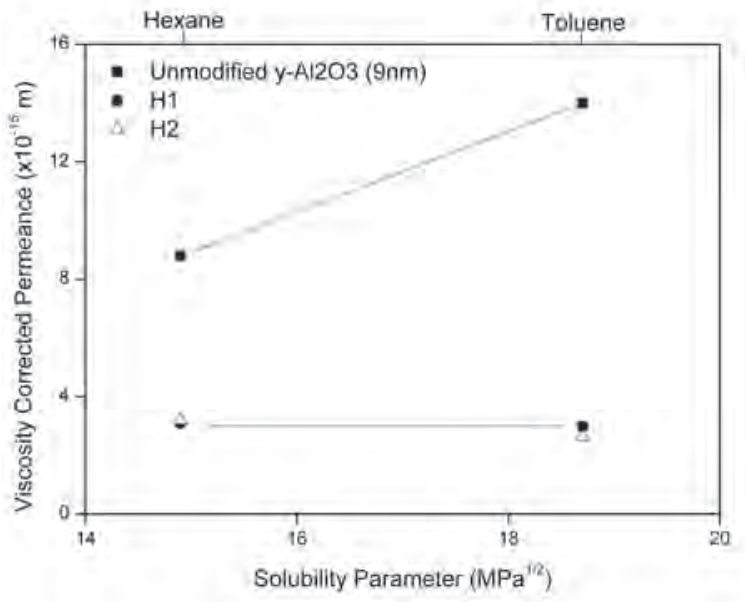

Figure 13: Toluene and hexane viscosity corrected permeances (VCP) as function of the solubility parameter for both unmodified $9 \mathrm{~nm} \gamma$-alumina membranes and modified with APTES/BTDA$\mathrm{ODA}(\mathrm{H} 1$ and $\mathrm{H} 2)$. The Hildebrand solubility parameter for a BTDA-ODA is around $31 \mathrm{MPa}^{1 / 2}$. 


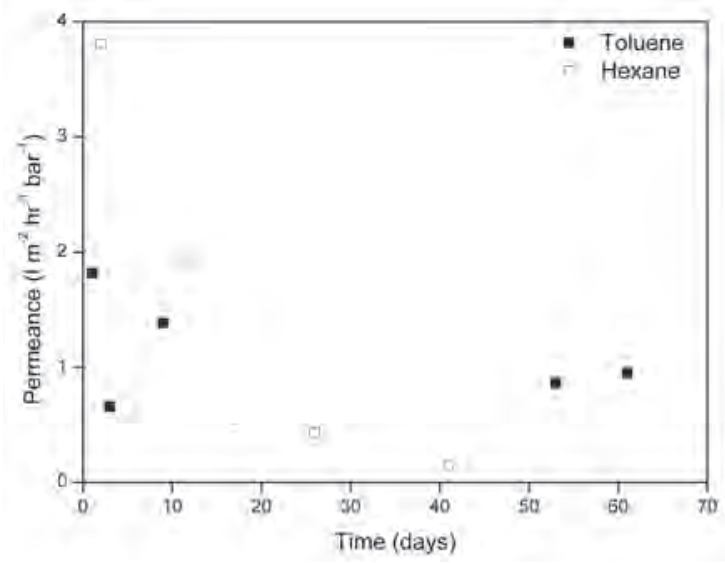

Figure 14: Toluene and hexane permeances as function of total soaking time in days for $9 \mathrm{~nm}$ Y-alumina modified with APTES/BTDA-ODA (H2). A trans membrane pressure of 11 bar was used.

As shown in figure 14 the toluene permeance initially shows a small decline, but at the end of the stability test series the permeance reaches a stable value (0.9 I m-2 $\mathrm{hr}^{-1}$ bar $^{-1}$ ). Contrarily, the hexane permeance drastically decreases and reached permeance values close to zero at the end of the test series, even though a higher permeance is initially measured for hexane compared to toluene.

The initial decrease in permeance for both solvents can be ascribed to startup effects due to some ppm of water adsorbed by the membrane. Capillary condensation of water in a pore with an effective Kelvin radius $\left(r_{k}\right)$ can occur after phase separation from the hydrocarbon-water mixture and is energetically favorable when:

$$
r_{k}<-\gamma_{s w} V_{m} / R T \ln \left(x_{w} x_{w}\right)
$$

where $\gamma_{s w}$ is the surface tension between the solvent and water, $V_{m}$ is the molar volume of water, $R$ is the gas constant, $T$ is the temperature, $x_{w}$ is the molar fraction of water in the solvent and $x_{w}$ is the activity coefficient of the water in the solvent [53-55]. Pores smaller than this critical Kelvin radius will be completely filled with water causing blocking of these pores for the transport of organic solvents. Pores larger than this critical radius will not be filled with water, but still a layer of water will be present on the pore walls as the interaction between water and the membrane will be stronger than the interactions between solvent and membrane. This leads to less pore volume, available for solvent permeation. This effect is expected to be more pronounced for hydrophilic membranes (Table 3 ID H1, H2) compared to 
hydrophobic membranes [56] (e.g. grafted PDMS $\gamma$-alumina membranes [39]) as the affinity towards water is higher. This is supported by the calculated Hildebrand solubility parameter which is discussed before (Table 4). In addition, water bridge formation which can occur between membrane and water is a much stronger interaction than the interactions between membrane and solvent.

An ongoing capillary condensation is observed by Chowdhury et al. [57] where filtration experiments on hydrophilic $\gamma$-alumina membranes of different pore sizes (3.5 - $5.9 \mathrm{~nm}$ ) were conducted with hexane and toluene dissolved with different amounts of water. It was observed that with increasing amount of water the hexane and toluene flux decreased, with a more pronounced reduction for hexane. Similar observations were made by Tsuru et al. [56], for $\mathrm{TiO}_{2}$ with pore sizes between 1 and $3 \mathrm{~nm}$. These membranes showed a decrease in flux with an increase in water concentration.

The drastic decrease in hexane permeance compared to the small decrease in toluene permeance can be ascribed to the solubility characteristics of water in these solvents. Because water is less soluble in hexane than in toluene (0.0067 mol l-1 for hexane and $0.015 \mathrm{~mol} \mathrm{I}^{-1}$ for toluene), more free water is present and consequently more pores will be blocked in the hexane-water mixture.

The negative intercepts (Figure 11) is here might be ascribed to solvent repulsion, presumably caused by water present in the solvents, resulting in a minimum pressure required for solvent filtration to (partially) open up the pores. One can imagine that an increasing amount of water absorbed in the membrane enhances solvent repulsion, assuming the water is spread along the membrane pore walls in the pores. This effect is likely to be more pronounced for hexane which can led to the drastic decrease in hexane permeance in the stability test series (Figure 14). Initial measurements showed comparable VCPs for hexane and toluene (Figure 13), however, as the stability test series proceeds, the hexane and toluene permeances decreased (and thus also the VCPs), resulting in a lower hexane VCP than toluene VCP. This might indicate that the capillary condensation of water limits pore-flow transport, in particular for hexane, and the Hagen-Poissuelle model is not obeyed anymore. Transport limitations caused by the capillary condensation of water and possible increase in solvent repulsion plus the differences between pore-flow and solution/diffusion make the solvent transport mechanism difficult to describe. Nonetheless, at the end of the stability test series the membrane still shows an appreciable toluene flux, whereas the hexane flux has severely decreased.

The viscosity effect, which can specifically be observed for hexane, makes the VCP 
appear to be lower than it actually is. This is due to an increase in viscosity, caused by interactions between the membrane and the solvent narrowly confined in the membrane pores, which then differs from the macrascopic/bulk viscosity [53, 58]. This is observed in the PDMS grafted $\gamma$-alumina membranes [38] but not observed in the BTDA-ODA grafted $\gamma$-alumina membranes. It is likely the viscosity effect is influenced by pore size and hydrophobicity.

\subsubsection{MWCO measurements}

The MWCO is determined for the BTDA-ODA grafted membranes using the method described by Zwijnenberg et al. [59] and described in detail in chapter 5 . A MWCO of $830 \mathrm{Da}$ is found, as indicated in Figure 15, which is in the nanofiltration range (MWCO $<1000 \mathrm{Da}$ ) as desired. A reduction in MWCO is observed when compared to an unmodified $\gamma$-alumina membrane (2500 Da) indicating that the polymer was grafted onto the pore walls. This supports the results obtained from both FTIR and permporometry as discussed before.

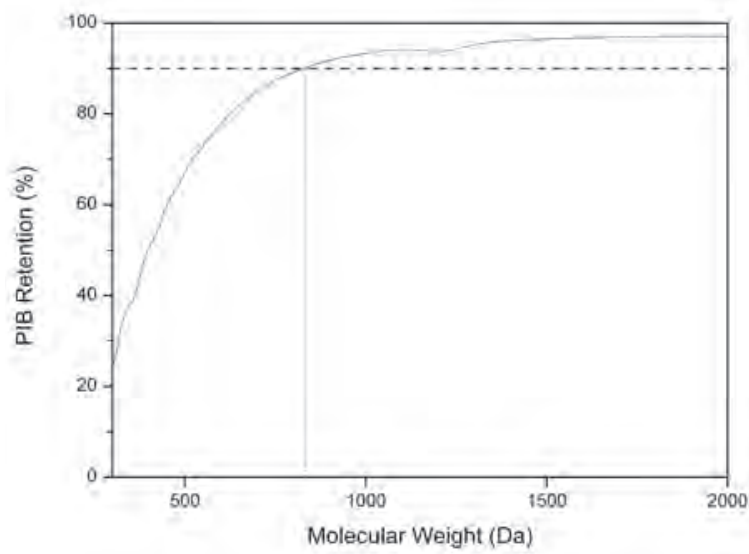

Figure 15: Rejection curve of poly isobutylenes (PIB's) in toluene for a $9 \mathrm{~nm} \gamma$-alumina modified with APTES/BTDA-ODA (H1) by layer by layer deposition.

\subsubsection{Comparison of PI-grafted with PDMS-grafted membranes}

Toluene and hexane permeances and contact angles for both a PDMS grafted system, as described in a previous study [38] (chapter 5) and a BTDA-ODA membrane are presented in Table 5. 
Table 5: Comparison between hexane and toluene permeance for a $5 \mathrm{~nm}$-alumina PDMS and a $9 \mathrm{~nm}$ Y-alumina BTDA-ODA layer by layer grafted membranes.

\begin{tabular}{lccc}
\hline Membrane & $\begin{array}{c}\text { Toluene permeance } \\
\left(\mathbf{I ~ m}^{-2} \mathbf{h r}^{-1} \text { bar }^{-1}\right)\end{array}$ & $\begin{array}{c}\text { Hexane permeance } \\
\left(\mathbf{I ~ m}^{-2} \mathbf{h r}^{-1} \text { bar }^{-1}\right)\end{array}$ & $\begin{array}{c}\text { Contact angle } \\
\left({ }^{\circ}\right)\end{array}$ \\
\hline $5 \mathrm{~nm} \mathrm{H}^{-\mathrm{Al}_{2} \mathrm{O}_{3} \text { PDMS }}$ & 3.1 & 4.8 & $44 \pm 1$ \\
$9 \mathrm{~nm} \mathrm{Al}_{2} \mathrm{O}_{3}$ BTDA-ODA & 1.7 & 3.9 & $94 \pm 3$ \\
\hline
\end{tabular}

As expected, higher permeances are observed for the PDMS system for both solvents. Due to their hydrophilic character, permeation of non-polar solvents through BTDA-ODA grafted membranes is lower when compared to hydrophobic membranes like the PDMS grafted ones.

\subsection{Conclusions}

Chemical modification of both $\gamma$-alumina flakes and membranes was achieved by grafting a polyimide-based polymer BTDA-ODA. A silylation reaction with an amino silane (APTES) resulted in the formation of a covalent bond between the inorganic surface and simultaneously with the BTDA-ODA polymer. Two different methods were used for the deposition of both linker and each monomer. Sequential grafting of the monomers (layer by layer) resulted in pore infiltration whereas an in-situ polymerization route showed that grafting mainly occurred onto the surface and in the entrance of the pores, resulting in a dense membrane. This demonstrated that a more controlled deposition was achieved by means of a layer by layer grafting of the monomers. Furthermore, an increase in thermal stability is achieved through grafting when compared to a non-grafted BTDA-ODA system.

Modification of $\gamma$-alumina membranes with BTDA-ODA resulted in an increase in contact angle confirming that the polymer was grafted onto the membrane surface. Filtration exepriments showed that the grafting method and membrane pore size directly influence membrane performance. Membranes prepared by the in-situ polymerization technique resulted in a dense membrane which led to no detectable permeation of either toluene or hexane. However, a membrane prepared by the layer by layer method showed both toluene and hexane permeation. Filtration of these solvents through two membranes prepared by identical experimental conditions demonstrated that reproducible membranes 
were obtained. A reduction in MWCO to the nanofiltration range was observed with a MWCO value of $830 \mathrm{Da}$ for a $\gamma$-alumina membrane grafted with APTES / BTDA-ODA, supporting that the pores walls were successefully grafted.

Initial filtration experiments showed that negative affinity/solvent repulsion towards hexane and toluene, with more solvent repulsion towards hexane than toluene could be expected. However, similar VCPs were observed for hexane and toluene implying the Hagen-Poissuelle model for pore-flow transport is obeyed and thus chemical transport can be neglected. In time, the Hagen-Poissuelle model was not obeyed anymore; the hexane permeance was decreased till approximately zero while the toluene permeance only slightly decreased. This is probably due to ongoing cappilary condensation of small amounts of water into the membrane, partially blocking the pores and limitting solvent transport. This effect was more pronounced for hexane which can be ascribed to the solubility characteristics of water in these solvents.

\section{Acknowledgement}

Marcel Boerrigter is acknowledged for performing the Gas Permeation Chromatography measurements. This is an ISPT project (Institute for Sustainable Process Technology). 


\subsection{References}

1. White, L.S., Development of large-scale applications in organic solvent nanofiltration and pervaporation for chemical and refining processes. Journal of Membrane Science, 2006. 286(1-2): p. 26-35.

2. Bhore, N.A., et al., New membrane process debottlenecks solvent dewaxing unit. Oil \& Gas Journal, 1999. 97(46): p. 67.

3. Othman, R., et al., Application of polymeric solvent resistant nanofiltration membranes for biodiesel production. Journal of Membrane Science, 2010. 348(1-2): p. 287-297.

4. Koseglu, S.S. and D.E. Engelgau, Membrane Applications And Research In The Edible Oil Industry - An Assessment. Journal of the American Oil Chemists Society, 1990. 67(4): p. 239-249.

5. Lin, L., K.C. Rhee, and S.S. Koseoglu, Bench-scale membrane degumming of crude vegetable oil: Process optimization. Journal of Membrane Science, 1997. 134(1): p. 101-108.

6. Subramanian, R., et al., Differential permeation of oil constituents in nonporous denser polymeric membranes. Journal of Membrane Science, 2001. 187(1-2): p. 57-69.

7. Ishikawa, F., et al., Transplanted human cord blood cells give rise to hepatocytes in engrafted mice, in Hematopoietic Stem Cells 2002: Genetics and Function, D. Orlic, et al., Editors. 2003, New York Acad Sciences: New York. p. 174-185.

8. Livingston, A., et al., Membrane separation in green chemical processing - Solvent nanofiltration in liquid phase organic synthesis reactions, in Advanced Membrane Technology, N.N. Li, et al., Editors. 2003, New York Acad Sciences: New York. p. 123-141.

9. Sheth, J.P., et al., Nanofiltration-based diafiltration process for solvent exchange in pharmaceutical manufacturing. Journal of Membrane Science, 2003. 211(2): p. 251-261.

10. Tian, R., et al., Optimization of APE1547-catalyzed Enantioselective Transesterification of (R/S)-2-methyl-1-butanol in an Ionic Liquid. Biotechnology and Bioprocess Engineering, 2011. 16(2): p. 337-342.

11. White, L.S. and A.R. Nitsch, Solvent recovery from lube oil filtrates with a polyimide membrane. Journal of Membrane Science, 2000. 179(1-2): p. 267-274.

12. Scarpello, J.T., et al., The separation of homogeneous organometallic catalysts using solvent resistant nanofiltration. Journal of Membrane Science, 2002. 203(1-2): p. 71-85.

13. Robinson, J.P., et al., Solvent flux through dense polymeric nanofiltration membranes. Journal of Membrane Science, 2004. 230(1-2): p. 29-37.

14. Stafie, N., D.F. Stamatialis, and M. Wessling, Effect of PDMS cross-linking degree on the permeation performance of PAN/PDMS composite nanofiltration membranes. Separation and Purification Technology, 2005. 45(3): p. 220-231.

15. Tarleton, E.S., et al., The influence of polarity on flux and rejection behaviour in solvent resistant nanofiltration-Experimental observations. Journal of Membrane Science, 2006. 278(1-2): p. 318-327.

16. Stafie, N., D.F. Stamatialis, and M. Wessling, Insight into the transport of hexane-solute systems through tailor-made composite membranes. Journal of Membrane Science, 2004. 228(1): p. 103-116.

17. Ebert, K., et al., Fundamental studies on the performance of a hydrophobic solvent stable membrane in non-aqueous solutions. Journal of Membrane Science, 2006. 285(1-2): p. 7580.

18. Stamatialis, D.F., et al., Observations on the permeation performance of solvent resistant nanofiltration membranes. Journal of Membrane Science, 2006. 279(1-2): p. 424-433.

19. Tarleton, E.S., J.P. Robinson, and M. Salman, Solvent-induced swelling of membranes Measurements and influence in nanofiltration. Journal of Membrane Science, 2006. 280(12): p. 442-451.

20. Vankelecom, I.F.J., et al., Physico-chemical interpretation of the SRNF transport mechanism for solvents through dense silicone membranes. Journal of Membrane Science, 2004. 
231(1-2): p. 99-108.

21. Whu, J.A., B.C. Baltzis, and K.K. Sirkar, Nanofiltration studies of larger organic microsolutes in methanol solutions. Journal of Membrane Science, 2000. 170(2): p. 159-172.

22. White, L.S., Transport properties of a polyimide solvent resistant nanofiltration membrane. Journal of Membrane Science, 2002. 205(1-2): p. 191-202.

23. White L.S., US Patent $6,108,008,2001$

24. Ohya H., Kudrayavtev V. V. and Semenove S. I., Polyimide Membranes: Applications, Fabrications and Properties, Gordon and Breach Publishers, Tokyo, Japan, 1996

25. a) Mulder M., Basic principles of Membrane Technology, Kluver Academic Publishers, 2003 b) Schafer, A.I., Fane A.G. White T.D., Nanofiltration - Principles and Applications, Elsevier, 2005

26. Beerlage, M. A. M., University of Twente, Enschede, 1994

27. Liu, Y., et al., Effect of crosslinking distribution on gas permeability and permselectivity of crosslinked polyimides. European Polymer Journal, 1999. 35(9): p. 1739-1741.

28. Kita, $H_{\text {., }}$ et al., Effect of photocrosslinking on permeability and permselectivity of gases through benzophenone-containing polyimide. Journal of Membrane Science, 1994. 87(12): p. 139-147.

29. Liu, Y., R. Wang, and T.S. Chung, Chemical cross-linking modification of polyimide membranes for gas separation. Journal of Membrane Science, 2001. 189(2): p. 231-239.

30. Yang, Q., et al., The development of chemically modified P84 Co-polyimide membranes as supported liquid membrane matrix for $\mathrm{Cu}(\mathrm{II})$ removal with prolonged stability. Chemical Engineering Science, 2007. 62(6): p. 1721-1729.

31. Shao, L., et al., Transport properties of cross-linked polyimide membranes induced by different generations of diaminobutane (DAB) dendrimers. Journal of Membrane Science, 2004. 238(1-2): p. 153-163.

32. Vanherck, K., et al., A simplified diamine crosslinking method for PI nanofiltration membranes. Journal of Membrane Science, 2010. 353(1-2): p. 135-143.

33. Vanherck, K., et al., Cross-linked polyimide membranes for solvent resistant nanofiltration in aprotic solvents. Journal of Membrane Science, 2008. 320(1-2): p. 468-476.

34. See Toh, Y.H., F.W. Lim, and A.G. Livingston, Polymeric membranes for nanofiltration in polar aprotic solvents. Journal of Membrane Science, 2007. 301(1-2): p. 3-10.

35. See-Toh, Y.H., M. Silva, and A. Livingston, Controlling molecular weight cut-off curves for highly solvent stable organic solvent nanofiltration (OSN) membranes. Journal of Membrane Science, 2008. 324(1-2): p. 220-232.

36. Gevers, L.E.M., I.F.J. Vankelecom, and P.A. Jacobs, Zeolite filled polydimethylsiloxane (PDMS) as an improved membrane for solvent-resistant nanofiltration (SRNF). Chemical Communications, 2005(19): p. 2500-2502.

37. N. Benes, A. Nijmeijer, H. verweij in : N. K. Kanellopoulos (Ed. ), Recent Advences In Gas Separation by Microporous Ceramic Membranes, Elsevier, Amsterdam, 2000, p. 335

38. Pinheiro F. M. Ana, chapter 5

39. Cao, G.Z., et al., Permporometry study on the size distribution of active pores in porous ceramic membranes. Journal of Membrane Science, 1993. 83(2): p. 221-235.

40. Pinheiro F. M. Ana, chapter 4

41. Leu, C.-M., Z.-W. Wu, and K.-H. Wei, Synthesis and Properties of Covalently Bonded Layered Silicates/Polyimide (BTDA-ODA) Nanocomposites. Chemistry of Materials, 2002. 14(7): p. 3016-3021.

42. Lee, K.W., S.P. Kowalczyk, and J.M. Shaw, Surface modification of BPDA-PDA polyimide. Langmuir, 1991. 7(11): p. 2450-2453.

43. Li, Q.T., Z.S. Xu, and C.F. Yi, Preparation of poly(amic acid) and polyimide derived from 3,3',4,4'-benzophenonetetracarboxylic dianhydride with different Diamines by microwave irradiation. Journal of Applied Polymer Science, 2008. 107(2): p. 797-802.

44. Park, H.B., et al., Imide-siloxane block copolymer/silica hybrid membranes: preparation, 
characterization and gas separation properties. Journal of Membrane Science, 2003. 220(12): p. 59-73.

45. Vora, R.H., S.H. Goh, and T.S. Chung, Synthesis and properties of fluoro-polyetherimides. Polymer Engineering and Science, 2000. 40(6): p. 1318-1329.

46. Leu, C.M., Z.W. Wu, and K.H. Wei, Synthesis and properties of covalently bonded layered silicates/polyimide (BTDA-ODA) nanocomposites. Chemistry of Materials, 2002. 14(7): p. 3016-3021.

47. Wang, L.H., et al., Formation of ordered macroporous films from fluorinated polyimide by water droplets templating. European Polymer Journal, 2007. 43(3): p. 862-869.

48. Niyogi, S. and B. Adhikari, Preparation and characterization of a polyimide membrane. European Polymer Journal, 2002. 38(6): p. 1237-1243.

49. García, M.G., J. Marchese, and N.A. Ochoa, Aliphatic-aromatic polyimide blends for H2 separation. International Journal of Hydrogen Energy, 2010. 35(17): p. 8983-8992.

50. Sing, K.S.W., et al., Reporting Physisorption Data For Gas Solid Systems With Special Reference To The Determination Of Surface-Area And Porosity (Recommendations 1984). Pure and Applied Chemistry, 1985. 57(4): p. 603-619.

51. Barrett, E.P., L.G. Joyner, and P.P. Halenda, The Determination Of Pore Volume And Area Distributions In Porous Substances .1. Computations From Nitrogen Isotherms. Journal of the American Chemical Society, 1951.73(1): p. 373-380.

52. Pinheiro F. M. Ana, chapter 5

53. Christenson, H.k., Capillary Condensation In Systems Of Immiscible Liquids. Journal of Colloid and Interface Science, 1985. 104(1): p. 234-249.

54. Christenson, H.K. and C.E. Blom, Solvation Forces And Phase-Separation Of Water In A ThinFilm Of Nonpolar Liquid Between Mica Surfaces. Journal of Chemical Physics, 1987. 86(1): p. 419-424.

55. Evans, R. and U.M.B. Marconi, Phase-Equilibria And Solvation Forces For Fluids Confined Between Parallel Walls. Journal of Chemical Physics, 1987. 86(12): p. 7138-7148.

56. Tsuru, T., et al., Nanoporous titania membranes for permeation and filtration of organic solutions. Desalination, 2008. 233(1-3): p. 1-9.

57. Chowdhury, S.R., et al., Effect of trace amounts of water on organic solvent transport through gamma-alumina membranes with varying pore sizes. Langmuir, 2004. 20(11): p. 4548-4552.

58. Granick, S., Motions And Relaxations Of Confined Liquids. Science, 1991. 253(5026): p. 1374-1379.

59. Zwijnenberg, H.J., et al., Important factors influencing molecular weight cut-off determination of membranes in organic solvents. Journal of Membrane Science, 2012. 390-391(0): p. 211-217. 


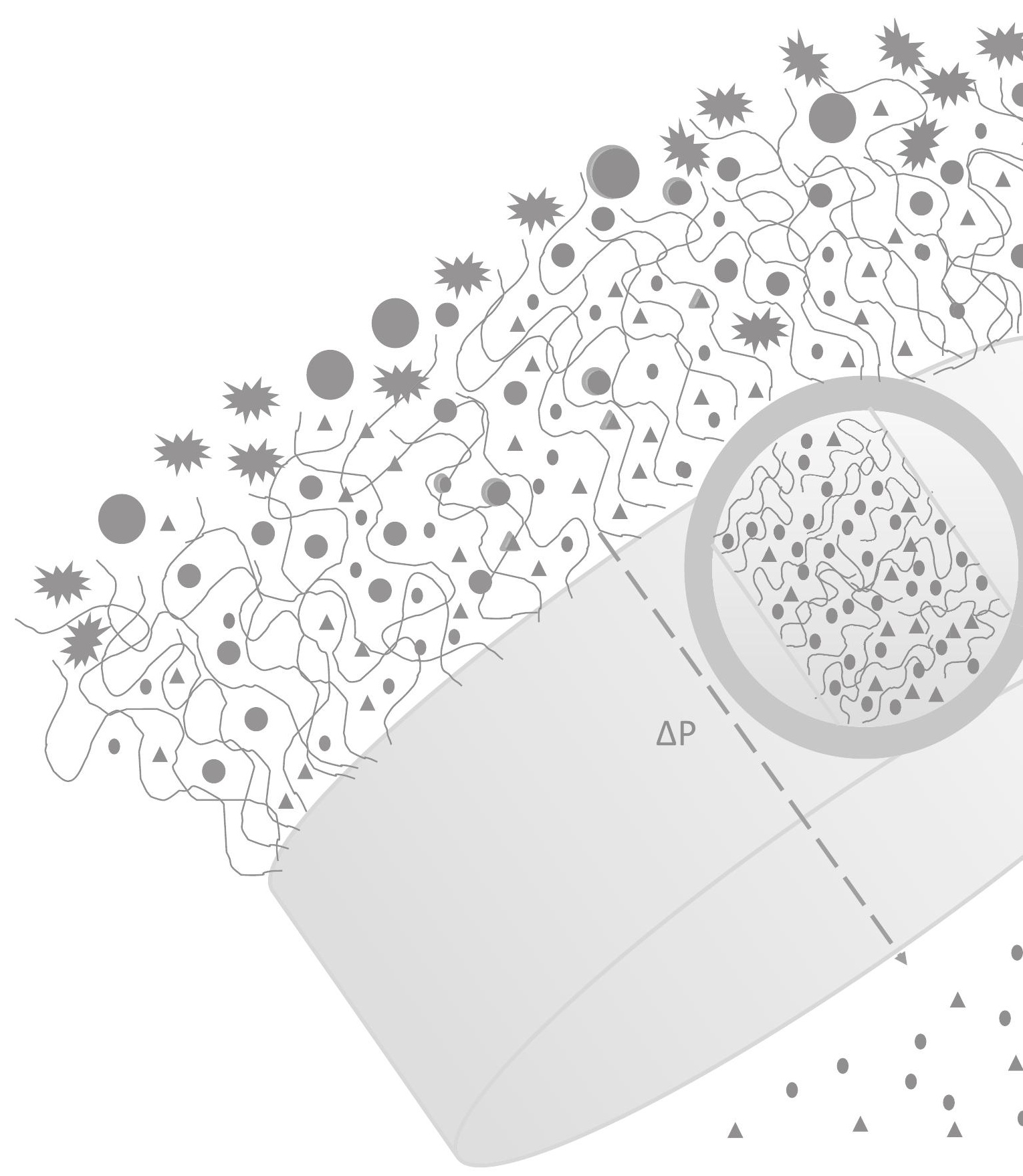


Chapter

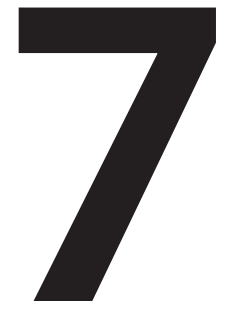

Fluoro-based polyimides grafted alumina as solvent resistant nanofiltration membranes

$$
\begin{aligned}
& \Delta^{\Delta} \Delta \\
& { }^{-} \bullet_{\bullet}^{\Delta} \bullet^{\bullet} \bullet^{\Delta}
\end{aligned}
$$

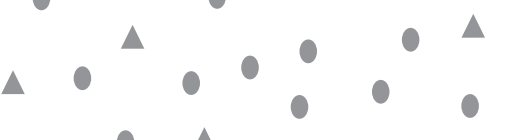

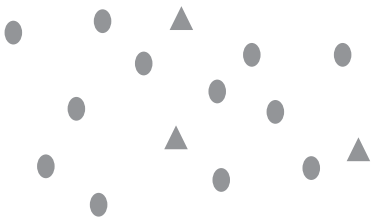




\section{Abstract}

Hydrophobic nanofiltration membranes are developed by grafting a fluoropolyimide-based polymer (6FDA-BDAF) into the pores of 5 or $9 \mathrm{~nm} \gamma^{-}$ alumina membranes and a $70 \mathrm{~nm}$ a-alumina membrane. The grafted membranes were prepared by a two-step synthesis which involved grafting of the linker (APTMS), using a vapor phase deposition (VPD) method followed by grafting of the dianhydride (6FDA) monomer and subsequently the diamine (BDAF) by using either an in-situ polymerization or a layer by layer method. Grafting (covalently bonding) of the subsequent monomers on alumina was proven by FTIR. Filtration experiments showed that grafting method and ceramic membrane pore size directly influence membrane performance. Polyimide (6FDA-BDAF)-grafted $\gamma$-alumina membranes resulted in too dense membranes for solvent permeation, while 6FDA-grafted $9 \mathrm{~nm}$ membranes show reproducible toluene $\left(5.7-6.0 \mathrm{I} \mathrm{m}^{-2} \mathrm{hr}^{-1}\right.$ $\left.\mathrm{bar}^{-1}\right)$ and hexane $\left(9.7 \mathrm{I} \mathrm{m}^{-2} \mathrm{hr}^{-1} \mathrm{bar}^{-1}\right)$ permeances. When the layer by layer method is applied in a $70 \mathrm{~nm}$ a-alumina membrane, toluene fluxes were observed after a complete polyimide is grafted. The layer by layer grafting method allows us to develop SRNF membranes with tailored pore size and reproducible performance. 


\subsection{Introduction}

Polyimide materials have been extensively investigated for membrane applications in various separation processes like gas separation [1-4], pervaporation [5-9] and more recently in solvent resistant nanofiltration (SRNF) [10-15]. Polyimide polymers are well known for their superior thermal stability, combined with their resistance to organic solvents (e.g. toluene, hydrocarbons, alcohols, ketones and a broad range of $\mathrm{pH}$ conditions), excellent mechanical properties and the easy formation of thin films [16], making these materials very attractive as SRNF membranes. It is also known that the chain stiffness and packing density of polyimides influence selectivity and permeability [17]. In this context, introduction of bulky pendent groups, as fluorine groups into high performance polymers like polyimides is one of the most widely used strategies for structural modification leading to substantial property enhancement [18].

It is found that by using dianhydrides with - $\mathrm{CF}_{3}$ groups, like 2,2-bis(3,4carboxyphenyl)- hexaflouropropane dianhydride (6FDA), the chain mobility and simultaneously chain packing can be restricted and therefore a significant improvement in selectivity can be reached $[4,19]$. The high free volume of the bulky - $\mathrm{CF}_{3}$ connector groups causes inter-chain steric hindrance, which disrupts chain order and packing efficiency, leading to a high free volume and consequently to an enhanced permeability $[17,20,21]$. The incorporation of trifluoromethyl $\left(-\mathrm{CF}_{3}\right)$ groups also results in an increased thermal and chemical stability and solvent solubility along with a hydrophobic character (low water uptake) [18, 22-27], rendering them suitable for separation of gases, solvent applications e.g. olefin/ paraffin $[1,28]$ and aromatic/aliphatic mixtures, like toluene/octane, naphthalene/ n-decane or benzene/cyclohexane [5, 29-34]. However, 6FDA-based polyimide membranes significantly swell when high concentrations of aromatics are present in the feed mixture. As a result, the flux increases with increasing aromatic content in the feed while the selectivity strongly decreases.

Crosslinking of polymer structures has been found as a suitable method to improve separation properties as well as chemical and thermal stability [10, 12, 35-38]. Crosslinking by aliphatic and aromatic diamines resulted in increased gas permeation performance [38-42] and enhanced chemical stability for SRNF [1012]. Carboxy groups containing 6FDA-based polyimides and copolyimides have been developed $[32,37]$, resulting in functional polymers which can be crosslinked or further modified. Introduction of 3,5-diaminobenzoic acid (DABA) groups 
into the polyimide structure and further crosslinking leads to an increase in flux without loss of selectivity and strongly reduces swelling. Pithan et al. reported for these membranes an increase in selectivity towards aromatics, e.g. benzene in an aromatic/aliphatic mixture [31].

More recently, new polyimide-inorganic hybrid nano-composites [43-47], polyimide modified poly(silsesquioxane) [48-52] and polyimide modified zeolites [53-56] have been developed. Improvements in thermal and mechanical stability have been reported compared with pure polymeric membranes.

Another approach is grafting (covalently-bonding) the polymer onto a porous inorganic material, which serves as a support. The confinement of the polymer in the pores of the ceramic membranes is expected to reduce swelling. In addition, an increase in thermal, mechanical and chemical stability of the polymer can be expected due to the formation of a covalent bond between inorganic support and polymer. Furthermore, this covalent bonding prevents detachment of the polyimide, even in solvents in which most polyimides are soluble, which can result in increased chemical and mechanical stability.

In this work an alumina membrane is grafted with a polyimide-based polymer. In order to covalently bond the polyimide to the membrane surface a linker is used, in this case 3-aminopropyltrimethoxysilane (APTMS). The alkoxy groups of APTMS reacts with the $\mathrm{OH}$ surface groups onto the alumina oxide support whereas the amino groups (linker) provides the anchoring groups for subsequent grafting of the dianhydride and diamine monomers resulting in a polyimide grafted alumina membrane. For the dianhydride we used 4,4'-(hexafluoroisopropylidene)diphthalic anhydride (6FDA) and 4,4'(hexafluoroisopropylidene)-bis(p-phenyleneoxy) dianiline (BDAF) was selected as the diamine (Figure 1). Both monomers are commercially available.

The influence of the pore size of the ceramic membrane support and the method of monomer addition to the membrane structure and filtration performance was evaluated. The molecular structure and morphology of the grafted-polyimides were characterized by FTIR, gas adsorption/desorption on grafted $\gamma$-alumina powders/ flakes, whereas the membrane structure and wettability were characterized by permporometry and contact angle. Furthermore, preliminary liquid permeation measurements were done to evaluate the membrane performance for nanofiltration. 
<smiles>O=C1OC(=O)c2cc(C(F)(F)C(F)(F)F)ccc21</smiles>

6FDA<smiles>CC(C)(c1ccc(Oc2ccc(N)cc2)cc1)c1ccc(Oc2ccc(N)cc2)cc1</smiles>

BDAF

Figure 1: Chemical structures of the monomers used for generating the correspondent polyimide: the dianhydride,2-bis(3,4-carboxyphenyl)hexafluoropropane dianhydride (6FDA) and diamine the 4,4'-(hexafluoroisopropylidene)bis(p-phenyleneoxy) dianiline (BDAF).

\subsection{Experimental}

\subsubsection{Materials}

The diamine, 4,4'-(hexafluoroisopropylidene)bis(p-phenyleneoxy) dianiline (BDAF) the dianhydride, 4,4'-(hexafluoroisopropylidene) diphthalic anhydride (6FDA), and 3-aminopropyltrimethoxysilane (APTMS) were supplied by Aldrich and used as received. The solvents toluene, $\mathrm{n}$-hexane and dimethylacetamide were obtained from Aldrich and used as received. All solvents were anhydrous. Ethanol was purchased from Aldrich and used as received.

The $\gamma$-alumina membranes consisted of a macroporous a-alumina membrane support and a thin mesoporous $\gamma$-alumina layer. Flat disc-shaped, a-alumina supports with a diameter of $39 \mathrm{~mm}$ and $2.0 \mathrm{~mm}$ of thickness and a pore size of 70 $\mathrm{nm}$ were purchased from Pervatech and were used as received. These supports were then coated with a $\gamma$-alumina layer of $300 \mathrm{~nm}$ of thickness by dip-coating and calcined at $625^{\circ} \mathrm{C}$ or $825^{\circ} \mathrm{C}$ for 1 hour at a heating rate of $1{ }^{\circ} \mathrm{C} \mathrm{min}-1$, as described in detail in ref. [57].

\subsubsection{Grafting procedure for $\gamma$-alumina flakes}

\section{Pre-treatment of $\gamma$-alumina flakes}

Before grafting, the $\gamma$-alumina flakes were pre-treated by soaking in an ethanol/ water (2:1) solution for 24 hours at ambient temperature, dried in a vacuum oven at $100^{\circ} \mathrm{C}$ for 24 hours and stored under nitrogen atmosphere until further use. This was done to remove impurities and to promote a suitable degree of hydroxylation. 
Grafting of $\boldsymbol{\gamma}$-alumina flakes with APTMS by vapor phase deposition (VPD)

The introduction of amino groups onto the $y$-alumina flakes, i.e. the preparation of an "initiator site", was achieved by a reaction of the surface OH groups with APTMS as described in previous work [58] (chapter 4). In this work a 100 ml, 50 mM APTMStoluene solution was used. A total amount of $700 \mathrm{mg}$ Y-alumina flakes was used.

\section{Grafting of APTMS-grafted $\gamma$-alumina flakes with polyimide: 6FDA-BDAF}

A two-step synthesis was employed. In a first stage, a poly(amic acid) was formed and subsequently through a thermal imidization process a polyimide was formed. Two methods were used to introduce the monomers, as described in a previous work [59] (chapter 6):

1) In situ polymerization: A reaction between the amino group of APTMS and the anhydride group of 6FDA, followed by a subsequent reaction between the anhydride and the amino group of diamine, BDAF

2) Layer by layer grafting: after the reaction with one monomer the product was washed and thermally imidized before the reaction with the next monomer.

A typical procedure for the in situ polymerization method is as follows: (1) To a solution of $300 \mathrm{mg}$ of APTMS-grafted $\mathrm{\gamma}$-alumina in dimethylacetamide (DMAc) (50 $\mathrm{ml}$ ) 6FDA was added $(6.66 \mathrm{~g}, 150 \mathrm{mmol})$, (2) the mixture was stirred for 24 hours at RT under nitrogen, (3) subsequently the diamine $\operatorname{BDAF}(5.18 \mathrm{~g}, 100 \mathrm{mmol})$ was added, (4) and finally the reaction mixture was stirred for 24 hours at RT under nitrogen. After the reaction was completed, the mixture was centrifuged with 20 $\mathrm{ml}$ of fresh DMAc at $7500 \mathrm{rpm}$ for $20 \mathrm{~min}$. This was repeated 2 more times with fresh DMAc to remove any non-bonded polymer. Immediately after, the modified flakes were thermal imidized by stepwise heating the modified flakes for 1 hour at $100,150,200$, and 250 to a final temperature of $300{ }^{\circ} \mathrm{C}$ with an intermediate heating rate of $1{ }^{\circ} \mathrm{C} / \mathrm{min}$ and then cooled down at $1{ }^{\circ} \mathrm{C} \mathrm{min}-1$ till room temperature. For the layer by layer method the reaction was stopped before addition of the diamine, BDAF. After reaction with 6FDA, the APTMS-grafted flakes were washed and thermal imidized as described above for the whole polymer. For the reaction with the second monomer, BDAF, the same procedure was used as for grafting 6FDA, followed again by a thermal imidization treatment. For this layer by layer method an excess of dianhydride was not required and therefore different 
concentrations of monomers were used: 6FDA $50 \mathrm{mmol}(2.22 \mathrm{~g})$ and BDAF 50 mmol (2.59 g).

\subsubsection{Grafting procedure for $\gamma$-alumina membranes}

\section{Pre-treatment of $\gamma$-alumina membranes}

Before grafting, the $\gamma$-alumina membranes were pre-treated to remove any particles and to promote a suitable hydroxylation and hydration degree by soaking in an ethanol/water (2:1) solution for 24 hours at ambient temperature and drying in a vacuum oven at $100{ }^{\circ} \mathrm{C}$ for 24 hours. The membranes were then stored under nitrogen atmosphere until further use.

\section{Grafting of $\gamma$-alumina with APTMS by vapor phase deposition (VPD)}

The introduction of amino groups onto the $\gamma$-alumina membrane was achieved by the reaction of the surface hydroxyl groups with APTMS as described in previous work [60] (chapter 5). In this work a $100 \mathrm{ml}$ toluene-silane solution, using an APTMS concentration of $50 \mathrm{mM}$ was used.

\section{Grafting of APTMS-grafted $\gamma$-alumina with 6FDA-BDAF}

A typical procedure for the in-situ polymerization method is as follows: (1) A $50 \mathrm{mM}$ APTMS-alumina grafted membrane is placed in a sample holder in a 5 -necked round flask, (2) $100 \mathrm{ml}$ of DMAc and $6.66 \mathrm{~g}$ (150 mmol) 6FDA were added to the flask, (2) The mixture was stirred for 24 hours at RT under nitrogen atmosphere and after 24 hours $5.18 \mathrm{~g}$ BDAF (100 mmol) was added, (3) The mixture was then stirred for another 24 hours under nitrogen atmosphere. After the reaction was completed, the membrane was washed and soaked in fresh DMAc to remove any non-bonded polymer. Immediately after, the modified membranes were thermally imidized at $300{ }^{\circ} \mathrm{C}$ using an identical thermal procedure as described for the $\gamma$-alumina flakes. In the layer by layer polymerization method the reaction was first stopped after reaction with 6FDA by means of thermal imidization before addition of the diamine, BDAF. The second monomer (BDAF) was added using the same procedure as for grafting 6FDA followed again by a thermal imidization. For the layer by layer method an excess of dianhydride was not required and therefore different concentrations of the monomers were used: 6FDA $50 \mathrm{mmol}(2.22 \mathrm{~g})$ and BDAF $50 \mathrm{mmol}(2.59 \mathrm{~g})$. 


\subsubsection{Membrane characterization Infrared spectroscopy}

FTIR spectra of the modified $\gamma$-alumina flakes were obtained with a TGA-IR Tensor 27 system spectrometer. An FTIR spectrum of unmodified $y$-alumina flakes was used for background correction. For further details see chapter 3 of this thesis.

\section{Gas adsorption measurements}

Nitrogen adsorption/desorption isotherms were collected at $77 \mathrm{~K}$ using a Gemini system, VII version (Micromeritics Instruments Corp.). Before each measurement the samples were vacuum-degassed at $200{ }^{\circ} \mathrm{C}$ for 12 hours. Pore size distribution, surface area and pore volume were determined. A detailed description of the method can be found in chapter 4 .

\section{Contact angle}

Static contact angle measurements were performed on the grafted membranes as described in chapter 3. A droplet of $5 \mu \mathrm{L}$ of water (Millipore Q2) was injected at a speed of $1 \mu \mathrm{l} / \mathrm{s}$. The calculated contact angle values were an average of 5 drops.

\section{Permporometry}

Permporometry [61] was employed to determine the pore size distribution of the modified and unmodified membrane layers. A detailed description is given in chapter 5.

\section{Solvent permeation experiments}

Steady-state solvent flux analyses of toluene and $\mathrm{n}$-hexane at room temperature were carried out on unmodified and 6FDA-BDAF modified $\gamma$-alumina membranes in a stainless steel dead-end filtration set-up pressurized with helium to the desired pressure. A trans membrane pressure (TMP) of 1-11 bar was used. A more detailed description can be found in chapter 5 .

\section{Molecular weight cut-off measurements}

The molecular weight cut off is determined by filtration experiments with a 0.3 $\%(\mathrm{w} / \mathrm{w})$ solution of polyisobutylenes (PIB's) in toluene with different molecular masses, using a dead-end filtration set-up, as described before in chapter 5. The MWCO measurements were performed for 90 minutes at a TMP of 10 bar with continuously stirring $(250 \mathrm{rpm})$. The feed, permeate and retentate were then 
analyzed by gel permeation chromatography (GPC).

\subsection{Results and discussion}

In this work two different methods in the two-step approach were used, as illustrated in Figure 2b) and 2c). The influence of the method applied on membrane characteristics and performance was evaluated. A similar way was developed for another polyimide system [59], a BTDA-ODA polyimide, as described in chapter 6 . In the first method, in situ polymerization, illustrated in figure 2b) the 4,4'-(hexafluoroisopropylidene)diphthalic anhydride, 6FDA, was added to the APTMS-grafted $\gamma$-alumina flakes/membranes system and allowed to react, subsequently the diamine, BDAF was added after which, by a thermal imidization process, the polyimide was formed. In the second approach, called layer by layer, the 6FDA/DMAc solution was added to the APTMS-modified flakes and allow to react, after which the flakes were imidized, Subsequently the BDAF/DMAc is added, and reacted for 24 hours, followed by a second imidization step at $300{ }^{\circ} \mathrm{C}$.

\subsubsection{Flakes characterization}

\section{Characterization of the grafted flakes by FTIR}

A similar procedure has been reported for a BTDA-ODA grafted $\gamma$-alumina flake, where the polyimide was successfully bonded to the alumina surface, as described in [59] (chapter 6). Figure 3 shows the FT-IR spectra of unmodified and modified flakes with an APTMS linker and the 6FDA-BDAF polyimide, respectively.

\section{a) Grafting the linker (APTMS)}
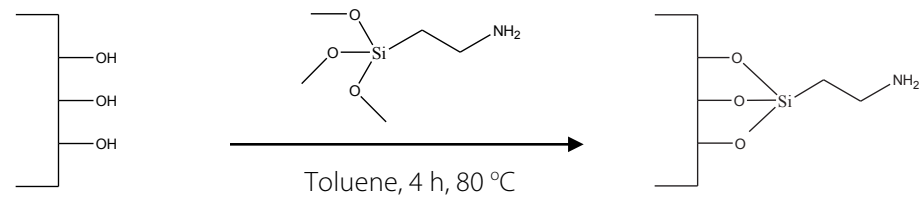
b) In situ polymerization method (1:3:2)

$\longrightarrow \begin{array}{ll} & \begin{array}{l}\text { 1. } 6 F D A, D M A C \\ \text { 2. BDAF, DMAC }\end{array} \\ {_{2}} } & \begin{array}{l}1.24 \mathrm{~h}, \mathrm{RT}, \mathrm{N}_{2} \\ 2.24 \mathrm{~h}, \mathrm{RT}, \mathrm{N}_{2}\end{array}\end{array}$

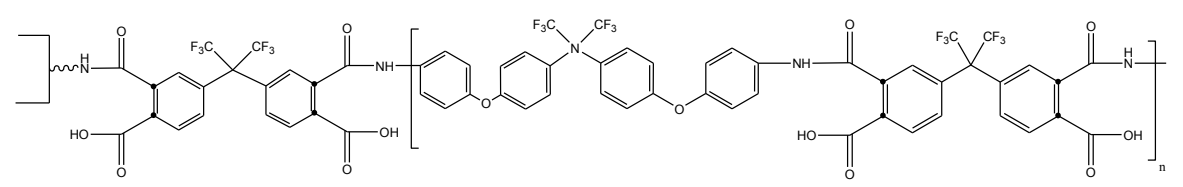

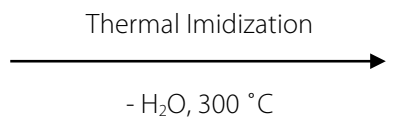

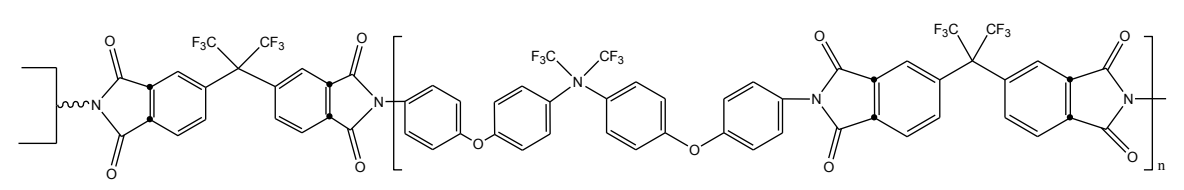

c) Layer by Layer grafting method (1:1:1)

1. Grafting 6FDA (M1)
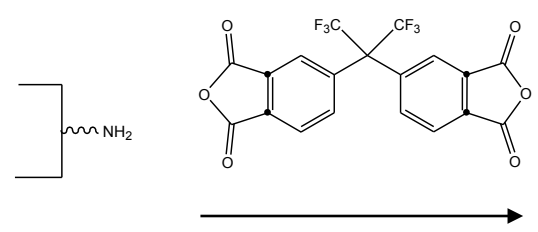<smiles>CCC(CC)NC(=O)c1cc(C(C)(C)c2ccc3c(c2)C(=O)OC3=O)ccc1C(=O)O</smiles>

DMAc, 24 h, RT<smiles>CCC(CC)N1C(=O)c2ccc(C(C)(C)c3ccc4c(c3)C(=O)OC4=O)cc2C1=O</smiles> 
2. Grafting BDAF (M2)<smiles>CCC1=C2C(=O)OC(=O)C2C1CC</smiles><smiles>Nc1ccc(Oc2ccc(C(c3ccc(Oc4ccc(N)cc4)cc3)(C(F)(F)F)C(F)(F)F)cc2)cc1</smiles>

DMAc, $3 \mathrm{~h}, 80^{\circ} \mathrm{C}$<smiles>CCCCC(=O)Nc1cccc(Oc2ccc(N(c3ccc(Oc4ccc(N)cc4)cc3)C(F)(F)C(F)(F)F)cc2)c1</smiles><smiles></smiles>

Figure 2: Scheme for the synthesis of an alumina membrane with (a) 3-aminopropyltrimethoxysilane (APTMS) and subsequently with both 4,4'-(hexafluoroisopropylidene) diphthalic anhydride (6FDA) and 4,4'-(hexafluoroisopropylidene)bis( $p$-phenyleneoxy) dianiline (BDAF) by (b) in-situ polymerization method or (c) a layer by layer method.

a

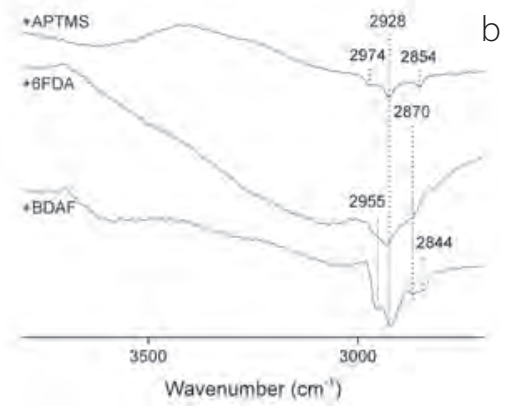

b

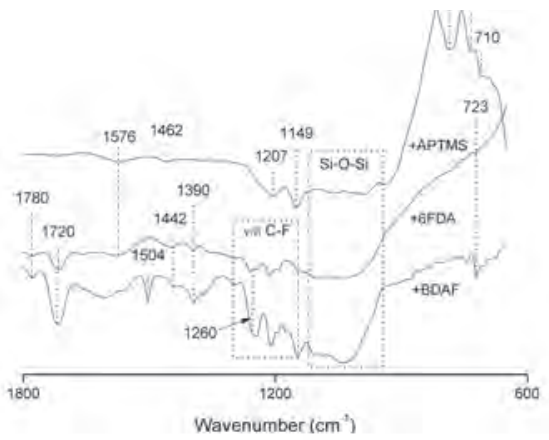

Figure 3: FTIR spectra of $\gamma$-alumina flakes, grafted with (a) 3-aminopropyltrimethoxysilane (APTMS) and subsequently with both 4,4'-(hexafluoroisopropylidene)diphthalic anhydride (6FDA) and 4,4'-(hexafluoroisopropylidene)bis(p-phenyleneoxy)dianiline (BDAF) 
APTMS modified-flakes exhibit some new FTIR peaks, such as the stretching of the methylene $\left(\mathrm{U} \mathrm{CH}_{2}\right)$ and methyl groups between 3000 and $2800 \mathrm{~cm}^{-1}$, the deformation mode of the $\mathrm{NH}_{2}$ group $\left(\delta \mathrm{NH}_{2}\right)$ around $1580 \mathrm{~cm}^{-1}$ and the band corresponding to the bending of the methylene at around $1470 \mathrm{~cm}^{-1}\left(\delta \mathrm{CH}_{2}\right)$ group, indicating the incorporating of the APTMS onto the alumina flakes. The bands between 1400-1100 are assigned to the twisting, rocking and wagging vibrations of the methylene groups. Finally, the incorporation of the APTMS is confirmed by the presence a broad band at 1000-1100 $\mathrm{cm}^{-1}$ due to the stretching of the Si-O-Si due to the formation of siloxane bonds.

After APTMS grafting was confirmed, the first monomer was added (Figure 2c). The presence of characteristic imide bands like a duplet band at 1780 and 1720 $\mathrm{cm}^{-1}$, the band at $1370 \mathrm{~cm}^{-1}$ and the band at $723 \mathrm{~cm}^{-1}$ attributed to the $\mathrm{C}=\mathrm{O}$ asymmetric stretching, $\mathrm{C}=\mathrm{O}$ symmetric stretching, $\mathrm{C}-\mathrm{N}$ stretching ( $\mathrm{C}-\mathrm{N}-\mathrm{C}$ ) and to the $C=O$ bending $(\delta C=O)$ suggesting the conversion of the amide groups into imide groups, proves that grafting of the imide groups of 6FDA was successful [22, 44]. This is also confirmed by the absence of the amide bands at $1660-1650 \mathrm{~cm}^{-1}$ ( $\cup \mathrm{C}=\mathrm{O}$ stretching of the CONH group) and at $1530-1550 \mathrm{~cm}^{-1}$ (coupling $\cup \mathrm{C}-\mathrm{N}$ and $\delta \mathrm{N}-\mathrm{H}$ of the (-NH group) [22].The bands between 1300-1100 $\mathrm{cm}^{-1}$ are due to the multiple C-F bonds indicating the presence of fluoromethyl groups of the 6FDA [62], confirms that the 6FDA was incorporated onto alumina flakes.

After the reaction with 6FDA there is still however, some free $\mathrm{NH}_{2}$ groups that haven't reacted with the dianhydride, as indicated by the weak band at $1580 \mathrm{~cm}^{-1}$. Since the 6FDA presents two dianhydride end groups and only one is expected to react with the amino group to form an imide, the band at $1780 \mathrm{~cm}^{-1}$ can also be attributed to the $\mathrm{C}=\mathrm{O}$.

After the reaction with the 6FDA, the diamine (BDAF) was added to the reaction mixture containing BDAF/DMAc. In this in-situ polymerization case the reaction was not stopped after the reaction with BTDA was completed. The amino group from the aromatic diamine ODA reacted with the anhydride ring through a nucleophilic acyl substitution of one of the carbonyl carbons of the phthalic anhydride unit, followed by a polymerization reaction forming the correspondent poly(amic acid) (Figure 2b). Through a thermal (imidization) treatment at $300^{\circ} \mathrm{C}$ the poly(amic acid) was transformed into its polyimide form. This is confirmed by the absence of amide I and II bands (1660-1650 $\mathrm{cm}^{-1}$ and $\left.1530-1550 \mathrm{~cm}^{-1}\right)$ and an increased intensity for the imide bands $\left(1780,1720,1390\right.$ and $\left.723 \mathrm{~cm}^{-1}\right)$. The incorporation of the diamine is also indicated by an increased intensity (1300-1100 
$\mathrm{cm}^{-1}$ ) regarding the bands attributed to the stretching and bending of the C-F due to the $\mathrm{CF}_{3}$ groups present in the diamine [63]. The asymmetric stretching of the -C-O-C- (originating from aromatic-O-aromatic) characteristic of the BDAF unit was expected at $1240 \mathrm{~cm}^{-1}$, however the presence of multiple peaks corresponding to stretching and bending modes of the $\mathrm{C}-\mathrm{F}$ of the $\mathrm{CF}_{3}$ groups present in the diamine overlaps with this band. Moreover, an increased intensity is observed for these bands after the reaction with BDAF and the appearing of a new band at 1504 $\mathrm{cm}^{-1}$ attributed to stretching modes of the phenyl rings $\left(\cup \mathrm{C}_{6} \mathrm{H}_{4}\right.$ or $\left.\cup \mathrm{C}_{6} \mathrm{H}_{2}\right)[44]$ also suggests grafting of the BDAF monomer.

The presence of the a broad band at between $1100-1000 \mathrm{~cm}^{-1}$, assigned to the Si-O-Si stretching modes due to siloxane bond formation is still present in the last step, indicating that the APTMS is still grafted and thus polyimide grafted $\gamma$-alumina flakes were successfully grafted.

\section{Gas adsorption/desorption}

In order to determine if the inner pore walls were grafted with the polyimide system, $\mathrm{N}_{2}$ adsorption/desorption measurements were performed. Figure 4 a) shows the $\mathrm{N}_{2}$ isotherms curves whereas Figure $4 \mathrm{~b}$ ) presents the pore size distribution curves of unmodified $\gamma$-alumina flakes calcined at $650{ }^{\circ} \mathrm{C}$ and $\gamma$-alumina modified with APTMS via a vapor phase method, followed by a reaction with the dianhydride 4,4'-(hexafluoroisopropylidene)diphthalic anhydride (6FDA) and subsequently with the diamine 4,4'-(hexafluoroisopropylidene) bis(p-phenyleneoxy)dianiline (BDAF).

a

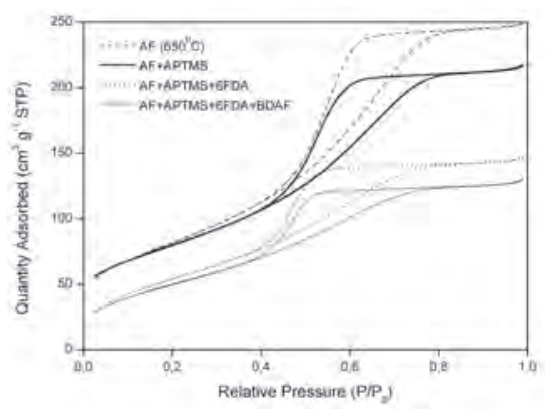

b

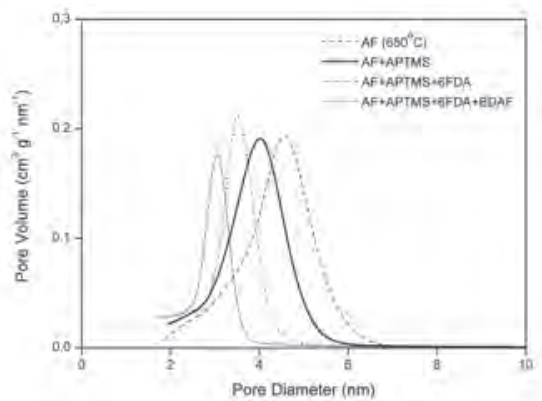

Figure 4: (a) $N_{2}$ physisorption isotherms and (b) Pore size distribution curves for pure $\gamma$-alumina flakes calcined at $650{ }^{\circ} \mathrm{C}$ and for materials modified with 3-amino-propyltrimethoxysilane by a vapor phase method, followed by a reaction with 4,4'-(hexafluoroisopropylidene)diphthalic anhydride (6FDA) and subsequently with 4,4'-(hexafluoroisopropylidene)bis( $p$-phenyleneoxy) dianiline (BDAF). 
For all samples the isotherms presented in Figure 4a) are characteristic of a type IV isotherm with a $\mathrm{H} 1$ hysteresis loop which is usually associated with mesoporous materials with narrow necks and a relative low level of pore connectivity [64]. In addition the pore size distribution curves, as calculated by the BJH method [65] on the desorption branch show for all samples a uniform and sharp pore size distribution. The mean pore diameter $\left(d_{p}\right)$, pore volume $\left(V_{p}\right)$ and BET surface area $\left(S_{B E T}\right)$ values are given in Table 1.

Table 1: Mean pore diameter $\left(d_{p}\right)$, pore volume $\left(V_{p}\right)$ and surface area $\left(A\left(N_{2}\right)\right)$ for pure $\gamma$-alumina flakes and modified with APTMS, 6FDA and BDAF.

\begin{tabular}{lccc}
\hline & $\begin{array}{c}\text { Mean } \mathbf{d}_{\mathbf{p}} \\
(\mathbf{n m})\end{array}$ & $\begin{array}{c}\mathbf{V}_{\mathbf{p}} \\
\left(\mathbf{c m}^{\mathbf{p}} \mathbf{g}^{-1}\right)\end{array}$ & $\begin{array}{c}\mathbf{A}\left(\mathbf{N}_{\mathbf{2}}\right) \\
\left(\mathbf{m}^{2} \mathbf{g}^{-1}\right)\end{array}$ \\
\hline $\mathrm{AF}\left(650^{\circ} \mathrm{C}\right)$ & 4.6 & 0.36 & 245 \\
AF+APTMS & 4.1 & 0.32 & 213 \\
AF+APTMS+6FDA & 3.5 & 0.23 & 141 \\
AF+APTMS+6FDA+BDAF & 3.1 & 0.21 & 124 \\
\hline
\end{tabular}

In all grafted systems both surface area, pore volume and pore size decreased, showing a sequential filling of the pores, which might indicate that both linker and monomers were grafted in the inner pore wall. Grafting is supported by the FTIR results presented in Figure 3. As discussed in previous work [58,59], a maximum length of $0.52 \mathrm{~nm}$ is expected for a bonded APTMS (assuming a complete stretched molecule). This corresponds to a maximum monolayer thickness for APTMS. A reduction of $0.4 \mathrm{~nm}$ in pore diameter excludes the formation of a multilayer of the linker and therefore only a monolayer can be formed (non-fully stretched). For both monomers the molecular size was determined as well. Assuming an angle of $109.5^{\circ}$ between the $\mathrm{C}$-atoms and a complete stretched structure, a molecular size of $0.9 \mathrm{~nm}$ and $1.7 \mathrm{~nm}$ is calculated for a 6FDA and BDAF monomer, respectively. By taking into account these values, a maximum decrease in pore radius of $2.7 \mathrm{~nm}$ can be expected for one 6FDA monomer bonded to one BDAF monomer. However, after the addition of the $6 F D A$ and BDAF monomers a reduction of only $0.6 \mathrm{~nm}$ and $0.4 \mathrm{~nm}$ is observed, respectively, while a pore size of $2 \mathrm{~nm}$ remains. This might be due to the rigid structure of both monomers, containing 5 and 6 ring structures, combined with the presence of bulky fluorine groups and thus difficult to diffuse in such small pores. This might result in a high grafting density on both the membrane surface and at the entrance of the pores, but restricted grafting inside of the pores. Therefore flakes/ membranes with bigger pore sizes are required for a proper grafting of the inner pore wall. Two alumina membranes with pore sizes of 9 and $70 \mathrm{~nm}$ were selected as supports for grafting 6FDA-BDAF polyimide. Since the maximum molecular length 
of alumina-APTMS-6FDA-BDAF (considering 1 layer of each monomer is $3.2 \mathrm{~nm}$, this membranes should have a suitable pore size.

\subsubsection{Structural characterization and membrane performance of $\mathrm{Y}$-alumina membranes}

a-alumina membranes with a pore size of $70 \mathrm{~nm}$ and $\gamma$ - alumina membranes with a pore size of 5 and $9 \mathrm{~nm}$ were used as supports for grafting a polyimide (6DA-BDAF). Two different monomers deposition methods were used: an in situ polymerization method and a layer by layer method. The influence of the pore size and deposition method on the membrane performance and on the pore size reduction was evaluated. In this section the focus is on $\gamma$-alumina membranes and the a-alumina membranes are evaluated in the next section.

In order to evaluate if grafting was succesfull contact angle measurments were performed. Contact angle values measured for the modified and unmodified membranes are listed in Table 2. In the case of the unmodified membranes no contact angle could be measured (Table 2, ID A and B, Table 3 ID A) due to the presence of $\mathrm{OH}$ hydrophilic groups on the membrane surface. After the linker (APTMS) and the first monomer (6FDA) is grafted by a layer by layer method (Table 2, sample E1), an increase in the contact angle value is observed indicating that the membrane surface is made hydrophobic meaning that the hydrophilic $\mathrm{OH}$ groups on the alumina have reacted with the alkoxy groups of the linker and subsequently the amino groups of APTMS have reacted with the dianhydride groups of 6FDA. Due to the presence of flourine $\left(-\mathrm{CF}_{3}\right)$ groups a hydrophobic membrane can be expected. Subsequently the diamine BDAF (Table 2, sample F) is grafted and a further increase in the contact angle is observed, as expected. This increase is mainly due to the introduction of more aromatic and flourine groups $\left(\mathrm{CF}_{3}\right)$ present in BDAF, as illustrated in Figure $\left.2 \mathrm{c}\right)$. This results in a hydrophobic membrane, which indicates that both APTMS, 6FDA and BDAF were grafted onto the membrane surface. This results are in agreemnt with the FTIR results. For the membranes prepared by an in-situ polymerization method an increase hydrophobic contact angle were also measured confirming that grafting has ocurred. This is supported by the FTIR results presented in Figure 3. 
Table 2: Contact angles $(\theta)$ for 6FDA-BDAF grafted on $\gamma$-alumina (5 and $9 \mathrm{~nm}$ )

\begin{tabular}{|c|c|c|}
\hline Membrane & Monomer Deposition & $\theta\left({ }^{\circ}\right)$ \\
\hline $\mathrm{Y}-\mathrm{Al}_{2} \mathrm{O}_{3}\left(650^{\circ} \mathrm{C}\right) 5 \mathrm{~nm}(\mathrm{~A})$ & - & $\sim 0$ \\
\hline $\mathrm{Y}-\mathrm{Al}_{2} \mathrm{O}_{3}\left(825^{\circ} \mathrm{C}\right) 9 \mathrm{~nm}(\mathrm{~B})$ & - & $\sim 0$ \\
\hline $\mathrm{Y}-\mathrm{Al}_{2} \mathrm{O}_{3}(5 \mathrm{~nm})+\mathrm{APTMS} / 6 \mathrm{FDA}-\mathrm{BDAF}(\mathrm{C})$ & in situ polymerization & $105 \pm 2$ \\
\hline $\mathrm{Y}-\mathrm{Al}_{2} \mathrm{O}_{3}(9 \mathrm{~nm})+\mathrm{APTMS} / 6 \mathrm{FDA}-\mathrm{BDAF}(\mathrm{D})$ & in situ polymerization & $98 \pm 3$ \\
\hline $\mathrm{Y}-\mathrm{Al}_{2} \mathrm{O}_{3}(9 \mathrm{~nm})+\mathrm{APTMS} / 6 \mathrm{FDA}(\mathrm{E} 1)$ & Layer by layer & $95 \pm 3$ \\
\hline $\mathrm{Y}-\mathrm{Al}_{2} \mathrm{O}_{3}(9 \mathrm{~nm})+\mathrm{APTMS} / 6 \mathrm{FDA}-\mathrm{BDAF}(\mathrm{F})$ & Layer by layer & $101 \pm 2$ \\
\hline
\end{tabular}

Permporometry and liquid filtration measurements were conducted to elucidate structure and performance of the membrane. The influence of both pore size of the support and the method by which the monomers were added (in-situ polymerization vs. layer by layer) on membrane structure was analyzed.

\section{Influence of the support pore size}

For non-grafted $5 \mathrm{~nm}$ and a $9 \mathrm{~nm}$-alumina membranes toluene permeances of $5.6 \mathrm{I} \mathrm{m}^{2} \mathrm{hr}^{1}$ bar $^{-1}$ and $8.5 \mathrm{I} \mathrm{m}^{-2} \mathrm{hr}^{-1} \mathrm{bar}^{-1}$ were measured respectively whereas permeance values of $8.51 \mathrm{~m}^{2} \mathrm{hr}^{1}$ bar $^{-1}$ and $10.8 \mathrm{I} \mathrm{m}^{-2} \mathrm{hr}^{-1}$ bar $^{-1}$ were measured for hexane. However, after grafting the 6FDA-BDAF system no detectable flux could be measured in both cases, meaning when either a $5 \mathrm{~nm}$ or a $9 \mathrm{~nm}$ alumina membrane was used as support a dense, impermeable, membrane is obtained. This might be an indication that grafting has occurred not only in the surface as supported by the contact angle measurements (Table 2 ID C and D) but also inside the pores, resulting in a dense membrane, as also shown by permporometry measurements, presented in Figure 5 (ID C and D).

As expected, for the unmodified membranes a clear increase in oxygen permeation is observed when the cyclohexane partial pressure decreases (Figure 5). When the cyclohexane partial pressure decreases even further another transition in oxygen permeance is observed, indicating adsorption on pore walls and capillary condensation, meaning that these structures are porous. This is not observed for the 6FDA-BDAF grafted membrane indicating that the structure is dense or microporous (pore size $<1.5 \mathrm{~nm}$ ). In conclusion, grafting of $\gamma$-alumina membranes with pores sizes of either 5 or $9 \mathrm{~nm}$ has not resulted in a suitable membrane for solvent permeation of e.g. toluene and hexane. Therefore, another approach was chosen for the addition of the monomers. 


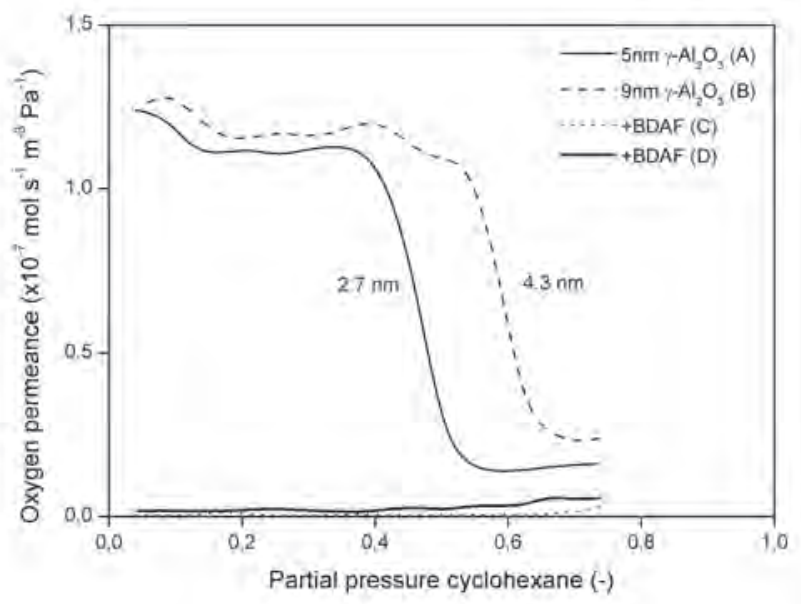

Figure 5: Oxygen permeation as function of the cyclohexane pressure for unmodified $\gamma$-alumina membranes with a pore size of $5 \mathrm{~nm}(A)$ and $9 \mathrm{~nm}(B)$ and membranes $A$ and $B$ grafted with APTMS/6FDA-BDAF by in-situ polymerization (C and D, respectively).

\section{Influence of the deposition method}

Instead of adding both reactants in a one-pot reaction as illustrated in Figure 2b (insitu polymerization), a sequential addition of each of the monomers is performed. This latter method is referred as layer by layer method (Figure 2c). In this approach only the membrane with a pore size of $9 \mathrm{~nm}$ was used. After the linker (APTMS) is grafted, the first monomer is added, 6FDA, after which the membrane is washed and thermal imidized, as illustrated in Figure $2 c$. Toluene and hexane permeances were measured and are listed in table 3.

Table 3: Toluene and hexane permeances for the unmodified $9 \mathrm{~nm} \gamma$-alumina and modified with 6FDA-BDAF by a in situ-polymerization method and a layer by layer method.

\begin{tabular}{|c|c|c|}
\hline Membrane & $\begin{array}{l}\text { Toluene Permeance } \\
\qquad \mathrm{I} \mathrm{m}^{-2} \mathrm{hr}^{-1} \mathrm{bar}^{-1}\end{array}$ & $\begin{array}{l}\text { Hexane Permeance } \\
\quad \mathrm{I} \mathrm{m}^{-2} \mathrm{hr}^{-1} \text { bar }^{-1}\end{array}$ \\
\hline $\mathrm{Y}-\mathrm{Al}_{2} \mathrm{O}_{3}\left(825^{\circ} \mathrm{C}\right) 9 \mathrm{~nm}(\mathrm{~B})$ & 8.5 & 10.8 \\
\hline $\mathrm{Y}-\mathrm{Al}_{2} \mathrm{O}_{3}(9 \mathrm{~nm})+$ APTMS/6FDA-BDAF (C) & 0 & 0 \\
\hline $\mathrm{Y}-\mathrm{Al}_{2} \mathrm{O}_{3}(9 \mathrm{~nm})+\mathrm{APTMS} / 6 \mathrm{FDA}(\mathrm{E} 1)$ & 5.7 & - \\
\hline $\mathrm{Y}-\mathrm{Al}_{2} \mathrm{O}_{3}(9 \mathrm{~nm})+\mathrm{APTMS} / 6 \mathrm{FDA}(\mathrm{E} 2)$ & 6.0 & 9.7 \\
\hline $\mathrm{Y}-\mathrm{Al}_{2} \mathrm{O}_{3}(9 \mathrm{~nm})+\mathrm{APTMS} / 6 \mathrm{FDA}-\mathrm{BDAF}(\mathrm{F})^{\mathrm{b})}$ & 0 & 0 \\
\hline
\end{tabular}

a) Prepared by in-situ polymerization, b) prepared by layer by layer

A reduction in permeance for both solvents is observed after grafting the alumina membrane with APTMS plus 6FDA (Table 3) implying that grafting has occurred what is also supported by the contact angle results (Table 2, ID E1). Therefore, the layer by layer 6FDA-grafted membrane was open enough for solvent filtration 
of which flux-pressure relationships are shown in Figure 6. A linear flux-pressure relationship was not found in this case. Instead a semi-exponential increase in flux can be observed as function of pressure, which might be explained by the opening of smaller pores at higher pressures. However, no hard conclusions can be drawn because only a small number of experiments were performed.

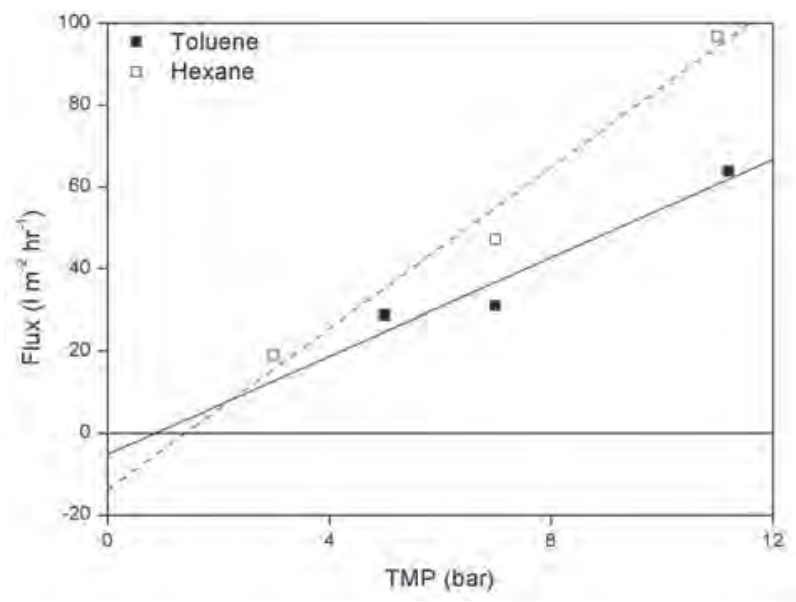

Figure 6: Flux-pressure relationship for the 6FDA-grafted $\gamma$-alumina membrane (ID E1 and E2).

Similar toluene permeances were achieved for two different grafted 6FDA membranes (Table 3, ID E1 and E2) indicating that membrane grafting was reproducible.

After subsequent grafting of the second monomer, the diamine BDAF, no detectable permeances of toluene and hexane were observed. Therefore, this layer by layer 6FDA-BDAF system is still too dense for solvent filtration. This is confirmed by permporometry measurements presented in Figure 7, where the oxygen permeance versus the cyclohexane partial vapor pressure are given for both unmodified and modified $9 \mathrm{~nm} \gamma$-alumina membranes by in situ polymerization or layer by layer methods.

For all modified membranes, no transition could be detected and thus dense membranes were produced independently of the deposition method used. This indicates that pore filling and thus grafting has occurred for both methods. However, except for the reproducible 6FDA grafted membranes, no suitable PI (6FDA-BDAF) grafted membrane was developed for solvent filtration. 


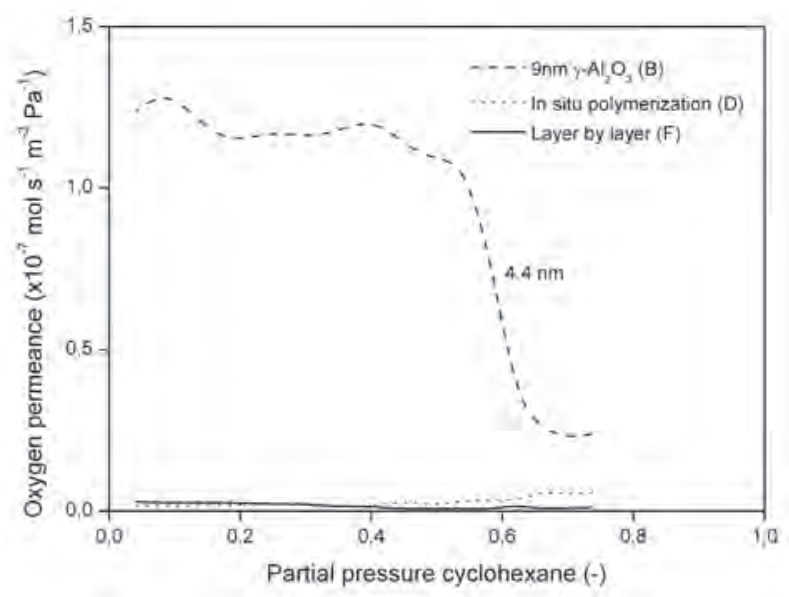

Figure 7 : Oxygen permeation as function of the cyclohexane pressure for the pure $\gamma$-alumina membranes with a pore size of $9 \mathrm{~nm}(B)$ and subsequently grafted with APTMS/6FDA-BDAF by an "in-situ polymerization" (D) or by a "layer-by-layer" method (F).

\subsubsection{Membrane performance of a-alumina membranes}

As observed in Table 3 (ID C and F) all $\gamma$-alumina membranes, grafted with 6FDABDAF, are still too dense for solvent filtration even when a layer by layer method is used. For this reason another support is used, and both linker and monomers are grafted in an a-alumina membrane with a poresize of $70 \mathrm{~nm}$. The layer by layer method was used, since it allows us to have a better control on pore size reduction, as demonstrated before.

Table 4: Toluene permeances of grafted 6FDA-BDAF on a-alumina

\begin{tabular}{|c|c|c|}
\hline Membrane & $\begin{array}{c}\text { Contact Angle } \\
\theta\end{array}$ & $\begin{array}{c}\text { Toluene Permeance } \\
\qquad \mathrm{I} \mathrm{m}^{-2} \mathrm{hr}^{-1} \mathrm{bar}^{-1}\end{array}$ \\
\hline $\mathrm{a}-\mathrm{Al}_{2} \mathrm{O}_{3}(70 \mathrm{~nm})(\mathrm{G})$ & - & 9.9 \\
\hline $\mathrm{a}-\mathrm{Al}_{2} \mathrm{O}_{3}(70 \mathrm{~nm})+\mathrm{APTMS}(\mathrm{H})$ & 65 & - \\
\hline $\mathrm{a}-\mathrm{Al}_{2} \mathrm{O}_{3}(70 \mathrm{~nm})+\mathrm{APTMS} / 6 \mathrm{FDA}(\mathrm{I1})$ & 85 & 8.4 \\
\hline $\mathrm{a}-\mathrm{Al}_{2} \mathrm{O}_{3}(70 \mathrm{~nm})+\mathrm{APTMS} / 6 \mathrm{FDA}(\mathrm{I} 2)$ & & 8.7 \\
\hline $\mathrm{a}-\mathrm{Al}_{2} \mathrm{O}_{3}(70 \mathrm{~nm})+\mathrm{APTMS} / 6 \mathrm{FDA}-\mathrm{BDAF}(\mathrm{J})$ & 123 & 9.7 \\
\hline
\end{tabular}

A sequentional increase in contact angle is observed after each grafting step, indicating that both linker and monomers could be grafted. After each step the toluene permeance was measured, and the permeances values are presented in Table 4. These preliminary results show that a small decrease in toluene permeance is observed after the linker and the first monomer, 6FDA (Table 4, ID I1 and I2) was. Moreover, similar toluene permeances were observed (Table 4 ID I1 and I2), implying that 6FDA a-alumina membranes were reproducibilly made. 
After grafting the second monomer, BDAF, the toluene permeance increases again. It is unclear whether this behaviour is the result of the degradation of the polyimide or the in increase affinity towards toluene (non polar solvents). However no hard conclusons can be made up to now, due to the few number of experiments performed. Nevertheless, this membrane was still porous after the diamine layer is applied and thus it might be suitable for SRNF.

\subsection{Conclusions}

The 6FDA-BDAF polyimide system was successfully grafted on $\gamma$-alumina flakes with a pore size of 5 and $9 \mathrm{~nm}$. For flakes with a pore size of $5 \mathrm{~nm}$ pore filling of both monomers was not efficient, most probably due to the stiff and bulky shape of the monomers hampering diffusion in such small pores, which might result in pore blocking and only allowed grafting in the surface and pore entrance. This is confirmed by the absence of solvent permeation.

It was proven that both $\gamma$ - and a-alumina membranes were grafted with the polyimide 6FDA-BDAF rendering in both cases hydrophobic membranes.

When grafting was applied by an in-situ polymerization method to $\gamma$-alumina membranes with pore sizes of 5 and $9 \mathrm{~nm}$ too dense membranes for solvent permeation were obtained. A better controlled grafting can be performed by applying a layer by layer method. A reproducible 6FDA grafted membrane was developed showing reproducible permeation of toluene and hexane. When a diamine (BDAF) layer is grafted on this membrane, the system is dense as demonstrated by permporometry and by the absence of detectable solvent permation. The same layer by layer method applied on to an a-alumina membrane with a pore size of $70 \mathrm{~nm}$, shows toluene permeances. If compared with the insitu polymerization method the better controlled layer by layer method gives more reproducible, porous, polyimide grafted membranes with tailored pore morphology, suitable for solvent permeation.

\section{Acknowledgement}

This is an ISPT project (Institute for Sustainable Process Technology). 


\subsection{References}

1. Staudt-Bickel, C. and W.J. Koros, Olefin/paraffin gas separations with 6FDA-based polyimide membranes. Journal of Membrane Science, 2000. 170(2): p. 205-214.

2. Cecopieri-Gomez, M.L., J. Palacios-Alquisira, and J.M. Dominguez, On the limits of gas separation in $\mathrm{CO}_{2} / \mathrm{CH}_{4}, \mathrm{~N}_{2} / \mathrm{CH}_{4}$ and $\mathrm{CO}_{2} / \mathrm{N}_{2}$ binary mixtures using polyimide membranes. Journal of Membrane Science, 2007. 293(1-2): p. 53-65.

3. Park, S.H., et al., Gas separation properties of 6FDA-based polyimide membranes with a polar group. Macromolecular Research, 2003. 11(3): p. 157-162.

4. Coleman, M.R. and W.J. Koros, Isomeric polyimides based on fluorinated dianhydrides and diamines for gas separation applications. Journal of Membrane Science, 1990. 50(3): p. 285-297.

5. Katarzynski, D. and C. Staudt, Temperature-dependent separation of naphthalene/ndecane mixtures using 6FDA-DABA-copolyimide membranes. Journal of Membrane Science, 2010. 348(1-2): p. 84-90.

6. Hao, J.Q., et al., The pervaporation properties of sulfonyl-containing polyimide membranes to aromatic/aliphatic hydrocarbon mixtures. Journal of Membrane Science, 1997. 132(1): p. 97-108.

7. Qiao, X., T.-S. Chung, and K.P. Pramoda, Fabrication and characterization of BTDA-TDI/MDI (P84) co-polyimide membranes for the pervaporation dehydration of isopropanol. Journal of Membrane Science, 2005. 264(1-2): p. 176-189.

8. Tanihara, N., et al., Pervaporation of organic liquid mixtures through membranes of polyimides containing methyl-substituted phenylenediamine moieties. Journal of Membrane Science, 1994. 95(2): p. 161-169.

9. Okamoto, K.-i., et al., Pervaporation of aromatic/non-aromatic hydrocarbon mixtures through crosslinked membranes of polyimide with pendant phosphonate ester groups. Journal of Membrane Science, 1999. 157(1): p. 97-105.

10. See Toh, Y.H., F.W. Lim, and A.G. Livingston, Polymeric membranes for nanofiltration in polar aprotic solvents. Journal of Membrane Science, 2007. 301(1-2): p. 3-10.

11. Vanherck, K., et al., A simplified diamine crosslinking method for PI nanofiltration membranes. Journal of Membrane Science, 2010. 353(1-2): p. 135-143.

12. Vanherck, K., et al., Cross-linked polyimide membranes for solvent resistant nanofiltration in aprotic solvents. Journal of Membrane Science, 2008. 320(1-2): p. 468-476.

13. White, L.S., Transport properties of a polyimide solvent resistant nanofiltration membrane. Journal of Membrane Science, 2002. 205(1-2): p. 191-202.

14. White, L.S. and A.R. Nitsch, Solvent recovery from lube oil filtrates with a polyimide membrane. Journal of Membrane Science, 2000. 179(1-2): p. 267-274.

15. White, L.S. and C.R. Wildemuth, Aromatics enrichment in refinery streams using hyperfiltration. Industrial \& Engineering Chemistry Research, 2006. 45(26): p. 9136-9143.

16. Ohya H., Kudrayavtev V. V. and Semenove S. I., Polyimide Membranes: Applications, Fabrications and Properties, Gordon and Breach Publishers, Tokyo, Japan, 1996

17. Kim, T.H., et al., Relationship Between Gas Separation Properties And Chemical-Structure In A Series Of Aromatic Polyimides. Journal of Membrane Science, 1988. 37(1): p. 45-62.

18. Dhara, M.G. and S. Banerjee, Fluorinated high-performance polymers: Poly(arylene ether)s and aromatic polyimides containing trifluoromethyl groups. Progress in Polymer Science, 2010. 35(8): p. 1022-1077.

19. Tanaka, K., et al., Effects Of Trifluoromethyl Side-Groups On Gas-Permeability And Permselectivity In Polyimides. Polymer Journal, 1994. 26(10): p. 1186-1189.

20. Stern, S.A., et al., Structure Permeability Relationships Of Polyimide Membranes Applications To The Separation Of Gas-Mixtures. Journal of Polymer Science Part B-Polymer Physics, 1989. 27(9): p. 1887-1909.

21. Kim, J.-H., et al., Incorporation effect of fluorinated side groups into polyimide membranes on their pervaporation properties. Journal of Membrane Science, 2000. 169(2): p. 185-196. 
22. Vora, R.H., S.H. Goh, and T.S. Chung, Synthesis and properties of fluoro-polyetherimides. Polymer Engineering and Science, 2000. 40(6): p. 1318-1329.

23. Lin, S.H., et al., Organo-soluble polyimides: Synthesis and polymerization of 2,2 '-bis(trifluoromethyl)-4,4',5,5'-biphenyltetracarboxylic dianhydride. Macromolecules, 1998. 31(7): p. 2080-2086.

24. Chung, I.S. and S.Y. Kim, Soluble Polyimides from Unsymmetrical Diamine with Trifluoromethyl Pendent Group. Macromolecules, 2000. 33(9): p. 3190-3193.

25. Bes, L., et al., Synthesis and properties of novel polyimides containing fluorinated alkoxy side groups. Macromolecular Chemistry and Physics, 2001. 202(14): p. 2954-2961.

26. Choi, H., et al., Soluble polyimides from unsymmetrical diamine containing benzimidazole ring and trifluoromethyl pendent group. Polymer, 2008. 49(11): p. 2644-2649.

27. Yang, C.-P.,Y.-Y.Su, and M.-Y. Hsu, Organo-soluble and Lightly-colored Fluorinated Polyimides Based on 2,2-Bis[4-(3,4-dicarboxyphenoxy)phenyl]hexafluoropropane Dianhydride and Aromatic Bis(ether amine)s Bearing Pendent Trifluoromethyl Groups. Polym. J, 2006. 38(2): p. 132-144.

28. Schmeling, N., et al., Functionalized copolyimide membranes for the separation of gaseous and liquid mixtures. Beilstein Journal of Organic Chemistry, 2010. 6: p. 789-800.

29. Xu, W.Y., D.R. Paul, and W.J. Koros, Carboxylic acid containing polyimides for pervaporation separations of toluene/iso-octane mixtures. Journal of Membrane Science, 2003. 219(1-2): p. 89-102.

30. Katarzynski, D., F. Pithan, and C. Staudt, Pervaporation of multi component aromatic/ aliphatic mixtures through copolyimide membranes. Separation Science and Technology, 2008. 43(1): p. 59-70.

31. Pithan, F., et al., Polymeric membranes for aromatic/aliphatic separation processes. Chemphyschem, 2002. 3(10): p. 856-862.

32. Ren, J.Z., C. Staudt-Bickel, and R.N. Lichtenthaler, Separation of aromatics/aliphatics with crosslinked 6FDA-based copolyimides. Separation and Purification Technology, 2001. 223(1-3): p. 31-43.

33. Katarzynski, D. and C. Staudt, Permeation properties of different aromatic substances in multicomponent aromatic/aliphatic pervaporation experiments. Desalination, 2006. 200(1-3): p. 23-25.

34. Wang, $H_{\text {., }}$ et al., Sorption and pervaporation properties of sulfonyl-containing polyimide membrane to aromatic/non-aromatic hydrocarbon mixtures. Journal of Polymer Science Part B: Polymer Physics, 2000. 38(22): p. 2954-2964.

35. Fang, J.H., et al., Pervaporation properties of ethynyl-containing copolyimide membranes to aromatic/non-aromatic hydrocarbon mixtures. Polymer, 1999. 40(11): p. 3051-3059.

36. Okamoto, K., et al., Pervaporation of aromatic/non-aromatic hydrocarbon mixtures through crosslinked membranes of polyimide with pendant phosphonate ester groups. Journal of Membrane Science, 1999. 157(1): p. 97-105.

37. Staudt-Bickel, C. and W.J. Koros, Improvement of $\mathrm{CO}_{2} / \mathrm{CH}_{4}$ separation characteristics of polyimides by chemical crosslinking. Journal of Membrane Science, 1999. 155(1): p. 145-154.

38. Shao, L., et al., Transport properties of cross-linked polyimide membranes induced by different generations of diaminobutane (DAB) dendrimers. Journal of Membrane Science, 2004. 238(1-2): p. 153-163.

39. Kita, H., et al., Effect of photocrosslinking on permeability and permselectivity of gases through benzophenone-containing polyimide. Journal of Membrane Science, 1994. 87(12): p. 139-147.

40. Liu, Y., R. Wang, and T.S. Chung, Chemical cross-linking modification of polyimide membranes for gas separation. Journal of Membrane Science, 2001. 189(2): p. 231-239.

41. Tin, P.S., et al., Effects of cross-linking modification on gas separation performance of Matrimid membranes. Journal of Membrane Science, 2003. 225(1-2): p. 77-90.

42. Qiao, X. and T.-S. Chung, Diamine modification of P84 polyimide membranes for pervaporation dehydration of isopropanol. AlChE Journal, 2006. 52(10): p. 3462-3472.

43. Yen, C.T., et al., Synthesis and properties of new polyimide-silica hybrid films through both 
intrachain and interchain bonding. Polymer, 2003. 44(23): p. 7079-7087.

44. Park, H.B., et al., Imide-siloxane block copolymer/silica hybrid membranes: preparation, characterization and gas separation properties. Journal of Membrane Science, 2003. 220(12): p. 59-73.

45. Chen, B.K., T.M. Chiu, and S.Y.Tsay, Synthesis and characterization of polyimide/silica hybrid nanocomposites. Journal of Applied Polymer Science, 2004. 94(1): p. 382-393.

46. Leu, C.M., Z.W. Wu, and K.H. Wei, Synthesis and properties of covalently bonded layered silicates/polyimide (BTDA-ODA) nanocomposites. Chemistry of Materials, 2002. 14(7): p. 3016-3021.

47. Cornelius, C.J. and E. Marand, Hybrid inorganic-organic materials based on a 6FDA6FpDA-DABA polyimide and silica: physical characterization studies. Polymer, 2002. 43(8): p. 2385-2400.

48. Huang, J.C., et al., Organic-inorganic nanocomposites from cubic silsesquioxane epoxides: direct characterization of interphase, and thermomechanical properties. Polymer, 2005. 46(18): p. 7018-7027.

49. Huang, J.C., et al., Cubic silsesquioxane-polyimide nanocomposites with improved thermomechanical and dielectric properties. Acta Materialia, 2005. 53(8): p. 2395-2404.

50. Huang, J.C., et al., Polyimide/POSS nanocomposites: interfacial interaction, thermal properties and mechanical properties. Polymer, 2003. 44(16): p. 4491-4499.

51. Choi, J., A.F. Yee, and R.M. Laine, Organic/inorganic hybrid composites from cubic silsesquioxanes. Epoxy resins of octa(dimethylsiloxyethylcyclohexylepoxide) silsesquioxane. Macromolecules, 2003. 36(15): p. 5666-5682.

52. Verker, R., et al., TriSilanolPhenyl POSS-polyimide nanocomposites: Structure-properties relationship. Composites Science and Technology, 2009. 69(13): p. 2178-2184.

53. Yong, H.H., et al., Zeolite-filled polyimide membrane containing 2,4,6-triaminopyrimidine. Journal of Membrane Science, 2001. 188(2): p. 151-163.

54. Mahajan, R. and W.J. Koros, Mixed matrix membrane materials with glassy polymers. Part 1. Polymer Engineering and Science, 2002. 42(7): p. 1420-1431.

55. Pechar, T.W., et al., Fabrication and characterization of polyimide-zeolite $L$ mixed matrix membranes for gas separations. Journal of Membrane Science, 2006. 277(1-2): p. 195-202.

56. Qiao, X., T.-S. Chung, and R. Rajagopalan, Zeolite filled P84 co-polyimide membranes for dehydration of isopropanol through pervaporation process. Chemical Engineering Science, 2006. 61(20): p. 6816-6825.

57. N. Benes, A. Nijmeijer, H. verweij in : N. K. Kanellopoulos (Ed. ), Recent Advences In Gas Separation by Microporous Ceramic Membranes, Elsevier, Amsterdam, 2000, p. 335

58. Pinheiro M. F. Ana, Chapter 4

59. Pinheiro M. F. Ana, Chapter 6

60. Pinheiro M. F. Ana, Chapter 5

61. Cao, G.Z., et al., Permporometry study on the size distribution of active pores in porous ceramic membranes. Journal of Membrane Science, 1993. 83(2): p. 221-235.

62. Mo, T.C., et al., Synthesis and characterization of polyimide-silica nanocomposites using novel fluorine-modified silica nanoparticles. Journal of Applied Polymer Science, 2007. 104(2): p. 882-890

63. Jeong K. U., Synthesis and characterization of novel aromatic polyimides from bis(3aminophenyl)3,5-bis(trifluoromethyl)phenyl phosphine oxide, Korean Polymer Journal. J 8 5, 2000, pp 215-223

64. Sing, K.S.W., et al., Reporting Physisorption Data For Gas Solid Systems With Special Reference To The Determination Of Surface-Area And Porosity (Recommendations 1984). Pure and Applied Chemistry, 1985. 57(4): p. 603-619.

65. Barrett, E.P., L.G. Joyner, and P.P. Halenda, The Determination Of Pore Volume And Area Distributions In Porous Substances .1. Computations From Nitrogen Isotherms. Journal of the American Chemical Society, 1951.73(1): p. 373-380. 


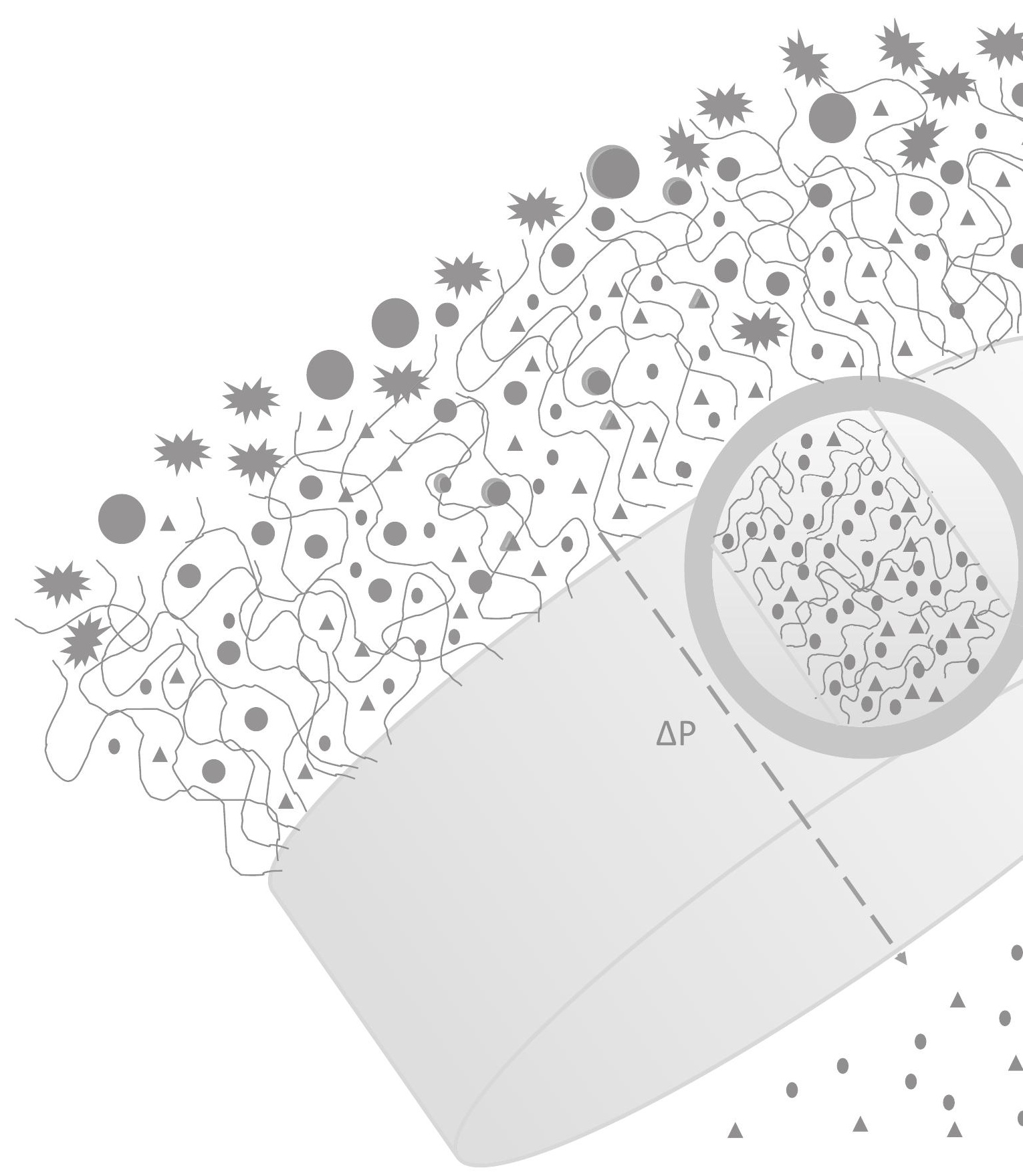


Chapter

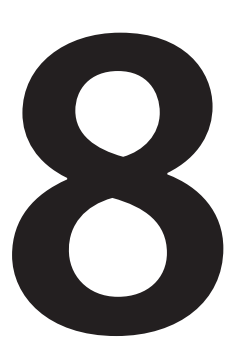

\section{Conclusions and}

Recommendations

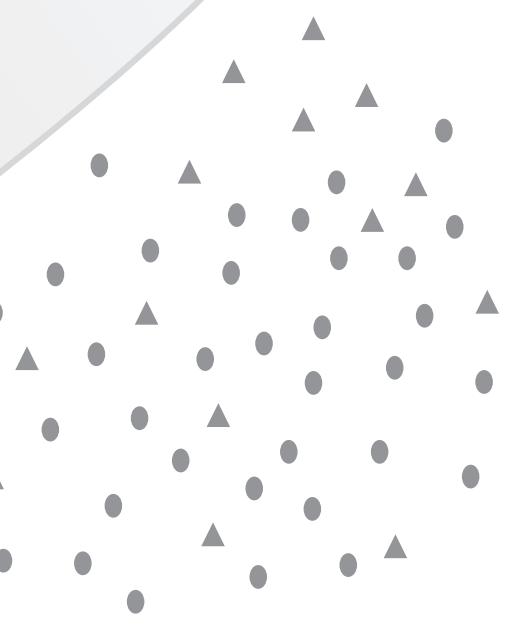


In this thesis different methods were described for functionalization of inorganic membranes by trifunctional silane coupling agents, containing alkyl and amino terminal groups, either for direct hydrophobization of the membrane surface (chapter 3) or for further attachment of polymers like PDMS (chapter 4) or polyimides (chapter 6 and 7). Grafting of PDMS resulted in hydrophobic membranes while polyimide grafting resulted in hydrophilic membranes. Furthermore, the introduction of - $\mathrm{CF}_{3}$ groups chapter $\mathbf{6}$ in polyimide polymers has resulted in hydrophobic membranes. In short it was demonstrated that:

- Polymers/silanes of different nature can easily be grafted on metal oxide surfaces.

- Properties as hydrophobicity/hydrophilicity, pore size, permeability and MWCO of inorganic membranes can be manipulated by grafting.

- Controlled deposition of the silanes can be achieved by a simple vapor phase method (VPD). This in turn results in a thin and homogeneous layer for further polymer attachments.

- Through this approach several different classes of polymers can be grafted, allowing easy tailoring of the surface chemistry.

In chapter 3 titania membranes with pore sizes of $5 \mathrm{~nm}$ were grafted with different alkylchlorosilanes and reaction parameters (reaction temperature and time) were studied as function of the silane used (number of hydrolysable groups and chain length). In all cases the result was a hydrophobic grafted membrane. Room temperature reactions yield an efficient and homogeneous grafting onto the pore walls, which were stable in toluene and hexane after 14 days of soaking. However for porous alkyl-grafted $\gamma$-alumina flakes, using the same reaction conditions, lower stability in solvents was observed if compared with alkyl-grafted titania powders (chapter 4). This can be related to lower reactivity of the $\gamma$-alumina flakes, type of bond formed and the pore shape, as well as the use of water and not $\mathrm{H}_{2} \mathrm{O}_{2}$ as hydroxylating agent, which all can result in poorly bonding of the organic moiety to the surface. For grafted titania membranes, applications as SRNF should be considered. In this respect solvent flux including MWCO measurements should be performed.

As described in literature that the alkyl chain length of the silane and the number of hydrolysable groups are crucial parameters for the solvent permeation performance of such membranes with nano-ranged pore sizes [1-3]. Further studies on the grafting of mono- and di-, alkyl silanes with different chain length or fluorinated silanes and its influence on the permeation properties should be 
performed. Preliminary results in fluorosilane grafted titania membranes (pore size $10 \mathrm{~nm}$, results not shown in this thesis) present toluene, hexane and IPA permeances up to $11 \mathrm{I} \mathrm{m}^{-2} \mathrm{hr}^{-1}$ barr $^{-1}, 30 \mathrm{I} \mathrm{m}^{-2} \mathrm{hr}^{-1} \mathrm{bar}^{-1}$ and $2.31 \mathrm{I} \mathrm{m}^{-2} \mathrm{hr}^{-1}$ bar $^{-1}$, respectively. In this respect, the use of a vapor phase (VPD) method (as described in chapter 4 and 5) can also lead to a better control on the structure of the grafting layer is avoiding pore blocking.

In chapter $\mathbf{4}$ an epoxy terminated PDMS is grafted onto a $\gamma$-alumina membrane using an amino silane as linker. The influence of the linker deposition method was studied by performing reactions in the solution (SPD) and in the vapor phase (VPD). It was demonstrated that the vapor phase method resulted in a thin silane layer (close to a monolayer thickness) whereas in the case of SPD a thick APTES layer was formed. The quality of the resulted APTES layer (thickness, uniformity, coverage density) has a profound influence on the amount and degree of pore infiltration on PDMS grafting. Solvent permeation experiments, described in chapter $\mathbf{5}$ and $\mathbf{6}$, show no detectable flux for any of the solvents studied when the linker is deposited by an SPD method. The formation of a monolayer was also proven for VPD by permporometry measurements. This method of deposition can find multiple uses not only in membranes, but also in coatings, (bio)sensors, micro/nanofluidic devices, etc.

The use of the VPD deposition method should be optimized for other silanes with different functional groups like vinyl, thiol, methacrylate and epoxy. This can allow us to graft a wide variety of polymers and thus to cover a wide range of applications.

Accurate measurements for the thickness of the PDMS-grafted layer can be done by means of atomic force microscopy or ellipsometry. This can also be performed on silica wafers (as described in chapter 5) or even on porous alumina membranes (lower accuracy). This can provide us with important information regarding pore blocking and consequently allowing a better choice of the suitable support.

The PDMS-grafted $\gamma$-alumina flakes were found to be thermally stable until $550^{\circ} \mathrm{C}$ and are stable in a series of solvents after 7 days of soaking, and therefore PDMS-grafted $\gamma$-alumina membranes are very promising for application in SRNF (chapter 5).

In chapter $\mathbf{5}$ hydrophobic microporous PDMS grafted $\gamma$-alumina membranes were fabricated. It was demonstrated that by the grafting route one is able to tune pore size and to engineer surface chemistry (e.g. hydrophobicity) of membranes. After APTES was grafted by a VPD method on a $\gamma$-alumina membrane, calcined at 650 ${ }^{\circ} \mathrm{C}$ with a pore radius of $2.6 \mathrm{~nm}$, a reduction of $0.5 \mathrm{~nm}$ in pore radius demonstrated 
that a monolayer of fully stretched APTES molecules was formed on the pore wall. This reduction in pore size by one monolayer of linking agent is also observed for $\gamma$-alumina membranes, grafted with BTDA-ODA (chapter $\mathbf{6}$ ). This validates that VPD is a useful method to graft silane layers with a controlled thickness on and in porous supports, and therefore is a more suitable method for further polymer attachments

Permeation at room temperature was examined for three solvents with different viscosities, molecular shapes and polarities, i.e. hexane, toluene and IPA. Membranes, where the linker was grafted by SPD, resulted in dense systems, which were impermeable to these solvents. Contrarily for PDMS-grafted membranes, in which the linker was grafted by means of a VPD technique, reproducible permeances (in I $\mathrm{m}^{-2} \mathrm{hr}^{-1} \mathrm{bar}^{-1}$ ) of $4.8 \pm 0.1$ for hexane, $3.1 \pm 0.5$ for toluene and $0.54 \pm 0.04$ for IPA. A molecular weight cut-off (MWCO) in the NF range of $509 \mathrm{Da}$ was attained. Furthermore, stability tests showed that this membrane was stable in all the tested solvents (up to 170 days), validating these membranes as SRNF membranes. Stability tests performed at high temperatures demonstrated that these membranes were also stable in toluene and IPA up to temperatures of $80^{\circ} \mathrm{C}$, enabling the use of these membranes for separations at elevated temperatures. However, no specific application was tested.

In this respect a selection should be made in order to find potential applications for this membrane in both solvent/solvent and solvent/solute mixtures at room temperature and higher temperatures. The last opportunity one presents more industrial potential like the recovery of homogeneous catalysts.

During the stability tests on both PDMS (chapter 5) and BTDA-ODA (chapter 6) grafted membranes a clear reduction in solvent flux was observed in the case of the BTDA-ODA for hexane leading to no detectable fluxes after 32 days. This is explained by the ongoing capillary condensation of water or impurities. This effect is expected to be more pronounced for hydrophilic than for hydrophobic membranes and for nanosized pores $[4,5][6]$. Permeation of organic solvents, containing known ppm amounts of water or impurities, can provide a better understanding on this phenomenon, which has a crucial effect in the permeance of non-aqueous solvents. A comparison between aromatic and aliphatic hydrocarbons might also be interesting. Aromatic solvents are known to dissolve water better than alifatics, however it is not clear if this has an effect on permeability or if the degree of water saturation is the main factor controlling the permeability decrease.

An attempt on elucidating the transport through these membranes was made. 
It was demonstrated that the transport mechanism is mainly controlled by pore flow transport and that solution/diffusion is less significant. However, higher viscosity corrected permeances (VCP's) are observed for toluene than for hexane and IPA, while swelling experiments on silicon wafers by ellipsometry show that more swelling is observed for hexane. This difference in swelling behavior was also observed for dense PDMS polymeric membranes. Viscosity related effects were proposed to play a role, meaning that the apparent viscosity of the liquid, confined in the pores, may differ from the macroscopic/bulk viscosity of the solvent. To prove the existence of this viscosity effect and to gain some insight in solvent transport through these systems towards a fundamental and application point of view the viscosity dependency has to be studied. The VCP $(\mathrm{Km})$ is obtained according to Darcy's law by multiplying the $\triangle J / \triangle T M P$ by the bulk viscosity.

$\mathrm{J}=(\mathrm{Km} / \eta)^{*} \mathrm{TMP} \rightarrow \mathrm{Km}=\eta^{*}(\Delta \mathrm{J} / \Delta \mathrm{TMP}) \rightarrow \mathrm{km}=\mathrm{TMP} \Delta \mathrm{J} / \Delta \eta$

When the VCP is equal for every solvent, viscous flow is dominating, as was observed in this work for PDMS grafted membranes. It is assumed that the viscosity of especially hexane inside the membrane pores is different than the bulk viscosity. To confirm this effect, one can fix the TMP and change the viscosity of the solvent by altering the temperature, since the temperature dependency of the viscosity follows an Arrhenius relation. Then the gradient $\Delta J / \Delta \eta$ can be determined and the VCP of each solvent can be acquired. The viscosity effect is confirmed when the VCP in hexane is equal to or higher than the VCP of toluene. In order to get a better insight of the transport, more classes of solvents with different polarities and shapes should be tested.

Finally, the use of a PDMS polymer with a larger MW (e.g.: $5000 \mathrm{~g} \mathrm{~mol}^{-1}$ ), combined with the use of ceramic membranes with different pore sizes can give valuable information on the influence of PDMS loading on chemical transport as well as elucidating whether the confinement of the polymer in the pores of the ceramic membrane suppresses swelling and to what extent.

In chapter $\mathbf{6}$ a hydrophilic polyimide (BTDA-ODA) grafted membrane was prepared. The influence of several parameters was studied including the support pore size, the linker deposition method and the way by which the monomers were added. The addition of the monomers in a sequential (layer by layer) way, combined with grafting the linker by VPD on a $\gamma$-alumina membrane with a pore size of $9 \mathrm{~nm}$ resulted reproducibly in a mesoporous (pore size $2.7 \mathrm{~nm}$ ) membrane with hexane 
and toluene permeances of $1.7 \mathrm{I} \mathrm{m}^{-2} \mathrm{hr}^{-1}$ bar $^{-1}$ and $4.0 \mathrm{I} \mathrm{m}^{-2} \mathrm{hr}^{-1}$ bar-1, $^{-1}$ respectively. A molecular weight cut-off of 830 Da was achieved. The membrane was stable in toluene while in hexane ongoing capillary condensation of water strongly affects its permeation. Permeation results should be repeated in hexane and a rigorous control of the water content should be done. Stability tests for longer periods are also needed.

A comparison of permeance data for all the developed membranes is made in figure 1. Clearly, hydrophobicity enhances the solvent permeation. The porous BTDA-ODA membrane with a MWCO of 830 Da presents lower fluxes than the hydrophobic microporous (or dense) PDMS membrane with a MWCO 500 Da.

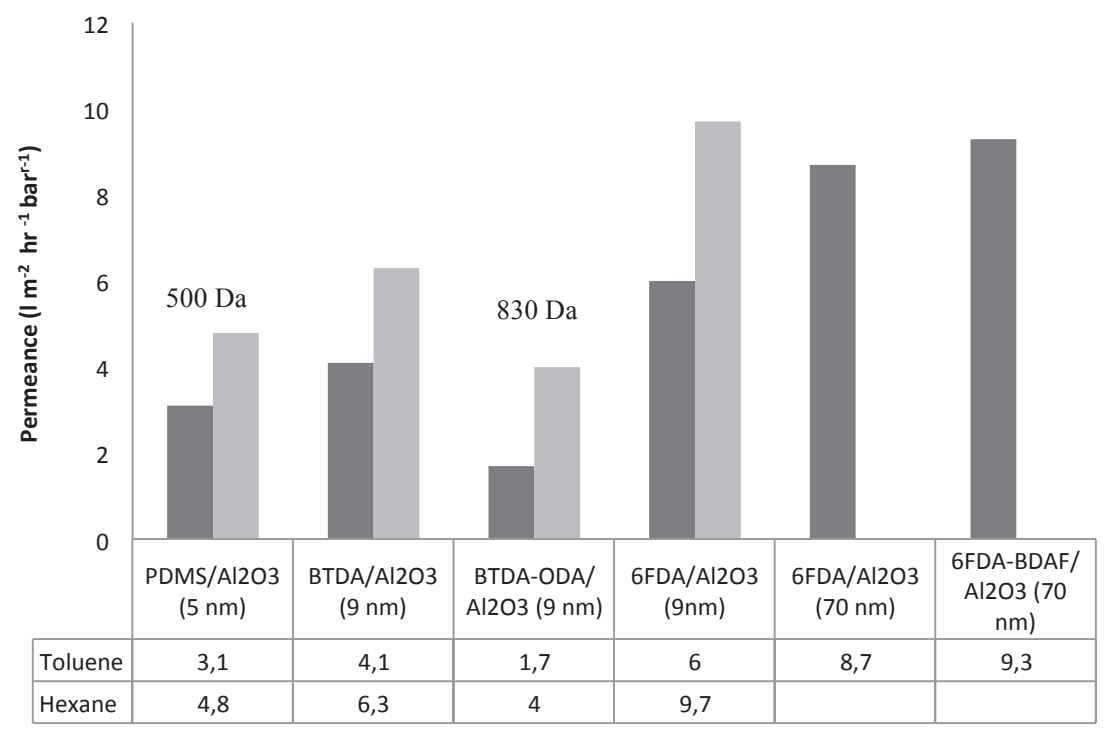

Figure 1: Toluene (black bars) and hexane (grey bars) permeances for the different membranes developed in this thesis in chapter 5,6 and 7. For the alumina with $70 \mathrm{~nm}$ modified with the $6 \mathrm{FDA}$ and BDAF no hexane permeance was measured.

In chapter $\mathbf{6}$ and $\mathbf{7}$ it was demonstrated that a sequential grafting of the monomers resulted in a sequential and controlled decrease in pore size (for membranes as well as for flakes) and solvent permeance (Figure 1). Therefore tailoring of the MWCO is expected to be possible. However, in this work only one layer of each monomer was applied and more iterations are needed and evaluation of toluene permeance and MWCO should be performed simultaneously. Thus, the use of a ceramic support with a bigger pore size is interesting to study, e.g. a-alumina membranes with a pore-size of $70 \mathrm{~nm}$. 
Further research should also focus on the permeation of other solvents, particularly solvents where presently polyimide membranes show instability such as amines, chlorinated and protic solvents e.g. n-methylpyrrolidone (NMP), tetrahydrofuran (THF), dimethylformamide (DMF), dimethylacetamide (DMAc), dimethylsulfoxide (DMSO). On the other hand, the incorporation of spacer groups like $\mathrm{C}\left(\mathrm{CF}_{3}\right)_{2}$ can increase solvent solubility, chemical as well as mechanical stability, permeability, hydrophobicity and can reduce swelling effects [7-9] (chapter 7). This is demonstrated in figure 1, where higher permeances were obtained for hexane and toluene for a 6FDA grafted $\gamma$-alumina membrane (chapter 7) when compared with a BTDA grafted $\gamma$-alumina membrane (chapter $\mathbf{6}$ ). Therefore, the introduction of fluorine diamines like 4,4'-(hexafluoroisopropylidene)bis( $p$-phenyleneoxy) dianiline (BDAF), 4,4'-hexafluoroisopropyldiene dianiline (6FpDA) or substituting the BTDA by the 6FDA and using ODA as the diamine can be useful to increase the permeability as well as to avoid undesired water condensation effects.

In chapter 7 hydrophobic polyimide (6FDA-BADF) grafted membranes were developed. In all cases the linker was grafted by a VPD technique. The influence of the support pore size and the monomer deposition method were studied. For ceramic supports with pore diameters of 5 and $9 \mathrm{~nm}$ no solvent permeation was detected for both monomer deposition methods of the polyimide. Even though, a hydrophobic and reproducible 6FDA-grafted $\gamma$-alumina membrane reproducible shows toluene and hexane permeances of resp. 5.7-6.0 and $9.7 \mathrm{I} \mathrm{m}^{-2}$ $\mathrm{hr}^{-1} \mathrm{bar}^{-1}$. a-Alumina membranes with a pore size of $70 \mathrm{~nm}$ were also grafted by a layer by layer method. Toluene permeation was observed and a hydrophobic, reproducible 6FDA grafted membrane was fabricated. The relatively large pore size of the a-alumina membrane offers the possibility of producing membranes with a tailored permeance and MWCO by making use of a layer by layer method.

In this respect more membranes need to be synthesized with increased number of layers of each monomer and a sequential analysis of both permeance and MWCO needs to be performed. Permeation experiments with different solvents should be done.

Pervaporation experiments with 6FDA-based polyimides and copolyimides and the introduction of aromatic diamines containing carboxyl groups as DABA and/ or crosslinking with ethylene glycol has demonstrated to increase the selectivity towards aromatics (e.g. benzene) in aromatic/aliphatic mixtures and to reduce swelling effects with no reduction in permeability. Furthermore, due to their thermal stability, it was also possible to operate at temperatures between $60{ }^{\circ} \mathrm{C}$ and 100 
${ }^{\circ} \mathrm{C}$ [10-14]. The preparation of 6FDA polyimide and copolyimide grafted ceramic membranes by using various diamines as the $4,4^{\prime}$-(Hexafluoroisopropylidene) bis(p-phenyleneoxy) dianiline (BDAF).4,4'-hexafluoroisopropyldiene dianiline (6FpDA), 3.5-diaminobenzioc acid (DABA) and 2,3,5,6 tetramethyl-1,4-phenylene diamine (4MPD) should be considered. Examples of monomer combinations are (6FDA/BADF/DABA), (6FDA/BADF)/(6FDA-DABA) or (6FDA/4MPD)/(6FDA/DABA). In this thesis silanes were used to introduce alkyl chains on a titania membrane (chapter 3). Alternatively the use of Grignard reagents, forming a M-C-Si bond, can be advantageous, because they are more stable towards hydrolysis than the M-O-Si bond, which are formed when silanes are used. However, when a further functionalization of the surface, other than with alkyl or aryl moieties, is required, e.g. for a post polymerization process, phosphoric acids can be considered as it has been demonstrated that the bond $\mathrm{M}$ (metal)-O-P, which is formed after reaction with the ceramic surface, is more stable, particularly at high and low pH values. This can represent an alternative for separations where $\mathrm{pH}$ stability is required.

Finally, some more general recommendations regarding the results as described in chapters 5, 6 and 7 are:

- Grafting and consequently solvent permeation is performed on flat supports. Tubular membranes are preferable since they possess a higher surface to volume ratio and the transport through these membranes can easily be modeled, which is an advantage in predicting solute retentions. Furthermore in the majority of industrial modules tubular membranes are preferred

- All permeation experiments were performed using a dead-end filtration system. However, measurements in a cross-flow system are preferable. 


\section{References}

1. Sah, A., et al., Hydrophobic modification of $y$-alumina membranes with organochlorosilanes. Journal of Membrane Science, 2004. 243(1-2): p. 125-132.

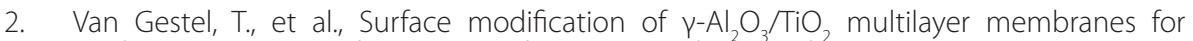
applications in non-polar organic solvents. Journal of Membrane Science, 2003. 224(1-2): p. 3-10.

3. Verrecht, B., et al., Chemical surface modification of gamma-Al2O3 TiO2 toplayer membranes for increased hydrophobicity. Desalination, 2006. 200(1-3): p. 385-386.

4. Tsuru, T., et al., Nanoporous titania membranes for permeation and filtration of organic solutions. Desalination, 2008. 233(1-3): p. 1-9.

5. Tsuru, T., et al., Permeation of nonaqueous solution through organic/Inorganic hybrid nanoporous membranes. AlChE Journal, 2004. 50(5): p. 1080-1087.

6. Chowdhury S.R., Ordered And Disordered: Porous Materials For Nanofiltration Application. PhD thesis, 2005, University of Twente, Enschede

7. Dhara, M.G. and S. Banerjee, Fluorinated high-performance polymers: Poly(arylene ether)s and aromatic polyimides containing trifluoromethyl groups. Progress in Polymer Science, 2010. 35(8): p. 1022-1077.

8. Staudt-Bickel, C. and W.J. Koros, Improvement of $\mathrm{CO}_{2} / \mathrm{CH}_{4}$ separation characteristics of polyimides by chemical crosslinking. Journal of Membrane Science, 1999. 155(1): p. 145154.

9. Vora, R.H., S.H. Goh, and T.S. Chung, Synthesis and properties of fluoro-polyetherimides. Polymer Engineering and Science, 2000. 40(6): p. 1318-1329.

10. Katarzynski, D., F. Pithan, and C. Staudt, Pervaporation of multi component aromatic/ aliphatic mixtures through copolyimide membranes. Separation Science and Technology, 2008. 43(1): p. 59-70.

11. Katarzynski, D. and C. Staudt, Temperature-dependent separation of naphthalene/ndecane mixtures using 6FDA-DABA-copolyimide membranes. Journal of Membrane Science, 2010. 348(1-2): p. 84-90.

12. Pithan, F., et al., Polymeric membranes for aromatic/aliphatic separation processes. Chemphyschem, 2002. 3(10): p. 856-862.

13. Ren, J.Z., C. Staudt-Bickel, and R.N. Lichtenthaler, Separation of aromatics/aliphatics with crosslinked 6FDA-based copolyimides. Separation and Purification Technology, 2001. 223(1-3): p. 31-43.

14. Staudt-Bickel, C. and W.J. Koros, Olefin/paraffin gas separations with 6FDA-based polyimide membranes. Journal of Membrane Science, 2000. 170(2): p. 205-214. 


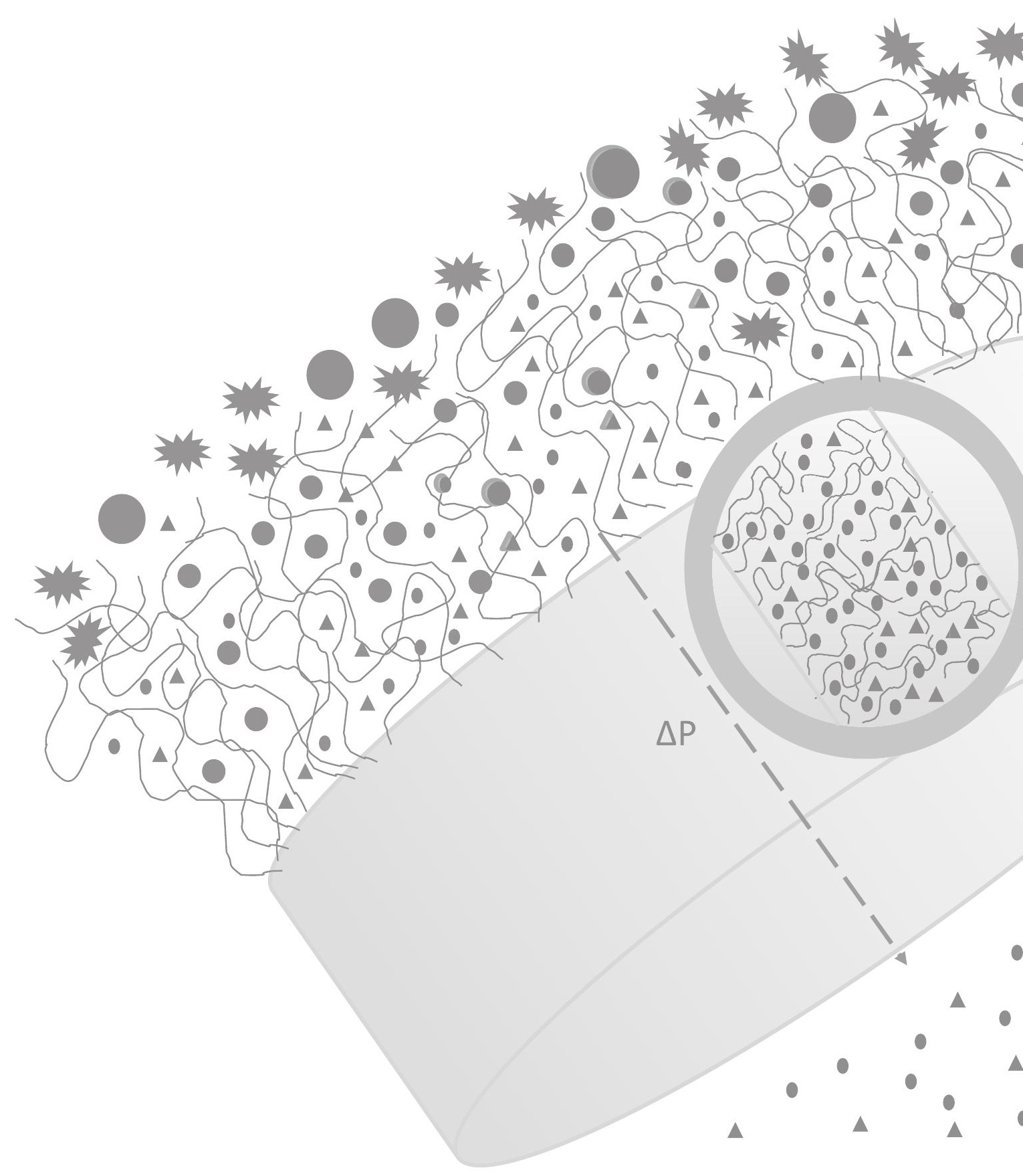




\section{Summary}

\section{Samenvatting}

\section{Acknowledgments}

$$
\begin{aligned}
& \Delta \stackrel{\Delta}{\Delta} \text {. } \\
& { }^{\circ} \bullet \bullet \bullet \Delta, \bullet \\
& \text { - } \Delta, 0 \quad 0 \Delta \\
& \Delta \bullet \bullet \bullet \bullet \bullet
\end{aligned}
$$

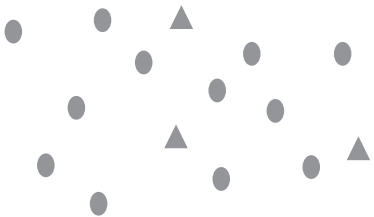




\section{Summary}

The research described in this thesis focuses on the functionalization and pore size tuning of $\gamma$ - and a-alumina membranes to be used for liquid separation. The research covers alumina grafted membranes with different silanes (alkyltrichlorosilanes and aminotrialkoxysilanes) and polymers like PDMS and polyimides. In addition, the application of these materials as membranes in solvent nanofiltration is described.

Chapter 1 gives a general introduction on currently used polymeric and ceramic nanofiltration membranes and further focuses on the so-called polymer-grafted ceramic membranes. This introductory chapter highlights the limitations and advantages of both polymeric and ceramic membranes presently used and emphasized the benefits of combining both materials by grafting polymers onto a porous ceramic support.

In chapter $\mathbf{2}$ an introduction is given about different methods for modifying the surface of ceramic materials. This literature review highlights silane and phosphorous coupling agents as suitable modifiers of the inorganic support. Through this approach it is demonstrated that pore size can be tuned and surface chemistry can be engineered to favor non-polar solvent permeation. These coupling agents, which are covalently bonded to the inorganic support, are either used to obtain a modified membrane or as a linker for further polymer attachment. Both approaches are potentially suitable for a broad field of applications for these classes of membranes. The role of these molecules as a linker for further attachment of several polymers is emphasized and some examples are given, including PDMS and polyimides.

In chapter $\mathbf{3}$ grafting of titania membranes with different alkylchlorosilanes is discussed. The effect of the reaction conditions (time, temperature, concentration) and nature of the silane (number of hydrolysable groups and the length of the alkyl chain) on membrane structure and pore infiltration are studied. It is proven by Fourier transform infrared spectroscopy that both tri- and dichlorosilanes were grafted onto titania at room temperature. For silanes with longer chain lengths, evidences were found that organized structures could be produced. By means of XPS it was demonstrated that a desired uniformed and packed layer over the surface and pore walls was obtained when mild conditions were used. An optimum in silane concentration was found. In addition, in this study it is highlighted that these systems presented a good solvent stability rendering them promising Sol- 
vent Resistant NanoFiltration (SRNF) membranes.

In chapter $\mathbf{4}$ grafting is described of $\gamma$-alumina flakes with several alkyltrichlorosilanes or with a PDMS polymer. A novel route is designed for grafting a PDMS polymer which involved a two-step approach. First 3-aminopropyltriethoxysilane (APTES) is grafted as linker, followed by grafting of a mono-epoxy PDMS polymer. The influence of the grafting method of the linker (vapor phase - VPD, or solution phase - SPD) on the grafting performance and membrane structure (pore size and pore volume) is studied. By means of Fourier transform infrared spectroscopy and nitrogen adsorption/desorption it is demonstrated that the vapor phase method results in a more controllable, uniform, mono layer of the linker and consequently in more efficient grafting of PDMS onto the pore walls. For accessing the potential of these materials as SRNF membranes, simple stability tests in different solvents on these organically-grafted inorganic powders are performed. Gamma-alumina flakes, grafted with alkyltriclhorosilanes, showed a low chemical stability in solvents like hexane and toluene which hampers their application as SRNF membrane. Contrarily, PDMS-grafted alumina showed to be stable in all tested solvents like isopropanol and toluene enabling them as potential SRNF membranes as demonstrated in chapter $\mathbf{5}$.

In chapter $\mathbf{5}$ a description is given of new SRNF membranes, made by grafting a PDMS polymer into the pores of a $5 \mathrm{~nm}$ alumina membrane, using the grafting methods as described in chapter 4. By means of permporometry it is proven that grafting the linker by a vapor phase technique results in a more uniform monolayer. The impact of the linker deposition method (SPD or VPD) on membrane performance is also shown. Covalently bonding of hydrophobic polymers like PDMS on ceramic membranes enables the opportunity to tune both pore size and surface chemistry in favor of non-polar organic solvent permeation. This results into the creation of very stable, hydrophobic nano-filtration membranes having a Molecular Weight Cut-Off (MWCO) of 500 Da with great potential for numerous applications. The interpretation of the filtration results for these PDMS grafted inorganic membranes seems at first rather straight forward, as solvent permeation through the hydrophobic membranes show the highest values for the most non-polar solvent and the lowest for the most polar solvent. After taking a closer look to the transport mechanisms it is found that besides polarity and hydrophobicity another key factor plays a role: solvent viscosity, in particular the viscosity inside the pores, which can differ to a large extend from bulk viscosity values. The performance of the developed membranes is compared with literature data of commercial and 
laboratory-made $100 \%$ polymeric PDMS based membranes.

Chapter $\mathbf{6}$ and $\mathbf{7}$ are dedicated to the preparation of polyimide grafted alumina membranes. In Chapter 6 hydrophilic BTDA-ODA polyimide-based SRNF membranes with a MWCO of $830 \mathrm{Da}$ are developed. It is proven that polyimide-based polymers can be successfully grafted onto alumina flakes/membranes. The influence of parameters like support pore size (5 or $9 \mathrm{~nm}$ ) and monomer grafting method on membrane structure and performance were studied. It is shown that the monomer grafting method (in-situ polymerization or layer by layer monomer addition) is crucial for achieving porous membranes that are suitable for solvent permeation. Solvent transport through these membranes obeyed the pore flow transport mechanism in the initial state, however, ongoing capillary condensation of small amounts of water into the membrane resulted in a decrease in solvent permeance, particularly for hexane.

A comparison of the permeance data of porous (pore size $4.8 \mathrm{~nm}$ ) hydrophilic BTDA-ODA polyimide membranes (chapter $\mathbf{6}$ ) with microporous (pore size $<1.5$ nm) hydrophobic PDMS-grafted membranes (chapter 5) revealed that hydrophobicity has a pronounced effect on the permeance of non-polar solvents and that for these membranes pore size is of less importance. Therefore, by using a similar grafting procedure as developed in chapter $\mathbf{6}$, hydrophobic polyimide nanofiltration membranes were fabricated and described in chapter 7 . This was achieved by grafting a 6FDA-BDAF polyimide based polymer into alumina membranes with pores sizes ranging from 5 to $70 \mathrm{~nm}$. Grafting of the subsequent monomers on alumina powders was proven by Fourier transform infrared spectroscopy. For ceramic supports with a pore size of 5 and $9 \mathrm{~nm}$, dense and solvent impermeable membranes were fabricated independently of the monomer addition method used. An increase in pore size combined with the layer by layer method for monomer grafting, resulted in a hydrophobic, porous and solvent permeable membrane. As already demonstrated in chapter 6 , the layer by layer method allowed us to manipulate pore size, solvent permeance and MWCO in a sequential and controlled manner. Reproducible toluene fluxes for 6FDA-grafted alumina membranes (pore size 9 and 70) nm using the layer by layer method highlights the reproducibility of this method for producing surface and pore grafted polyimide ceramic membranes.

Finally, the conclusive chapter $\mathbf{8}$ summarizes the main results as described in the previous chapters and provides ideas and needs for future research. In this chapter an evaluation of the grafting chemistry and pore-size tuning of different 
polymer-grafted ceramic membranes is presented. The work described in this thesis shows that a wide range of polymers/molecules can be used for grafting ceramic membranes. An evaluation of membrane performances clearly show that the functionality/chemistry of the grafted polymer/molecule effects solvent permeation behavior. Evaluation of the solvent transport through these membranes gives us a better understanding of the mechanisms occurring inside pores of the membranes, which can result in a better selection of the most suitable materials to be grafted. This means that an extensive toolbox of options is available for tailor made ceramic membranes for SRNF. 


\section{Samenvatting}

Het onderzoek, beschreven in dit proefschrift, richt zich op het functionaliseren of "graften" van poreuze keramische membranen en het aanpassen van de poriegrootte. Keramische membranen op basis van $\gamma$-alumina, a-alumina of titania worden chemisch gemodificeerd met verschillende silaan moleculen (alkyltrichlorosilanen en aminotrialkoxysilanen) of polymeren, zoals PDMS en polyimides. Tevens worden de nanofiltratie resultaten van deze membranen bediscussieerd. Het gaat hierbij ook om de stabiliteit van deze membranen in verschillende organische oplosmiddelen zoals tolueen, hexaan, isopropanol, tetrahydrofuraan (THF), dimethylfomamide (DMF) en N-methyl-2-pyrrolidone (NMP).

Hoofdstuk 1 geeft een algemene inleiding van polymere en keramische nanofiltratie membranen die thans gebruikt worden en besteed daarnaast aandacht aan de zogenaamde polymeer gegrafte keramische membranen. In deze gegrafte hybride membranen zijn polymeren chemisch (covalent) gebonden aan keramische membranen. De voor- en nadelen van zowel polymere als keramische membranen voor nanofiltratie toepassingen worden aangegeven en aandacht wordt besteed aan het belang van de van het graften van polymeren op poreuze keramische dragers voor verbetering van nanofiltratie en stabiliteit,

In hoofdstuk 2 wordt een literatuuroverzicht gegeven van de verschillende methoden voor het modificeren van anorganische materialen. Als eerste worden organo-silaan en organo-fosfor verbindingen behandeld, die een chemische binding vormen met anorganisch materialen. Door deze benadering is aangetoond dat zowel de oppervlakte chemie als de gewenste porie grootte van het membraan kunnen worden ingesteld, zodat apolaire oplosmiddelen worden doorgelaten. Deze organo-silaan en -fosfor verbindingen worden aan de ene kant gebruikt om een organisch gemodificeerd keramisch membraan te verkrijgen en aan de andere kant als een mogelijkheid om polymeren aan het keramiek te binden. Beide benaderingen bieden de mogelijkheid voor een breed scala van toepassingen van deze klasse van membranen. Voor het graften van polymeren worden met name PDMS en polyimides als voorbeeld gegeven

In hoofdstuk $\mathbf{3}$ wordt het graften van titania membranen met verschillende alkyl-chlorosilananen beschreven. De invloed van reactie condities (reactie tijd, temperatuur, concentratie) en de aard van het silaan molecuul (aantal hydrolyseerbare groepen en de lengte van de alkyl keten) op membraan structuur en mate van 
porie infiltratie worden beschreven. Fourier Transform Infrarood (FTIR) spectroscopie heeft laten zien dat zowel di- als trichlorosilanen covalent gebonden zijn aan het titania na reactie bij kamertemperatuur. Het is aangetoond dat geordende structuren verkregen worden voor silanen met langere koolstofketens. XPS analyse heeft laten zien, dat onder milde reactie omstandigheden een gewenste uniforme silaan laag is gevormd aan het oppervlak en de wanden van de poriën van het membraan. Daarnaast is aangetoond dat deze gegrafte systemen een goede stabiliteit vertonen in verschillende organische oplosmiddelen.

In hoofdstuk 4 wordt het graften beschreven van poreuze $\gamma$-alumina poeder deeltjes met verschillende alkyl tricholorosilanen of met een PDMS polymeer. Een nieuwe twee staps reactie route is ontwikkeld voor het graften van PDMS. Als eerste wordt 3-aminopropyltriethoxysilane (APTES) aangebracht als tussenverbinding ("linker") gevolgd door het graften van een mono-epoxy PDMS polymeer. Twee manieren van aanbrengen van deze APTES tussenverbinding worden behandeld, nl. via de dampfase (VPD) of via de vloeistoffase (SPD). Door middel van FTIR en stikstof adsorptie/desorptie metingen is aangetoond dat de dampfase methode resulteert in de gecontroleerde vorming van een uniforme monolaag van de tussenverbinding en met als gevolg een meer efficiënt aanbrenging van het PDMS op de poriewanden. Eenvoudig stabiliteits experimenten zijn uitgevoerd in verschillende oplosmiddelen om het potentieel gebruik te bestuderen van deze materialen als (organisch) oplosmiddel resistente nanofiltratie (ORNF) membraan. Poreuze $\gamma$-alumina poeders, chemisch gemodificeerd met alkyltricholorosilanen, vertonen een lage chemische stabiliteit in oplosmiddelen als hexaan en tolueen, wat deze systemen beperkt in de toepassing als ORNF membranen. Daarentegen vertonen alumina membranen, gemodificeerd met PDMS, een stabiel gedrag in oplosmiddelen als isopropanol, tolueen, THF en DMF.

In hoofdstuk 5 wordt een beschrijving gegeven van de ontwikkeling van ORNF membranen door het graften van een PDMS polymeer in de poriën van een $5 \mathrm{~nm}$ alumina membraan, waarbij gebruik gemaakt wordt van de methodes, zoals beschreven in hoodstuk 4. Permporometrie analyse heeft aangetoond, dat het graften van de tussenverbinding (APTES) d.m.v. de VPD methode resulteert in een meer uniforme monolaag in vergelijking met APTES aangebracht via de SPD methode. Het covalent binden aan keramische membranen van hydrofobe polymeren zoals PDMS biedt de mogelijkheid om zowel de poriegrootte als de oppervlakte chemie zodanig in te stellen dat een gunstig transport plaats kan vinden van apolaire organische oplosmiddelen. Stabiele, hydrofobe ORNF membranen zijn ontwikkeld 
en hebben een moleculaire massa cut off waarde (MWCO) van 500 Da. In eerste instantie lijken de filtratie resultaten eenvoudig gecorreleerd te kunnen worden met de hydrofobe eigenschap van het membraan, omdat de hoogste flux waardes zijn gevonden voor het meest apolaire oplosmiddel. Echter bij verdere analyse van de resultaten blijkt dat ook de viscositeit van het oplosmiddel een belangrijke factor is in het transportgedrag en dan met name de viscositeit in de poriën, welke kan verschillen van de bulk viscositeit. Als laatste is het gedrag van de hier ontwikkelde membranen vergeleken met literatuur gegevens van $100 \%$ polymere PDMS membranen.

De hoofdstukken $\mathbf{6}$ en $\mathbf{7}$ behandelen de bereiding van polyimide gegrafte alumina membranen. In hoofdstuk 6 wordt de ontwikkeling van hydrofiele BTDA-ODA polyimide ORNF membranen beschreven. Deze membranen hebben een moleculaire massa cut off waarde van 830 Da. Polymides kunnen met succes op alumina poeders en membranen worden aangebracht. De invloed van de poriegrootte van de drager (5 of $9 \mathrm{~nm}$ ) en de manier van graften van de monomeren op membraan structuur en eigenschapen zijn bestudeerd. Aangetoond is dat de aanbrengingsmethode (in-situ polymerisatie of laag na laag monomeer toevoeging) van belang is om membranen te verkrijgen met een poriegrootte, die geschikt is voor oplosmiddel permeatie. Transport door het membraan volgt in eerste instantie een model, dat transport door een poreus membranen beschrijft. Echter na verloop van tijd zorgt capillaire condensatie van kleine hoeveelheden water in de oplosmiddelen voor een afname in de permeatie, in het bijzonder voor hexaan. Vergelijking van de permeatie door poreuze (porie grootte $4.8 \mathrm{~nm}$ ) hydrofiele BTDA-ODA membranen (hoofdstuk 6) met permeatie door microporeuze (porie grootte $<1.5 \mathrm{~nm}$ ) hydrofobe PDMS membranen (hoofdstuk 5) laat zien dat hydrofobiciteit van het membraan een sterk effect heeft op transport gedrag van apolaire oplosmiddelen en dat voor de hier onderzochte membranen de poriegrootte van minder belang is. Om die reden zijn hydrofobe polyimide membranen gemaakt, zoals beschreven in hoofdstuk 7. Door gebruik te maken van de in hoofdstuk 6 beschreven grafting methodes is een 6FDA-BDAF polyimide aangebracht op alumina membranen met porie groottes variërend van 5 tot $70 \mathrm{~nm}$. Graften is hier ook aangetoond met FTIR. Door gebruik te maken van keramische dragers met een poriegrootte van 5 of $9 \mathrm{~nm}$ zijn, na (in-situ) graften van 6FDA en BDAF, membranen verkregen, die te dicht zijn om organische oplosmiddelen door te laten. Door een drager met grotere poriegrootte te nemen en de laag na laag methode toe te passen kan wel oplosmiddel door het membraan getransport- 
eerd worden. Als voorbeeld wordt het transport van tolueen besproken door een membranen gegraft met 6FDA, wat eveneens de reproduceerbaarheid van deze laag na laag methode aantoont.

Tenslotte worden in het afsluitende hoofdstuk $\mathbf{8}$ de belangrijkste resultaten uit dit proefschrift samengevat en worden suggesties gegeven voor verder onderzoek. Een evaluatie van de chemie van het graften van verschillende polymeren en het instellen van de poriegrootte met deze methode wordt gegeven. Het werk, zoals beschreven in dit proefschrift, toont aan dat een breed scala van polymeren gebruikt kan worden voor het graften van keramische membranen. De functionaliteit en de chemie van het polymeer hebben effect op het oplosmiddel permeatie gedrag. Nadere beschouwing van het transport van deze oplosmiddelen biedt de mogelijkheid om een beter inzicht te krijgen in het transport mechanisme in de poriën van het membraan, wat kan resulteren in een betere selectie van de meest geschikt polymeren/monomeren. Dit houdt in dat een uitgebreide "toolbox" beschikbaar gemaakt kan worden voor het op maat maken van keramische membranen voor organische oplosmiddel resistente nanofiltratie. 


\section{Acknowledgments}

During the last five years I have been an incredible experience. Although, all the ups and downs, I have been very lucky with the friends and colleagues who helped me enjoy this journey. So I would like to thank everyone who helped making my stay in Enschede an incredible one. Hartelijk Bedankt!

Arian I would like to thank you for giving me the opportunity to do my PhD in Inorganic Membrane Group. Thanks for all the advices, inputs and scientific discussions and for your confidence in my work. Helping me writing this thesis was a long process requiring a lot of effort and I would like to thank you for your help.

Louis, I couldn't have wished for a better supervisor WE MADE IT, LOUIS! I am very grateful for the help and guidance you have given me during my PhD. I value all you efforts in improving my writing and time planning, as well as your efforts to always try to focus my work in one and not several ideas (contrarily to me that wanted to do all!). Above all, your patience, enthusiasm and always constructive discussions were fundamental for successfully finishing this thesis. Thank you for your constant support and confidence in me. I am also very grateful for all the freedom you gave me to conduct my research. I think I could not have successfully completed my thesis without your help and advice. Helping me to write this thesis was a long process requiring a lot of effort from your side but you patiently review draft after draft, even if sometimes I was disturbed by your comments. I realize now how much I learnt from it. During this time our relationship has developed to a great friendship. I would like to thank not only as your PhD student but also as your friend for your support and patience in the good but also during the difficult times in my personal life. Thank you for all your efforts you have done to make me feel belter. I think with you I have grown not only as a researcher but also as a person. But along these years, outside of the work, I also had great fun with you. It was always fun to party and drink with you.

All the conferences that we attended together (Washington, London, Leuven, and Utrecht) bring me great memories. Thank you Louis! I wish you all the best in your professional and personal life. See on the 15 tth March for a great celebration! 
Another person who contributed to this work in the last months is Marcel Boerrigter. Thanks for all the efforts in the measurements.

This was an ISPT project where several partners and institutes where involved. Rob Kreiter I would like to thank you for all your critical discussions and input in my work. Menno Platenga I would like to thank you for your support and positive critics. Gerrald I would like to thank you for your scientific input and especially, in the last months for your help regarding my job search. I would also like to thank Petrus Cuperus, Peter Alderstein, Dimitris Stamatialis, Nieke Benes and Peter Veenstra for their support and encouragement.

Finally I would like to thank the all the students I had during my PhD. Thanks for all your work. Soubhik, Danny, David, Jeremy, Wouter, Patrick. I learned a lot coaching you and I hope you too. Soubihk, it was a hard path but thanks to you a start in the polyimides was made. Danny, thanks to you, we were able to validate and prove the feasibility of these membranes as SRNF. I would like to thank you both for the hard work.

I would like also to thank Erna Fränzel-Luiten for all the help with the FTIR measurements and other equipment's.

During my time in the Netherlands, I had the opportunity of meeting a lot of great persons to which I would like to thank.

First I would like to thanks, first to my paranymfers, Michiel and Nick, without you it would have been so much harder to get here. Michiel, I would like thank you for all the love, support, patience, motivation and devotion that you have given me for the two years we were together. Even though we are not together anymore, without you I wouldn't be here today defending my thesis. I know that these two years were not easy for you. My stress and lack of time for personal life and the few accidents that had have not helped. I will never forget all the happy moments together, all the trips and places that we went together. Thank you for all the happy memories and I wish you all the happiness in the world. I would also like to thank your family for their love and support. Nick, thank you for all your support and friendship during all this time. I admire your honesty and kindness and your devotion to your friends. You have been there in the good and in the bad moments and I will never forget that. I would like to thank you for all the nice moments that 
we share, the nice dinners, parties and trips together. You always made me see the positive side even when I couldn't.

I would like to do special thanks to the "jabardolas club": Tiago, Sara, Martin (adopted Portuguese), Helder, João, Goncalo. Tiago and Sara and now, little Sofia, it was fantastic to meet you. I still remember the way that we meet, in a Dutch train in Enschede, three persons inside a coupe and all Portuguese. What are the changes of that? Tiago, it was always fun to be around you even when you were correcting my English (thanks for that). Sara thanks for all the moments that we share. It was nice to have a girl to take with (and in Portuguese!). I had my best moments with you guys (and Martin). Thanks for all the nice dinners, concerts and trips, but above all for your support. I am very happy that I could be there during your pregnancy and for the birth of Sofia. Estes ultimos anos não teriam sido tão fantàsticos sem vocês! Obrigado! Martin (the almost Portuguese man) I would like to thank you for your support and friendship. Thank for all the funny parties, concerts and dinners and off course all your dance moves. In the last year I would like to thank for being there for me and giving me a place to sleep. Thank for all the help with the bureaucratic issues.

Maria and Damir, thank you for making my first year in Enschede do great. I still remember arriving to my dorm in the second day and there was the sweet girl that tried to show me the way around. It was nice to share the house with you Maria. I never felt alone because of you. It was nice to get home and just have a coffee and talk. Thanks for all the nice coffee moments, the nice weekends, dinners, parties together. I could not have asked for a better housemate and friend. Congratulations with the new addition to the family, a baby girl (born in the same day as me!) Geraldine and Schawn, thank you for making my time in Enschede so amazing. Geraldine, I know you cannot be present at my defense (Canada is too far away for walking. (-). First, thanks for all the fun moments together (which were a lot). At work the coffee breaks and especially, the smoke breaks. The innumerous dinners and parties together, the trips (Paris, Germany, Belgium), the volleyball games made my time in The Netherlands so much more fun. Above all, thanks for being there for me in the good but also in the worst days. All the best for you two in Canada! Merci Beaucoup mon ami!

Nazeli, thank you for the nice moments that we shared during your stay in the Netherlands. It was nice to share the house with you (Hoogstraat) even for only some days. I still remember getting home and there was this new girl in the living room to which I started to talk and four hours after we realized that we will be 
working close to each other. I know you were happy to go back to Spain to Santi, but I was glad that I had the opportunity to meet you. Thank you for all the dinners and trips together, above all for your support. I know that you cannot come to my defense, I will miss you.

Maria it was pity that you only spend three months in the group. It was really fun to meet you. Thank you for your always positive attitude, kindness and almost forgot your craziness (in a good way). It was nice to visit you in Valencia and hopefully we see each other soon, in my defense.

Zeynep, was nice to have you in the group, but more importantly, it was nice to spend time with you besides work. Even though you had to go and go back every day to Munster we still manage to do some trips. I am very glad that I meet you. Do you remember when we get lost in PARIS? Thanks for all the adventures and good moments together. See you in my defense.

Gerard, the Catalan macho man and guitar player, thanks for your support and friendship. Thank you for all the fun coffee/smoke breaks. I really had great fun talking with you, sometimes too long ones (I miss those times!). Thanks for all, papple!

Mariana, I would like to thank you for your support and all our conversations. The last years off the $\mathrm{PhD}$ were not easy but it was nice to have you to talk or just laugh with. It is finished!!!!! Let's celebrate on the $15^{\text {th }}$

I would also like to thank you Gregory, the master chef of desserts. I had very fun memories of our times together. It was really nice that you came to Portugal last year. The only thing that I regret is that I never found a nickname for you to joke, as perfect as the one you found for me.:)! (still trying). I hope to see you in my defense.

Guillaume, I would like to thank for the nice times pass during the many lunches together (the wonder trio you, me and Maria). Even though, you don't believe in mobiles $(;)$, we still manage still have a lot nice dinners together. Federico, I would like to thank you for all the nice moments that we share and your support. I really enjoyed our conversations (even the non-sense ones) and our trip to Valencia. Enrique, even though we have known for long time it was always fun to be around you.

I would like all the members in the IM group (present and past) for making it a fun place to work in addition to a high quality scientific environment. Giri, Martin, Zeynep, Hammad, Bas, Frank, Chung, Tan, Wei, Weihua, Sergei, Maria, Zeynep, Tan, 
Wei, Michiel, Cheryl, Susanne, Marcel, Cindy, Shushumma, Kishore, Can, Emiel, Henny, Nieck, Song and Mieke. Frank, (Frankiiiii) thank for your help with building my setup at last, and for all the other big and small things that you build for me. Without you I would not have done it. Besides, thank you for all non-work related talks, all the smoke breaks or just fresh breaks (with Bas and sometimes Tan). It made my days better. Giri (Mr. Siripi!), I would like to thank you for all the scientific discussions and input in my work. It was nice to have somebody to share ideas. I would like to thank you as friend for all the relaxing talks during the coffee breaks in TCCB- or the MTO-coffee corner, the lunch and of course for the times spending playing volleyball. It was always nice to still have somebody to talk when we had to work late. I wish you all the best for your future. Martin, I would like to thank you for all the nice moments together (during coffee breaks, lunch, in the house in the Hoogstraat, in ROCKamRING) and for your always rare humor. It was nice to see the changes in your life as getting married and raising a family. I am very happy for you and wish all the best for you and for your family. Hammad (Mr. Ham!), I would like to say thanks for all the support and kind words. It was nice to have a person with who you could talk about your problems, as well as, just making jokes. Like nobody else, you really know how to complement a girl (no examples given to avoid embarrassing you). I really miss our discussions/nonsense conversations. I hope all the best for your life and good luck in finishing your thesis, my friend. Bas (Mr. Sebastian!), our first impression 5 years ago was, just let say, it was not very positive, if I recall it was I hated you (joke). I really enjoyed knowing you. Having you in the group was so much more fun (my event co-organizer). It was nice to have somebody to be open to, especially when things were not OK. Above all, I thank you for your friendship. I wish you all the best for you and Rianne. Chung, thanks for all good moments together (Amsterdam, Portugal...) I wish all the best in Korea. Tan (Mr. Tan meister) thanks for all the fun and nice moments. I wish all the best in concluding your thesis. Michiel, even though we just met more recently I would like to thank for all the nice times in the office but also for the nice dinners and party moments. I would like to extend that to Karin. Can, I would like to thank for the funny parties and smoke brakes that we share. It was always fun to spend time with you (as ex-SFI and now as IM). Susanne, thank you very much for helping me through the procedures and paperwork and all bureaucratic issues. Cheryl, it was nice to meet you, even though it was for a short while, I am glad that I have. I wish all the best and I hope that my suggestions helped in succeeding in your PhD. Cindy, I would like to thank you for all the help that you have given me. 
I would like to thank all the members of MST--group and SFI-group and EMI for making it a fun place to work. I also would like to thank the staff for all the help. Anne Corinne, I have great respect for you. Thanks for all the nice moments even when things were hard for you. I wish you all the best for your thesis. Mayur, I would like to thank you for welcoming me in such a friendly way. Thank you for all the moment both at work, DSTI meetings and parties. Elif, thank you for the nice smoke breaks and the nice parties (always an adventure).. I would also like to thank to Jereon, Jumeng, and Olga.

Nico \& Caro thank you for all the times together (barbeques, volleyball games). It was nice to meet you. I hope your life in Grenoble goes OK.

Sandra \& Juan, I was very glad to be present in your wedding. Thank you for all the nice barbaques. I wish all the best for the future. I would also like to thank Oana, Arturo, Marcin, Marion and Ana\&Hugo all the nice moments together

To all persons of Campuslaan 37 I would like to thank for kindness and open attitude towards me, Inge, Bart, Freddy, Bas, Roelof, Bram, Nico, Julia, Moana, Rick, Bote Ale, Boudewijn and Daan. It was really fun to live, party and to get a hangover with you all. Inge, it was really nice to meet you and spend some fun time with you in concerts, parties or to just talk and drink or see a movie. Thanks for the days in Indonesia, even when you had to sleep in the kids bed I hope it was fun for you. Bart (mr. run Bart run) always enjoyable nonsense conversations and off course the nice cakes. Nico, Thanks for all the (surreal-) conversations, game nights and off course table football lessons (thank you, master). Bas and Bram, without you the smoke breaks would not be so much fun (even in the rain!), Roelof, I particularly liked the cougar town nights with the red wine glasses. It was nice to meet you in Bangkok, and share the same tank during the fish massage. Kjell, thank you for your always particular humor and for all the nice movie night or card nights (yes, you are a lucky.....). Freddy, I would like to thank you for all the nice moments. I never thought that I would find somebody that talks more than me, but I found. Surprise! IT IS YOU. Thanks for your help on the job search. I wish all the best to you and Selda. Gideon, Mr. Potato head, thank you for all the entertaining lunches. I would also like to thank Jouke and Richard for welcoming me in Houten/Utrecht.

Carina, Nadia, Ritinha, Tania, Sandra, Manel, Saul, Ana, Elsa, Garizo and Gabriel I would like to thank for all the moments that we shared together during my university time and after. Having you in my life only made it better. Even though, 
I am not there either in Portugal or wherever you are, and we just see each other once in a while, seeing you and being with you always make me feel like home. There are no words to express what your friendship means for me. Carina, thank you for coming all the way from Denmark for my defense. Nadia and Sandra thank you for being here with me in this day. I wish you all could be here, but I know you would if you could.

Danny, thank for your love and support over the last year. You have been my strength when the only thing that I want to do was give up, cheering me up when I've had a bad day or when a received another bad news. Thank you for your patience in the bad days. Thank you for helping me in finishing the thesis. Without you love and motivation I would never have pushed myself to work such long hours. The last year has been the hardest year of all, writing and looking for a job. Thank you for making it better, my love. I love you! I also want to thank your parents for their support and the rest of your family.

Finally I would like to thank to the persons that have support me above all, my parents, my brother and family and dedicate this thesis to them. Mama e Papà sem o vosso suporte, carinho e amor, eu hoje nao estaria aqui. Voces tem sido o meu support moral e emocional e um exemplo todos estes anos mesmo agora a distancia. Obrigado pela vossa motivaÇão contante e encoregamento mesmo nos momentos mais dificies. Eu sei que esta mudanÇa para a holanda nao foi facil para voces ( As saudades sao muitas!) mas mesmo assim voces nunca deixaram de me apoiar. Obrigado! Eu estou muito contente por partilhar este dia com voces. João, obrigado pelo amor e suporte que me tens dado ao longo dos anos. Eu gostava de poder partilhar este dia contigo, manito mas eu sei que nao podes estar presente, porque estàs pelo Brazil. Eu vou sentir a tua ausência, mas eu sei que hàs-de estar a torcer por mim. Avòs, obrigado pelo vosso supporte e amor durante todos estes anos. Avô Ze e Adelia, obrigado por virem ver a minha defesa não hà melhor presente que este. Avô Armènio e Avò Rosa, eu sei se vocês pudessem estariam aqui nest dia. 



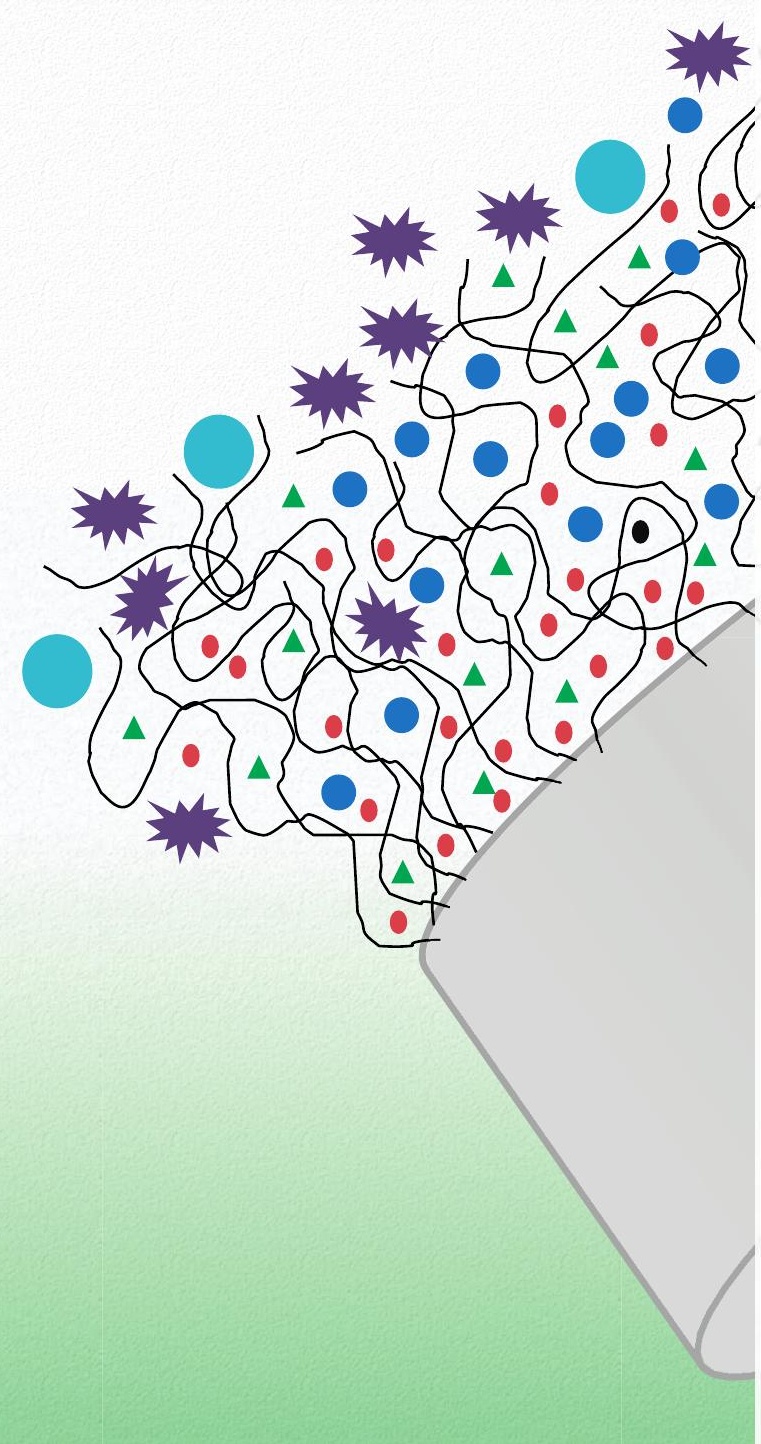

